UNIVERSIDADE DE SÃO PAULO

FACULDADE DE ECONOMIA, ADMINISTRAÇÃO E CONTABILIDADE. DEPARTAMENTO DE CONTABILIDADE E ATUÁRIA

\title{
SISTEMAS EMPRESARIAIS INTEGRADOS - ERP NA EMPRESA CONTÁBIL: UM ESTUDO DE CASO DE MUDANÇA ORGANIZACIONAL COM O USO DA PESQUISA-AÇÃO
}

\section{JOSÉ SANTOS PEREIRA}

Dissertação apresentada à Faculdade de Economia, Administração e Contabilidade da Universidade de São Paulo, para concorrer ao título de Mestre, pelo curso de pós-graduação em Contabilidade e Controladoria junto ao Departamento de Contabilidade e Atuaria.

ORIENTADOR:

PROF. DR. EDSON LUIZ RICCIO

SÃO PAULO 
UNIVERSIDADE DE SÃO PAULO

FACULDADE DE ECONOMIA, ADMINISTRAÇÃO E CONTABILIDADE DEPARTAMENTO DE CONTABILIDADE E ATUÁRIA

\title{
SISTEMAS EMPRESARIAIS INTEGRADOS - ERP NA EMPRESA CONTÁBIL: UM ESTUDO DE CASO DE MUDANÇA ORGANIZACIONAL COM O USO DA PESQUISA-AÇÃO
}

\author{
JOSÉ SANTOS PEREIRA
}

Dissertação apresentada à Faculdade de Economia, Administração e Contabilidade da Universidade de São Paulo, para concorrer ao título de Mestre, pelo curso de pós-graduação em Contabilidade e Controladoria junto ao Departamento de Contabilidade e Atuaria.

ORIENTADOR:

PROF. DR. EDSON LUIZ RICCIO

SÃO PAULO 


\section{FICHA CATALOGRÁFICA}

\section{Pereira, José Santos}

Sistemas Empresariais Integrados - ERP na empresa contábil: Um estudo de caso de mudança organizacional com o uso da pesquisaação / José Santos Pereira. -- São Paulo : FEA/USP, 2003.

$$
271 \mathrm{p} \text {. }
$$

Dissertação - Mestrado

Bibliografia

1. Contabilidade - Pesquisa 2. Contabilidade - Aspectos sociais 3. Contadores I. Faculdade de Economia, Administração e Contabilidade da USP.

CDD - 657 


\section{DEDICATÓRIA}

A meus pais,

que criaram meu mundo.

À minha esposa,

que transformou o meu em nosso mundo.

Aos meus irmãos,

um mundo generoso de apoio e carinho. 
Caminante, son tus huellas el camino, y nada más;

caminante, no hay camino, se hace camino al andar. $\mathrm{Al}$ andar se hace camino, y al volver la vista atrás se ve la senda que nunca se ha de volver a pisar. Caminante, no hay camino, sino estelas en la mar.

ANTÓNIO MACHADO 


\section{AGRADECIMENTOS}

Meu profundo agradecimento a todos que, de algum modo, tornaram viável a realização desse trabalho, mas de modo especial:

- $\quad$ Ao professor-doutor Edson Luiz Riccio, por privilegiar-me com seus ensinamentos e experiência, não medindo esforços para me orientar com dedicação e segurança;

- Ao professor-doutor Roberto Vatan dos Santos e a professora-doutora Rosana C.M. Grillo Gonçalves, por terem me honrado com suas participações no exame de qualificação, oferecendo observações essenciais para o trabalho;

- $\quad$ A todos os professores do Departamento de Contabilidade e Atuária da Universidade de São Paulo, pelos ensinamentos recebidos;

- Ao Conselho Federal de Contabilidade e ao Conselho Regional de Contabilidade de Santa Catarina, na pessoa do Presidente Contador Juarez Domingues Carneiro, pela iniciativa e apoio financeiro concedido;

- A Universidade do Vale do Itajaí, em especial aos Professores José Carlos Terres e Ciro Renato Rebelo que proporcionaram apoio com recursos materiais, financeiros e de tempo para que esse projeto se concretizasse;

- $\quad$ A Maria Lúcia (Malú) e sua equipe eficiente e dedicada;

- Aos companheiros do site de Florianópolis, em especial aos amigos Balduíno, Anacleto, Koki, Cris e Eliane;

- A empresa Conjel, seus colaboradores e a equipe do projeto Promil, fontes inspiradoras desta pesquisa, em especial ao Nildo e ao João pelo apoio incondicional, e ao Vitor pelas reflexões e ajuda na confecção gráfica;

- $\quad$ À minha família, especialmente à minha esposa Adélcia e aos meus Pais Manoel e Maria, pela compreensão e apoio nos momentos de ausência, muito obrigado.AGRADECIMENTOS 


\section{SUMÁRIO}

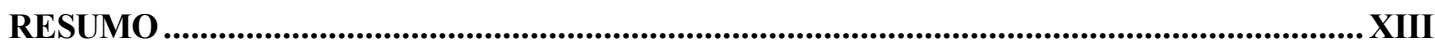

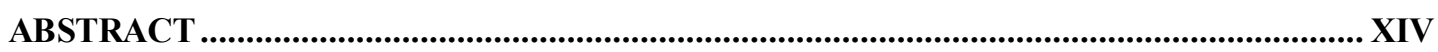

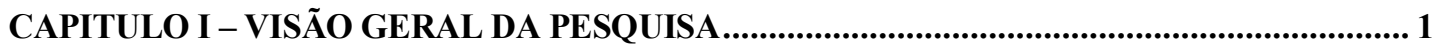

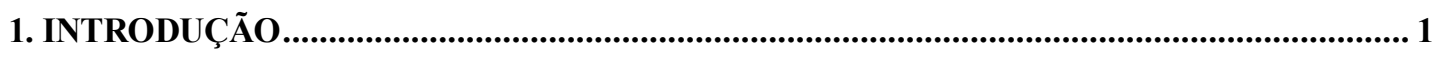

1.1 A PROFISSÃO CONTÁBIL EM ESTADO CONTÍNUO DE MUDANÇAS ............................... 2

1.2 O FUTURO DA CONTABILIDADE E A EMPRESA CONTÁBIL ....................................... 4

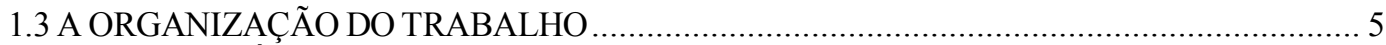

1.3.1 OS CAPÍTULOS DA PESQUISA E SEU DESENHO ................................................ 5

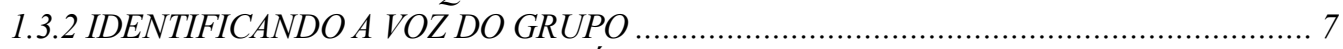

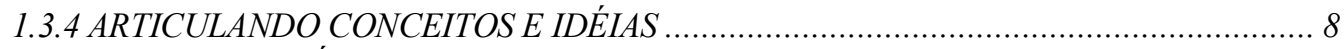

1.4. A EMPRESA CONTÁBIL PESQUISADA E SEUS PROBLEMAS..................................... 11

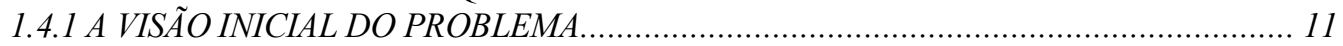

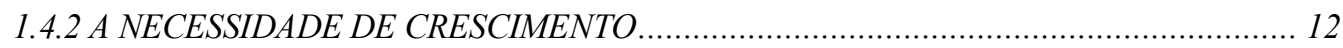

1.4.3 O AMBIENTE INTERNO E OS PROJETOS ANTERIORES....................................... 13

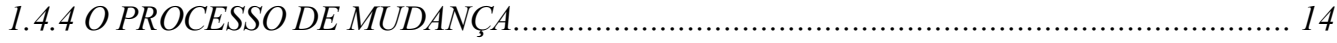

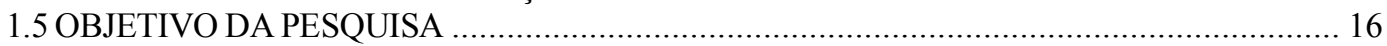

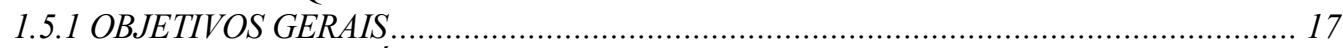

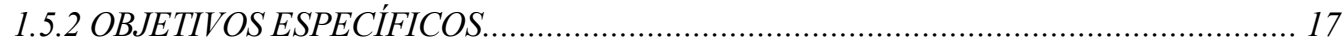

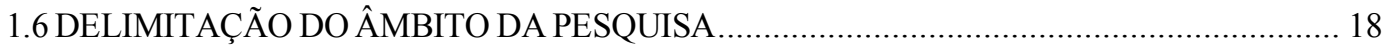

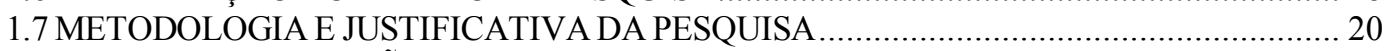

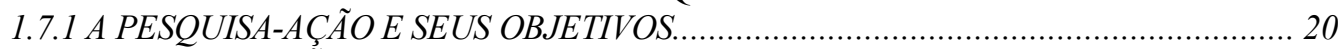

1.7.2 PESQUISA-AÇÃO E PESQUISA ORGANIZACIONAL …………............................. 22

1.7.3 RELEVÂNCIA DO TEMA AS EMPRESAS CONTÁBEIS .............................................. 24

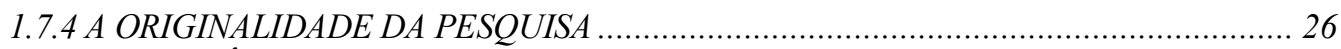

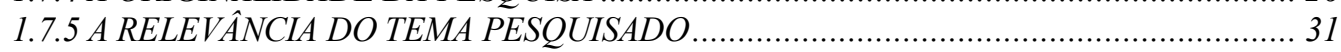

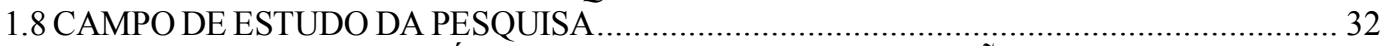

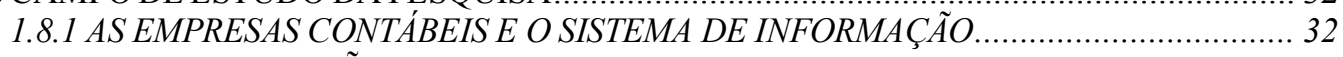

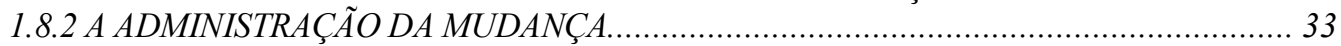

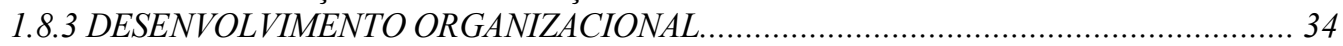

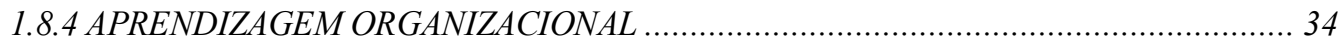

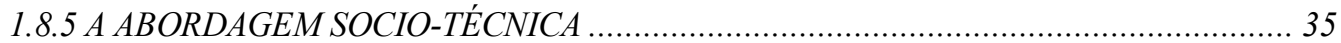

1.8.6 DESENHO DA ABORDAGEM UTILIZADA PARA CONDUZIR A PESQUISA …............ 36

CAPÍTULO II - A EMPRESA CONTÁBIL E AS QUESTÕES DE PESQUISA........................... 39

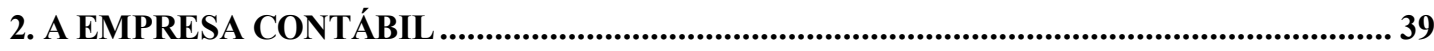

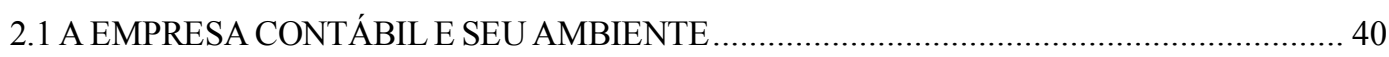

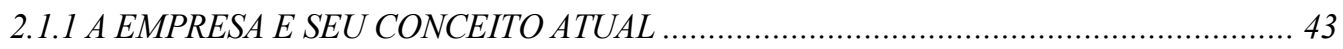

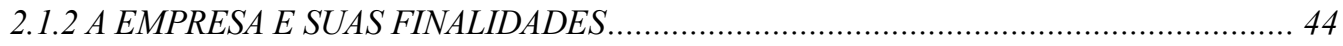

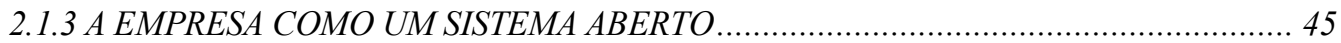

2.1.4 A EMPRESA COMO SISTEMA TÉCNICO E HUMANO ............................................ 47

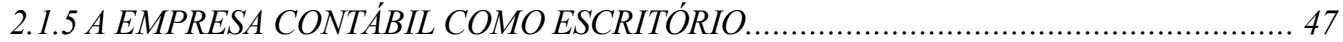

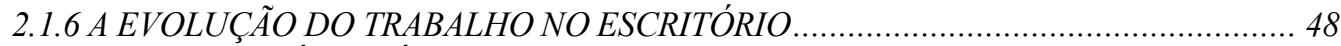

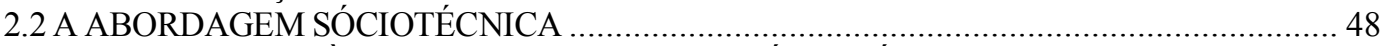

2.2.1 O IMPULSO ÀS MUDANÇAS NA ESCOLA SÓCIO-TÉCNICA ………................................. 49

2.2.2 OS PRINCÍPIOS DA ESCOLA SÓCIO-TÉCNICA E OS GRUPOS SEMI-AUTONOMOS 49

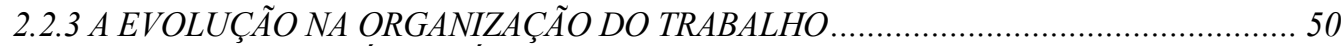

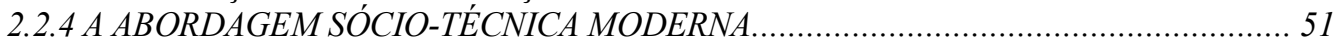

2.2.5 CONCEITOS PARA O PROJETO ORGANIZACIONAL............................................... 52

2.2.6 O TRABALHO NO ESCRITÓRIO VISTO COMO UM PROCESSO …............................ 52

2.2.7 VISÃO HORIZONTAL E AS CARACTERÍSTICAS DE UM PROCESSO ......................... 53 
2.2.8 PRINCIPIOS BÁSICOS DE PROJETO ORIENTADO A PROCESSOS …………............ 54

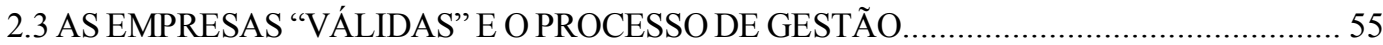

2.3.1 O SISTEMA DE GESTÃO E OS SEUS SUBSISTEMAS …………………………............ 56

2.3.2 OS SUBSISTEMAS DE GESTÃO E A INTEGRAÇÃO ............................................. 57

2.4 AS ORGANIZAÇÕES VISTAS COMO CÉREBROS...................................................... 57

2.4.1 ORGANIZAÇÕES (CÉREBROS) PROCESSADORES DE INFORMAÇÕES ................... 58

2.4.2 CIBERNÉTICA APRENDIZAGEM E APRENDER A APRENDER ................................ 60

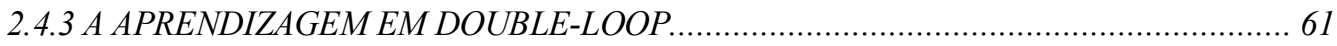

2.4.3.1 O PROFISSIONAL REFLETIVO ............................................................................63

2.4.4 NOVAS TECNOLOGIAS - NOVAS MANEIRAS DE ORGANIZAR O TRABALHO........... 67

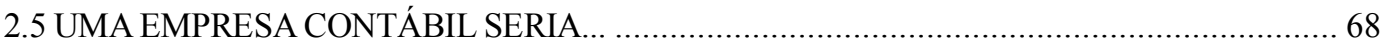

2.6 PROBLEMAS E QUESTÕES DE PESQUISA - REFINAMENTO EM 4 ITERAÇÕES ........... 69

2.6.1 PROBLEMA E QUESTÕES DE PESQUISA: $1^{a}$ ITERAÇÃO ……............................. 70

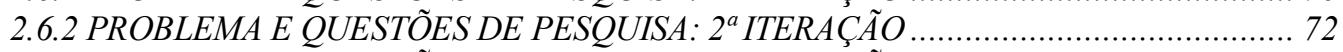

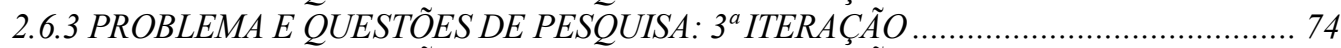

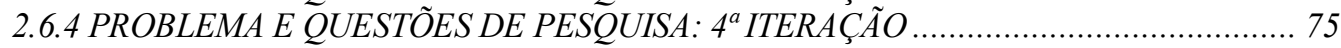

CAPÍTULO III - A DIMENSÕES DA MUDANÇA ORGANIZACIONAL.................................. 78

3. O PROCESSO DE MUDANÇA NAS ORGANIZAÇÕES .....................................................78

3.1 A TECNOLOGIA E AS MUDANÇAS ORGANIZACIONAIS............................................ 79

3.1.1 O RELACIONAMENTO ENTRE A TI E A ORGANIZAÇÃO ......................................... 79

3.1.2 O REFERENCIAL TEÓRICO SOBRE MUDANÇA …................................................. 80

3.1.3 A ADMINISTRAÇÃO DA MUDANÇA ORGANIZACIONAL E SUAS VARIÁVEIS........... 83

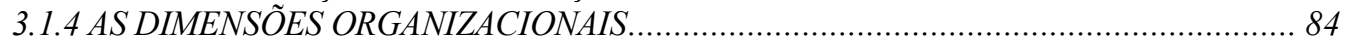

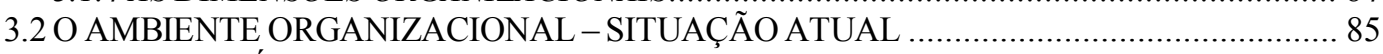

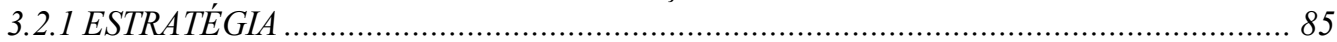

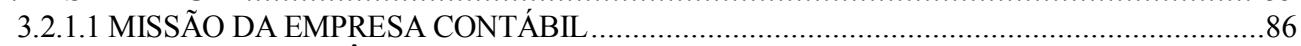

3.2.1.2 FORÇAS ANTAGÔNICAS MOLDANDO OS RELACIONAMENTOS .................................87

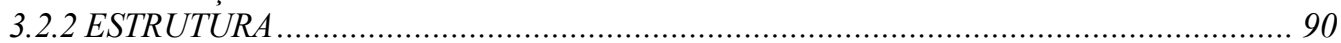

3.2.2.1 REGULAMENTAÇÃO PROFISSIONAL........................................................................90

3.2.2.2 A ARQUITETURA ORGANIZACIONAL ..............................................................91

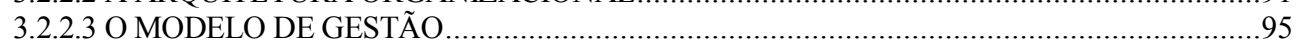

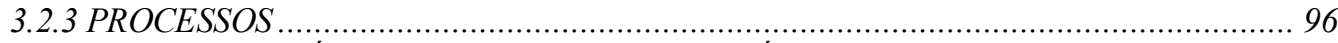

3.2.3.1 CARACTERÍSTICAS DAS EMPRESAS CONTÁBEIS ...................................................96

3.2.3.2 AS PRÁTICAS ATUAIS NAS EMPRESAS CONTÁBEIS ..................................................97

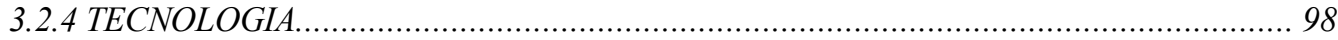

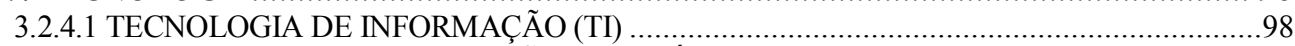

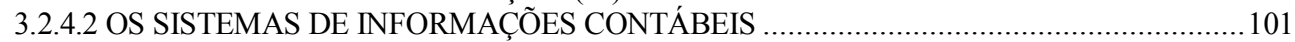

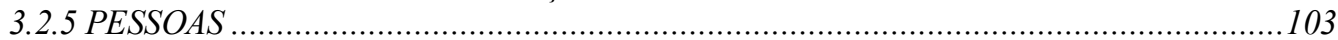

3.2.6 ESTADO ATUAL: AS EMPRESAS CONTÁBEIS COMO MÁQUINAS ……....................104

3.3 O AMBIENTE ORGANIZACIONAL - SITUAÇÃO DESEJADA ……..................................104

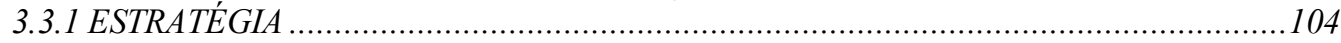

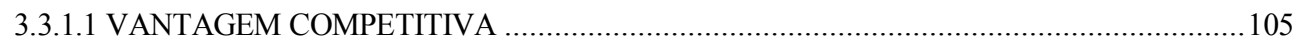

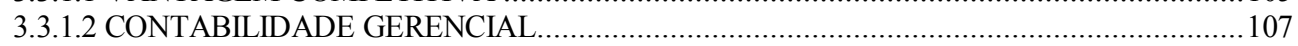

3.3.1.2.1 O SISTEMA DE CONTROLE GERENCIAL …………............................................... 108

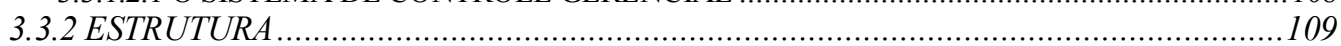

3.3.2.1 SISTEMA ORGANIZACIONAL E SEUS OBJETIVOS ..................................................... 109

3.3.2.2 ORGANIZAÇÃO ORIENTADA A PROJETOS............................................................110

3.3.2.2.1 O QUE É UM PROJETO? ................................................................................111

3.3.2.2.2 ABORDAGEM DE PROJETO ……………………………………………....112

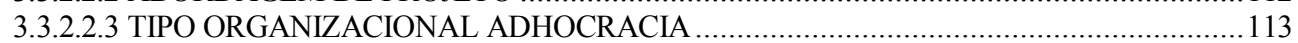

3.3.2.2.4 EQUIPES MULTIFUNCIONAIS AUTO-GERENCIÁVEIS..........................................113

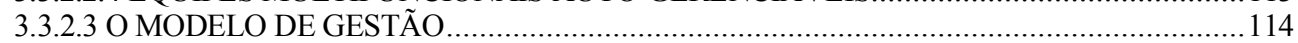

3.3.2.3.1 GESTÃO PARTICIPATIVA …………………………………………………....114

3.3.2.3.2 CONSOLIDAÇÃO DO ESPÍRITO DE EQUIPE........................................................115

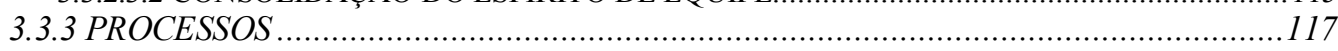

3.3.3.1 ORIGEM DA ABORDAGEM PROCESSOS ……..............................................118

3.3.3.2 A VISÃO HORIZONTAL DA ORGANIZAÇÃO...............................................................118

3.3.3.3 GESTÃO POR PROCESSOS E AS INTERFACES FUNCIONAIS .....................................119

3.3.3.4 PROJETO E ANÁLISE DE PROCESSOS DE SERVIÇOS ...................................................120 
3.3.3.5 RELAÇÃO ENTRE OS (SEI) ERPS E OS PROCESSOS ............................................... 123

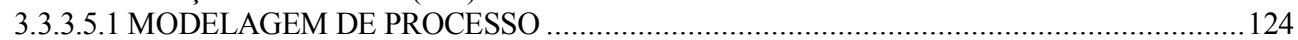

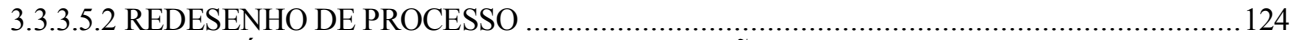

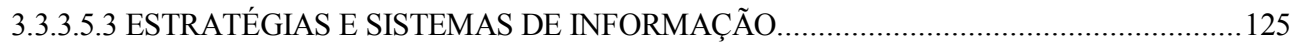

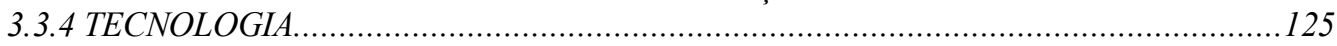

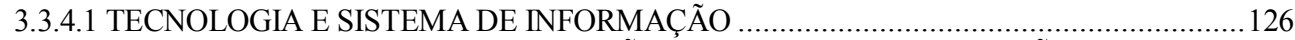

3.3.4.2 COMO OS SISTEMAS DE INFORMAÇÃO AFETAM AS ORGANIZAÇÕES ..................126

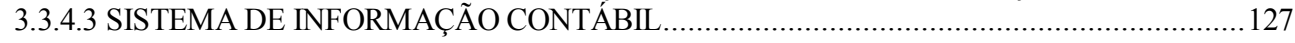

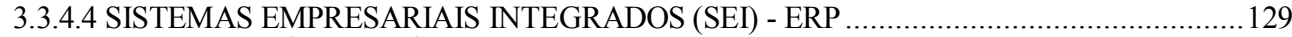

3.3.4.4.1 INTEGRAÇÃO: NOÇÃO CHAVE DO SISTEMA ERP ADVINDA DA CONTABILIDADE

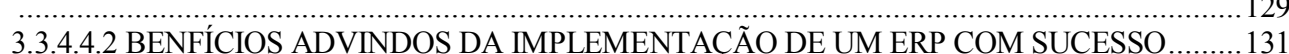

3.3.4.5 BENEFÍCIOS DA IMPLEMENTAÇÃO DE UM ERP NA EMPRESA CONTÁBIL .............131

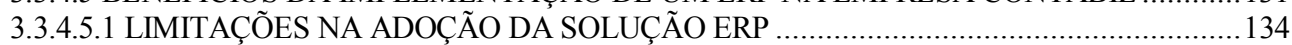

3.3.4.6 OPÇÃO DECISIVA NA IMPLEMENTAÇÃ̂O DO SEI - ERP ......................................... 135

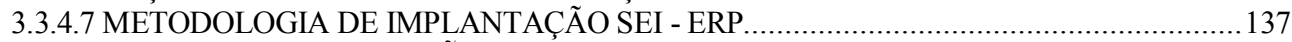

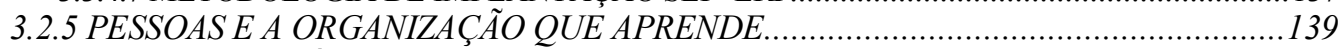

3.2.5.1 CARACTERÍSTICAS: A ORGANIZAÇÃO QUE APRENDE ...........................................139

CAPÍTULO IV - MÉTODO DE PESQUISA .......................................................................142

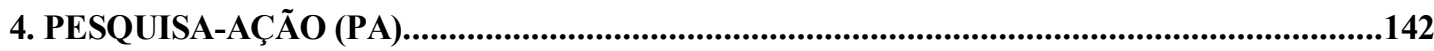

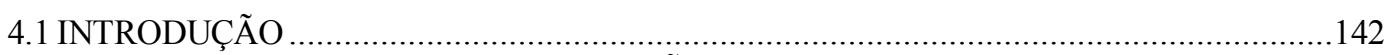

4.2 OS COMPROMISSOS DA PESQUISA-AÇÃO

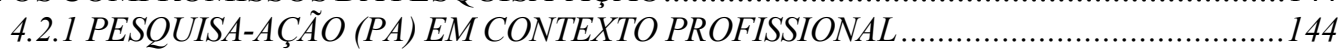

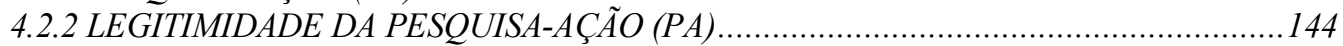

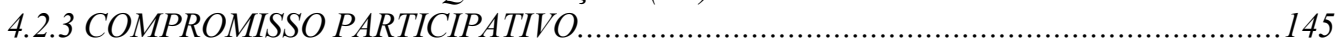

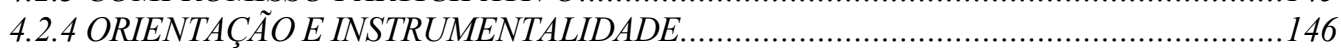

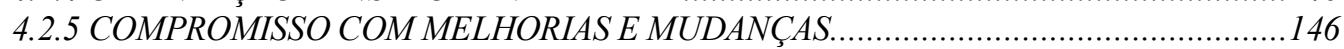

4.2.6 CIENTIFICIDADE E OBJETIVIDADE DA PESQUISA ............................................ 147

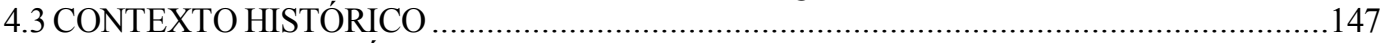

4.3.1 NADA MAIS PRÁTICO QUE UMA BOA TEORIA (KURT LEWIN)...........................148

4.3.2 A PA ORGANIZACIONAL E AS CAUSAS DA SUA POUCA DIVULGAÇÃO ..................149

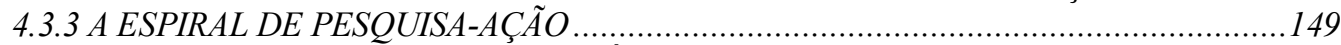

4.3.4 AS CINCO PRINCIPAIS CARACTERÍSTICAS DA PESQUISA-AÇÃO ….....................150

4.4 METODOLOGIA DE PA APLICADA E DE DIAGNÓSTICO ……........................................151

4.4.1 PESQUISA BÁSICA E PESQUISA APLICADA ………...........................................151

4.4.2 METODOLOGIA DE DIAGNÓSTICO E SUA CONCEPÇÃO......................................152

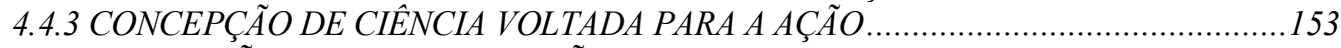

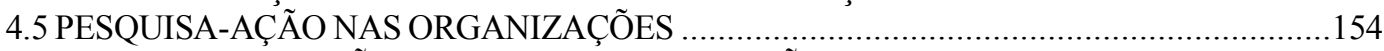

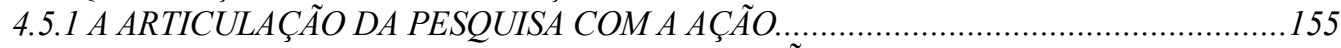

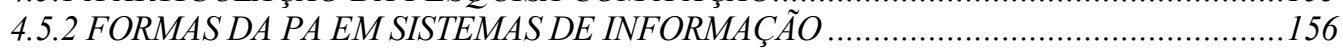

4.5.3 O ESCOPO DA PESQUISA E O MODELO GENERALIZADO - ITERAÇÕES .................157

4.5.4 DISTINGUINDO PESQUISA-AÇÃO DE CONSULTORIA ...........................................157

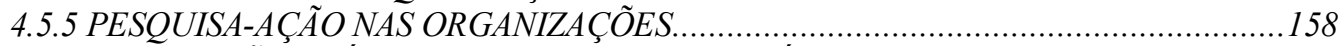

4.5.6 PA E A AÇÃO PRÁTICA NAS EMPRESAS CONTÁBEIS ..........................................................

4.5.7 PA E O SEU PONTO FORTE: RESOLVER PROBLEMAS CONCRETOS .....................161

4.6 ROTEIRO PRÁTICO DE PA NO CONTEXTO DE MUDANÇA ORGANIZACIONAL .........162

4.6.1 PROCESSO DE MUDANÇA BASEADO NA PA …............................................162

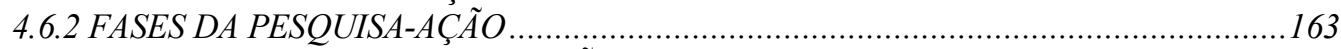

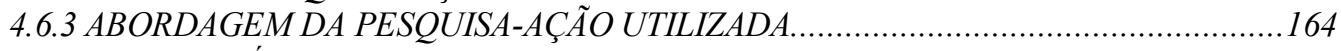

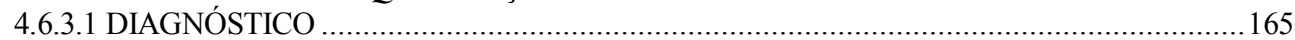

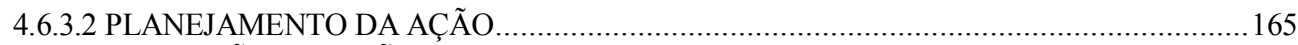

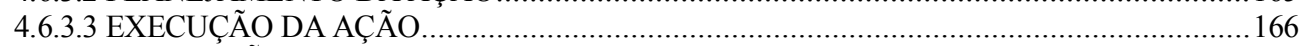

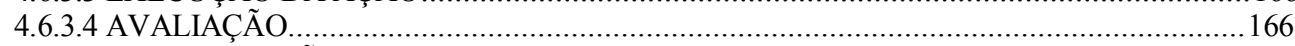

4.6.3.5 ESPECIFICAÇ̃̃O DO APRENDIZADO.................................................................166

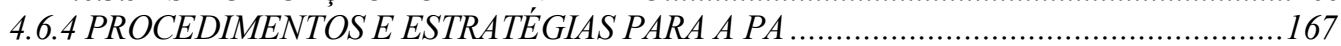

4.6.4.1 CONDIDERAR A MUDANÇA DE PARADIGMA DE PESQUISA …………………….....168

4.6.4.2 ESTABELECER UMA CONCORDÂNCIA FORMAL A PESQUISA ……………………...168

4.6.4.3 FORNECER UM ENUNCIADO TEÓRICO DO PROBLEMA …………………………........169

4.6.4.4 PLANEJAR MÉTODOS DE COLETA DE DADOS.......................................................169 
4.6.4.5 MANTER A COLABORAÇÃO E O APRENDIZADO DOS ATORES …..........................170

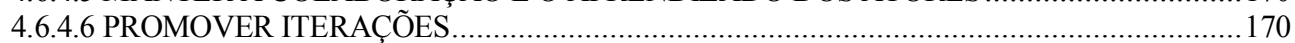

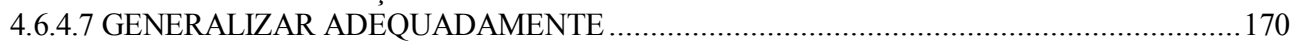

4.7 TÉCNICAS DE PESQUISA APLICADA AO CASO ESTUDADO ....................................171

4.7.1 OBSERVAÇÃO PARTICIPANTE ....................................................................... 171

4.7.2 DINÂMICA DE GRUPO E SEMINÁRIOS ....................................................... 172

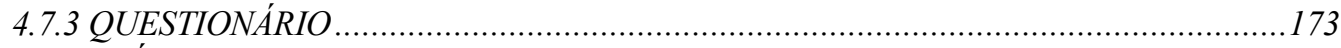

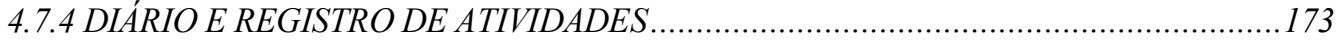

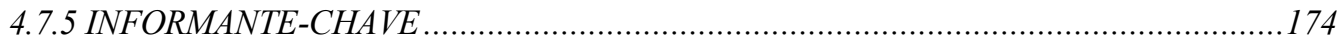

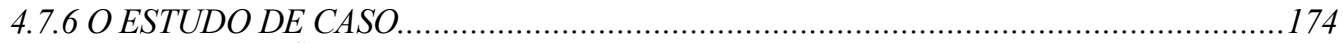

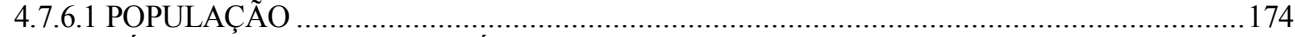

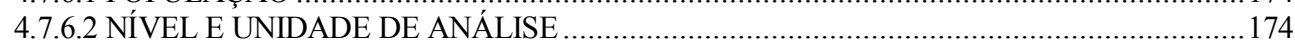

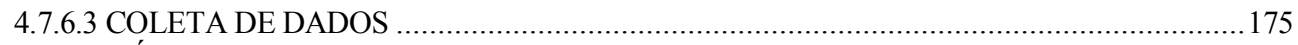

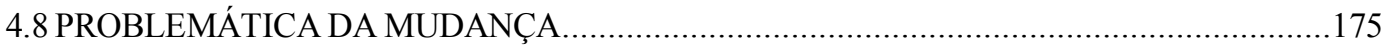

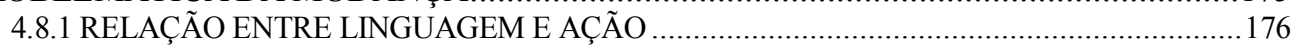

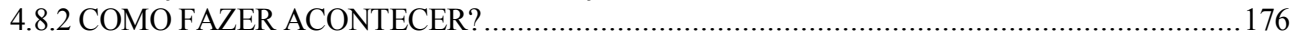

CAPÍTULO V - RESUMO DAS CONCLUSÕES ..................................................................177

5. ANÁLISE DOS DADOS COLETADOS ..........................................................................177

5.1 ADMINISTRAÇÃO DA MUDANÇA E OS PROCESSOS DE GERÊNCIA DO PROJETO ...178

5.2 CRIAÇÃO DA EQUIPE DE AGENTES DA MUDANÇA .................................................180

5.3 O PROCESSO CICLICO E AS DESCOBERTAS DA PESQUISA......................................182

5.3.1 DIMENSÃO ESTRATÉGIA ........................................................................ 183

5.3.1.1 RESPOSTA E ANÁLISE DO APRENDIZADO APLICANDO OS 05 ESTÁGIOS DE PA.. 184

5.3.1.2 CONCLUSÕES SOBRE AS MUDANÇAS NA DIMENSÃO ESTRATÉGIA.......................185

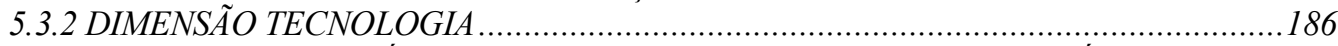

5.3.2.1 RESPOSTA E ANÁLISE DO APRENDIZADO APLICANDO OS 05 ESTÁGIOS DE PA .. 186

5.3.2.2 O PROCESSO DE ESCOLHA DO SEI - ERP PARA A EMPRESA CONTÁBIL .................188

5.3.2.3 CONCLUSÕES SOBRE AS MUDANÇAS NA DIMENSÃO TECNOLOGIA.....................190

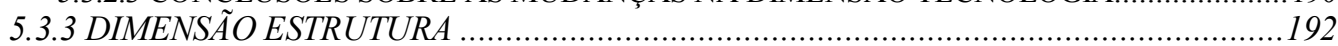

5.3.3.1 RESPOSTA E ANÁLISE DO APRENDIZADO APLICANDO OS 05 ESTÁGIOS DE PA.. 192

5.3.3.2 CONCLUSÕES SOBRE AS MUDANÇAS NA DIMENSÃO ESTRUTURA........................194

5.3.4 DIMENSÃO PROCESSOS....................................................................... 196

5.3.4.1 RESPOSTA E ANÁLISE DO APRENDIZADO APLICANDO OS 05 ESTÁGIOS DE PA ..197

5.3.4.2 CONCLUSÕES SOBRE AS MUDANÇAS NA DIMENSÃO PROCESSOS.........................198

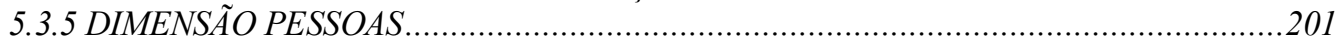

5.3.5.1 RESPOSTA E ANÁLISE DO APRENDIZADO APLICANDO OS 05 ESTÁGIOS DE PA ..201

5.3.5.2 METODOLOGIA TRANSMETH E AS BARREIRAS À MUDANÇA .................................203

5.3.5.3 CONCLUSÕES SOBRE AS MUDANÇAS NA DIMENSÃO PESSOAS.............................204

CAPÍTULO VI - CONTRIBUIÇÃO AO CORPO DE CONHECIMENTO ................................207

6. A RELAÇÃO ENTRE A MUDANÇA TECNOLÓGICA E A APRENDIZAGEM ...................207

6.1 AS QUESTÕES-CHAVE DA IMPLEMENTAÇÃO EFICAZ DA TI ....................................208

6.2 TRANSFORMAÇÃO ORGANIZACIONAL: A ABORDAGEM SÓCIO-TÉCNICA..............2.214

6.3 MODELO DE MUDANÇA ORGANIZACIONAL ABRANGENTE......................................217

6.4 PESQUISA-AÇÃO: FATORES PRINCIPAIS, PONTOS FORTES E LIMITAÇÕES. ...............218

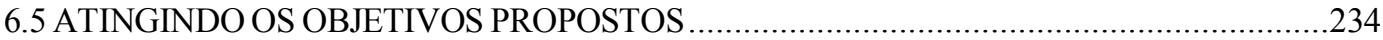

6.6 CONCLUSÃO FINAL E RECOMENDAÇÃO PARA ESTUDOS FUTUROS ………….........238

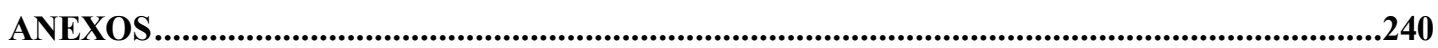

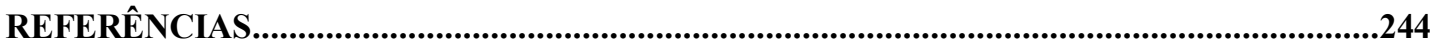

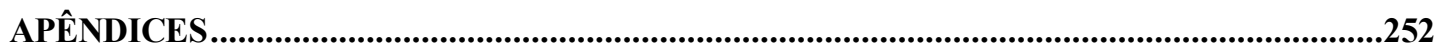

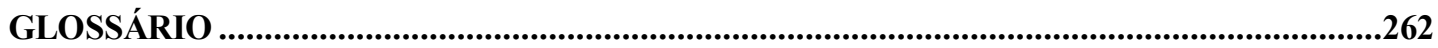




\section{LISTA DE FIGURAS, TABELAS E GRÁFICOS}

FIGURA 1 -ESTRUTURA DOS CAPÍTULOS DA PESQUISA. 6

FIGURA 2: OBJETIVOS DO PROCESSO DE MUDANÇA NA FORMA DE UMA REDE DE CAUSA E EFEITO (VG)......

FIGURA 3 - INTER-RELACIONAMENTO E AJUSTE MÚTUO DA TECNOLOGIA E DA ORGANIZAÇÃO...

FIGURA 4 - CICLO BÁSICO DA PESQUISA-AÇÃO.

FIGURA 5 - O SISTEMA DE INFORMAÇÃO CONTÁBIL INTEGRADO ESTENDIDO 28

FIGURA 6 - ARQUITETURA TECNOLÓGICA DA EMPRESA CONTÁBIL INTERLIGANDO A EMPRESA CLIENTE.

FIGURA 7 -DESENHO DA ABORDAGEM UTILIZADA PARA CONDUZIR A PESQUISA: LIGA O PROBLEMA INICIAL AO REFERENCIAL TEÓRICO, MOSTRANDO A ABORDAGEM UTILIZADA PARA IDENTIFICAR AS UNIDADES DE ANÁLISE... 37

FIGURA 8 - A EMPRESA VISTA COMO UM SISTEMA ABERTO .. 46

FIGURA 9-A EMPRESA VISTA COMO UM CONJUNTO DE PROCESSOS . .53

FIGURA 10 - CICLOESTENDIDO DA PESQUISA AÇÃO: INCLUI O LOOP DUPLO PARA QUEBRA DE PARADIGMA...

FIGURA 11 - CICLO ESTENDIDO DA PESQUISA-AÇÃO, CONFORME A FIGURA ANTERIOR: DETALHAMENTO LÓGICO DA ETAPA DE AVALIAÇÃO OCORRE EM CICLOS - * LOOP SIMPLES (SINGLE LOOP) ** LOOP DUPLO (DOUBLE LOOP).

FIGURA 12 - PROBLEMA INICIAL DE PESQUISA: SISTEMA DE INFORMAÇÃO CONTÁBIL NÃO INTEGRADO DE FORMA NATURAL, CAUSANDO RETRABALHO E BAIXO APROVEITAMENTO DO POTENCIAL DO CONTADOR.

FIGURA 13 - IDENTIFICAÇÃO DE OPORTUNIDADES SURGIDAS DA ATUALIZAÇÃO TECNOLOGICA ATRAVÉS DA ADOÇÃO DE UM SISTEMA EMPRESARIAL INTEGRADO - ERP.

FIGURA 14 - A MUDANÇA ORGANIZACIONAL E SEUS MÚTIPLOS REFLEXOS

FIGURA 15 - A FUNÇAO DOS PROCESSOS NO SISTEMA DE OPERAÇÕES DE SERVIÇOS......121

FIGURA 16 - CICLO DE VIDA DE SISTEMAS

FIGURA 17 - CICLO BÁSICO DA PA: A ESPIRAL ASCENDENTE EM(LOOP SIMPLES). RELACIONAMENTO ENTRE O ESCOPO DA PESQUISA E O MODELO GENERALIZADO.

FIGURA 18 -O PROCESSO CICLICO DE 05 FASES DA PA (ABORDAGEM UTILIZADA) .........165

FIGURA 19 - EXEMPLO DE SEQUÊNCIAS NO PROCESSO DE PESQUISA-AÇÃO....................168

FIGURA 20 - ORGANOGRAMA FUNCIONAL DA EQUIPE DO PROJETO ORGANIZACIONAL (AGENTES DA MUDANÇA)

FIGURA 21 -O PROCESSO CICLICO DE 05 ESTÁGIOS DA PA (ABORDAGEM UTILIZADA PARA DESCREVER AS DESCOBERTAS DE PESQUISA)

FIGURA 22 - DIVERSIFICAÇÃO ESTRATÉGICA DA EMPRESA CONTÁBIL ATRAVÉS DA CONSULTORIA DE GESTÃO A PME, RESGATANDO A CONTABILIDADE GERENCIAL ATRAVÉS DA IMPLANTAÇÃO DE SISTEMA EMPRESARIAL INTEGRADO - ERP.

FIGURA 23 - ESTRUTURA RESUMIDA DA TEORIA E DA PRÁTICA PARA IMPLEMENTAÇÃO EFICAZ DA TI. 
FIGURA 24 -O GERENCIAMENTO DA TRANSFORMAÇÃO ORGANIZACIONAL, ATRAVÉS DE UMA ABORDAGEM SÓCIO-TÉCNICA AOS NEGÓCIOS E A FORMAÇÃO DA ESTRATÉGIA DE SISTEMA DE INFORMAÇÃO.

TABELA 1 - REPRESENTAÇÕES: DIRIGIDAS E FUNDAMENTADAS POR PARADIGMAS (MODELOS).

TABELA 2 - ABORDAGENS: DIRIGIDAS E FUNDAMENTADAS POR METODOLOGIAS (COMO OS CONCEITOS PODEM SER APLICADOS)

TABELA 3 - COMPARAÇÃO DE TÉCNICAS PARA ANALISAR PROCESSOS DE SERVIÇOS ..122

TABELA 4 - PROCESSOS PRINCIPAIS DE GERENCIA DE PROJETO .180

TABELA 5 - AVALIAÇÃO DOS REQUISITOS QUANTO A CARACTERÍSTICAS TECNOLÓGICAS E DE NEGÓCIOS DESEJÁVEIS EM UM SISTEMA EMPRESARIAL INTEGRADO - ERP PARA A EMPRESA CONTÁBIL

TABELA 6 - SÍNTESE DAS PRINCIPAIS VARIÁVEIS DE MUDANÇAS TECNOLÓGICAS IDENTIFICADAS E O GRAU DE APLICAÇÃO OBSERVADO.

TABELA 7 - SÍNTESE DAS PRINCIPAIS VARIÁVEIS DE MUDANÇAS ESTRUTURAIS IDENTIFICADAS E O GRAU DE APLICAÇÃO OBSERVADO.

TABELA 8 - SÍNTESE DAS PRINCIPAIS VARIÁVEIS DE MUDANÇAS COMPORTAMENTAIS IDENTIFICADAS E O GRAU DE APLICAÇÃO OBSERVADO.

TABELA 9 - RESULTADO DA ANÁLISE DE BARREIRAS AO PROCESSO DE MUDANÇAS ...212

TABELA 10 - FATOR PRINCIPAL: PARTICIPAÇÃO

TABELA 11 -FATOR PRINCIPAL: PESSOAS-CHAVE .223

TABELA 12 -FATOR PRINCIPAL: RELACIONAMENTO PESQUISADOR-PARTICIPANTE DA PA.

TABELA 13 -FATOR PRINCIPAL: FOCO NA REALIDADE (MUNDO REAL) _...........................227

TABELA 14 -FATOR PRINCIPAL: PROCESSO E GERENCIAMENTO DO PROJETO.................230

TABELA 15 -FATOR PRINCIPAL: CONHECIMENTO.

GRÁFICO 1 - PROFISSIONAL OU ENTIDADE PROCURADO PARA ASSESSORIA POR PEQUENAS EMPRESAS NO ESTADO DE SÃO PAULO 


\section{LISTA DE SIGLAS E SÍMBOLOS}

ABM - Activity Based Management - Gerenciamento Baseado em Atividades.

ASP - Application Service Provider - Provedor de Serviços de Aplicação.

CFC - Sigla do Conselho Federal de Contabilidade.

CRC/SC - Sigla do Conselho Regional de Contabilidade de Santa Catarina.

CVM - Sigla de Comissão de Valores Mobiliários.

DBMS - Data Base Management System - Sistema de Gestão de Banco de Dados.

DSS - Decision Support Systems - Sistema de Apoio à Decisão (SAD).

ERP - Enterprise Resources Planning - Sistema Empresarial IntegradoSistema Empresarial Integrado (Tradução não literal).

ERP II - Enterprise Resources Planning II - Sistema Empresarial IntegradoSistema Empresarial Integrado II.

FIPE - Fundação Instituto de Pesquisas Econômicas

IBGE - Sigla de Instituto Brasileiro de Geografia e Estatística.

IBRACON - Sigla de Instituto Brasileiro de Contadores.

ICMS - Sigla de Imposto sobre a Circulação de Mercadorias e Serviços.

IOB - Informações Objetivas publicações Jurídicas Ltda.

IMA - Institute of Management Accountants - A associação de contadores gerenciais dos Estados Unidos.

LAN - Local Area Network - Rede Local

MBC - Manegement By Collaboration - Gestão por colaboração.

NBC - Sigla de Normas Brasileiras de Contabilidade.

PA - Pesquisa-Ação, ou AR - Action Research.

PME - Pequena e Média Empresa

TCO - Total Cost of Ownership - Custo Total de Propriedade.

TI - Tecnologia de informação.

TQM - Total Quality Management - Gestão da qualidade Total.

SAE - Sistema de automação de escritório

S/C - Sigla utilizada para abreviar Sociedade Civil.

SEBRAE - Sigla de Serviço Brasileiro de Apoio às Micro e Pequenas Empresas.

SEI - Sistemas Empresariais Integrados.

SGE - Sistema de Gestão Empresarial.

SI - Sistema de Informação.

SIC - Sistema de Informação Contábil

SIC i - Sistema de informações contábeis integrado

SIG - Sistema de informação gerencial

SPT - Sistemas de processamento de transação

SRF - Secretaria da Receita Federal. 
SSD - Sistema de suporte de decisão

SSE - Sistema de suporte executivo

STC - Sistema de trabalho do conhecimento 


\section{RESUMO}

PEREIRA, J.S. Sistemas Empresariais Integrados - ERP na Empresa Contábil: Um estudo de caso de mudança organizacional com o uso da pesquisa-ação. 2003. 271 p. p. Dissertação Mestrado - Faculdade de Economia, Administração e Contabilidade - Departamento de Contabilidade e Atuaria, Universidade de São Paulo - São Paulo.

Este trabalho discute as mudanças nos processos de serviços de uma empresa contábil em fase de expansão de suas atividades utilizando-se de novas tecnologias de sistemas de informações. A implantação de uma nova arquitetura de serviços com o uso de tecnologia avançada é um desafio, e ao mesmo tempo uma oportunidade para empresa contábil transformar-se num provedor de serviços de aplicação, com a oferta de valor adicionado aos clientes. O trabalho foi desenvolvido utilizando-se o paradigma da pesquisa-ação, que vem sendo intensamente utilizado nas pesquisas em sistemas de informação, principalmente na condução eficaz das mudanças organizacionais necessárias ao aproveitamento de todo o seu potencial, com resultados positivos em termos econômicos e sobre o pessoal. Os resultados mostram que o uso da tecnologia de informação avançada através da implantação de sistema empresarial integrado ERP - requer o desenvolvimento de um modelo de mudança organizacional abrangente, permitindo melhora significativa nos processos da empresa contábil e exigindo a construção de um ambiente de comprometimento entre as pessoas, contribuindo para a diversificação estratégica dessas empresas de maneira compatível com missão tradicional da contabilidade.

Palavras-Chave: Contabilidade Gerencial, Sistema Empresarial IntegradoSistema Empresarial Integrado - ERP, Tecnologia de informação, Mudança Organizacional, Pesquisa-Ação. 


\begin{abstract}
PEREIRA, J.S. Integrated Company Systems - ERP in the Accounting Company: A case study about organizational change using Action Research. 2003. 255271 p. p. Master's Dissertation - School of Economy, Administration and Accountancy - Department of Accountancy and Actuarial Science, University of São Paulo - São Paulo.

This study discusses the changes in the service process of an accounting company that is expanding its activities by means of new information system technologies. The implantation of a new service architecture with the use of advanced technology is a challenge and, at the same time, an opportunity for the accounting company to turn into an application service provider, offering value added to the clients. The study was developed using the Action Research paradigm, which has been intensely used in research on information systems, mainly in the efficient realization of the necessary organizational changes for using their full potential, with positive results in economic and staff terms. The results show that the use of advanced information technology through the implementationantation of an integrated company system - ERP - requires the development of a broad organizational change model, allowing for a significant improvement in the accounting company's processes and demanding the construction of an environment of mutual engagement among persons, contributing to the strategic diversification of these companies in a way that is compatible with the traditional mission of accounting.
\end{abstract}

Keywords: Management Accounting, Enterprise Resources Planning Integrated Company System - ERP, Information Technology, Organizational Change, Action Research. 


\section{CAPITULO I - VISÃO GERAL DA PESQUISA}

Este capítulo fornece uma visão geral da pesquisa. Introduz o problema central de pesquisa, seu objetivo geral e os objetivos específicos, e então "ajusta o cenário" delineando o caminho pelo qual o pesquisador se moverá em direção aos resultados, demonstrando a estrutura dos capítulos e seu ordenamento na medida em que as descobertas foram acontecendo. Inicialmente apresenta-se um contexto geral, explicando a necessidade do estudo e identificando as questões urgentes de aplicação da teoria ou a inexistência dela com aplicação prática, bem como qual o método de pesquisa será utilizado. Um quadro de referencia teórico com os principais temas abordados são apresentados através do desenho da pesquisa.

\section{INTRODUÇÃO}

Por volta do ano 500 a.C., o filósofo grego Heráclito observou que "não se pode pisar duas vezes o mesmo rio, já que as águas continuam constantemente rolando”. A idéia de que o universo se encontra em constante transformação, incorporando tanto características de permanência quanto de mudança, estava lançada por Heráclito, que observou: "tudo flui e nada permanece igual; tudo se desintegra e nada continua, (...) O frio se torna quente e o quente, frio; o úmido se torna seco e o seco umedece, (...) É ao mudar que as coisas encontram repouso”. Para ele, os segredos do universo seriam descobertos nas tensões ocultas e nas conexões que simultaneamente criam padrões de unidade e mudança. (Morgan, 1996).

Essa idéia milenar sobre a natureza contínua do processo de mudança propõe uma reflexão sobre a contabilidade e o processo de trabalho nas empresas: as empresas contábeis não precisam mudar? Se precisam, como fazê-lo? A tecnologia de informação contribui para essas mudanças? Como? Em que nível? A relação entre a arquitetura tecnológica e a arquitetura organizacional das empresas contábeis e as suas múltiplas e recíprocas influências durante um processo de mudança são os assuntos dominantes nesta pesquisa.

Neste trabalho utilizar-se-á a expressão “empresa contábil” para designar de forma abrangente todas as entidades que tem como missão principal a prestação de serviços de contabilidade, independente da forma jurídica de sua constituição. 
Esta expressão incorpora, também, a definição que o conselho federal de contabilidade (CFC) fez através da resolução $n^{\circ}$ 825/98, onde utiliza o nome organização contábil tanto para a empresa como para o escritório individual, referindo-se as atividades de prestação de serviços profissionais de contabilidade em forma de organização, isto é, de empresa que detém a responsabilidade técnica pelos serviços de contabilidade da empresa-cliente.

\subsection{A PROFISSÃo CONTÁBIL EM ESTADo CONTÍNUO DE MUDANÇAS}

A crescente participação das Pequenas e Médias Empresas $(\mathrm{PME})^{1}$ na economia mundial e, principalmente, sua importância na economia brasileira, é hoje uma realidade incontestável. O aumento da concorrência, a escassez de recursos disponíveis, as novas tecnologias e a globalização têm contribuído para as constantes mudanças na gestão dessas empresas, forçando-as na busca da competitividade e da modernização, permitindo o crescimento.

Para apoiá-las nesta modernização, essas empresas vão, com freqüência, buscar fora as competências que lhes faltam, principalmente buscando informações que auxiliem seus gestores nas tomadas de decisão, através das empresas de serviços contábeis (Thomé, 2001), popularmente conhecidas como "escritórios de contabilidade" e antigamente denominados de "guarda-livros".

Esses serviços concentram-se, via de regra, nos aspectos legais da contabilidade, de reconhecida utilidade, porém, aquém das reais necessidades empresariais e da importância que a contabilidade representa para o sucesso dos negócios nos tempos atuais, como o principal sistema de informações da empresa.

Sobre a evolução histórica da contabilidade no Brasil, Schmidt (2000) concluiu em suas pesquisas que a regulamentação fiscal foi o seu grande agente impulsionador

\footnotetext{
${ }^{1}$ Como não há uma definição única na literatura sobre os parâmetros para enquadramento das empresas entre pequenas, médias e grandes, consideramos aquelas que buscam a terceirização de serviços relacionados à contabilidade, gestão fiscal e de pessoal, objetivando agilidade nas respostas e eficácia na administração destes custos.
} 
de criação e desenvolvimento - ou limite a este, devido principalmente à inoperância das associações de contadores. Este fato amarrou de forma decisiva a contabilidade nacional às normas legais, contribuindo para a formação da visão de uma grande parte do mercado, de que os objetivos das empresas contábeis centram-se no atendimento de questões fiscais.

Essa constatação, de que a empresa contábil está colocada em posição intermediária entre o poder público e as empresas-cliente, concentrando-se no processo de escrituração, tendo como conseqüência principal as regulamentações fiscal e social, pode ser superada, e as oportunidades para isso já foram lançadas pela informática.

A aplicação da tecnologia de informação (TI) aos negócios está provocando mudanças profundas nas organizações, com reflexos na contabilidade e no campo de atuação do contador. A profissão contábil está em estado contínuo de mudanças, mais do que qualquer outra profissão, na medida em que os contadores redefinem o trabalho que fazem. (Moscove., Simkin, Bagranoff, 2002).

Se por um lado, estas mudanças estão introduzindo uma banalização do saberfazer contábil tradicional, que vê a contabilidade como algo distante da realidade dos processos empresariais, por outro lado, surgem enormes oportunidades e desafios no uso da tecnologia como ferramenta para o tratamento e divulgação da informação contábil. Observou-se uma distâancia enorme entre a realidade do ambiente empresarial moderno e as práticas existentes nas empresas contábeis, principalmente na empresa contábil pesquisada.

A palestra de aberturaO professor Iudícibus ${ }^{1}$ na palestra de abertura do $2^{\circ}$ seminário USP de contabilidade em Outubro de 2002, chamou atenção para as profundas mudanças que devem ocorrer na contabilidade, destacando as inovações no processo contábil com os sistemas de informação contábil integrados, e enfatizando que "somente sobrevivem às espécies que se adaptam às mudanças no meio ambiente", o que vem de encontro ao principal objetivo desta pesquisa, qual seja, de como administrar um processo de mudança numa empresa contábil que permita

\footnotetext{
${ }^{1}$ Sérgio de Iudícibus. $2^{\circ}$ Seminário USP de Contabilidade, realizado no Período de 1 e 2 de outubro de 2002 em São Paulo-SPP.
} 
implementar um sistema empresarial integradoSistema Empresarial Integrado - ERP maximizando o seu potencial.

\subsection{O FUTURO DA CONTABILIDADE E A EMPRESA CONTÁBIL}

A frase "Pacioli se sentiria muito confortável com os sistemas contábeis que encontramos hoje”, proferida por Hendriksen e Van Breda (1999, pg.49), encerra uma verdade incontestável sobre a prática contábil: a contabilidade propriamente dita tem permanecido virtualmente constante, nos últimos 500 anos, apesar da revolução informacional observada na atualidade.

Particularmente, nas empresas contábeis isto fica mais evidente, a partir da análise dos processos de trabalho dessas empresas, cujas atividades são restritas ao processo de escrituração, decorrentes da visão dos seus gestores, isto é, entendendo a contabilidade como um ato de "Escriturar" - de registrar as operações exercidas e comprovadas pela empresa que ocorreram no decorrer de um período.

$\mathrm{O}$ ambiente de informática deveria ter afetado a contabilidade de maneira dramática, mas o que se observa é uma defasagem muito grande entre as invenções e as aplicações práticas decorrentes. A contabilidade ainda não tirou proveito das novas invenções tecnológicas. A evolução dos meios de geração e difusão da informação, no final do século passado, propiciaram profunda mudança nas relações existentes entre o contador e o ambiente captador de seus serviços. Observa-se uma diferença cada vez maior entre as informações disponíveis no ambiente empresarial, seus níveis de análise, interpretação e uso, e o que é ensinado aos profissionais em algumas universidades do interior do país, evidenciado pela maneira como é enfocada a contabilidade nos livros texto e sua prática nas empresas contábeis.

Prevendo que a tecnologia proporcionará uma verdadeira revolução na contabilidade, pois todas as informações estarão acessíveis aos usuários sem restrições de formato, tempo e local, Hendriksen e Van Breda, já citados, concluem que a aplicação da tecnologia disponível transformará em realidade este futuro. A questão é quando essas previsões chegarão à realidade das empresas contábeis do interior do Brasil? Ou mesmo se chegarão? 


\subsection{A ORGANIZAÇÃO DODESTE TRABALHO}

A organização deste trabalho, segue, em linhas gerais as propostas feita por Dick (1997) e Perry (1998,) e especificamente para a área organizacional os modelos sugeridos por Sankaran (2001) e Thiollent (1997), adaptadas pelo autor ao ambiente da empresa contábil pesquisada. O modelo foi construído com base no paradigma da pesquisa-ação, visto tratar-se de pesquisa qualitativa com o uso do estudo de caso, diferente dos modelos de pesquisa tradicional.

\subsubsection{OS CAPÍTULOS DA PESQUISA E SEU DESENHO}

A dissertação tem uma estrutura unificada. O capítulo (I) introduz o problema central de pesquisa, e então "ajusta o cenário" delineando o caminho pelo qual o pesquisador se moverá em direção aos resultados. Inicialmente apresentou-se um contexto geral, explicando a necessidade do estudo e identificando as questões urgentes de aplicação da teoria ou a inexistência dela com aplicação prática. Um quadro de referencia teórico com os principais temas abordados são apresentados no item 1.7.6 pela figura 7 desenho da pesquisa.

A pesquisa em si está descrita nos capítulo II a V. O problema inicial de pesquisa, seus refinamentos e as questões vão emergindo do corpo de conhecimentos desenvolvido durante a pesquisa prévia no Capítulo II, onde discute-se a empresa contábil e o seu ambiente; aprofunda-se a pesquisa teórica através da revisão da literatura no capítulo III, onde discute-se o processo de mudança que fundamenta a abordagem utilizada, de acordo com o desenho da pesquisa da figura 7. Pela abordagem desenvolvida algumas das conclusões teóricas da pesquisa sobre as questões vão emergindo ao longo do texto.

O capítulo IV explica a metodologia utilizada para coletar os dados, esboçando como os resultados serão alcançados e justificando a abordagem utilizada. Neste capítulo foram identificados o paradigma de pesquisa-ação numa visão geral, a metodologia utilizada no contexto particular da empresa contábil e os métodos utilizados, descrevendo-os e justificando-os para este fim específico. São demonstrados de forma clara e cuidadosa os passos utilizados, descrevendo com rigor como o resultado foi alcançado. 
$\mathrm{O}$ capítulo $\mathrm{V}$ apresenta os resultados da aplicação destes métodos na pesquisa e as conclusões sobre as questões e os problemas de pesquisa, apresentando a análise dos dados coletados. No capítulo VI discute-se a contribuição para o corpo do conhecimento delineado previamente nos capítulos II, III e IV, ou seja, o que se compreende agora e que não era compreendido antes.

\section{FIGURA 1 - ESTRUTURA DOS CAPÍTULOS DA PESQUISA}

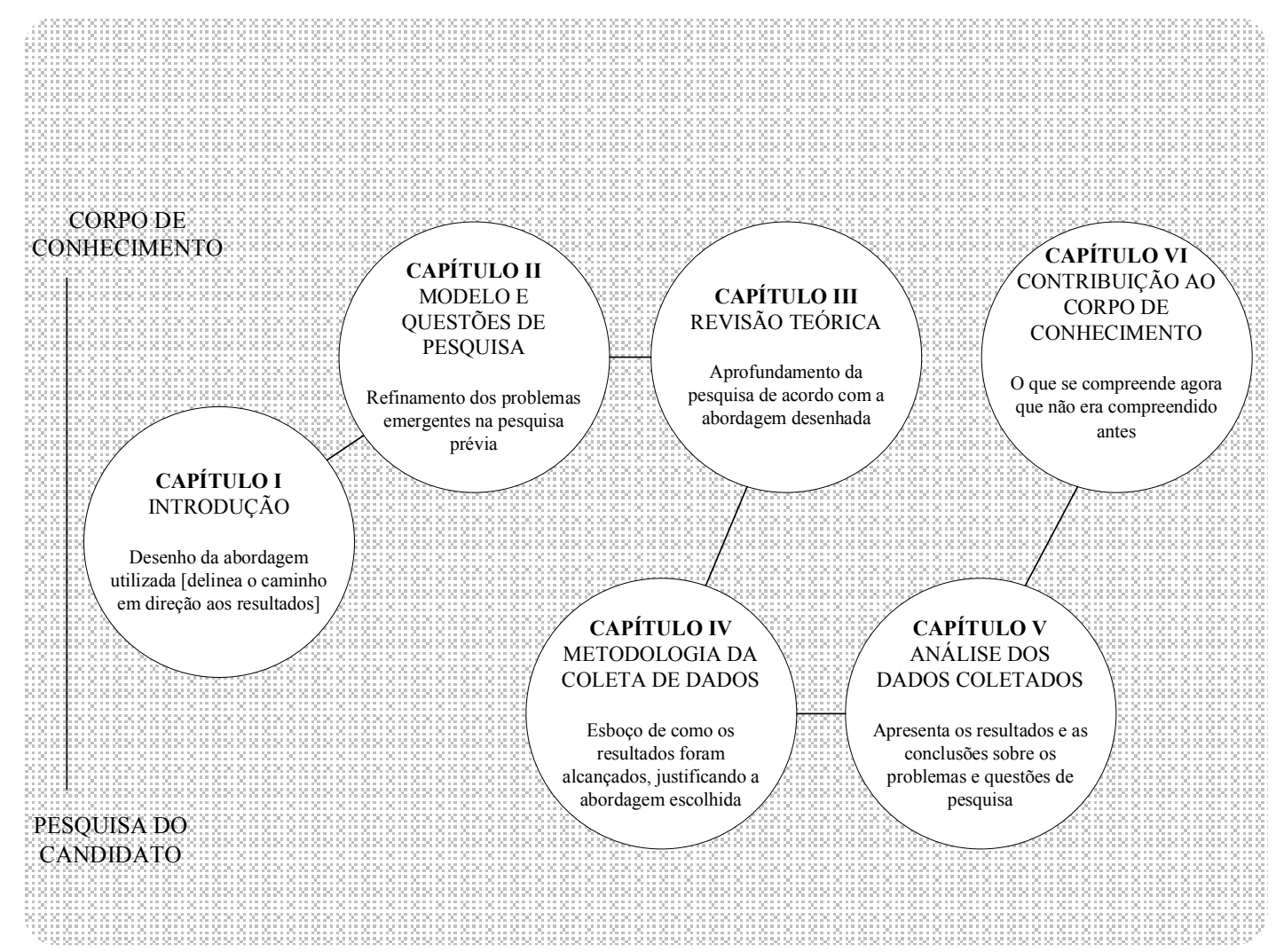

Fonte: Perry (1998) - Adaptado pelo Autor

A estrutura dos capítulos da pesquisa e seu ordenamento, demonstrado acima, procurou ser fiel o máximo possível aos momentos (evolução no tempo) em que as descobertas foram acontecendo e a necessidade de embasamento teórico para as questões que iam sendo levantadas pelo grupo. A abordagem PA tem entre outras essa 
característica e que foi fundamental para o andamento do trabalho e a construção do modelo proposto.

\subsubsection{IDENTIFICANDOÇÃO A VOZ DO GRUPO}

Ao longo da pesquisa houve uma interação muito forte entre os membros do cliente (empresa pesquisada) e o pesquisador, até porque a mudança é um processo contínuo que foi se construindo durante ao longo do trabalho. O pesquisador procurou relatar as conclusões do grupo, na medida do possível, respeitando a linguagem utilizada pelos atores envolvidos, e em muitos casos as conclusões (planejamento das ações) e decisões (especificação das ações) foram relatadas na forma que foram sendo compreendidas e estão descritas na pesquisa, identificadas no texto ou no desenho pelas letras maiúsculas VG (voz do grupo) no fim do parágrafo e o (conteúdo sublinhado), diferenciando-se assim dos relatos das conclusões do próprio pesquisador. Em muitos casos a compreensão e a aplicação da teoria no caso estudado veio das discussões dos atores envolvidos com a orientação do pesquisador, como por exemplo, as conclusões sobre a avaliação e escolha do sistema integrado a ser utilizado. O próprio Thiollent (1997, pg.37) esclarece que existe uma relação muito forte ligando a articulação da pesquisa com a ação. Tema central da metodologia pesquisa-ação, a articulação da pesquisa e da ação é concebida de modo diferenciado e em função de uma tipologia das formas de participação. Vista como pesquisa inserida na ação, a pesquisa-ação comporta três aspectos simultâneos (Thiollent; 1997, pg.37):

(a) Pesquisa SOBRE os atores sociais, suas ações, transações, interações; seu objetivo é a explicação;

(b) pesquisa PARA dotar de uma prática racional as práticas espontâneas; seu objetivo é a aplicação.

(c) Pesquisa POR, ou melhor, PELA ação, isto é, assumida por seus próprios atores (auto-diagnóstico e auto-prognóstico) tanto em suas concepções como em sua execução e seus acompanhamentos; seu objetivo é a implicação.

Além dos três tipos de pesquisas correspondentes à explicação, aplicação e implicação, complementarmente a PA possui cinco dimensões (Thiollent; 1997, pg.38) a saber:

(i) Contrato, que pode ser informal entre o pesquisador e atores e consiste em definir os objetivos de conhecimento e mudança; (ii) Participação, que varia entre as formas de colaboração, cooperação ou co-gestão; (iii) Mudança, deriva da aplicação de uma teoria, de um processo de cooperação ou de co-gestão; (iv) Discurso, pode ser espontâneo, esclarecido ou engajado; e (v) Ação, que apresenta aspectos individuais, coletivos ou comunitários. 
Esclarece o autor, tanto com relação às cinco dimensões da PA discutidas acima, quanto ao que diz respeito à tipologia das modalidades de articulação entre, de um lado, a pesquisa e os autores (pesquisadores) e, de outro lado, a ação e os atores, que existe multiplicidade de configurações a serem escolhidas, elaboradas ou adaptadas em função das situações concretas da investigação e das ações possíveis.

Neste trabalho, o contrato estabelecido foi informal e aberto, pois o pesquisador faz parte da equipe de trabalho, e os objetivos traçados foram a condução do processo de mudança na arquitetura (organizacional e tecnológica) da empresa contábil que permita o crescimento das suas atividades.

A participação foi a co-gestão e a mudança foi desenvolver um processo de cogestão tendo como teoria o Desenvolvimento Organizacional (DO), a abordagem sócia-técnica, a ciência-ação e análise dos seus reflexos nas dimensões da organização com base no triâangulo estratégico proposto por Walton (1998), isto é, a conexão entre a estratégia de negócios, estratégia de organização e estratégia de Tecnologia de informação.

Finalmente o discurso foi o espontâneo e a ação apresenta aspectos de mudança individual e coletiva, ou seja, na cultura da organização.

\subsubsection{ARTICULANDO CONCEITOS E IDÉIAS}

A analogia é um dos mais importantes artifícios do pensamento. Octávio Paz, apud Alves (2001, pg.87), em seu livro "Los hijos Del limo", afirma que a "analogia torna o mundo habitável”. Ela é o reino da palavra como, essa ponte verbal que, sem suprimí-las, reconcilia as diferenças e oposições. A analogia nos permite caminhar do conhecido para o desconhecido. Utilizar-se-á, na medida do necessário, analogias e figuras de linguagem ao longo desta pesquisa, para melhor expressar as idéias e tornar possível seu entendimento.

Este trabalho tem a preocupação central de descrever um processo de aprendizagem na prática, construindo uma representação e explicação da ação de mudança organizacional numa empresa contábil do interior do Brasil, de acordo com o entendimento do seu ambiente, através de um conjunto de variáveis do comportamento organizacional. 
Nos estudos organizacionais, alguns conceitos e definições a respeito de elementos como paradigma, sistema, esquema, modelo, processo, procedimento, técnica, método e ferramenta são fundamentais para se entender o papel de um modelo (Lima, 2001). Várias formas de representações (sistema, esquema, mapa e modelo) e de aplicações (processos, procedimentos, técnicas, métodos e ferramentas) podem ser classificados tendo como base duas dimensões: que vão do aplicado (ação concreta e o ambiente prático ou operacional) ao conceitual (abstração e / ou entendimento de uma situação); ou do estático (relacionado à estrutura e ao posicionamento dos elementos em um sistema) ao dinâmico (referindo-se às relações causais e de interação entre os elementos de um sistema) .

Para este trabalho foi importante resgatar alguns conceitos estabelecidos em Shehabuddeen, Probert e Phaal, apud Lima (2001, pg.132), para esquemas (frameworks), mapas conceituais, modelos e processos, e que serão definidos de forma sumarizada adiante:

(i) ESQUEMA (FRAMEWORK): Pode ser definido para: (i) descrever como um determinado objetivo pode ser alcançado (saber como); (ii) - identificar e representar uma determinada situação (saber o quê). Os esquemas (frameworks) são utilizados como uma forma de traduzir temas complexos em formas que possam ser analisadas. Empregam-se em particular para: (i) comunicar idéias e descobertas a uma ampla comunidade, entre acadêmicos, ou entre academia e indústria; (ii) realizar comparações entre diferentes situações e abordagens; (iii) definir o domínio ou os limites de uma situação; (iv) descrever o contexto ou argumentar a validade de uma descoberta; (v) sustentar o desenvolvimento de procedimentos, técnicas ou métodos e ferramentas. Destaca-se o papel dos esquemas (frameworks) em facilitar o entendimento e a comunicação entre participantes que possam ter diferentes perspectivas. Esquemas também suportam o processo de tomada de decisão e de resolução de problemas, fornecendo as categorias e representações normalmente em uma linguagem de símbolos. Também são fundamentados por um determinado paradigma.

(ii) MAPAS CONCEITUAIS: São comumente usados como uma forma de se representar um momento "foto instantânea" das relações entre vários elementos de um sistema. Os mapas mostram as relações posicionais ou espaciais entre os elementos. Portanto, permitem aos pesquisadores estabelecer as conexões entre os elementos de um sistema, não de forma a estabelecer as causalidades, mas em termos de posicionamento e estrutura, dentro de uma visão integral ou sistêmica.

(iii) MODELOS: São muito utilizados, dentro da teoria organizacional, e em particular na área de gestão de operações, com a finalidade de estimar, prever e também para o processo de tomada de decisão. Modelos (i) são representações de objetos e situações reais; (ii) são uma abstração seletiva da realidade, e podem ser descritos pelas seguintes características: (i) um modelo é uma representação dinâmica da realidade; (ii) tem como objetivo aclarar as relações entre diferentes elementos, indicando causalidades e interações efetivas. Um modelo é um tipo particular de esquema, tendo um papel fundamental na difusão de práticas, ainda que delas se diferencie, por ser um processo abstrato. Os modelos estabelecem um modo de pensar, abordar e articular os problemas organizacionais e desempenham um papel de referência, ou seja, operam como prescrição para os agentes que tomam decisões a respeito de práticas a serem 
empregadas nas operações e processos organizacionais. Há uma espécie de dialética entre o modelo, como modo de pensar o problema organizacional, frente às condições do ambiente e à necessidade de viabilidade por parte das organizações empresariais, e as práticas que estas adotam. Um modelo é certamente produzido e reproduzido por atores sociais, mas é também aquilo que se impõe aos atores como um quadro, geralmente tanto ou mais implícito do que explícito, de definição e avaliação da racionalidade de ação. Um modelo é visto como uma forma de solucionar os problemas de eficiência colocados à organização, buscando uma teoria local para a efetividade, na medida da ação e de sua especificação.

(iv) PROCESSOS: Um processo gerencial se constitui de rotinas explícitas ou implícitas que determinam como decisões-chave são tomadas em um determinado contexto de negócios. De outra forma, pode-se utilizar os processos como uma forma de integrar conceitos da literatura e esquemas existentes a situações práticas.

Os conceitos e definições desses elementos vistos anteriormente, foram resumidos por Lima (2001, pg.136) adaptado de Shehabuddeen, Probert e Phaal, nos quadros I e II a seguir:

TABELA 1 - REPRESENTAÇÕES: DIRIGIDAS E FUNDAMENTADAS POR PARADIGMAS (MODELOS)

\begin{tabular}{|c|c|}
\hline Representaçōes & Definições \\
\hline Sistema & $\begin{array}{l}\text { Um sistema define as fronteiras, os elementos e as relaçóes dentro de uma } \\
\text { determinada área de interesse, e a resposta no contexto de um paradigma. }\end{array}$ \\
\hline Esquema [framewotk] & $\begin{array}{l}\text { Um esquema suporta o entendimento e a comunicação de uma estrutura e suas } \\
\text { relaçóes dentro de um sistema que está definido para um deteminado } \\
\text { propósito. }\end{array}$ \\
\hline Mapa & $\begin{array}{l}\text { Um mapa suporta o entendimento das relações estáticas entre os elementos de } \\
\text { um sistema. }\end{array}$ \\
\hline Modelo & $\begin{array}{l}\text { Um modelo suporta o entendimento da dinâmica de interação entre os } \\
\text { elementos de um sistema. }\end{array}$ \\
\hline
\end{tabular}

Fonte: Lima (2001) - Adaptado Pelo Autor

TABELA 2 - ABORDAGENS: DIRIGIDAS E FUNDAMENTADAS POR METODOLOGIAS (COMO OS CONCEITOS PODEM SER APLICADOS)

\begin{tabular}{|c|c|}
\hline Abotdagens & Definicios \\
\hline Processo & 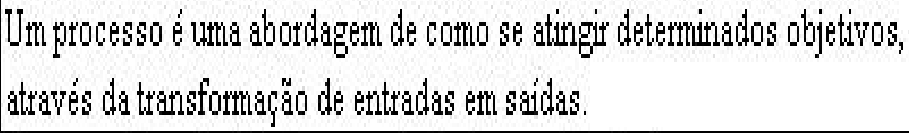 \\
\hline Procedimento, Témica, Método & 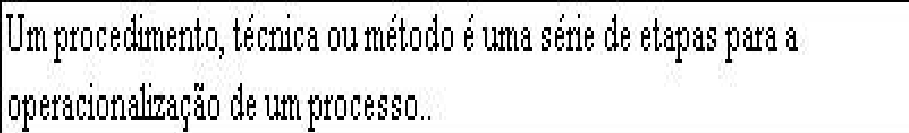 \\
\hline Fiffatlentita & 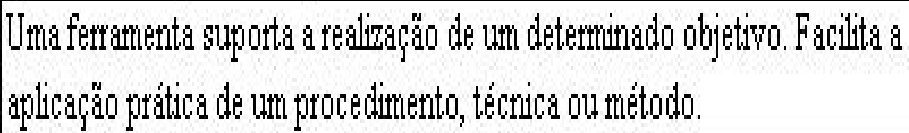 \\
\hline
\end{tabular}

Fonte: Lima (2001) - Adaptado Pelo Autor 


\subsection{A EMPRESA CONTÁBIL PESQUISADA E SEUS PROBLEMAS}

O estudo de caso foi desenvolvido na empresa contábil CONJEL SERVIÇOS CONTÁBEIS E ADMINISTRATIVOS S/C LTDA, sociedade civil por quotas de responsabilidade limitada, situada na cidade de Balneário Camboriú, Estado de Santa Catarina, à Rua 990 n 161 - centro.

Esta empresa atua no mercado como "escritório de contabilidade" a mais de 20 anos, na região do vale do Itajaí e Litoral Norte Catarinense. Tem como atividade principal (prestação de serviços técnicos) contabilidade "fiscal" para 150 micro, pequenas e médias empresas aproximadamente, da sua região de atuação, possuindo uma equipe composta por 32 profissionais, na sua maioria com formação acadêmica na área de ciências contábeis, alguns com especialização em áreas afins a contabilidade e finanças e outros em formação. Possui, também, em seus quadros profissionais formados em Administração, Ciência da computação e Ciência Jurídica e Sociais.

Pela equipe que congrega, sua estrutura organizacional e pelo perfil dos clientes ativos observou-se durante a pesquisa que a empresa contábil pesquisada pode ser classificada como média caminhando para grande, isto considerado com relação ao seu mercado de atuação e as empresas concorrentes existentes na região. Junto aos sindicatos e associações de classe de Santa Catarina não existe este perfil traçado nas suas bases de dados.

\subsubsection{A VISÃO INICIAL DO PROBLEMA}

Desde o final do ano de 1993, a empresa vem tentando incluir no seu portfólio de serviços a contabilidade gerencial, visando a diversificação estratégica com pouco ou nenhum sucesso em função de 03 fatores principais identificados, pelo pesquisador e pela equipe de lideres interna: (i) falta de um sistema que capture, mensure, trate e relate de forma permanente, os dados necessários à produção dessas informações nas empresas-cliente, possibilitando que as informações sejam validadas e consolidadas na visão contábil; (ii) Qualificação inadequada de seu corpo funcional para essa atividade, pela visão que possuía do que era um sistema de informação contábil e pela formação recebida nos cursos e universidades; (iii) pouca ou nenhuma importância por parte do gestor da empresa-cliente, com relação a compreensão dessas informações, no sentido 
de possibilitar implementação de ações que alterem a situação evidenciada, a custos suportáveis em termos valor agregado da informação ao processo de decisão. (VG)

Convém ressaltar que o "produto" de uma organização que presta serviços profissionais na área contábil é a interação entre a empresa contábil e a empresacliente, e que a percepção dessa interação pelo cliente é definida e redefinida cada vez que ele interage com os atores que prestam o serviço. (VG)

Por isso, o maior desafio é fazer com que os processos da empresa ocorram de forma que a interação entre clientes e atores leve os próprios clientes a crer que a empresa contábil corresponde às essas expectativas, no sentido de transformar dados em informação e essa em conhecimento para o gestor (empresa-cliente) melhore o seu processo de decisão. Outro ponto destacado é a importância fundamental da participação da empresa-cliente no processo de serviço da empresa contábil, obrigando essa a só conseguir trabalhar com qualidade e produtividade na medida em que consiga negociar adequadamente essa participação, ou seja, na medida em que consiga tornar os processos empresariais da empresa-cliente organizados e estruturados adequadamente pois vão influenciar diretamente os resultados finais dos processos que são concluídos na empresa contábil. (VG)

Em consonância com o desenho da pesquisa, o paradigma e a abordagem utilizada os problemas e questões de pesquisa foram sendo refinados e são descritos no capítulo II, de forma detalhada.

\subsubsection{A NECESSIDADE DE CRESCIMENTO}

A percepção geral da equipe da empresa contábil é que os clientes precisavam gerir seus negócios de forma mais eficiente, pois estavam sofrendo forte pressão competitiva e não dispunham de ferramentas e informações adequadas para tomar decisões que efetivamente contribuíssem para melhoria do seu negócio em termos de resultados econômicos. (VG)

O crescimento da empresa contábil, na situação inicial, estava vinculado ao aumento do número de clientes e este, pelo menos era a percepção geral, só ocorria pela queda no valor dos honorários mensais, o que vinham sendo sentido a partir do inicio do "plano real", que gerou um forte desemprego empurrando as pessoas com alguma qualificação na área afim a buscar seu próprio negócio e a função contábil, 
através dos "escritórios de contabilidade", representava uma boa oportunidade de sobrevivência, sem a necessidade de grandes investimentos materiais. (VG)

Além do que, a percepção de diferenciais na prestação de serviços contábeis é muito limitada e de difícil mensuração por parte da empresa contábil, e de difícil percepção por parte do gestor da empresa-cliente, e que pode ser resumida na frase seguinte, extraída das discussões ao longo da pesquisa: Como o cliente pode valorizar aquilo que ele não sabe, pois tem dificuldade de compreender (informação contábil gerencial), e se não sabe os benefícios, como pode sentir falta?. (VG)

Estas e outras questões foram amplamente debatidas ao longo da pesquisa, cuja preocupação central podia ser resumida na seguinte frase: $\underline{\text { se os nossos clientes estão }}$ com poucas condições de sobrevivência, como nós que somos uma extensão dessas empresas, poderemos sobreviver e até crescer?. (VG)

\subsubsection{O AMBIENTE INTERNO E OS PROJETOS ANTERIORES}

O ambiente interno era de um certo "ceticismo" com relação às ações de mudança que realmente possibilitassem alterar de forma substancial e permanente a maneira de realizar o processo de serviço na empresa contábil, pois nas tentativas anteriores de implantação de contabilidade gerencial na empresa-cliente, o trabalho não eliminou a necessidade de re-trabalho interno, e muitas vezes até dobrou o serviço sem um resultado efetivo para a empresa-cliente (o resultado gerencial era apresentado, porém, as ações de melhoria propostas não podiam ser acompanhadas ou mesmo efetivadas), e um aumento considerável nos custos e resultados da empresa contábil sem uma receita correspondente, em resumo, o valor adicionado aos serviços não é percebido pela empresa-cliente em termos de benefícios econômicos mensuráveis. (VG)

Noutro ponto, a empresa contábil e sua equipe haviam participado de alguns projetos patrocinados pelas empresas-cliente com o objetivo de implantar "sistema de automatização de faturamento", algumas vezes chamados de gestão, porém, após algum tempo de trabalho para conhecê-los e entendê-los a conclusão que se chegava era que não atendiam plenamente as necessidades de integração contábil, mesmo que através da transferência de arquivos (integração forçada ou não natural), pois ou não tratavam as questões fiscais adequadamente, ou não possuíam a possibilidade de 
formatação de centro de custos e ainda, em grande parte dos casos foram projetados sem a visão contábil o que resultava, quando da necessidade de integração numa autentica "colcha de retalhos". Além do que as regras de negócios tanto tributárias quanto de procedimentos gerenciais não eram respeitadas. (VG)

As informações resultantes não são "confiáveis" e na maioria das vezes não "fechavam", se conciliadas pelo método de partidas dobradas, na visão dinâmica do "fluxo" (movimento dos recursos - DRE) integrado com a visão estática do Balanço Patrimonial (estoque dos recursos), impossibilitando a agregação e desagregação da informação desde sua origem no evento que gerou a transação. (VG)

$\mathrm{Na}$ maioria dos casos os que tinham uma visão contábil, mesmo que incipiente, tratavam a contabilidade como um sistema de partida única, mostrando já de início que o "projeto" do sistema era fadado ao fracasso, apesar dos esforços heróicos de seus idealizadores, normalmente profissionais de formação exclusiva da área de informática. (VG)

\subsubsection{O PROCESSO DE MUDANÇA}

A idéia inicial de mudança surgiu a partir das discussões internas por um grupo de membros da equipe formado para realizar um curso de análise e mapeamento de processos via Internet. O grupo era formado por 06 membros internos e um externo e tinha como objetivo principal: dar aos participantes conhecimentos que auxiliem suas habilidades na condução de projetos de Análise e Modelagem de Processos de Negócio. (VG)

A necessidade do curso surgiu da oportunidade de participar de um projeto de parceria com uma softhouse numa empresa-cliente na implantação de um sistema integrado de gestão.

Apesar do curso não ter oferecido os conhecimentos necessários, ele possibilitou o contato com ferramentas de mapeamento de processo e desencadeou as discussões preliminares da necessidade de mudança interna visando organizar melhor o trabalho e possibilitar o crescimento da empresa. Ora, se o desafio principal do contador, conforme amplamente discutido ao longo do trabalho e nas discussões acadêmicas, é tornar a informação contábil distribuída por toda a empresa, e se esse desafio só pode ser alcançado se os sistemas de informação foram construídos e 
implementados na visão contábil - com a participação do contador, então, uma maneira eficaz de implementar uma mudança cultural numa empresa contábil é envolver sua equipe no projeto para implantar o sistema empresarial integradoSistema Empresarial Integrado - ERP na própria empresa contábil, e ao longo do processo ir discutido e registrando os conhecimentos e experiências que forem sendo adquiridos. Só ainda, então, esses profissionais estarão preparados para multiplicar seus conhecimentos e experiências levando os benefícios da informação contábil e da tecnologia para as empresas-cliente. (VG)

Os principais objetivos a serem atingidos com o processo de mudança foram estabelecidos pelo grupo, que tem como meta final possibilitar o crescimento da empresa, na forma de uma rede de causa e efeito demonstrado na figura seguinte e serve de referência para avaliação do andamento do projeto. (VG)

FIGURA 2: OBJETIVOS DO PROCESSO DE MUDANÇA NA FORMA DE UMA REDE DE CAUSA E EFEITO (VG)

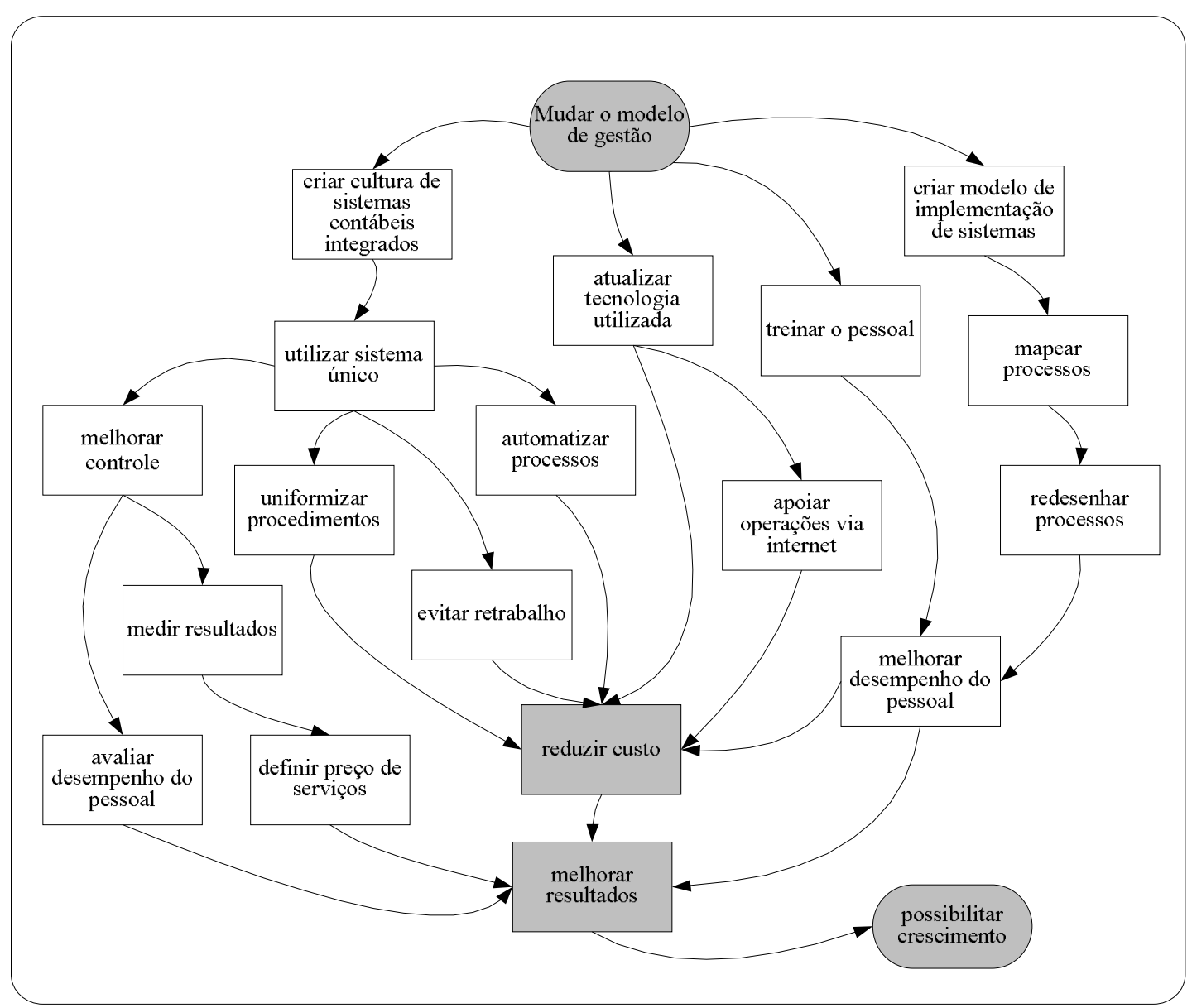

Fonte: Elaborado pelo Autor 
Surgiram debates no grupo que um outro limitador para o trabalho do contador está relacionado com o aproveitamento pleno dos recursos tecnológicos disponíveis, pois em muitos casos, como o mercado de atuação da empresa contábil são empresas de menor porte e em crescimento, o custo total de propriedade (TCO) torna os projetos inviáveis em termos de investimentos iniciais, pelo menos, numa arquitetura clienteservidor. (VG) As respostas para esta e outras questões foram encontradas através da pesquisa, evidenciadas na necessidade do desenho de uma nova arquitetura organizacional e tecnológica para a empresa contábil estudada.

\subsection{OBJETIVO DA PESQUISA}

Antes da definição precisa dos objetivos gerais e específicos da pesquisa, é importante destacar que a literatura pesquisada converge para uma visão unânime dos autores, no sentido que as mudanças tecnológicas tem dupla potencialidade (ou múltiplas). Assim, uma tecnologia, no caso específico o sistema empresarial integradoSistema Empresarial Integrado - ERP ${ }^{1}$, é capaz de produzir um conjunto de efeitos organizacionais e seus opostos, isto é, a tecnologia pode reforçar na organização a gestão de recursos humanos com uma orientação voltada ao controle / submissão ou facilitar uma mudança orientada ao comprometimento, indicando claramente o que fazer (parte da solução).

Entre estes autores, destaca-se a visão abrangente de Walton (1998), de que a organização formal da empresa e a TI devem ser desenhadas refletindo os componentes da visão estratégica, e levando em conta os fatores ambientais e as opções de desenho da organização formal e da tecnologia de informação, sendo estes fatores importantes porque moldam os padrões de comportamento organizacional ( " $o$ comprometimento e a competência dos empregados, e o alinhamento de suas ações com as prioridades da organização”), que por sua vez afeta os resultados dos negócios

\footnotetext{
${ }^{1}$ ERP - Enterprise Resources Planning - Planejamento de recursos empresariais: São sistemas de informação que visam a sincronização em tempo real dos processos de uma empresa, pelo emprego da tecnologia de informação avançada. São compostos de módulos pré-formatados, integrados e que contém em suas rotinas conjunto de padrões (benchmarks) de processos empresariais que interessam a qualquer negócio que queira ser competitivo. Historicamente, representaram uma série de soluções criadas pela indústria de TI no esforço de prover uma solução única e abrangente para os problemas de sincronismo e integração dos processos de produção, evoluindo de forma natural para a solução dos problemas de controle e gestão de uma empresa (Riccio, 2001).
} 
e o bem estar dos empregados. Todos os autores pesquisados, porém, não indicam como fazer, o que foi respondido pela aplicação do paradigma de pesquisa utilizado - a pesquisa-ação.

\subsubsection{OBJETIVOS GERAIS}

Este trabalho tem o objetivo de discutir uma empresa contábil, a mudança na sua arquitetura organizacional e tecnológica que permita o crescimento das atividades, num ambiente de atuação em constante transformação, através da oferta de valor adicionado ao cliente.

\subsubsection{OBJETIVOS ESPECÍFICOS}

Para atingir o objetivo principal, concomitantemente ou por etapas - de acordo com as condições exigidas e identificadas ao longo da pesquisa, foi necessário desenvolver um modelo - este no sentido de mapeamento do caminho - de administração da mudança organizacional planejada na empresa contábil Conjel Serviços Contábeis e Administrativos S / C Ltda, visando a condução do processo e permitindo estruturar a pesquisa de forma a facilitar sua leitura e entendimento, em função do paradigma de pesquisa-ação utilizado.

Observe-se que, o próprio modelo elaborado denominado de: "Desenho da pesquisa: liga o problema inicial ao referencial teórico, mostrando a abordagem utilizada para identificar as unidades de análise", conforme explicado no item 1.7.6 e através da figura 7 já faz parte das descobertas de pesquisa e foi desenvolvido pelo autor ao longo dela, na medida em que as descobertas foram sendo testadas através dos referenciais teóricos pesquisados e relatados, podendo ser generalizado para outros processos semelhantes com as devidas adaptações.

$\mathrm{Na}$ medida em que a pesquisa foi evoluindo, o pesquisador e os atores pertencentes ao quadro da empresa contábil observaram que será possível atingir a médio e longo prazo outros objetivos específicos, relatados a seguir e necessários para 
atingir os objetivos principais, possibilitando a empresa utilizar o sistema na visão de futuro descrita por Riccio (2001, pg.67) e denominada ERP II ${ }^{1}$ :

(i) Possibilitar a disponibilização às empresas-cliente de um sistema de gestão empresarial integrado - ERP, numa relação custo x benefício aplicável a pequenas e médias empresas;

(ii) Mapear, analisar e redesenhar os processos operacionais e de apoio da empresa contábil, automatizando e informatizando todos os processos através da implementação de um sistema empresarial integradoSistema Empresarial Integrado ERP;

(iii) Proporcionar as condições para a diversificação estratégica da Empresa contábil, desenvolvendo um modelo de implementação de sistema empresarial integradoSistema Empresarial Integrado - ERP;

(iv) Identificar necessidade de treinamento visando desenvolver novas habilidades e competências no pessoal para o uso de tecnologia avançada, conhecendo e aplicando ferramentas que possam ajudar a resolver problemas organizacionais identificados em processos de mudança;

(v) Contribuir para a mudança de paradigma dos profissionais contábeis organizados em empresas contábeis com relação ao uso de sistemas de informação;

\subsection{DELIMITAÇÃO DO ÂMBITO DA PESQUISA}

Este estudo de caso através da pesquisa-ação restringe-se, primeiramente quanto à sua abrangência, à identificação de: (i) quais dimensões e variáveis de mudanças organizacionais são necessárias trabalhar para implementar um sistema empresarial integradoSistema Empresarial Integrado - ERP, de maneira a maximizar o aproveitamento do seu potencial, numa empresa contábil do interior de Santa Catarina?; (ii) que tipo de mudança e em que ordem de magnitude ela deve ocorrer?;

\footnotetext{
${ }^{1}$ ERP II - sistema empresarial do século 21, cuja diferença com o seu antecessor é a colaboração. Além de ser a estrutura mestra da empresa, ele será a conexão informativa para uma empresa situada dentro da cadeia de fornecimento, como os seguintes desafios: (I) agregar e gerenciar os dados de todas as transações de maneira precisa em tempo real; (II) abrir o sistema para tornar essas informações disponíveis aos parceiros de negócios; Em resumo ele será uma estratégia de negócios que criará valor para o acionista e os clientes.
} 
(iii) qual abordagem de mudança utilizar para a sua efetivação?; e (iv) como a mudança deve ser gerenciada?.

Em segundo lugar, com relação aos seus fundamentos teóricos, o estudo restringe-se ao referencial teórico sobre mudança organizacional utilizando uma adaptação com base no modelo (framework) desenvolvido no MIT*, fundamentado nos estudos realizados por: (i) Alfred Chandler (1962), apud Walton (1998, pg.61) nos comentários sobre o triangulotriângulo estratégico - demonstrando a conexão entre estratégias de negócios, de TI e de organização; e (ii) Lavitt (1965) apud (Laudon \& Laudon; 2001) concluindo que o único modo de trazer mudanças é mudar a tecnologia, as tarefas, a estrutura e as pessoas simultaneamente.

\section{FIGURA 3 - INTER-RELACIONAMENTO E AJUSTE MÚTUO DA TECNOLOGIA E DA ORGANIZAÇÃO}

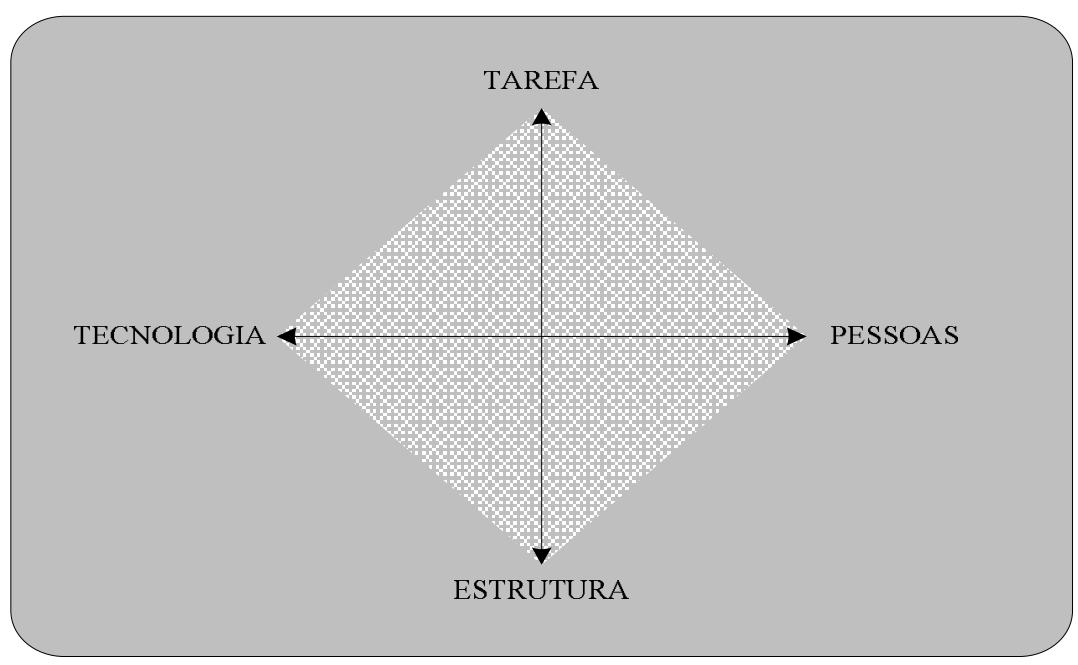

Fonte: (Laudon \& Laudon; 2001, pg 64)

Além dos fundamentos quanto às influências mútuas entre os componentes tecnologia e organização no processo de mudança, é necessário considerar também a escola sócio-técnica, cuja abordagem foi desenvolvida em resposta aos problemas associados com o rápido avanço tecnológico nas indústrias, uma vez que a revolução tecnológica nos escritórios tem problemas similares. Como um método participativo de projeto, a abordagem sócio-técnica tem grande potencial para engendrar uma espécie

\footnotetext{
* Instituto de Tecnologia de Massachusetts-EUA por Rockart e Scott e Morton (1984), no desenvolvimento de um programa de pesquisa intitulado "The Management in the 1990's".
} 
de mudança e aprendizado organizacional requerido para obter vantagens tangíveis de equipamentos e sistemas altamente desenvolvidos.

Quanto à pesquisa empírica, o paradigma de pesquisa usado foi à pesquisaação. Como o próprio nome define o que se pretende com a pesquisa-ação é que ela produza ambos conhecimento (pesquisa) e mudança (ação). Neste sentido, as duas dimensões - conhecimento e mudança, estão sendo consideradas de grande utilidade prática em cada um dos aspectos desta proposta de pesquisa. Utilizou-se ainda, no decorrer da pesquisa, algumas metodologias indicadas na literatura administrativa, como abordagens para encaminhar e entender o processo de mudança, principalmente relacionadas a vencer as barreiras de resistência à mudança.

A metodologia TransMeth* (Rentes, 2000) como uma proposta de abordagem estratégica, abrangente e integrada para gerenciar o processo de melhoria organizacional, foi utilizada no sentido de entender as barreiras que seriam encontradas durante o processo de mudança nas diversas frentes negócios, cultura, recursos e operações.

\subsection{METODOLOGIA E JUSTIFICATIVA DA PESQUISA}

Pesquisa-ação é um tipo de pesquisa social com base empírica que é concebida e realizada em estreita associação com uma ação ou com a resolução de um problema coletivo, onde estão envolvidos de modo cooperativo e participativo os pesquisadores e os participantes da situação. A ligação dos termos pesquisa e ação realçam as características essenciais desta abordagem, a qual envolve o teste de idéias na prática como um meio de melhoria nas condições sociais e no crescimento do conhecimento.

\subsubsection{A PESQUISA-AÇÃO E SEUS OBJETIVOS}

De acordo com Thiollent (1997) a expressão pesquisa-ação foi lançada por Kurt Lewin (1948) ao se referir aos fenômenos de grupos identificados e trabalhados no próprio grupo, com objetivos de pesquisa em psicologia social e dinâmica de grupo.

\footnotetext{
* Esta metodologia foi resultante de um esforço conjunto entre a equipe de desenvolvimento da metodologia MIE da EESC-USP, dirigida pelo professor Dr. Antonio Carlos Rentes, e da equipe responsável pela metodologia Transformation Cycle na Virginia Tech.
} 
Para ele pesquisa-ação é igual à pesquisa no próprio campo. A PA, como descrita por Lewin, ocorre numa espiral de passos compostos de planejamento, ação e avaliação dos resultados da ação:

O processo de PA começa com uma idéia geral de que uma melhoria ou mudança em uma área de trabalho do profissional é desejável. Um grupo então é formado para esclarecer a preocupação mútua que havia sido identificada, e em seguida toma decisão de trabalhar em conjunto, focando suas estratégias de melhoria (ação) no tema de interesse.

Há várias características que distinguem a PA de outras formas de pesquisa. As principais são: (i) colaboração entre o pesquisador e os agentes; (ii) solução de problemas práticos; (iii) mudança nas práticas; (iv) desenvolvimento da teoria e (v) publicação dos resultados da pesquisa.

A figura seguinte mostra o ciclo básico de pesquisa-ação. É importante observar, de acordo com Susman e Evered (1978) apud Thiollent (1997, pg.44) que:

(1) No estágio de Diagnóstico (identificar do problema), o pesquisador e a organização cliente identificam e especificam uma oportunidade de melhoria na organização cliente, e a compatibilizam com as metas da pesquisa.

(2) No estágio de Planejamento da Ação (planejar), o pesquisador e a organização cliente consideram cursos alternativos de ação para realizar a melhoria identificada, e desenvolvem um plano para implementar um destes cursos alternativos de ação.

(3) No estágio de Tomada da Ação (agir), o pesquisador e a organização cliente implementam o plano desenvolvido.

(4) No estágio de Avaliação (observar), o pesquisador e a organização cliente avaliam os resultados da implementação do plano.

(5) No estágio de Especificação do Aprendizado (refletir) o pesquisador identifica e descreve as descobertas gerais, baseadas nas informações geradas no estágio anterior.

FIGURA 4 - CICLO BÁSICO DA PESQUISA-AÇÃO

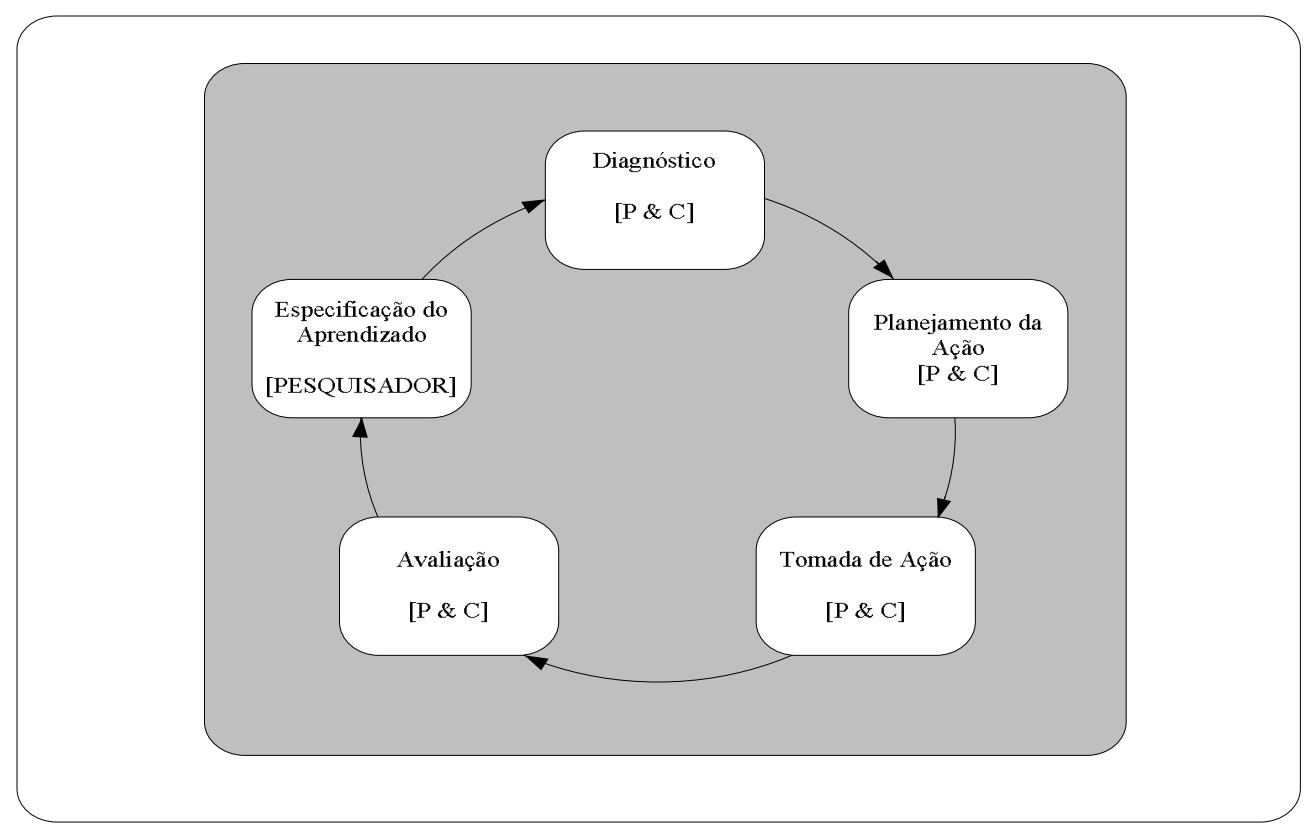

Fonte: Susman e Evered (1978) apud Thiollent (1997, pg.44) Adaptado Pelo Autor 
Constata-se pelo modelo apresentado acima que nos estágios 1 até 4 participam o pesquisador \& cliente (P \& C), enquanto no estágio 5 a especificação do aprendizado é feita pelo pesquisador, que normalmente publica os resultados contribuindo para refinar a teoria ou mesmo mudá-la.

O objetivo da pesquisa-ação é aprender com a experiência, e aplicar este aprendizado para provocar a mudança. Como a dinâmica de um sistema social é freqüentemente mais aparente em tempos de mudança (Lewin, 1948), aprendizagem e mudança tem influência mutua. Porém, é mais provável que se aprenda na experiência ao agir com tal intenção. É desejável entrar na experiência com expectativas, estar à procura de experiências não-metódicas, e buscar entendê-las.

\subsubsection{PESQUISA-AÇÃO E PESQUISA ORGANIZACIONAL}

Uma das abordagens para administrar a mudança organizacional é através da pesquisa-ação. Robbins (2002) refere-se a ela como um processo de mudança baseado na coleta de dados, seguida da seleção de uma ação de mudança, com base no que indicam os dados analisados. Sua importância em mudança organizacional reside em oferecer uma metodologia científica para a administração da mudança planejada.

Em termos práticos, a pesquisa-ação abre novos caminhos para a pesquisa social em diversos setores de atuação, e em particular na área organizacional. Fonte de informação insubstituível, as intervenções em organizações são oportunidades para os pesquisadores terem acesso a informações e problemas que freqüentemente não se encontram diretamente nos estudos e pesquisas tradicionais. A preocupação metodológica em torno da pesquisa organizacional situa-se no âmbito da pesquisa social aplicada e não das propostas gerenciais imediatistas. Conceber e realizar a pesquisa-ação em organizações pressupõe um investimento teórico e prático de médio ou longo prazo, no intuito de repensar a organização em seus vários níveis, o que fica evidente através deste trabalho.

Em estudos organizacionais, a Pesquisa-ação PA é caracterizada pela intervenção positiva do pesquisador, aplicada à organização do cliente, enquanto coleta dados de campo sobre a organização, avaliando e refletindo sobre os efeitos da intervenção. Esta característica fornece um fundamento particularmente sólido para a decisão de utilizar a PA neste estudo. 
Nesta procura - numa perspectiva organizacional - de como conduzir o processo de maneira a otimizar os resultados, entendeu-se que se tratava da necessidade de administrar um processo de mudança no ambiente organizacional, para criar as condições técnicas e sociais ideais visando implementar um sistema empresarial integradoSistema Empresarial Integrado - ERP numa empresa contábil do interior do Brasil.

Em linhas gerais, não foram encontrados na literatura disponível relatos voltados especificamente para as empresas contábeis, com as suas especificidades de serviços profissionais técnicos, seu tamanho e da forma como são projetados seus processos de serviços.

Foram encontrados estudos de casos, principalmente relacionados a grandes companhias, que comentavam sobre os sucessos e fracassos na implementação dos referidos sistemas, e o que chamou a atenção é que na maioria deles a abordagem é simplesmente técnica, ou seja, com pouco ou nenhum comentário sobre os aspectos sociais, especificamente humano-comportamentais. Este fato contribui para $o$ entendimento sobre a verdadeira causa do fracasso ou do baixo nível de sucesso: não tratar a intervenção como um processo mais amplo e profundo de mudança, com seus aspectos técnicos e sociais (abordagem sócio-técnica). (VG)

Nesse ponto foi encontrado o que fazer, mas e o como fazer? Isso eliminava virtualmente a possibilidade de usar uma abordagem de intervenção que não pesquisa, e que basicamente deixou duas alternativas à escolha: (i) pesquisa experimental, que é caracterizada através de controle artificial (laboratório); e (ii) Pesquisa-ação, que é por sua natureza de baixo controle artificial, porém, é uma proposta de pesquisa mais aberta (com característica de diagnóstico e de consultoria), para tentar clarear uma situação complexa - sair da situação atual para a situação desejada, e encaminhar possíveis - ações de mudança, especialmente nestas situações criticas. (VG)

O processo de mudança é sempre um momento crítico, e a pesquisa-ação contribui levando os atores envolvidos a encontrar as respostas aos seus próprios problemas, comprometendo-se com a mudança e aprendendo com ela, possibilitando desenvolver a chamada "organização que aprende", que será discutida com mais detalhe no capítulo II, através das figuras e os comentários sobre o ciclo estendido da pesquisa-ação, incluindo o loop duplo para a quebra de paradigma. 
A abordagem de pesquisa-ação específica seguida é descrita no terceiro capítulo em maiores detalhes, com a abordagem desenvolvida para este trabalho. Ela é centrada no ciclo da pesquisa-ação proposto por Susman e Evered (1978) apud Thiollent (1997, , pg.44), compreendendo cinco estágios, descritos e desenhados anteriormente na figura anterior.

A abordagem Pesquisa-Ação (PA) deve ser entendida, neste trabalho e como decorrência das próprias descobertas da pesquisa - conforme trata especificamente o terceiro quarto - em dois sentidos: (i) como paradigma de pesquisa; (ii) como abordagem para administrar a mudança organizacional.

\subsubsection{RELEVÂNCIA DO TEMA AS EMPRESAS CONTÁBEIS}

A profissão contábil no Brasil está passando por grandes transformações, pois os movimentos de modernização da economia exigem novas posturas diante dos desafios de sobrevivência das empresas nacionais, de características familiares. A profissão contábil liberal ou através de escritórios é uma atividade protegida legalmente, porém, as necessidades do mercado estão eliminando gradativamente o poder de monopólio dessa atividade, exigindo nova forma de atuação, sofrendo forte ameaça das ditas profissões da informação.

Esta mudança de paradigma profissional primeiro tem que ocorrer internamente, na cabeça do contador, na sua visão da utilidade das informações contábeis e na sua empresa, para então corresponder às necessidades latentes das empresas-cliente, que evidenciarão as competências profissionais do controller como gestor principal do sistema de informações contábeis, graças a sua prática, estudos constantes e aos ensinamentos que pôde obter através da observação do ambiente empresarial e da tecnologia aplicada, tornando-se capaz de refletir sobre os interesses da empresa-cliente, de posicionar seus problemas, de hierarquizá-los, de imaginar soluções e de implementá-las, questões essas percebidas pelo autor pelos debates e idéias desenvolvidas nos congressos profissionais.

No vale do Itajaí e região do litoral norte de Santa Catarina a economia é baseada em negócios desenvolvidos pelas pequenas e médias empresas, vinculadas desde sua criação a empresas contábeis. As empresas contábeis nesta região têm forte atuação representando parcela significativa da mão-de-obra especializada ocupada, 
possuindo o estado de Santa Catarina, na condição de ativos no Conselho Regional de Contabilidade, na sua maioria atuando nas empresas contábeis, no mês de Outubro do ano de 2002 exatamente 13.228 contabilistas, representado $3,87 \%{ }^{* 1}$ dos profissionais registrados no País, que nesta data possuía registrados 341.791 contabilistas, na mesma condição de ativos, isto é, em tese trabalhando.

O estado de Santa Catarina possuía em Outubro de 2002 exatamente 3.567 empresas contábeis ${ }^{*}$, atuando em todo o estado, representando 5,5\% das empresas contábeis de todo o Brasil, que possuía na mesma data 64.319, empresas de contabilidade na condição ativa.

No artigo intitulado "função social das empresas de serviços contábeis", apresentado no $\mathrm{V}$ congresso brasileiro de gestão estratégica de custos, Ripamonti (1999) conclui com dados levantados junto ao Conselho Regional de Contabilidade do Estado de São Paulo em 1997, que existiam no Brasil cerca de 55.000 (cinqüenta e cinco mil) empresas de serviços contábeis e que estes atendiam, como clientes, a quantia de 2.575.000 pequenas empresas. $O$ autor informa ainda que, 92,4\% das empresas brasileiras possuem até 9 pessoas ocupadas, representando $26,10 \%$ do total das pessoas ocupadas no segmento empresarial.

Apesar das dificuldades no levantamento de números exatos sobre a quantidade de entidades atendidas pelas empresas contábeis no Brasil, pois não há estatísticas disponíveis com essa informação, a importância das empresas contábeis está diretamente vinculada à existência destas entidades denominadas como pequena e média empresa, conforme Kassai (1996, p.192):

Percebemos, então, que o papel a ser desempenhado pelo contador na pequena empresa não difere grandemente daquele desempenhado na grande empresa. Poderia resumi-lo como a responsabilidade pela estruturação de um sistema de apoio à decisão de forma a auxiliar a empresa na busca da melhor utilização de recursos, ou seja, o alcance da eficácia empresarial.

\footnotetext{
* Fonte: Conselho Federal de Contabilidade. Disponível no site www.cfc.org.br. Base: Outubro/2002

${ }^{1}$ Fonte: Conselho Federal de Contabilidade. Disponível no site www.cfc.org.br. Base: Outubro/2002
}

\footnotetext{
* Total de Escritórios - sociedade ativos 1.145; Total de escritórios - individuais ativos (profissionais autônomos) 2.414. Fonte Conselho Regional de Contabilidade - Santa Catarina. Disponível no site da entidade. Base: Setembro/2002.
} 
O especialista contábil é muitas vezes o único interveniente exterior permanente neste segmento, é o homem de confiança dos gestores dessas empresas, seu conselheiro escolhido, conhece profundamente suas dificuldades, suas finanças e seus projetos. O ciclo de vida desses negócios está diretamente vinculado às informações recebidas das empresas contábeis, e essas empresas representam hoje um grande gerador de oportunidades de emprego e renda no País. (VG)

\subsubsection{A ORIGINALIDADE DA PESQUISA}

O contador, principalmente aquele que atua através das empresas contábeis, tem utilizado a informática, no que diz respeito ao sistema de informação contábil foco central do seu trabalho - simplesmente como uma ferramenta na visão de mecanização do processo contábil como função de escrituração, atendendo unicamente ao usuário fisco, deixando de cumprir sua missão junto aos demais usuários.

A originalidade desta pesquisa é desenvolver e aplicar uma abordagem para administração da mudança organizacional necessária em uma empresa contábil, através da implementação de um sistema de gestão empresarial integrado, concentrando-se nos benefícios para o negócio, no sentido de redefinição de processos de serviços e estrutura organizacional, no conhecimento das pessoas e nas estratégias de atuação, possibilitando que seja levada contabilidade gerencial às empresas-cliente, utilizando-se da mesma tecnologia interna, possibilitando disseminar e distribuir o conhecimento contábil a todos os níveis, segmentos e negócios.

A pesquisa tornará possível tratar adequadamente as seguintes questões: (i) Em que formatação estão os dados atuais? Até que ponto são divergentes, ao longo da empresa os dados principais? (ii) Em que estágio se encontram, relativamente ao sistema empresarial integradoSistema Empresarial Integrado - ERP, a qualificação do atual grupo de colaboradores? São capazes de formatar novos processos, configurar novos sistemas, adaptar-se a novos métodos de trabalho, e de administrar um alto índice de mudança organizacional a longo prazo? (iii) Quais as condições da infraestrutura tecnológica da empresa? (iv) Quais as principais estratégias do negócio, tanto no nível corporativo quanto para unidades de negócios, regiões geográficas, serviços, etc? (v) Quanto a empresa estaria disposta e em condições de investir no sistema? (vi) 
Qual é o clima organizacional atual? (vii) As barreiras às mudanças foram ultrapassadas? (viii) Que ferramentas e metodologias podem ser usadas e devem ser dominadas para criar um modelo de mudança? (ix) Como criar uma organização que aprende?. (VG)

Em um só tempo a pesquisa pretende mostrar que a diversificação estratégica para as empresas contábeis, através do uso da informática, é plenamente possível, e que sua relação personalizada com o dirigente da empresa permite posição competitiva privilegiada no mercado de consultoria gerencial ao seu cliente foco. Na verdade, a empresa contábil utiliza diversas ferramentas de informática no seu dia-a-dia, e essa intimidade com a tecnologia permitirá a integração das atividades administrativas de gestão à apuração contábil tradicional. Em outras palavras, o sistema empresarial integradoSistema Empresarial Integrado - ERP permite uma transformação na apuração contábil tradicional, no sentido de inserir cada vez mais aspectos de gestão em suas intervenções, e para tanto, o aprendizado pode ocorrer na própria empresa contábil. (VG)

O trabalho fundamenta-se na visão proposta por Riccio (1989) sobre que o sistema de informação contábil de fato "abrange não somente a Contabilidade Financeira (Nível Operacional), mas também a Contabilidade Gerencial (Nível Tático)

e já contém os elementos essenciais do que poderíamos denominar Contabilidade Estratégica". 
FIGURA 5 - O SISTEMA DE INFORMAÇÃO CONTÁBIL INTEGRADO ESTENDIDO

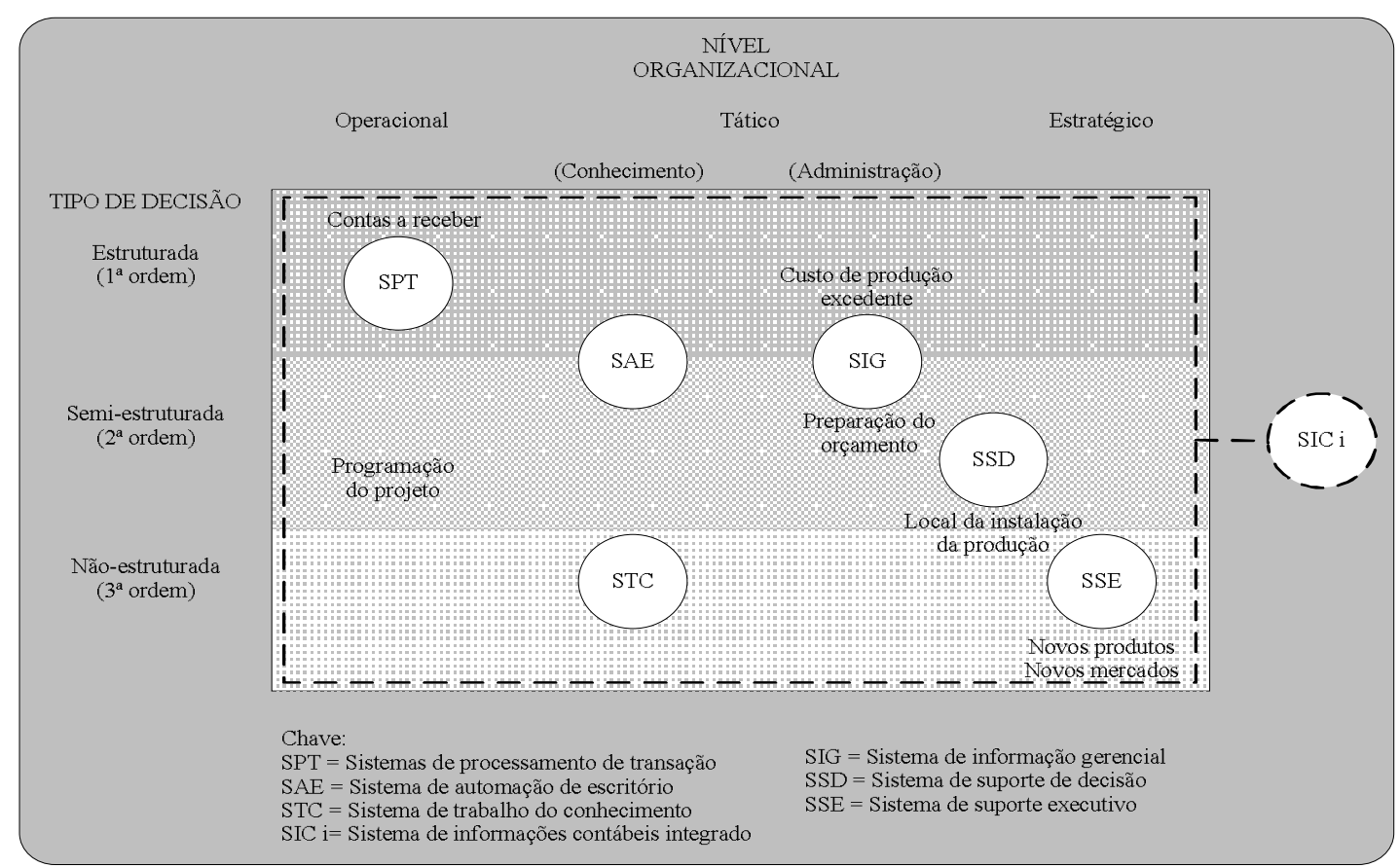

Fonte: Laudon \& Laudon $(2001,67)$ Adaptado pelo Autor

A figura materializa esta visão estendida onde o sistema de informação contábil integrado abrange diferentes tipos de sistemas de informação nos vários níveis organizacionais dando suporte aos diferentes tipos de decisão, no entendimento que a linguagem contábil deve estar na modelagem dos dados quando da organização dos processos nos diversos sistemas e que isso proporcionará um modelo de decisão em linguagem universalmente entendida e eficaz.

Os sistemas de nível operacional dão suporte aos gerentes operacionais no acompanhamento das atividades e transações elementares da organização. Esses sistemas denominados de SPT é um sistema computadorizado que executa e registra as transações rotineiras diárias necessárias para a condução do negócio.

Os sistemas de nível de conhecimento dão suporte aos trabalhadores do conhecimento e de dados em uma organização. O seu propósito é ajudar a empresa a integrar novos conhecimentos no negócio e a controlar o seu fluxo de papelada. De acordo com Laudon \& Laudon (2001, pg.29) esses sistemas, especialmente na forma de estações de trabalho e sistemas de escritório, são as aplicações que mais crescem nas empresas hoje em dia. Esses sistemas denominados de: STC promovem a criação 
de conhecimento novo e asseguram que esses novos conhecimentos ou especialidades técnicas sejam corretamente integrados ao negócio; e SAE servem para manipular e gerenciar documentos e imagens.

Sistemas de nível gerencial são projetados para servir ao monitoramento, ao controle, à tomada de decisão e às atividades administrativas dos gerentes médios. Esses sistemas denominados SIG resumem e produzem relatórios sobre as operações básicas da empresa.

Sistemas de nível estratégico ajudam a administração sênior a atacar e enfocar assuntos estratégicos e tendências de longo prazo, tanto na empresa como no ambiente externo. Esses sistemas denominados de: (i) SSD são construídos explicitamente com uma variedade de modelos para analisar dados (inclusive de fontes externas), ou condensam grandes quantidades de dados dentro de um formulário onde podem ser analisados pelos tomadores de decisão. (ii) SSE são projetados, diferentemente de outros tipos de sistemas - não são projetados para resolver problemas específicos, mas por serem altamente analíticos visam mudar a ordem dos problemas.

O sistema de informação contábil integrado visa cobrir todos os níveis anteriormente discutidos e sua importância reside na capacidade de integrar todos os outros sistemas numa linguagem única e natural, conforme a visão proposta por Riccio (1989) e discutido anteriormente. Já naquela época o autor se preocupava com a passagem dos conceitos desenvolvidos para o plano prático, o que também faz parte das preocupações deste trabalho quanto às empresas contábeis, e para tanto as seguintes questões devem ser observadas (Riccio; 1989, pg.164):

“(i) O sistema de informação contábil deve ser desenvolvido dentro do conceito de sistema amplo, isto é, voltado para a empresa, ao contrário do conceito de sistema particular da área contábil; (ii) Deve haver utilização intensa da tecnologia de informática para permitir que o sistema opere no modo de tempo real, suportado por banco de dados e com funções que permitam a troca de dados com outros sistemas internos e externos (outras empresas e redes públicas); (iii) Os lideres do Sistema (contadores e administradores), devem estar perfeitamente conscientes das mudanças culturais que devem acompanhar a passagem do sistema de informação contábil para esse novo patamar dentro da estrutura de sistemas de informação da empresa".

A passagem para este novo modelo de gestão baseado na informação contábil seria inconcebível sem a tecnologia de informação, materializada nos sistema empresarial integradoSistema Empresarial Integrado - ERP . Porém, este trabalho propõe que o sistema suporte antes a gestão da própria empresa contábil, o que 
facilitaria a mudança de cultura, visão e aprendizagem necessária a esta quebra de paradigma com relação ao sistema de informação contábil integrado.

Atualmente, a tecnologia já permite que o sistema empresarial integradoSistema Empresarial Integrado - ERP chegue às empresas menores, pois além dos custos destes sistemas estarem diminuindo consideravelmente, as questões relativas a ambiente de TI podem ser suportadas via Internet, reduzindo drasticamente os custos total de propriedade (TCO), e os conhecimentos relativos ao gerenciamento do banco de dados e customização do sistema poderiam ser atribuições gerenciadas pelos contadores, como evidenciam diversas pesquisas nesta área (Riccio, 2001; Granlund \& Malmi, 2002; Caglio, 2001; Peleias \& Parisi,2001).

Neste sentido o trabalho desenvolve um modelo de atuação para a empresa contábil no qual está inserido uma nova arquitetura tecnológica que trará benefícios mútuos, tanto para a empresa contábil quanto para a empresa cliente, pois facilitará acesso e treinamento ao uso de tecnologia de ponta com a redução do custo total de propriedade (TCO) para ambas, transformando-se a contábil num provedor de serviços de aplicação (ASP) interagindo ambas no sistema em tempo real com poder de trabalho com multiempresas. A figura seguinte retrata esta nova arquitetura tecnológica na empresa contábil como extensão da arquitetura tecnológica da empresa cliente. (VG) 
FIGURA 6 - ARQUITETURA TECNOLÓGICA DA EMPRESA CONTÁBIL INTERLIGANDO A EMPRESA CLIENTE

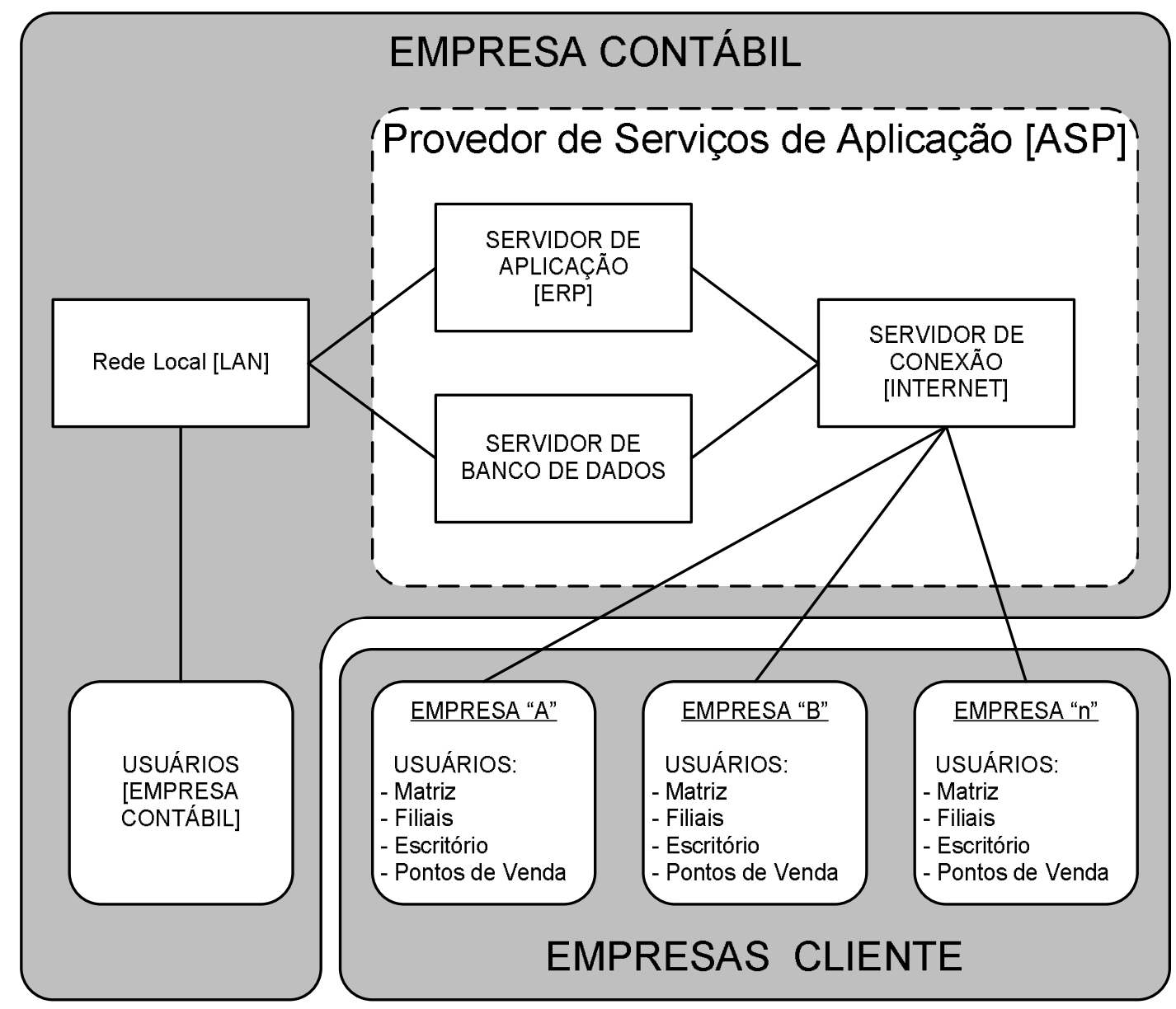

Fonte: Elaborado pelo Autor

Nesta arquitetura tecnológica a empresa contábil poderá realizar sua missão principal, bem como resgatar a missão tradicional da contabilidade - evidenciado nas conclusões deste trabalho e ainda, atuar como Provedor de Serviços de Aplicação (ASP - Application Service Provider) levando tecnologia de ponta para as empresas cliente com custo total de propriedade (TCO) minimizado.

\subsubsection{A RELEVÂNCIA DO PROBLEMTEMA PESQUISADOA}

Em termos científicos, a relevância do trabalho é desenvolver e testar um paradigma de pesquisa - Pesquisa-Ação (PA) na prática - possibilitando aos agentes envolvidos a produção de conhecimento no ambiente empresarial; além disso, o método contribui para a produção de ferramentas profissionais adequadas para apreender na prática, através da intervenção. 
Em termos práticos, a solução pesquisada possibilitará desenvolver uma metodologia de intervenção necessária à implementação de sistema empresarial integradoSistema Empresarial Integrado - ERP, permitindo as empresas contábeis aproximar o conhecimento contábil da realidade dos negócios - conhecimento contábil distribuído - e a obtenção, a partir daí, das vantagens da utilização da contabilidade gerencial e da tecnologia de informática na diversificação estratégica dos seus negócios, contribuindo efetivamente para a vida e o crescimento das empresas-cliente.

\subsection{CAMPO DE ESTUDO DA PESQUISA}

As organizações de serviços profissionais, entre elas as empresas contábeis e consultorias, são empresas que prestam serviços especiais a seus clientes. O tipo especial de serviço é um serviço profissional porque é prestado por equipe treinada de forma rigorosa. Comparadas com as empresas que produzem e fornecem bens tangíveis, as empresas contábeis têm, entre outras, as seguintes características exclusivas: ausência de um estoque de mercadorias vendáveis, importância dos profissionais, dificuldade de medir a quantidade e a qualidade da produção e pequeno porte do negócio. O campo teórico de estudos envolve diversas áreas, pesquisadas ao longo do trabalho e especificada no desenho da pesquisa, as quais podem ser resumidas através dos temas voltados com a questão da arquitetura organizacional e tecnológica e seus reflexos sobre o sistema humano-comportamental, em outras palavras, o inter-relacionamento e ajuste mútuo no sistema técnico e humano da empresa contábil decorrentes dos avanços da TI, tratado com mais detalhes nos tópicos seguintes.

\subsubsection{AS EMPRESAS CONTÁBEIS E O SISTEMA DE INFORMAÇÃO}

A informação contábil básica para as empresas contábeis refere-se a quando e como cobrar pelos serviços prestados, sendo fundamental um sistema de tempo e de cobrança que reconheça que o recurso mais importante desse tipo de organização é constituído por seus profissionais, ou seja, conhecimento tácito e explícito. Os sistemas de informação contábil de tempo e faturamento são semelhantes aos sistemas de custeio por projetos. O sistema contabiliza as horas e os custos associados a cada projeto, isto é, cada cliente e cada funcionário (cada profissional). Existem três 
relatórios principais nesses sistemas: (i) a conta do cliente e (ii) o registro de horas faturáveis dos profissionais; e (iii) as horas não cobráveis, que são horas gastas em treinamento, marketing e pesquisa em geral. Neste sentido o sistema de informação contábil é um sistema que abrange toda a empresa.

A proposta deste trabalho é fundamentada na visão proposta por Riccio (1989, pg.164) sobre que o sistema de informação contábil de fato "abrange não somente a Contabilidade Financeira (Nível Operacional), mas também a Contabilidade Gerencial (Nível Tático) e já contém os elementos essenciais do que poderíamos denominar Contabilidade Estratégica”. Já naquela época o autor se preocupava com a passagem dos conceitos desenvolvidos para o plano prático, o que também faz parte das preocupações deste trabalho quanto às empresas contábeis, e para tanto as seguintes questões devem ser observadas:

(i) O sistema de informação contábil deve ser desenvolvido dentro do conceito de sistema amplo, isto é, voltado para a empresa, ao contrário do conceito de sistema particular da área contábil; (ii) Deve haver utilização intensa da tecnologia de informática para permitir que o sistema opere no modo de tempo real, suportado por banco de dados e com funções que permitam a troca de dados com outros sistemas internos e externos (outras empresas e redes públicas); (iii) Os lideres do Sistema (contadores e administradores), devem estar perfeitamente conscientes das mudanças culturais que devem acompanhar a passagem do sistema de informação contábil para esse novo patamar dentro da estrutura de sistemas de informação da empresa.

Esta nova visão para o sistema de informação contábil, apesar da direção cristalina que propõe, não chegou à gestão das empresas menores, que ainda convivem com a visão tradicional de sistemas não integrados à contabilidade, o que parece ser a regra na maioria das empresas contábeis. A passagem para este novo modelo de gestão baseado na informação contábil seria inconcebível sem a tecnologia de informação, materializada nos sistemas empresariais integrados - ERP. Porém, este trabalho propõe que o sistema dê suporte antes à gestão da própria empresa contábil, o que facilitaria as mudanças de cultura, visão e aprendizagem necessárias a esta quebra de paradigma com relação ao sistema de informação contábil.

\subsubsection{A ADMINISTRAÇÃO DA MUDANÇA}

A administração da mudança organizacional deve ser vista como o equilíbrio de um sistema constituído por cinco variáveis interativas dentro da organização pessoas, processos (tarefas), tecnologia, estrutura e estratégia. Uma mudança em qualquer uma delas vai repercutir nas outras. Essa perspectiva é episódica, uma vez 
que trata a mudança organizacional essencialmente como um esforço de sustentação do equilíbrio. Uma mudança em uma variável inicia uma cadeia de eventos que, se adequadamente administrada, exige ajustes nas demais variáveis para obter um novo estado de equilibro.

Numa síntese, a organização, internamente, é estruturada em diversificados sistemas, que podem ser resumidos a três, para efeito de análise: o tecnológico, o social e o gerencial. Pela interdependência existente, uma mudança, em qualquer um dos sistemas, inevitavelmente afetará os demais (Cury, 2000). No caso que estamos estudando, por exemplo: uma nova tecnologia (tecnológico), para poder ser utilizada plenamente, poderá exigir novos tipos de recursos humanos (social) e novos arranjos estruturais (arquitetura) e / ou redefinições de processos e métodos de trabalho (gerencial). Neste sentido, discutiremos a missão da empresa contábil passando a representar o papel de agente de mudança nas empresas-cliente.

\subsubsection{DESENVOLVIMENTO ORGANIZACIONAL}

Nenhuma discussão sobre administração da mudança estaria completa sem a inclusão do desenvolvimento organizacional. O desenvolvimento organizacional não é um conceito de fácil definição (Robbins, 2002). O termo é utilizado para englobar uma série de intervenções de mudança planejada, com base em valores humanísticos e democráticos, que buscam melhorar e eficácia organizacional e o bem estar das pessoas.

O paradigma do Desenvolvimento Organizacional valoriza o crescimento humano e organizacional, os processos colaborativos e participativos e o espírito investigativo. Uma moderna definição de desenvolvimento organizacional (DO), citada por Cury (2000, pg.46) deve ressaltar certos aspectos e métodos de administração de mudanças, como o de autoria de French e Bell:

(...) um esforço de longo prazo para melhorar os processos de solução de problemas e de renovação de uma organização, particularmente por meio de uma administração mais eficaz e mais cooperativa da cultura da organização, com a ajuda de um agente de mudança, catalisador, e com a aplicação da teoria e da tecnologia da ciência do comportamento, inclusive pesquisa e ação.

\subsubsection{APRENDIZAGEM ORGANIZACIONAL}

A ciência-ação é uma abordagem criada por Argyris que evoluiu para um corpo teórico direcionado para a pesquisa participante, buscando conhecimento útil à ação, 
isto é, o conhecimento que possa ser implementado em contextos de ação no qual o cientista da ação é um interventor que procura ao mesmo tempo promover o aprendizado no sistema-cliente e contribuir para o conhecimento geral.

O organismo humano é destinado à ação, e realiza seu destino aprendendo a agir. As organizações, criados pelos homens, não podem comportar-se de forma diferente, desde que tenham-se posto em ação. Já que aprender é um processo que dura a vida toda, Argyris (1992) coloca que o problema da aprendizagem organizacional é que se deve trabalhar as deficiências de aprendizado.

Neste sentido, como referência na área de aprendizagem organizacional o autor faz a diferença entre aprendizado de circuito simples (single loop) e de circuito duplo $\left(\right.$ double loop ${ }^{l}$ ), cuja principal distinção entre uma organização que aprende, e uma que não, está na reflexão, que ocorre no aprendizado em circuito duplo (double loop learning). O double loop é, pois, umfeedback (loop) de segunda ordem: uma reflexão sobre o sistema de ação como um todo.

Morgam (1986) entende que, nas organizações, o single loop representa o aprendizado na forma de detecção de erros, enquanto que o double loop significa aprender a aprender, através da reflexão sobre o funcionamento da detecção de erros.

\subsubsection{A ABORDAGEM SOCIO-TÉCNICA}

A Escola Sócio-técnica surgiu na década de 50 como uma corrente de pensamento que procura oferecer, como alternativa ao modelo clássico, com base em estudos e pesquisas realizadas pelo Instituto Tavistock de Londres nas minas de carvão de Durham na Inglaterra (1949) e numa empresa textil em Ahmedabad na Índia (1952), e em diversas empresas Norueguesas nas décadas de 60 e 70.

A essência do procedimento desenvolvido pelo Instituto Tavistock é promover a auto-mudança organizacional por meio de processos grupais ocorrendo em vários níveis organizacionais. O alvo imediato é melhor compreensão das pessoas com

\footnotetext{
${ }^{1}$ As expressões "single-loop" (quando os erros são corrigidos em relação às normas operacionais estabelecidas) e "double-loop" (quando os erros são corrigidos através da alteração das normas empresariais que o causaram), são amplamente consagras na língua inglesa e serão assim tratadas nesta pesquisa. Alguns autores usam essas expressões como "circuito-simples" e "circuito-duplo", porém não há consenso e não expressam o significado original. As expressões "loop simples" e "loop duplo" poderão ser utilizadas com o sentido das expressões originais em inglês.
} 
referência aos seus inter-relacionamentos organizacionais e seus próprios motivos pessoais, sendo o alvo remoto a promoção da reestruturação organizacional pelas próprias pessoas. Os pesquisadores externos são agentes de mudança, mas os principais agentes de mudança são os próprios membros da organização. Neste ponto seus métodos e procedimentos se identificam muito com o paradigma de pesquisaação. No enfoque sócio-técnico, indivíduos e grupos são vistos como manifestações progressivamente mais complexas de um princípio estrutural básico, sendo encarados como sistemas abertos. Com relação ao trabalho e as tarefas, a abordagem sóciatécnica assume que existe uma gama de modelos e estruturas de trabalho que satisfazem e motivam os indivíduos, e seguindo a linha de Lewin (1948), admite que o comportamento face ao trabalho relaciona-se à forma de organização do trabalho e ao conteúdo da tarefa.

\subsubsection{DESENHO DA ABORDAGEM UTILIZADA NAPARA CONDUZIR A PESQUISA PESQUISA}

O esquema (framework) seguinte objetiva auxiliar o encadeamento lógico da pesquisa, ligando as questões teóricas tratadas no trabalho ao problema de pesquisa inicial e à sua evolução ao longo das descobertas. 
FIGURA 7 - DESENHO DA ABORDAGEM UTILIZADA PARA CONDUZIR A PESQUISA: LIGA O PROBLEMA INICIAL AO REFERENCIAL TEÓRICO, MOSTRANDO A ABORDAGEM UTILIZADA PARA IDENTIFICAR AS UNIDADES DE ANÁLISE

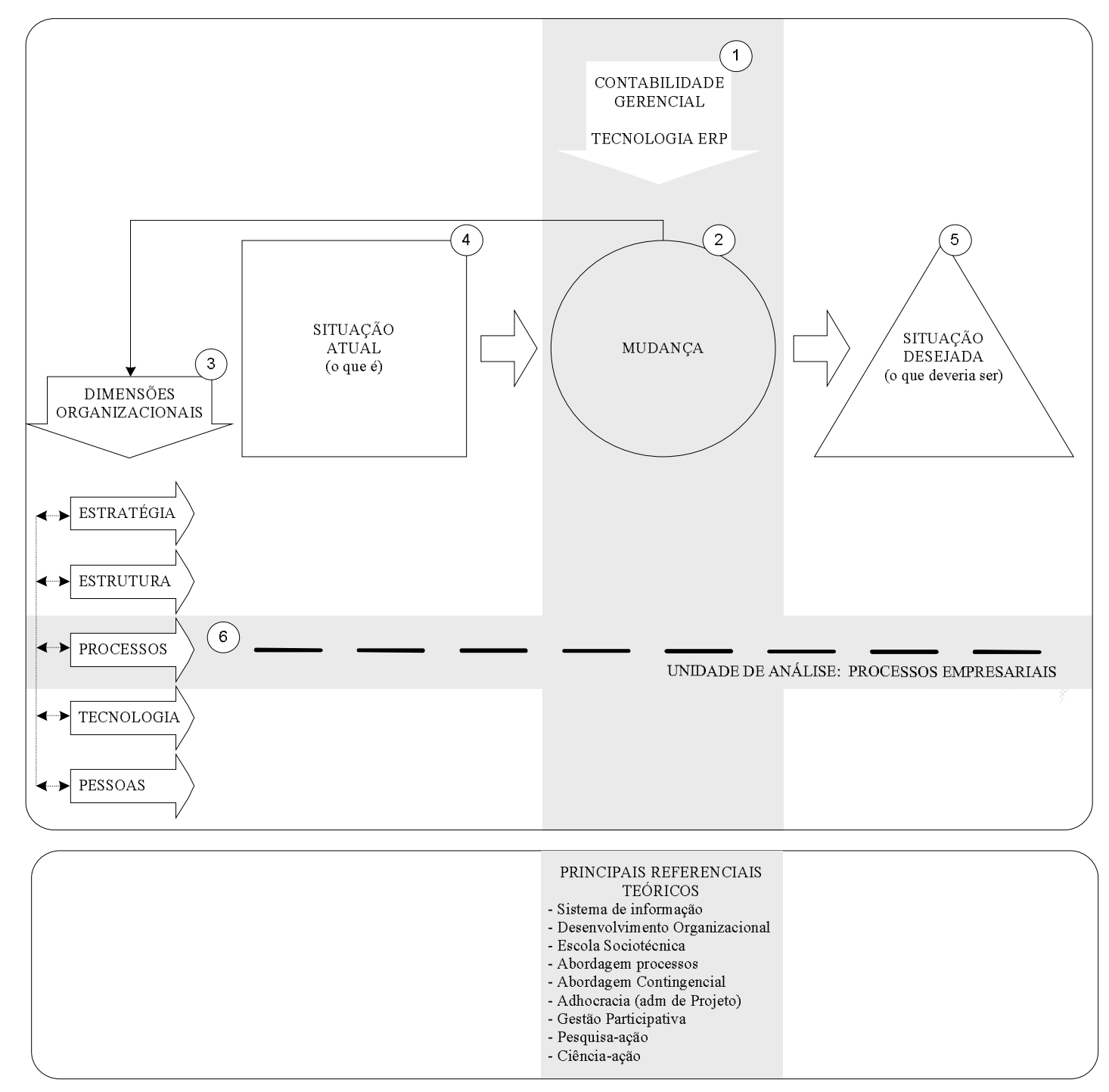

Fonte: Elaborado pelo Autor

Para ler e compreender o modelo, os números destacados em ordem seqüencial representam:

1 - As forças que impulsionam as mudanças na empresa contábil: (i) a diversificação estratégica representada pela contabilidade gerencial e a própria mudança nos paradigmas do profissional contábil; (ii) a tecnologia do sistema empresarial integradoSistema Empresarial Integrado - ERP, que possibilitará colocar em prática essa nova visão do sistema de informação contábil; 
2 - O processo de mudança que deverá ocorrer nas empresas contábeis visando implementar o sistema empresarial integradoSistema Empresarial Integrado ERP, possibilitando maximizar seu potencial;

3 - As mudanças que devem ocorrer nas dimensões organizacionais (arquitetura) das empresas contábeis, de acordo com o triângulo estratégico proposto por Walton (1998, pg.60), considerando que a mudança no domínio tecnologia provoca mudanças nos demais domínios, e como resultado possível da mudança teremos a organização orientada para o comprometimento, na definição de Walton (1998);

4 - A situação atual - o que é uma empresa contábil - pretende mostrar, através da revisão bibliográfica existente, os fundamentos teóricos de como é a arquitetura organizacional dessas empresas nas respectivas dimensões;

5 - A situação desejada - o que deveria ser uma empresa contábil - pretende mostrar uma visão de futuro para essas organizações, considerando a revisão bibliográfica efetuada e os fundamentos teóricos de como deveria ser a arquitetura organizacional dessas empresas nas respectivas dimensões, para que as forças que impulsionam as mudanças sejam plenamente aproveitadas;

6 - A dimensão processos empresariais será o foco central de análise nesta pesquisa, por isso a pesquisa centrou-se no mapeamento, redesenho e melhoria dos processos, no sentido de moldar a empresa orientada a processos, que Davenport (2002, pg.132-133) assim definiu: “Um processo é, portanto, uma ordenação especifica de atividades de trabalho no âmbito de tempo e lugar, com um começo, um fim e inputs e outputs claramente definidos: uma estrutura para a ação”, ou seja, a maneira pela qual se supõe que determinado trabalho deva ser conduzido em uma organização.

Saliente-se que a metodologia utilizada PA como paradigma de pesquisa influenciou fortemente todo o processo de pesquisa, desde a descoberta do problema inicial até a forma como os resultados foram alcançados. A PA representa para esta pesquisa ao mesmo tempo a metodologia (no sentido de método "como o caminho para") e a base da teoria utilizada para conduzir o processo (no sentido de ser a própria ferramenta) de mudança, o que ficará mais claro ao longo da pesquisa. 


\section{CAPÍTULO II - A EMPRESA CONTÁBIL E AS QUESTÕES DE PESQUISA}

Neste capítulo procura-se entender o que seja uma empresa contábil como organização, através da incursão na literatura da teoria da administração resgatando-se conceitos e definições necessárias ao entendimento das "diversas visões" correntes sobre a empresa. Busca-se então compreender, através da análise organizacional, as forças que impulsionam as mudanças neste tipo de organização humana e como elas devem ser tratadas na busca da eficácia (sistema técnico) e a satisfação (sistema humano), principalmente decorrentes das múltiplas e complexas relações existentes entre a tecnologia, a organização e o processo de gestão. O problema inicial de pesquisa, seus refinamentos e as questões vão emergindo do corpo de conhecimentos desenvolvido durante a pesquisa prévia neste capítulo.

\section{A EMPRESA CONTÁBIL}

A análise formal e o diagnóstico das organizações, à semelhança do processo de leitura, baseia-se em algum tipo de teoria aplicada à situação que está sendo considerada (Morgan, 1996). As teorias, como as leituras, são interpretações da realidade. Desta forma, uma análise eficaz, assim como para uma leitura eficaz, fundamenta-se na capacidade de realizá-la levando em conta teorias ou explicações rivais.

O autor salienta que muitas das idéias convencionais sobre organizações e administração, que embasam estudos científicos das diversas disciplinas, foram construídas sobre um pequeno número de imagens tidas como certas, especialmente a mecânica e a biológica. Novas maneiras de pensar sobre a organização podem surgir, explorando um conjunto alternativo de imagens que possibilite seu uso como um instrumento prático de diagnóstico dos problemas organizacionais.

Neste sentido, o modo de encarar o fenômeno, isto é, de ver com outras lentes, transforma a compreensão da natureza do fenômeno que se está observando. 
As teorias podem ser usadas de maneira prática para compreender, gerir e conceber organizações, e as imagens ou metáforas ${ }^{1}$ * são teorias ou arcabouços conceituais. Na visão de Morgan (1996, p.343) gerentes eficazes e profissionais experientes têm consciência que "novas descobertas sobre uma situação ocorrem quando se le esta situação a partir de novos ângulos e que ampla variedade de leituras pode criar ampla variedade de possibilidades de ação". Usar uma metáfora implica um modo de pensar e uma forma de ver que permeia a maneira pela qual entendemos nosso mundo em geral.

Neste sentido, a empresa contábil pode ser pensada como um grande "cérebro" processador de informações para a empresa-cliente. Cada aspecto do seu funcionamento depende do processamento de informações, através dos sistemas de informação, de comunicação e de tomada de decisão.

A empresa contábil, neste sentido e visão, tem por objetivo gerir o subsistema de informações da empresa-cliente, fazendo parte do sistema maior que são essas organizações.

\subsection{A EMPRESA CONTÁBIL E SEU AMBIENTE}

O ambiente no qual estão inseridas as empresas contábeis é tão dinâmico quanto o ambiente das demais organizações nacionais. Um ponto de diferenciação, porém, é que estas empresas além de lutarem para sobreviver neste ambiente turbulento, participam com co-responsáveis pela sobrevivência de outras entidades, notadamente pequenas e médias empresas.

A vida dessas entidades (empresa-cliente) está diretamente ligada às orientações recebidas da empresa contábil, conforme comprovam as pesquisas realizadas por entidades representativas deste segmento, dentre as quais destaca-se o

\footnotetext{
${ }^{1}$ Metáfora: Metaphorá (ou metaphorai) é uma palavra grega que expressa "transferência". Segundo Aristóteles, é a transposição do significado de uma coisa para outra diferente. Usamos a metáfora sempre que tentamos compreender um elemento da nossa experiência em face de outro. Assim, a metáfora prossegue por meio de afirmações implícitas ou explícitas de que Aé (ou parece) B.

* Metáfora: Metaphorá (ou metaphorai) é uma palavra grega que expressa "transferência". Segundo Aristóteles, é a transposição do significado de uma coisa para outra diferente. Usamos a metáfora sempre que tentamos compreender um elemento da nossa experiência em face de outro. Assim, a metáfora prossegue por meio de afirmações implícitas ou explícitas de que Aé (ou parece) B.
} 
levantamento efetuado pelo SEBRAE e FIPE $^{1 *}$ mostrado no gráfico abaixo, onde evidencia-se que 66\% (sessenta e seis) por cento do segmento buscam assessoria no contador ao longo do seu ciclo de vida.

GRÁFICO 1GRÁFICO 1 - PROFISSIONAL OU ENTIDADE PROCURADO PARA ASSESSORIA POR PEQUENAS EMPRESAS NO ESTADO DE SÃO PAULO

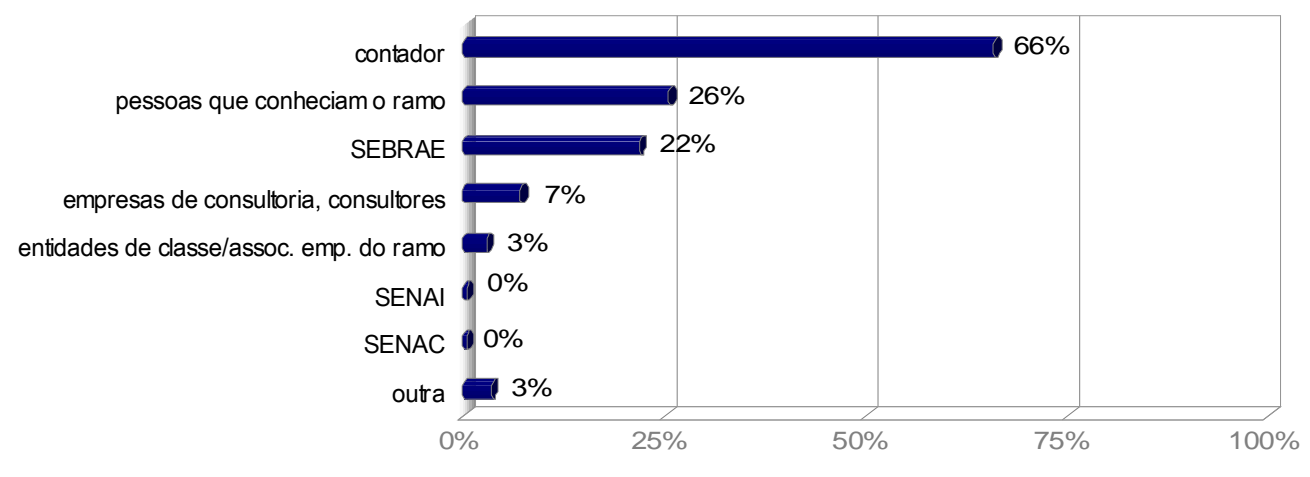

Fonte: SEBRAE-SP / FIPE (Pesquisa de Campo) nota: a soma das respostas ultrapassa 100\% porque a questão admitia mais de uma resposta.

A empresa contábil atua especificamente no mercado dos médios e pequenos negócios, cuja definição dos elementos para seu enquadramento não é unânime entre os autores especializados, uns utilizando o faturamento como parâmetro, outros o número de empregados e outros ainda utilizando as definições do enquadramento tributário. Existem contradições entre os diversos enquadramentos e suas variações atualmente, principalmente em função das características dos negócios modernos, e outros trabalhos $^{* 2}$ já tentaram fazê-lo. Para esta pesquisa utilizaremos a abordagem

\footnotetext{
${ }^{1}$ SEBRAE-SP [Serviço de Apoio às Micro e Pequenas Empresas de São Paulo]; FIPE (Fundação Instituto de Pesquisas Econômicas). Coordenadores: Marco Aurélio Bedê (SEBRAE-SP); Carlos Roberto Azzoni (FIPE). Sobrevivência e Mortalidade de Empresas Paulistas de 1 a 5 anos. São Paulo, outubro de 2001. Disponível em: http://www.sebraesp.com.br. Acesso em: 29 dezembro 2002.p.13.

* SEBRAE-SP (Serviço de Apoio às Micro e Pequenas Empresas de São Paulo); FIPE (Fundação Instituto de Pesquisas Econômicas). Coordenadores: Marco Aurélio Bedê (SEBRAE-SP); Carlos Roberto Azzoni (FIPE). Sobrevivência e Mortalidade de Empresas Paulistas de 1 a 5 anos. São Paulo, outubro de 2001. Disponível em: http://www.sebraesp.com.br. Acesso em: 29 dezembro 2002.p.13.

* Kassai (1996) As empresas de Pequeno Porte e a Contabilidade.

${ }^{2}$ Kassai (1996) As empresas de Pequeno Porte e a Contabilidade.
} 
proposta pelo professor Nelson Carvalho ${ }^{* 1}$ na disciplina teoria da contabilidade referindo-se a necessidade das informações contábeis no ambiente dos pequenos negócios e sua importância para a economia de uma nação. Ele refere-se ao universo dos pequenos, utilizando uma figura de linguagem, na qual classifica estas empresas em três categorias, a saber:

(i) Pequeno Anão (desorganizado), entendido como aquele "ser" que é uma deformidade do ambiente, já nasceu sentenciado à morte pela própria incapacidade do seu fundador (gestor) de entender as condições naturais de manter e desenvolver um negócio;

(ii) Pequeno Pigmeu (organizado para o seu tamanho), entendido como aquele "ser" aceito e plenamente adaptado ao ambiente empresarial, porém, por decisão do seu fundador (gestor) não quer e nem pretende crescer, manterá para sempre o tamanho que escolheu, qual seja, ser um pequeno "perfeito";

(iii) Pequena Criança (organizado e estruturado para crescer), entendido como aquele "ser" que tem como missão "ser grande", e foi para isso que nasceu, o ambiente empresarial no qual está inserido espera isso dele-crescer para ser forte e grande. A maioria das grandes empresas nasceu pequena, crescendo como condição própria da sua natureza, e é isso que seu fundador deseja e é condição de sobrevivência - $o$ seu desenvolvimento.

Este é especificamente o ambiente no qual deve operar a empresa contábil objeto deste estudo e onde deve desenvolver sua missão junto a empresa "pequeno criança" que por necessidade de crescimento está necessitando estruturar seu sistema de informação visando gerir adequadamente os recursos que processa e opera.

\footnotetext{
* Carvalho, Nelson. Nas aulas da disciplina de teoria da contabilidade do mestrado em controladoria e contabilidade convênio Conselho Federal de Contabilidade-FIPECAFI-USP no site de Florinaópolis - $1^{\circ}$ semestre de 2001.

${ }^{1}$ Carvalho, Nelson. Nas aulas da disciplina de teoria da contabilidade do mestrado em controladoria e contabilidade convênio Conselho Federal de Contabilidade-FIPECAFI-USP no site de Florinaópolis - $1^{\circ}$ semestre de 2001.
} 


\subsubsection{A EMPRESA E SEU CONCEITO ATUAL}

As palavras "organização" e empresa têm o mesmo significado no ambiente atual, representando um conjunto interativo de pessoas ou de organismos. Em outras palavras, a empresa é uma sociedade.

Raramente as organizações são propostas como um fim em si mesmas, elas são instrumentos criados para se atingirem outros fins. Morgan (1996, pg.24) esclarece que isso é refletido pelas origens da palavra organização que deriva do grego organon, significando uma ferramenta ou instrumento, trazendo-nos idéias sobre tarefas, metas, propósitos e objetivos, sendo estes conceitos organizacionais fundamentais. Este conceito está quase sempre carregado de significado mecânico e instrumental.

Contrário ao seu significado mecânico - e visão única, Morgan (1996) cunha a palavra imaginização simbolizando a estreita ligação entre imagem e ação, no sentido de "organização" como um modo de pensar, e a tarefa de organizar sendo realizada conforme se imaginiza, e é sempre possível imaginizar-se de muitas formas diferentes. $\mathrm{Na}$ visão deste autor as imagens e metáforas não são somente construtos de interpretação ou formas de se encarar a realidade: "fornecem também uma estrutura para a ação". A sua utilização gera descobertas que freqüentemente permitem agir dentro de estratégias nunca antes consideradas, o que reforça um dos objetivos deste trabalho: ver a empresa contábil com outros olhos, com sentido e missão diferente, e entender a partir desta nova visão qual o processo de mudança pelo qual ela deve passar.

A grande maioria das realizações na sociedade moderna só ocorre porque as pessoas em grupos se envolvem em projetos comuns, e a primeira justificativa para a existência de organizações é a de que certas metas só podem ser alcançadas mediante ação convergente de grupos de pessoas. (Pereira in Catelli, 1999).

Seus objetivos prioritários são econômicos. Porém, para que esses objetivos sejam atingidos, a empresa deve garantir a satisfação daqueles que nela trabalham, e deve ter um conjunto de valores compartilhados que orientam a ação e o comportamento das pessoas no atingimento dos objetivos econômicos. 
As empresas modernas estão em constante transformação. Na visão tradicional, a empresa é tida como um arranjo de especialistas estruturado, hierárquico e centralizado, baseado num conjunto fixo de procedimentos operacionais padronizados.

O novo estilo de empresa é um arranjo de generalistas enxuto, descentralizado e flexível que se baseia na informação. (Laudon \& Laudon; 2001, pg.4). Apesar desta direção ser clara, a maioria das empresas ainda é gerida na visão tradicional, o que parece ser a regra na maioria das empresas contábeis, e a passagem para este novo estilo seria inconcebível sem a tecnologia de informação, materializada nos sistemas o empresariais integrados - ERP, na visão proposta por Riccio (1989) sobre que o sistema de informação contábil de fato "abrange não somente a Contabilidade Financeira (Nível Operacional), mas também a Contabilidade Gerencial (Nível Tático) e já contém os elementos essenciais do que poderíamos denominar Contabilidade Estratégica”.

Já naquela época o autor se preocupava com a passagem dos conceitos desenvolvidos para o plano prático, o que também faz parte das preocupações deste trabalho. A pesquisa-ação e a abordagem de mudança utilizada nesta pesquisa procuram responder a esta questão.

Uma empresa também tem identidade e cultura, tem uma forma própria de agir, interagir e pensar. Enfim, uma empresa contábil é um organismo sócio-cultural; é um conjunto integrado de pessoas, funções e sistemas; um arranjo de generalistas enxuto, descentralizado e flexível, que se baseia na informação.

\subsubsection{A EMPRESA E SUAS FINALIDADES}

São várias as visões sobre as finalidades das empresas. Arantes (1998, pg.19) comenta que todos sabem que as empresas produzem alguma coisa, mas que não há concordância sobre a razão pela qual elas fazem isso, e expõe essas diferentes visões: "Para os economistas as empresas são agentes econômicos, para os cientistas sociais são organizações humanas, para os educadores são agentes de treinamento $e$ desenvolvimento, para os sindicatos são exploradoras dos trabalhadores, para o povo em geral são as responsáveis pela inflação e desemprego"

A finalidade para qual a empresa existe é fundamental para a vida dela, pois é em função de como vê esse papel que a empresa define seus rumos e seus objetivos, 
estabelece suas práticas e avalia seu desempenho. Essas finalidades podem ser: (i) externas - a relação que mantém com a sociedade onde atuam em termos de função que desempenham, as características do que produzem, como obtém e usam os recursos necessários à sua operação, e às condições que orientam sua atuação; (ii) internas - atender aos motivos e expectativas pelos quais elas foram criadas e são mantidas examinado a estrutura interna, as suas partes componentes e de como essas partes se relacionam.

Nesta visão, quanto às suas finalidades, as empresas contábeis buscam atender o processo de terceirização dos serviços contábeis das empresas-cliente.

\subsubsection{A EMPRESA COMO UM SISTEMA ABERTO}

A análise da empresa sobre o enfoque sistêmico tem sua origem principalmente nos estudos de Ludwig Von Bertalanffy, iniciados na década de 20 e publicados em 1968, no livro General System Theory (Oliveira; 2002, pg.154). O enfoque apresentado por Bertalanffy como uma teoria das organizações formais, define que a melhor forma de se estudar uma empresa, sob o ponto de vista de um sistema, é tratá-la como um sistema de variáveis (ou fatores) mutuamente dependentes. Desta forma, a empresa pode ser definida como um sistema composto por um conjunto de elementos unidos por ações interativas e de inter-relacionamento, para atingirem objetivos, metas e projetos de interesse comum, e para os quais estão dirigidas todas as forças, na busca do resultado sinérgico.

As expressões sistema, empresa e organização podem ser utilizadas como sinônimo, possibilitando uma definição filosófica de sistema empresa, a ser utilizado nesta pesquisa, como:

Empresa é um conjunto, uma estrutura, uma composição de elementos integrados por recursos humanos e materiais, que, por processos interativos e integrativos dentro de sistemas administrativos e empresariais, agem em atividades hierarquizadas, com determinadas responsabilidades e autoridade, compondo a organização. (Oliveira; 2002:161)

Decorrente deste conceito, o autor relaciona dois fatores básicos são constitutivos do sistema administrativo: (i) o fator estrutural relacionado com os recursos humanos e materiais dispostos na composição orgânica da empresa; e (ii) o fator operacional relacionado com o estabelecimento de padrões e parâmetros de comportamento e avaliação. 
$\mathrm{Na}$ abordagem sistêmica, o foco da atenção se transfere da análise da interação das partes para o todo, diferentemente da abordagem analítica do pensamento présistêmico, entendendo que: (i) todo fenômeno é parte de um fenômeno maior; (ii) as partes são explicadas em função de sua participação num sistema maior; (iii) a causa é uma condição necessária, mas nem sempre suficiente para surtir o efeito; (iv) a busca do objetivo. É preferível uma visão incompleta do todo, do que apenas um preciso conhecimento das partes (Tachizawa \& Scaico; 1997, pg.36).

FIGURA 8 - A EMPRESA VISTA COMO UM SISTEMA ABERTO

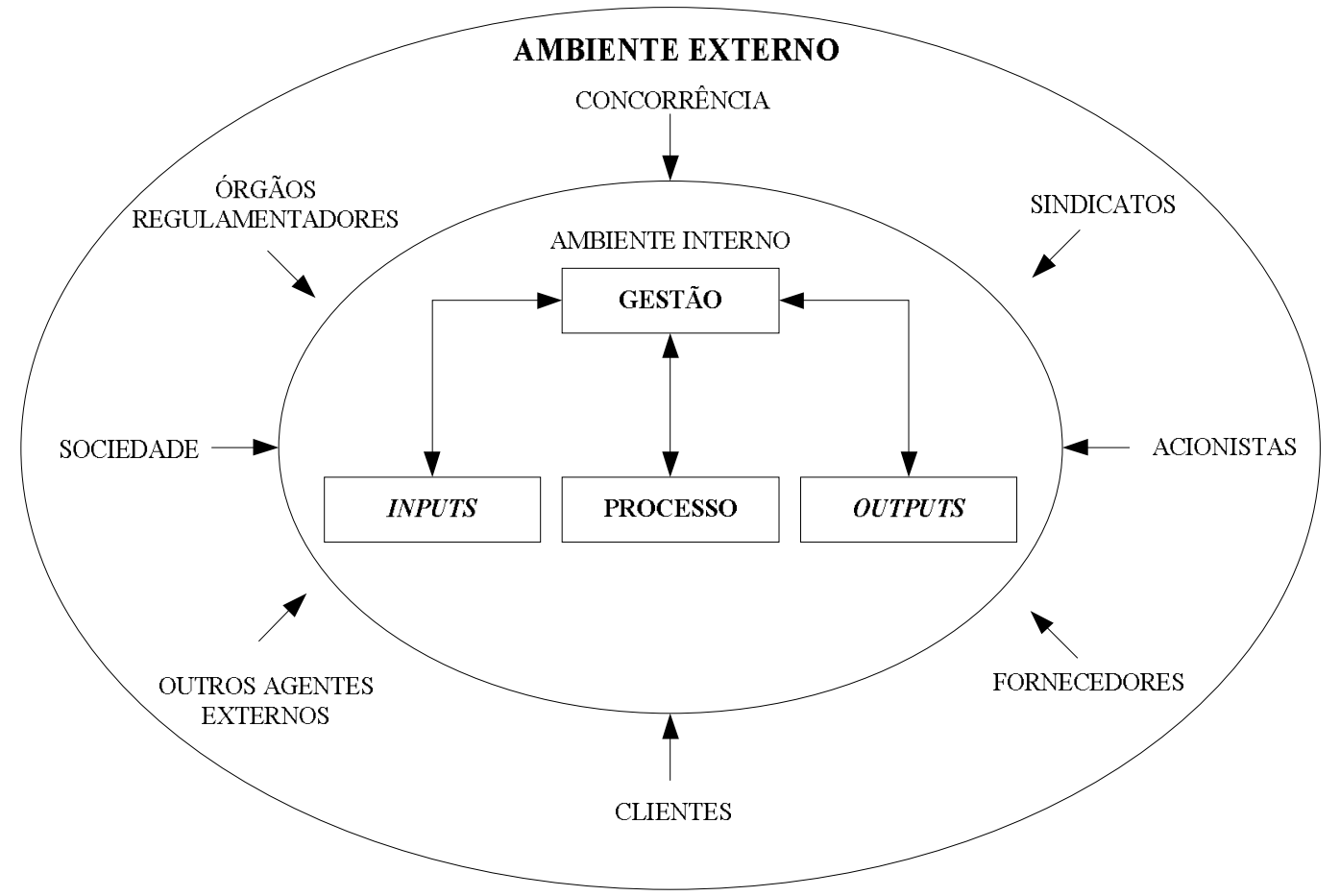

Fonte: (Pereira, 2002: 48) - Adaptado pelo Autor

Nesta visão, a empresa é um grande sistema que interage com os diversos agentes e variáveis externas que impactam direta ou indiretamente a sua gestão, sendo a informação o elemento chave para otimização do seu relacionamento com todos os agentes envolvidos no negócio.

A empresa contábil, neste sentido e visão, tem por objetivo gerir o subsistema de informações das organizações, fazendo parte do sistema maior das empresascliente. 


\subsubsection{A EMPRESA COMO SISTEMA TÉCNICO E HUMANO}

A empresa vista como sistema tem suas relações com o ambiente externo através de variáveis técnicas (regras, processos e métodos) e variáveis humanas (personalidade, convicções e comportamento), e a combinação dessas variáveis é que irá permitir a eficácia da ação empresarial na obtenção dos resultados coerentes com as suas finalidades (Arantes; 1998, pg.46).

Alguns cuidados devem ser tomados na abordagem dos sistemas. A comparação das organizações com organismos biológicos pode levar à chamada ilusão científica, onde passa-se a acreditar que o objeto de seu estudo é tão previsível quanto os sistemas biológicos. A maioria dos teóricos de sistemas valoriza excessivamente o ambiente, considerando que a sobrevivência da organização depende de sua capacidade de se adaptar a ele, privilegiando o sistema cultural em detrimento dos sistemas social e técnico, negligenciando o papel dinâmico das contradições internas das organizações.

\subsubsection{A EMPRESA CONTÁBIL COMO ESCRITÓRIO}

O trabalho administrativo em oposição ao trabalho fabril (industrial) é chamado de "escritório", termo que evoca a idéia geral de um espaço organizado, geralmente dentro de uma organização, e às vezes confundindo-se com esta, ocupado por móveis, equipamentos e pessoas. Numa visão moderna o termo "escritório" pode ser definido como "uma interação de pessoas para desempenhar uma série de processos que requerem o manuseio de informações com a ajuda da tecnologia visando aprimorar o processo de decisão". (Andreoni; 2001 pg.12).

As empresas contábeis podem vistas como "escritório" das empresas-cliente, entendido que a sua função é fornecer suporte administrativo às demais funções da empresa-cliente, conceito este ligado profundamente à Escola Clássica de Organização do Trabalho, ou seja, considera-se o "escritório" como sendo uma atividade facilitadora que corta transversalmente as outras funções da empresa-cliente. 


\subsubsection{A EVOLUÇÃO DO TRABALHO NO ESCRITÓRIO}

A partir da segunda metade do século XIX, ocorreu uma revolução nos escritórios quando o trabalho dos mesmos começou a ser mecanizado, com o surgimento da máquina de escrever.

Os primeiros passos para a grande revolução nos escritórios deram-se durante a segunda guerra mundial, quando o primeiro computador experimental foi desenvolvido. $\mathrm{O}$ desenvolvimento tecnológico dos equipamentos de escritório seguiu o padrão exponencial dos desenvolvimentos gerais obtidos pela nossa civilização, porém, a maneira de organizar o trabalho, apesar dos novos instrumentos de automação, continua a mesma. Andreoni (2001, pg.27) conclui que os avanços efetivos nos escritórios sé ocorreram recentemente:

Somente nos últimos vinte anos do século $\mathrm{XX}$, com o advento da tecnologia de informação, do inicio do uso da gestão por processos, e da difusão dos princípios da Escola Sóciotécnica de organização do trabalho, é que aparecem novas formas organizacionais para o trabalho nos escritórios.

A declaração deste ator não corresponde ao que é observado particularmente no processo de trabalho da empresa contábil, que se mantém quase o mesmo, em termos de visão do processo, nos últimos 30 anos, mesmo com a informatização das principais rotinas, pois que ainda mantém a visão de mecanização da contabilidade, iniciada a mais de meio século. Isto será detalhado no tópico 3.2.4.1 quando será abordado o tema tecnologia de informação na empresa contábil no estado atual.

\subsection{A ABORDAGEM SÓCIOTÉCNICA}

A Escola Sócio-técnica surge na década de 50 como uma corrente de pensamento que procura oferecer, uma alternativa ao modelo clássico, com base em estudos e pesquisas desenvolvidas no Tavistock Institute of Human Relations de Londres, nas minas de carvão de Durham na Inglaterra (1949) e numa empresa têxtil em Ahmedabad na Índia (1952), e em diversas empresas Norueguesas nas décadas de 60 e 70 .

A teoria do sistema Sócio-técnico (também na linha de sistemas abertos), diz respeito à interação dos fatores tecnológicos com os sociais, no sistema de produção industrial, tendo como principais fontes conceituais a psicanálise e a teoria de campo de Lewin (Minicucci, 2002). Esta interação influenciaria o equilíbrio do sistema, sendo 
possível uma "escolha organizacional correta", desde que, como adotada pelos pesquisadores, a forma de organização do trabalho fosse a de grupos autônomos (cujos membros poderiam atuar com uma pluralidade de habilidades técnicas). Esta abordagem, durante muito tempo negligenciada e mal compreendida nos Estados Unidos, pode ser considerada mais bem sucedida nos processos de mudança.

\subsubsection{O IMPULSO ÀS MUDANÇAS NA ESCOLA SÓCIO- TÉCNICA}

Duas frentes de mudanças na organização industrial motivaram e deram impulso às idéias desenvolvidas pela escola sócio-técnica: (i) a crescente insatisfação dos trabalhadores, e (ii) a introdução de equipamentos de base automatizada, gerando perda de produtividade. (Andreoni; 2001, pg.40).

No enfoque sóciotécnico, indivíduos e grupos são vistos como manifestações progressivamente mais complexas de um princípio estrutural básico, sendo encarados como sistemas abertos. Com relação ao trabalho e às tarefas, a abordagem sóciotécnica assume que existe uma gama de modelos e estruturas de trabalho que satisfazem e motivam os indivíduos, e seguindo a linha de Lewin (1948), admite que o comportamento face ao trabalho, relaciona-se à forma de organização do trabalho e ao conteúdo da tarefa.

\subsubsection{OS PRINCÍPIOS DA ESCOLA SÓCIO-TÉCNICA E OS GRUPOS SEMI-AUTONOMOS}

A escola sócio-técnica de organização do trabalho pode ser sistematizada em 9 princípios, descritos por Andreoni (2001, pg.44) e assim relacionados:

(i) Princípio da compatibilidade; (ii) Princípio da mínima especificação; (iii) Princípio do critério sóciotécnico; (iv) Princípio multifuncional; (v) Principio da locação de fronteiras; (vi) Princípio do fluxo de informações; (vii) Princípio da congruência; (viii) Princípio do planejamento e valores humanos; e (ix) Princípio do incompleto. Neste ponto é importante comentar o sexto princípio do fluxo de informações, que estabelece que os sistemas de informação devem ser planejados para prover informações, em primeiro lugar, para o ponto onde ela é necessária para gerar uma ação.

Os nove princípios e o conceito de grupo semi-autônomo - no qual um grupo assume a responsabilidade completa pela produção de um produto ou serviço, foram a base da organização do trabalho na escola sócio-técnica. Vale esclarecer que o termo 
semi-autônomo quer dizer que nem todas as decisões são tomadas pelo grupo, os aspectos estratégicos permanecem como atribuição de diretores.

Defendendo que o determinismo tecnológico pode ser desobedecido, com benefícios tanto econômicos quanto sociais, deve-se priorizar o enfoque sócio-técnico, onde aspectos técnicos e sociais relativos ao projeto de tarefas e das organizações devem ser respeitados. Desta forma, não existe subordinação do sistema social ao técnico, nem vice-versa. A definição do formato organizacional deve ser feita levandose em conta alternativas tecnológicas disponíveis frente às suas relações com os indivíduos envolvidos na operação do sistema em questão.

\subsubsection{A EVOLUÇÃO NADA ORGANIZAÇÃO DO TRABALHO}

Enquanto a escola de Taylor (mecanicista) considerava o homem como "homoeconomicus", onde sua motivação seria resultado do aumento da produtividade com o conseqüente aumento salarial, e a escola de Relações Humanas pregava a satisfação no trabalho como conseqüência das boas relações entre as pessoas, a escola sócio-técnica mostra-se dissociada destas duas correntes, no sentido de não privilegiá-las individualmente, mas sim considerando a otimização conjunta dos aspectos sociais e técnicos.

A forma como os sistemas são planejados no enfoque sócio-técnico, entretanto, depende dos objetivos finais do sistema, se é lucrativo ou não, da cultura e do ambiente organizacional em que se situa. Os objetivos determinam a escolha do modelo organizacional, a cultura marca os limites dentro dos quais a tecnologia pode ser aplicada e o ambiente, constituído pela cultura, valores e práticas genericamente aceitas, define quais as funções possíveis para os organismos que nela se encontram.

A abordagem sócio-técnica foi desenvolvida em resposta aos problemas associados com o rápido avanço tecnológico nas indústrias. Contudo, a revolução tecnológica nos escritórios expõe problemas similares, e, além disso, os sistemas hoje estão por todos os cantos da empresa. Como método participativo de projeto, a abordagem sócio-técnica tem grande potencial para engendrar uma espécie de mudança e uma aprendizagem organizacional necessária para se obter vantagens competitivas no uso da alta tecnologia. 


\subsubsection{A ABORDAGEM SÓCIO-TÉCNICA MODERNA}

Por volta de 1995, a história do paradigma do projeto de sistemas Sócio-técnico tinha já se estendido por quase meio século. Neste período diversas abordagens sóciotécnica se desenvolveram e a literatura sugere a história das abordagens em três períodos de evolução, distintos: (i) Sócio-técnica Pioneira: 1949 - 1959; (ii) Sóciotécnica Clássica: 1959 - 1971; e (iii) Sócio-técnica Moderna: 1971 - atual.

Nosso interesse é pela sócio-técnica moderna, que pode ser divida em quatro correntes paralelas e distintas (Andreoni; 2001, pg.51): (i) A Sócio-técnica Australiana ou "Projeto Participativo"; (ii) Sócio-técnica Holandesa ou "Renovação Organizacional Integral"; (iii) Sócio-técnica Escandinávia ou Diálogo Democrático; e (iv) Sócio-técnica Norte-Americana ou "Consultoria Norte-Americana".

Para este trabalho utilizar-se-a a abordagem da moderna sócio-técnica holandesa. A moderna sócio-técnica holandesa desenvolveu uma teoria por meio de uma rede de pesquisadores organizacionais, consultores e gerentes, que se autoorganizaram no Instituto Holandês para a melhoria da qualidade do Trabalho e Organização (NKWO).

A teoria do projeto que emergiu deste esforço foi construída sobre o trabalho teórico de Sitter; a teoria do sistema sócio-técnico tradicional; o trabalho desenvolvido pela Swedish Employers Federation; e a pratica de projeto do escritório de consultoria KOERS - Consultores. Estes esforços resultaram na abordagem IOR - Integral Organizations Renewal ou Renovação Integral Organizacional (Sitter, Hertog e Dankbaar, 1997) apud (Andreoni; 2001 pg.53), cujo objetivo foi desenvolver uma estrutura para o redesenho organizacional que satisfizesse as seguintes condições:

a)- A teoria de projeto deve conter conceitos e princípios que são genericamente aplicáveis, qualquer que seja a natureza específica da organização.; b)

- A teoria de projeto deve focalizar-se no projeto estrutural, assim como nos aspectos de aprendizagem do desenvolvimento organizacional. ; c)

- A teoria deve abrir possibilidades para customizar o projeto para organizações especificas; .d)

- A teoria deve ser facilmente aplicável e gerenciável na prática real; e) .

- A teoria de projeto deve ser facilmente comunicável e providenciar uma linguagem na qual gerentes e trabalhadores de áreas funcionais diferentes possam conversar efetivamente sobre os mesmos problemas e soluções organizacionais; f) .

- A teoria deve incorporar o envolvimento da gerência e o "empowerment" dos trabalhadores; h) .

- A teoria não pode ser parcial na abordagem, mas deve lidar com a organização como um todo. 


\subsubsection{CONCEITOS PARA O PROJETO ORGANIZACIONAL}

A estratégia de projeto do IOR é baseada no uso de um corpo estruturado de conhecimento, relativo ao projeto de organizações, no contexto de processo de projeto participativo. A elaboração da estratégia, portanto, requer por um lado a formulação de princípios de projeto, estratégia de projeto, e regras seqüenciais de projeto para construir e estruturar um corpo de conhecimento, que pode ser usado como uma ferramenta na estruturação do sistema; por outro lado, requer a especificação de um modelo para a participação nas atividades de projeto. Neste sentido, Sitter, Hertog e Dankbaar (1997) apud Andreoni (2001, pg.72) delineiam quatro conceitos básicos para o projeto organizacional:

(i) O conceito de Projeto Integral, como um genuíno projeto organizacional, é um projeto estrutural. Deve ser baseado na integração entre aspectos do sistema (logística, qualidade, manutenção, pessoal, etc.) e subsistemas (vendas, projeto do produto, fabricação, serviços, etc.); .

(ii) $\mathrm{O}$ conceito de Controlabilidade, não se refere a controlar objetivos específicos ou interesses a serem atingidos, mas antes a moldar condições estruturais para prover o sistema de dirigibilidade, de modo que o mesmo possa ter novas oportunidades e objetivos. A questão sócio-técnica básica é, por esta razão, não a capacidade do sistema para atingir um certo objetivo de acordo com critérios previstos, mas melhorar a habilidade de atingir uma gama de objetivos. Isto porque não sabemos o que o futuro nos trará e, portanto, não sabemos o que irá ser demandado; .

(iii) O Conceito Duplo de Estrutura de Produção e de Estrutura de controle (dirigibilidade), do ponto de vista da metodologia do projeto, que propõe introduzir uma distinção entre as estruturas básicas do sistema; .

(iv) $\mathrm{O}$ Conceito de Parâmetros Estruturais, refere-se às dimensões arquiteturais primárias da estrutura de produção e da estrutura de controle.

Os conceitos básicos acima expostos apontam para a possibilidade do projeto / re-projeto integral das organizações pela variação dos principais parâmetros arquiteturais que caracterizam a estrutura de produção e controle.

\subsubsection{O TRABALHO NO ESCRITÓRIO VISTO COMO UM PROCESSO}

O trabalho em escritório pode ser visto como um processo que tem entradas de solicitações, informações, etc. e que através de um conjunto de atividades, tomadas conjuntamente, produz um resultado de valor para o cliente interno ou externo.

Salerno (1999) tem uma definição mais ampla de processos operacionais: "Uma cooperação de atividades distintas para a realização de um objetivo global, orientado ao cliente final e comum". Um processo é repetido de maneira recorrente dentro da empresa. De acordo com este autor, a um processo correspondem: 
(i)- Um desempenho (performance) que formaliza o seu objetivo global (um nível de qualidade, um prazo de entrega, etc.); (ii)

- Uma organização que materializa e estrutura transversalmente a interdependência das atividades do processo, durante a sua duração.

(iii) - Uma co-responsabilidade dos atores nesta organização, com relação ao desempenho global;. (iv)

- Uma responsabilidade local de cada grupo de atores ao nível de sua própria atividade.

\subsubsection{VISÃO HORIZONTAL E AS CARACTERÍSTICAS DE UM PROCESSO}

A visão horizontal, ou de sistema, de uma organização, representa uma perspectiva diferente da estrutura vertical (organograma tradicional), permitindo (Tachizawa \& Scaico; 1997, pg.94):

(1) incluir os três elementos que normalmente faltam nos modelos de representação de uma organização, quais sejam: o cliente, o produto e o fluxo de trabalho;

(2) visualizar como o trabalho é realmente feito por processos que cortam as fronteiras funcionais; e

(3) evidenciar os relacionamentos internos entre cliente-fornecedor, por meio dos quais são gerados produtos / serviços.

A compatibilização entre as visões vertical e horizontal da organização gera grande vantagem organizacional e é necessária a implementação de um sistema empresarial integrado - ERP, pois a dimensão horizontal permite visualizar as significativas oportunidades de melhoria no desempenho que estão nas interfaces funcionais, aqueles pontos em que o serviço é passado de uma unidade organizacional para outra, ou em outras palavras, vendo os processos de negócio como uma "corrida de revezamento", naquele ponto em que o "bastão é passado de um atleta para o outro".

\section{FIGURA 9 - A EMPRESA VISTA COMO UM CONJUNTO DE PROCESSOS}

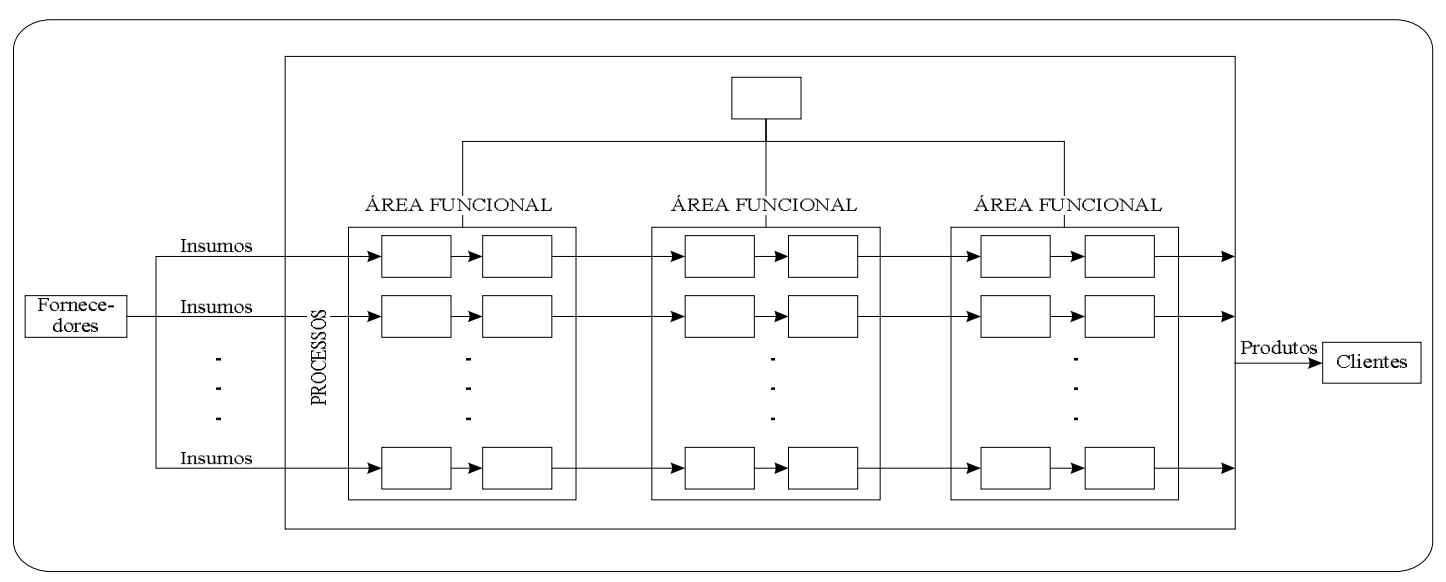

Fonte: Tachizawa \& Scaico (1997 pg.99) 
As características de um processo, então, na visão de Salerno (1999) citado por estes autores seriam:

- Uma organização estruturada, modelada em termos de troca entre as atividades construtivas. Esta organização se constitui pela ligação ao cliente final.

- Entradas, tangíveis (produtos, faturas, pedidos, etc.) ou intangíveis (decisão de lançar um novo produto, demanda de investimento, etc.).

- Saídas: o resultado do processo. É o ponto de partida para a construção da organização.

- Recursos: não é a somatória dos recursos locais, mas a utilização racional dos recursos que são, ao mesmo tempo, localmente necessários e úteis ao processo. É possível que alguns recursos fiquem dedicados a um processo, mas outros não, podendo ter um uso variado.

- Custo dos recursos locais globais, valorizados, dão o custo de um processo.

- Um desempenho global medido por alguns poucos indicadores, que deve ser explicitado em desempenhos locais para cada atividade. Esses indicadores seriam a única referencia de avaliação sobre o resultado do processo, o único critério de coresponsabilidade entre os atores. Localmente, têm-se indicadores de meios, e não de objetivos.

- Fatores de desempenho ligados aos pontos críticos: são pontos privilegiados de reflexão sobre a gestão econômica do processo e sobre os principais instrumentos de ação. Pontos críticos podem ser atividades ou coordenações.

- Um desenrolar temporal, dado que um evento detona o processo (ex. chegada de um pedido) e outro o fecha (ex. entrega). O processo se desenrola segundo uma temporalidade organizável e mensurável.

\subsubsection{PRINCIPIOS BÁSICOS DE PROJETO ORIENTADO A PROCESSOS}

Os princípios de projeto referem-se a soluções estruturais com pouca orientação genérica. $\mathrm{Na}$ abordagem IOR, estes princípios estão primariamente relacionados com o problema da complexidade (Andreoni, 2001). A complexidade de um sistema é função do numero de seus elementos, o número de suas relações internas e externas, e sua variabilidade no tempo.

A complexidade crescente dos sistemas está relacionada com a variação dos processos, a probabilidade de distúrbio e a sensibilidade ao distúrbio. Essa complexidade crescente resulta numa inabilidade crescente de lidar rápida $\mathrm{e}$ adequadamente com mudanças de demanda na organização, isto é, causa uma dirigibilidade reduzida.

Os princípios básicos do projeto integral devem, portanto, ser: (a) Reduzir as probabilidades de distúrbios pela redução das variações iminentes; e (b) Reduzir a sensibilidade aos distúrbios pelo aumento da capacidade de controle.

Prosseguem os autores estabelecendo uma série de aspectos de projeto, estratégias e regras seqüenciais que devem ser observados na elaboração do projeto 
IOR. Enfatizam, entretanto que tais aspectos não esgotam o assunto, e que devem ser vistos mais como uma reunião de exemplos e comentários.

SALERMO (1999), com base em seus desenvolvimentos sobre processos, eventos, comunicação e espaços de negociação, e na proposição de SITTER, HERTOG e DANKBAAR (1997), “considera que um projeto organizacional mais flexível, mais coerente com as necessidades de desempenho da indústria contemporânea", poderia se dar pela observação dos seguintes aspectos e fatores imprescindíveis, quando se aborda o tema de projeto de organizações integradas e flexíveis:

1) Elaboração de carta de valores / princípios do projeto; 2) Definição dos processos;: .

3) Paralelização;: 4) Segmentação;: 5) Critérios de seleção de tecnologia do processo de transformação; (equipamentos):

6) Sistemas de informação, produção da informação e espaços formais de comunicação / negociação;: .

7) Sistemas sociais de apoio.

Nesta visão, a empresa contábil pode ser entendida no conceito de grupo semiautônomo dentro da abordagem sócio-técnica, isto é, sua finalidade sendo vista um "processo no trabalho do escritório" das empresas-cliente com função de fornecer suporte administrativo às demais funções da organização, respondendo aos problemas associados com a revolução tecnológica decorrente dos avanços na informática.

\subsection{AS EMPRESAS “VÁLIDAS” E O PROCESSO DE GESTÃO}

O termo "empresas válidas" - aquelas que efetivamente contribuem para a sobrevivência e progresso da sociedade, colocando seu talento e dedicação à disposição desta mesma sociedade em que está inserida, foi criado por Arantes (1998 pg.18), procurando distinguí-las das empresas não-válidas, através de um conjunto de premissas que caracterizam suas práticas empresariais:

As empresas são mais do que agentes econômicos, suas finalidades devem abranger o crescimento e o bem estar da sociedade para que alcancem uma posição de organizações bem sucedidas ao longo da história. A história das empresas com visão inovadora e de tradição no mercado mostra que a existência de uma ideologia central que determine a presença de valores permanentes e relevantes, com objetivos além do 
ganhar dinheiro, exercem um tipo de inspiração e orientação aos participantes da organização, permanecendo estes valores inalterados por muito tempo.

O autor denomina estas empresas de "empresas válidas", conceituando-as como organizações que vêem o lucro como resultado de um trabalho eficaz e efetivo, com princípios transparentes e duradouros de contribuição para o desenvolvimento da sociedade onde estão inseridas. A função destas organizações é criar, produzir e desenvolver-se para atender continuamente às necessidades e desejos humanos, participando ativamente do progresso da sociedade.

\subsubsection{O SISTEMA DE GESTÃO E OS SEUS SUBSISTEMAS}

Para gerir "empresas válidas" dispomos de um conjunto de conceitos e técnicas de gestão que dão suporte à ação administrativa nas várias atividades que compõem a tarefa empresarial. Os componentes do sistema de gestão empresarial com base nesses conceitos e técnicas podem ser divididos em três subsistemas (Arantes; 1998 pg.88):

- O subsistema Institucional reúne os instrumentos que auxiliam a administração a fixar a razão de ser do empreendimento de acordo com crenças, valores, convicções e expectativas dos empreendedores. Ele define a identidade da empresa como instituição, caracterizando as finalidades externas e internas que ela se propõe a atender;

- Os subsistemas tecnológicos são constituídos pelos instrumentos que dão suporte à administração na fixação dos resultados empresariais e na orientação, organização, coordenação e controle das atividades de forma a assegurar que elas sejam dirigidas às finalidades pelas quais a empresa foi criada e é mantida. São cinco os subsistemas destinados ao suporte tecnológico de gestão à administração: gerencial, operacional, organização, comunicação e informação;

- O subsistema humano-comportamental inclui os instrumentos que a administração precisa para mobilizar as pessoas que integram a empresa e conseguir que seu comportamento esteja dirigido aos resultados e às finalidades empresariais.

O professor Catelli ${ }^{* 1}$ identifica nove subsistemas componentes do sistema empresa, que interagem no sentido do cumprimento de sua missão, podendo para fins de entendimento do modelo de funcionamento serem divididos em seis áreas, a saber: "Subsistema físico, subsistema institucional e modelo de gestão, subsistema de gestão e dos processos, subsistema organizacional e social, subsistema de informações e subsistema econômico".

\footnotetext{
* Catelli, Armando nas aulas da disciplina de controladoria do mestrado em controladoria e contabilidade convênio Conselho Federal de Contabilidade-FIPECAFI-USP no site de Florinaópolis - $1^{\circ}$ semestre de 2002

${ }^{1}$ Catelli, Armando nas aulas da disciplina de controladoria do mestrado em controladoria e contabilidade convênio Conselho Federal de Contabilidade-FIPECAFI-USP no site de Florinaópolis $-1^{\circ}$ semestre de 2002
} 


\subsubsection{OS SUBSISTEMAS DE GESTÃO E A INTEGRAÇÃO}

Conceitualmente as abordagens para a divisão do sistema empresa são muito convergentes, ambos os autores enfatizando a importância fundamental de os subsistemas de gestão serem integrados e terem uma forte interdependência, pois só assim conseguem contribuir de forma consistente para realização da missão da empresa.

Observa-se que a abordagem de Arantes enfatiza mais a questão social, enquanto que a abordagem de Catelli dá mais ênfase a questão econômica, porém, ambas confirmam a necessidade da visão sistêmica da empresa de forma integrada.

Neste sentido, as empresas contábeis têm uma dupla responsabilidade perante a sociedade do qual atuam e diante dos novos cenários de negócios: (i) modernizar seu modelo de gestão, aproveitando-se das modernas tecnologias existentes pela utilização dos sistemas integrados de gestão baseados na filosofia ERP; (ii) contribuir para que a mesma modernização possa chegar à gestão das suas empresas-cliente, cumprindo assim a sua responsabilidade principal: gerir o sistema de informação contábil integrado.

Esta responsabilidade lhes é conferida em função dos seus conhecimentos específicos que, aplicados, ajudaram a desenvolver a visão sistêmica, entendendo o seu objeto de estudo como o sistema empresa e suas variáveis.

\subsection{AS ORGANIZAÇÕES VISTAS COMO CÉREBROS}

Qualquer abordagem realista da análise organizacional deve ser iniciada a partir da premissa de que organizações podem ser muitas ao mesmo tempo, e de que elas são complexas, ambíguas e paradoxais. A análise baseada em metáforas fornece meios eficazes para se lidar com essa complexidade. Para aplicar esse método na prática, Morgan (1996, pg.328) propõe dois passos: (i) produzir uma leituradiagnóstico da situação que está sendo investigada, utilizando diferentes metáforas para identificar ou ressaltar aspectos-chave da situação; (ii) elaborar uma avaliação crítica do significado e da importância das diferentes interpretações efetuadas.

O cérebro é um sistema que dá início à ação inteligente, permanecendo supremo entre todos os sistemas naturais e feitos pelo homem dos quais se tem conhecimento. A metáfora do cérebro auxilia na compreensão de que uma organização 
pode ser vista como um sistema cognitivo, corporificando tanto uma estrutura de pensamento, como um padrão de ações.

Para compreender o funcionamento do cérebro e relacioná-lo melhor com a metáfora, Morgan (1996) cita como exemplo um experimento com ratos, realizado por neurocientistas em laboratório, em que foram removidas grandes porções do cérebro desses animais que haviam sido ensinados a correr num labirinto. Descobriu-se que se o córtex visual não fosse removido, portanto não os cegando, poderia se remover até $90 \%$ do córtex cerebral deles, sem deterioração significativa da sua capacidade de encontrar o caminho através do labirinto. Isso ocorre, de acordo com a neurociência porque o cérebro funciona de acordo com os princípios holográficos, em que a memória é distribuída através do sistema (cérebro) e pode assim ser reconstituída a partir de qualquer das partes.

\subsubsection{ORGANIZAÇÕES (CÉREBROS) PROCESSADORES DE INFORMAÇÕES}

Cada aspecto do funcionamento organizacional depende do processamento de informações, seja de um tipo ou de outro. As organizações são sistemas de informações. São sistemas de comunicação, sendo também sistemas de tomada de decisão. Nas organizações mecanicistas esses sistemas são altamente rotinizados. Nas organizações matriciais e orgânicas estes sistemas são altamente temporários e fluem livremente. Pode-se então, fazer um longo percurso no sentido da compreensão das organizações, bem como na variedade de formas organizacionais na prática, focalizando características do seu processamento de informações.

Explorando os paralelos entre a tomada de decisão humana e a tomada de decisão organizacional, Simon argumentou (Morgan, 1996) que as organizações nunca podem ser perfeitamente racionais, porque os seus membros têm habilidades limitadas de processamento de informações. Neste sentido, Morgan (1996, pg.85) esclarece argumentando que as pessoas:

(a) usualmente têm que agir sobre bases de informações incompletas a respeito de possíveis cursos de ação e as suas conseqüência;

(b) são capazes de explorar somente um limitado números de alternativas relativas a qualquer dada decisão; e

(c) são incapazes de dar acurados valores aos resultados. 
Simon sugeriu que, na melhor das hipóteses, elas podem chegar somente a limitadas formas de racionalidade. Esses limites sobre a racionalidade humana são institucionalizados na estrutura e modelos de funcionamento das nossas organizações.

Quanto maior a incerteza, mais difícil é programar e rotinizar a atividade através do planejamento prévio de uma resposta. À medida que incerteza aumenta, as organizações tipicamente encontram formas de controlar os resultados (objetivos e alvos) em lugar de controlar comportamentos (através de regras e regulamentos).

Nesta sentido, o sistema de informação contábil oferece a melhor solução como o principal sistema da organização, o que corrobora com a visão proposta neste trabalho. A perspectiva do processamento de informação, dessa forma, oferece meios de contabilizar as diferenças entre formas de organização mecanicista e aquelas mais orgânicas. Enquanto as primeiras são baseadas em informação e sistemas de tomada de decisão que são altamente programados e pré-planejados, as últimas são tipicamente baseadas em processos que são mais flexíveis e temporários. Nas organizações orgânicas, enfatiza-se mais a prudência e o julgamento, bem como maior confiança é colocada no feedback do que na programação como um meio de controle.

Morgan (1996, pg.87) cita que o enfoque de Galbraith identifica dois planejamentos estratégicos para lidar com a incerteza:

(i) procedimentos que visam reduzir a necessidade de informação - por exemplo, através da criação de recursos excedentes e tarefas autolimitadas;

(ii) Crescente capacidade de processar informação - por exemplo, investindo em sofisticados sistemas de informação e expandindo os relacionamentos laterais através do uso de papéis de coordenação, grupos tarefas e estruturas matriciais.

O enfoque da tomada de decisão na organização tem assim criado uma nova forma de pensar sobre como as organizações realmente operam e tem feito contribuições à compreensão do planejamento organizacional. Existe, porém, outra implicação da metáfora do processamento de informação que provavelmente será mais importante a longo prazo. Se a organização é, na verdade, um produto ou reflexo da capacidade de processamento da informação como Simon sugeriu, então novas capacidades levarão a novas formas organizacionais. A introdução dos computadores e microprocessamento criaram mudanças radicais em relação à natureza e estilo da organização. Redes de relações entre as pessoas dão lugar à interface entre instrumentos eletrônicos assegurados por novos tipos de operadores, programadores e outros especialistas em informática. 
Muitas organizações do futuro podem não ter localização fixa, com membros interagindo através de microcomputadores pessoais e recursos audiovisuais para criar uma rede de trocas e atividades inter-relacionadas, talvez com robôs desempenhando os trabalhos físicos.

\subsubsection{CIBERNÉTICA APRENDIZAGEM E APRENDER A APRENDER.}

A cibernética instrumentaliza seu jeito de enquadrar o mundo, afastando-se da visão linear de pares "causa e efeito", através da idéia de sistemas - que são de fato processadores de informação; e da idéia de equivalentes e modelos que, na verdade, são formas de se apresentar os sistemas, onde fenômenos vários e díspares possam ser reunidos e compreendidos simultaneamente.

A cibernética é uma ciência interdisciplinar relativamente nova que tem como foco o estudo da informação, comunicação e controle. O termo foi cunhado em 1940 pelo matemático Norbert Wiener, do MIT, como uma aplicação metafórica do grego Kubernetes, que significa "homem guia". Esta imagem foi usada por Wiener de acordo com Morgan (1996) para caracterizar processos de troca de informações através dos quais máquinas e organismos engajam-se em comportamentos de auto-regulação que mantêm estados estáveis.

Para planejar uma máquina que possa aproximar-se de previsões estatísticas e computacionais complexas, dirigir e monitorar o seu próprio comportamento, requerse uma habilidade de planejar uma máquina que seja capaz de engajar-se em comportamento tão flexível e adaptativo como aquele de um cérebro vivo. A cibernética emergiu desse desafio, qual seja, de como cientistas especializados em matemática, teoria da comunicação, engenharia, ciência social e medicina combinaram as suas habilidades e descobertas para criar máquinas com a capacidade adaptativa dos organismos, e a descoberta central foi de que "a habilidade de um sistema de engajarse num comportamento auto-regulador depende de um processo de troca de informação que envolve o feedback negativo" (Morgan; 1996, pg.89). Os organismos vivos operam dessa maneira: "quando o calor do corpo aumenta, o cérebro e o sistema nervoso central iniciam uma ação que nos leva a diminuir a velocidade, suar e respirar pesadamente, para iniciar mudanças na direção oposta". 
A cibernética conduz à teoria da comunicação e aprendizagem, ressaltando quatro princípios-chave, a saber (Morgan; 1996, pg.92):

(i) que os sistemas devem ter a capacidade de sentir, monitorar e explorar aspectos significantes do seu ambiente; (ii) que eles também devem ser capazes de relacionar essa informação com as normas operacionais que guiam o sistema comportamental;

(iii) que eles devem ser capazes de detectar desafios significativos dessas normas;

(iv) que eles devem ser capazes de iniciar a ação coletiva quando são detectadas discrepâncias.

Se essas condições forem satisfeitas, um processo contínuo de troca de informação é criado entre um sistema e o seu ambiente, permitindo ao sistema monitorar mudanças e iniciar respostas apropriadas. Dessa forma, o sistema pode operar de maneira inteligente e auto-reguladora, porém, limitado pelas normas operacionais ou padrões que o orientam. Isso tem levado a moderna cibernética a delinear a distinção entre o processo de aprendizagem e o processo de aprender a aprender.

Sistemas cibernéticos simples, assim como os termômetros domésticos, são capazes de aprender no sentido de serem capazes de detectar e corrigir desafios a partir de normas pré-determinadas. Mas são incapazes de questionar a propriedade daquilo que estão fazendo. A diferença essencial entre esses dois tipos (níveis) de aprendizagem é, algumas vezes, identificada em termos de uma distinção entre uma aprendizagem do tipo "circuito simples" (single-loop) e "circuito duplo" (doubleloop). Esta diferença, pergunta Morgan (1996, pg.92): “Podem as organizações aprender e aprender a aprender?" e esclarece:

A aprendizagem em circuito único apoia-se numa habilidade de detectar e corrigir o erro com relação a um dado conjunto de normais operacionais;

A aprendizagem em circuito duplo depende de ser capaz de "olhar-se duplamente" a situação, questionando a relevância das normas de funcionamento.

\subsubsection{A APRENDIZAGEM EM DOUBLE-LOOP}

A aprendizagem em "double-loop", conforme definido por Argyris (1992) é o processo de fazer perguntas não apenas sobre fatos objetivos, mas também sobre as razões e os motivos por trás deles. Essa aprendizagem incentiva as pessoas a examinarem seu próprio comportamento, assumirem responsabilidade por seus próprios atos ou pela ausência deles, e a revelarem informações potencialmente ameaçadoras ou embaraçosas, capazes de produzir mudança genuína. O problema não 
está em os empregados fugirem deste tipo de auto-exame organizacional, o problema é que ninguém lhes exige auto-exame.

Enquanto algumas organizações têm sido bem-sucedidas institucionalizando sistemas que revêem e desafiam normas básicas, políticas e procedimentos operacionais em relação a mudanças que ocorrem nos seus ambientes - por exemplo, encorajando o debate contínuo e a inovação - muitas falham em fazer isso. Esse fracasso é especialmente verdadeiro nas organizações burocráticas. Neste sentido o autor (Morgan 1996, pg. 96) diz que três obstruções existem inicialmente, também em organizações não burocráticas:

(i) Imposição de estruturas fragmentadas de pensamento aos seus membros, que na realidade, não encorajam os empregados a pensar por si próprios; fomentar o desenvolvimento de sistemas políticos que colocam ainda maiores barreiras na forma de aprendizagem; e as racionalidades limitadas, inerentes ao planejamento organizacional, que realmente criam barreiras;

(ii) Associação com o princípio da responsabilidade burocrática, isto é, dizer aos gerentes exatamente aquilo que alguém pensa, empurrar as coisas para baixo dos panos e estarem acima dos fatos;

(iii) Nasce do fato de que existe freqüentemente uma defasagem entre aquilo que as pessoas dizem e aquilo que fazem, no que Argyris e Schon do MIT referindo-se a isso como a defasagem entre a "teoria adotada" e a "teoria utilizada", e que pode ser assim entendida: as pessoas se engajam em comportamento de disfarce, consciente ou inconscientemente, quando vêem surgir ameaças a um modelo básico de prática que leva um indivíduo a desviar a culpa para outro lugar e prender-se àquela prática, intensificando-a em lugar de questionar a sua natureza e os seus efeitos.

A aprendizagem e a mudança são inseparáveis, enquanto aprende você muda e a mudança efetiva só ocorre através da aprendizagem, esses são dois aspectos que igual e continuamente se completam. Aprender, todavia, é alcançado quando nós adquirimos novas habilidades e conhecimentos. Os resultados e insights obtidos na pesquisa-ação devem ser não apenas de importância teórica mas, também, devem conduzir a melhorias práticas nas áreas dos problemas identificados através de mudanças que dependerão da natureza dos problemas identificados. A reflexão sobre a ação registrada durante a observação normalmente é auxiliada pela discussão entre os membros do grupo.

As reflexões podem levar à reconstrução do entendimento da situação social e fornece uma base para planejamento futuro de ações criticamente informadas, assim o ciclo continua. Estes passos são executados de um modo mais cuidadoso, sistemático e rigoroso do que normalmente acontece na prática diária. 


\subsubsection{O PROFISSIONAL REFLETIVO}

Donald Schon (1991) forneceu um processo aprendizagem e desenvolvimento profissional individual, autodirigido e baseado na experiência para o profissional com o conceito do profissional refletivo. Estes profissionais incorporaram aos seus repertórios de habilidades, a arte do aprendizado que transforma através da reflexão.

Este conceito representa a interpretação de Schon do caminho para o desenvolvimento e das características de especialidades profissionais que previamente eram definidos usando o tradicional modelo tecnocrático como um paradigma. $\mathrm{O}$ uso do modelo tecnocrático foi desenvolvido de uma convicção de que a resolução de problemas profissionais pode ser dominada singularmente através da habitual e rigorosa aplicação de uma disciplina com conhecimentos, teorias e técnicas comprovadas.

Para ilustrar os processos descritos no profissional refletivo vários conceitos foram revistos e incluem Argyris e Schon (1974) com a aprendizagem em "singleloop" e "double-loop". O diagrama seguinte é um "modelo de processo de aprendizagem do profissional Refletivo" que inclui o loop duplo para quebra de paradigma:

Argyris e Schon (1974, p.18) se referem à confiança em um quadro de referência estático como "aprendizagem de ciclo único" (1) (single-loop learning). Em uma sociedade estática na qual sistemas sociais permanecem constantes, o conhecimento é relativamente estável e dilemas da vida são bastante previsíveis. A resolução de problemas é grandemente padronizada pelas experiências prévias e pelas soluções comprovadas.

Em uma sociedade que muda rapidamente e na qual a direção da mudança não pode ser prevista, a habilidade para a análise critica e julgamentos com base em informações e ações diretas é muito importante e deve ser valorizada. 
FIGURA 10 - CICLO ESTENDIDO DA PESQUISA AÇÃO: INCLUI O LOOP DUPLO PARA QUEBRA DE PARADIGMA

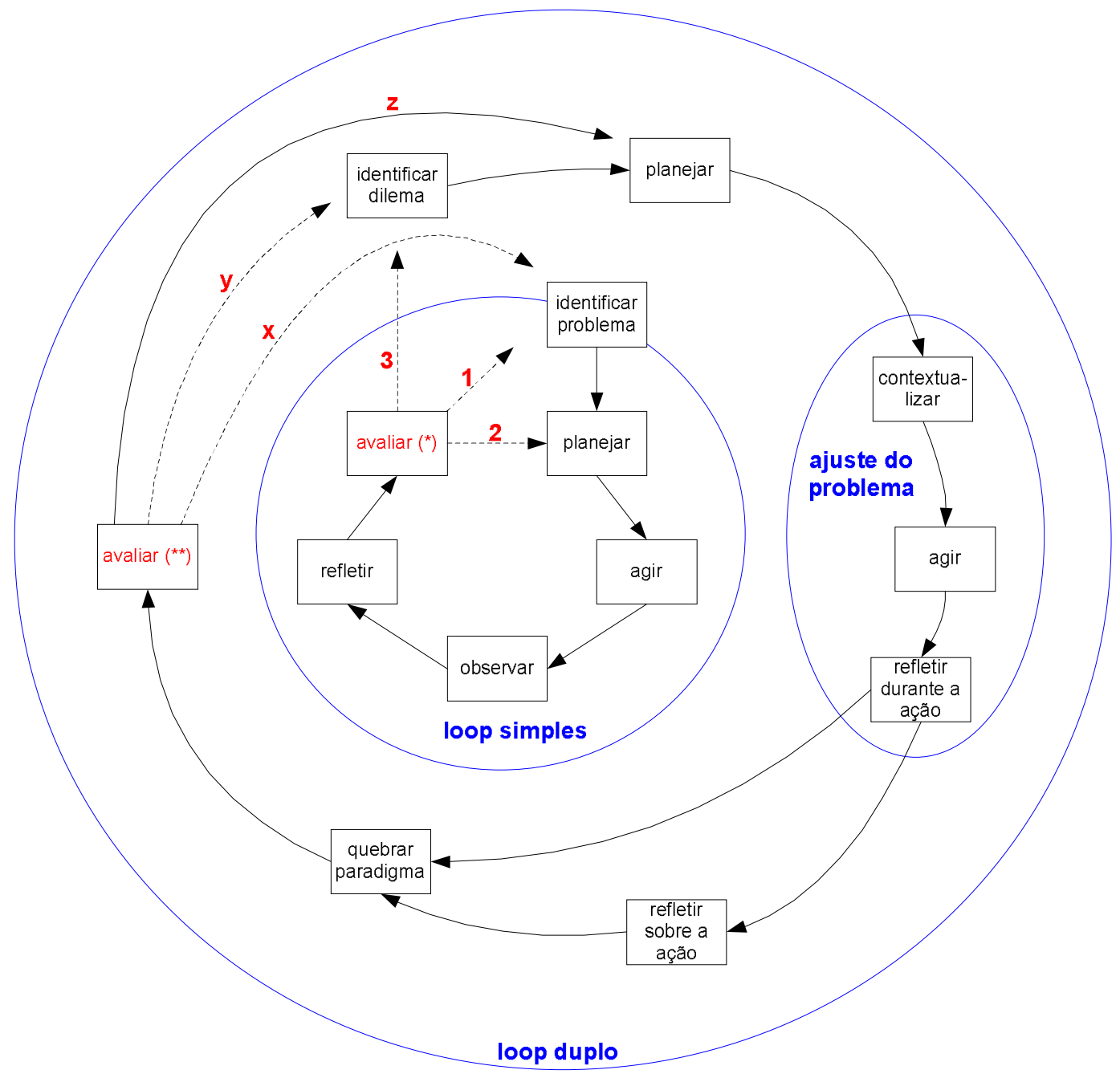

Autor . Hatten (1997) Adaptado pelo autor

Esta habilidade é o resultado da combinação de experiência, conhecimento proposto, conhecimento tácito ou "know-how", pensamento crítico e outros tipos de processo de conhecimento intuitivo que foram desenvolvidos por reflexões prévias. Uma compreensão da natureza do profissional refletivo pode ajudar a iluminar as habilidades necessárias a aprendizagem transformativa ou de "double-loop" (Argyris \& Schon, 1974).

Reflexão (2) é o processo da experiência e re-avaliação de percepções as quais então se tornam as bases do novo conhecimento transformado, e de decisões sobre ações futuras. O verdadeiro "profissional refletivo" (Schon, 1991) participa ativamente nesta moldagem da ordem social através da "práxis", mas nem todos os profissionais 
atingem o mesmo nível de atividade refletiva e compromisso com a ação. O questionamento e mudança nos quadros de referência utilizados para aprendizagem foi chamado de "aprendizagem de duplo ciclo" (4) (Double-loop learning) por Argyris e Schon (1974, p.19).

Schon (1991) diz que esta habilidade é essencial à sobrevivência em um mundo profissional no qual ambos os extremos do espaço entre teoria e a prática, estão mudando rapidamente. $\mathrm{O}$ conhecimento está evoluindo e sendo difundido rapidamente, e o contexto de prática está sendo constantemente modificado. Até mesmo as expectativas da sociedade sobre os resultados de especialistas estão sendo continuamente revisadas, e a base dessa especialidade é a habilidade para resolver problemas únicos.

O argumento básico de Schon (1991) é que os problemas não se apresentam como pacotes ordenados de elementos relacionados para os quais a aplicação de uma série de perguntas (sim/não) lógicas é suficiente para produzir uma solução. Os problemas (5) são "situações problemáticas que confundem, aborrecem e trazem incerteza" e que podem ser descritos como dilemas (Schon, 1991, p.40).

Eles podem transformar-se constantemente de forma que os meios e os fins estão sempre escondidos. O processo mais importante a aplicar é "o cenário do Problema (6) no qual, interativamente, nós nomeamos as coisas para as quais nós atentamos e moldaremos o contexto no qual nós prestaremos atenção a eles" (Schon, 1991, p.40).

Este saber sobre o que nomear e moldar está freqüentemente implícito em nossas ações e freqüentemente forma uma grande parte das especialidades profissionais. Estas especialidades são compostas de informações fragmentadas que, se explícitas, podem subjugar a capacidade da mente consciente (Schon, 1991, p.49). Schon recorre a conhecimento tácito como instruído-em-ação que permanecerá implícito a menos que seja feito um esforço para torná-lo explícito.

Esta reflexão-em-ação normalmente é ativada por algum "dilema de desorientação" dentro de ações profissionais que são habitualmente com guiadas pelo conhecimento tácito. A desorientação (7) ocorre quando estas ações não produzem os resultados esperados habitualmente - isto é, definido por experiência prévia, e são 
necessárias reflexões e o enquadramento do problema para provocar uma mudança de paradigma (8) que determina então a próxima ação (9).

FIGURA 11 - CICLO ESTENDIDO DA PESQUISA-AÇÃO, CONFORME A FIGURA ANTERIOR: DETALHAMENTO LÓGICO DA ETAPA DE AVALIAÇÃO OCORRE EM CICLOS - * LOOP SIMPLES (SINGLE LOOP) ** LOOP DUPLO (DOUBLE LOOP)
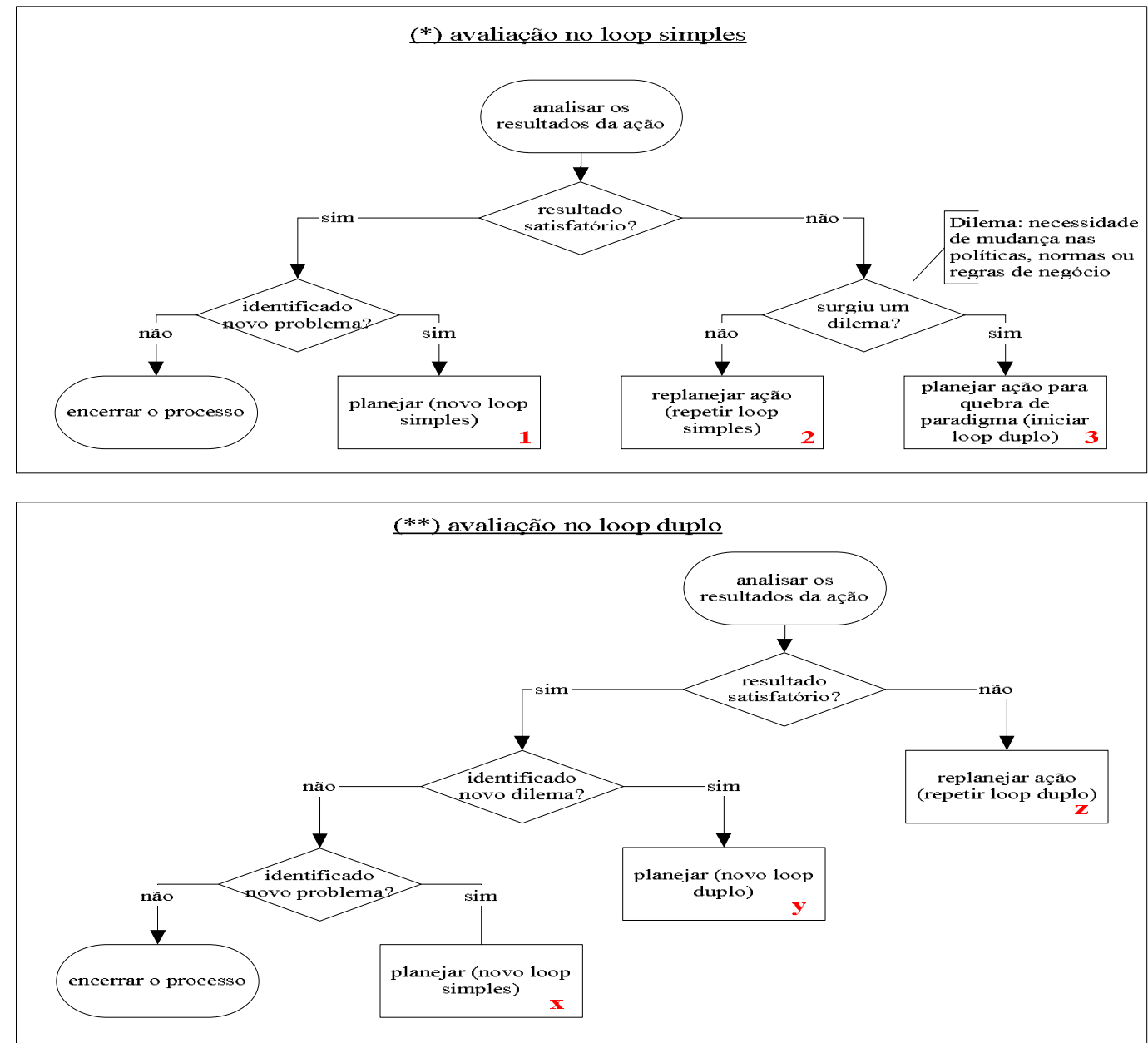

Fonte: Elaborado pelo Autor

A esquema acima explica o ciclo estendido da pesquisa-ação, conforme a figura anterior detalhando na forma de um processo lógico as etapas de avaliação em que ocorre em ciclos - loop simples (single loop) loop duplo (double loop), para facilitar a aplicação dos conceitos discutidos neste tópico. (VG)

A aprendizagem em loop duplo requer que se ligue esse hiato entre a teoria e a realidade, o que é particularmente realizado através da pesquisa-ação e está no fundamento deste trabalho de pesquisa. Uma nova filosofia de administração é necessária para dar raízes ao processo de organizar sob forma de investigação aberta, e Morgan (1996, pg.95) enfatiza: "o processo todo de aprender a aprender é 
contingente à habilidade de desafiar hipóteses operacionais de maneira mais fundamental", e propõe quatro diretrizes com esse enfoque organizacional orientado para a aprendizagem que podem ser desenvolvidos:

(i) encorajar e valorizar uma abertura e flexibilidade para aceitar erros e incertezas como um aspecto inevitável da vida em ambientes complexos e mutáveis (erros legítimos e não enganos que podem ser evitados);

(ii) encorajar um enfoque de análise e solução de problemas complexos que reconheça a importância de exploração de diferentes pontos de vista;

(iii) evitar imposição de estruturas de ação em ambientes organizados - isto é, ação dirigida para a investigação, sendo que é importante vislumbrar meios em que a inteligência e a direção podem emergir do processo organizacional corrente, usando a abordagem participativa; e

(iv) a necessidade de fazer intervenções que criem estruturas e processos organizacionais que ajudem a implementar os princípios anteriormente apresentados.

Este é o foco central desta pesquisa, qual seja, criar uma nova arquitetura organizacional orientada a processos na empresa contábil, suportada por uma nova arquitetura tecnológica através da implantação de um sistema empresarial integradoSistema Empresarial Integrado - ERP.

Sistemas cibernéticos mais complexos, tais como o cérebro humano ou computadores avançados têm essa capacidade. São freqüentemente capazes de detectar e corrigir erros nas normas de operação e então influenciar os padrões que guiam as suas operações em detalhes.

\subsubsection{NOVAS TECNOLOGIAS -EXIGEM NOVAS MANEIRAS DE ORGANIZAR O TRABALHO}

As principais forças das idéias exploradas pela metáfora do cérebro são suas contribuições à compreensão da aprendizagem organizacional e às suas capacidades de auto-organização. Por isso, Morgan (1996, pg.110) sugere às organizações inovadoras:

(i) serem planejadas como sistemas de aprendizado que colocam ênfase especial em estar abertas à investigação e a autocrítica e podendo, portanto, auto-organizar-se;

(ii) a administração estratégica pode ser planejada para facilitar o aprender a aprender usando princípios da cibernética para criar graus de liberdade dentro dos quais a organização pode evoluir, formulando a missão organizacional em termos de aspectos "nocivos" a serem evitados mais do que em termos de alvos a serem alcançados;

(iii) reinterpretação sobre a natureza da organização burocrática a partir da perspectiva de processamento da informação, através da holografia;

(iv) pensar como desenvolvimento na computação e outras tecnologias em microprocessamento podem ser usados para facilitar novos estilos de organização.

Concluindo, o autor enfatiza o uso da tecnologia e as mudanças nas organizações, corroborando com o processo de mudança suportado na pesquisa-ação na empresa contábil e objeto deste trabalho: 
(...) à medida que se usa a nova tecnologia para implementar velhas maneiras de fazer o trabalho, provavelmente se estará diminuindo o seu potencial. Como Marshall McLuhan observou, (o meio é a mensagem). A burocracia pertence à idade da palavra escrita e da revolução industrial. $\mathrm{O}$ microprocessamento pertence à idade da comunicação eletrônica, e pode-se esperar que essa nova tecnologia seja acompanhada por maneiras de organizar talhadas à sua própria imagem. Os princípios da cibernética, aprendizagem organizacional e auto-organização holográfica oferecem orientações de valor no que diz respeito à direção que essa mudança deva tomar.

Convém salientar, entretanto, que essas mudanças devem ser acompanhadas por importantes mudanças de atitudes e valores, pois, a aprendizagem e autoorganização geralmente pedem reenquadramento de atitudes, enfatizando a importância da atividade sobre a passividade, a autonomia sobre a dependência, da flexibilidade sobre a rigidez, da colaboração sobre a competição, da abertura sobre o fechamento, da prática democrática sobre a crença autoritária.

\subsection{UMA EMPRESA CONTÁBIL SERIA...}

Pelas diversas abordagens apresentadas com relação à forma como pode ser vista uma empresa e suas variações, e com relação ao processo permanente de aprendizagem e mudança de paradigmas conclui-se que a empresa contábil seria: (i) no conceito atual de empresa um organismo sócio-cultural, é um conjunto integrado de pessoas, funções e sistemas, um arranjo de generalistas, descentralizado e flexível que se baseia na informação; (ii) quanto às suas finalidades, busca atender o processo de terceirização dos serviços contábeis das empresas-cliente; (iii) um sistema aberto que tem por objetivo gerir o subsistema de informações das empresas-cliente, fazendo parte do sistema maior que são estas empresas; (iv) um grupo semi-autônomo na abordagem sócio-técnica cujo objetivo é visto como um processo no trabalho do escritório das empresas-cliente, com função de fornecer suporte administrativo às demais funções da organização, respondendo aos problemas associados com a revolução tecnológica Decorrente dos avanços na informática; (v) como empresa válida busca contribuir para que as modernas técnicas de gestão possam chegar à empresa-cliente, cumprindo assim a sua missão principal de gerir os sistemas de informações contábeis de forma integrada, desenvolvendo a visão sistêmica nos gestores através da informação contábil distribuída para os diversos níveis de decisão.

As conclusões anteriores foram resumidas nas definições de: (i) Missão - que tem a ver com "a razão da existência" da empresa-contábil, ou seja, quais as necessidades de seus clientes ela pretende atender, hoje e no futuro; (ii) Visão - que 
define para onde a empresa está indo, isto é, quando se fala em Visão, estamos tentando situar a Missão da empresa-contábil no tempo, enxergando a possibilidade de materializar a Missão sob a forma de produtos ou serviços inovadores; (iii) Valores quando Missão e Visão estão bem definidas, as empresas conseguem estabelecer um conjunto de Valores que devem balizar os comportamentos aceitáveis e socialmente recomendáveis.

De forma resumida, o grupo elaborou a missão, a visão e os valores da empresa contábil em consonância com o objetivo de transformá-la numa organização que aprende:

MISSÃO: Fornecer informação contábil de forma distribuída, com qualidade, contribuindo para a excelência no desempenho dos sistemas de gestão. (VG)

VISÃO: Ser líder em tecnologia e resultados na implantação e gestão de sistemas de informação integrado no mercado de atuação das empresas-contábeis.(VG)

VALORES: Satisfação do Cliente; Compromisso com o Resultado; Conhecimento contábil aplicado; Transparência e Ética; Valorização Profissional e Humana; Inovação; Gestão Participativa; Espírito de Equipe.(VG)

\subsection{PROBLEMAS E QUESTÕES DE PESQUISA - REFINAMENTO EM 4 ITERAÇÕES}

A questão da pesquisa foi evoluindo e mudando ao longo da própria pesquisa. Um dos motivos dessa evolução foi a descoberta, entendimento e escolha pelo autor da pesquisa-ação como paradigma de pesquisa.

A Pesquisa-Ação (PA) é um tipo de pesquisa social com base empírica que é concebida e realizada em estreita associação com uma ação ou com a resolução de um problema coletivo, onde estão envolvidos de modo cooperativo e participativo os pesquisadores e os participantes da situação (Thiolent, 1997). Há métodos de pesquisa-ação cuja ênfase principal está na ação na realidade, com a pesquisa como um benefício secundário. No extremo, este paradigma aumenta o entendimento direto por parte dos envolvidos das situações problema vivenciadas, resultando em mudança, levando as partes ao processo de aprendizagem. 
Neste sentido, a PA permitiu aumentar o conhecimento por parte dos envolvidos durante a prática, refletindo no melhoramento do processo de mudança, e assim permitindo que a questão de pesquisa fosse sendo refinada.

Este tema está sendoserá aprofundado no capítulo IV adiante onde está sendo descrito o método de pesquisa e a abordagem utilizada. Como insinua o próprio nome Pesquisa-Ação espera-se que ela produza ambos: conhecimento ("pesquisa") e mudança ("ação"). Estas duas dimensões - conhecimento e mudança podem ser consideradas úteis para cada aspecto desta proposta de pesquisa.(Dick, 2002).

As questões de pesquisa foram divididas em fases, na medida em que foram sendo identificados e compreendidos os problemas a elas relacionados, para se responder ao problema central do trabalho e direcionar as conclusões relatadas no capítulo V.

\subsubsection{PROBLEMA E QUESTÕES DE PESQUISA: $1^{\text {a }}$ ITERAÇÃO}

Os sistemas de informações contábeis têm dois componentes de informação básica: a contabilidade financeira e a contabilidade gerencial. Em linhas gerais, estes componentes definem o potencial de atividades profissionais do contabilista, e conseqüentemente, das empresas contábeis.

As empresas contábeis têm seus negócios principais relacionados com a contabilidade financeira, posicionando-se mais como uma intermediária entre o poder público e as empresas, devido principalmente às regulamentações físcal e social, sofrendo constante pressão do governo em termos de obrigações tributárias e suas complexas obrigações acessórias. Além disso, seus esforços estão mais voltados a moldar a empresa-cliente segundo as orientações do poder público, do que atender às necessidades gerenciais desta.

A matéria prima da contabilidade compõe-se dos documentos fonte contendo os dados dos eventos dos processos de negócio da empresa-cliente, mais conhecidos como transações. Estes documentos, melhor entendidos como documentos fiscais, são registrados no processo denominado de escrituração, tornando-se dados estruturados que serão tratados pelo Sistema de informação contábil, capturando somente parte da realidade empresarial, notadamente os aspectos fiscal e legal. 
Entre outros fatores, a informática tem tornado os ciclos transacionais das organizações muito mais complexos - em termos de variáveis, e de curta duração - em função da rapidez com que são gerados, obrigando-as a ter volume para desenvolver ganhos em escala, sofrendo forte pressão competitiva, que por falta de informação gerencial adequada aumenta os riscos dos seus negócios. Sem dados organizados e estruturados sobre a realidade, na forma contábil, não há como produzir informação gerencial com as suas características qualitativas, só obtidas através dos modelos desenvolvidos pela contabilidade gerencial.

Da distância entre a realidade da empresa-cliente e as empresas contábeis, surgiram as duas primeiras questões de pesquisa, evidenciadas a partir do seguinte problema:

Problema: A inexistência de dados dos eventos de negócios, ou sua existência de forma não estruturada contabilmente - na empresa-cliente, impede a diversificação estratégica das empresas contábeis e limita, por um lado, o potencial do contador, e por outro o crescimento e a vida destas empresas.

Quais ações proporcionariam a diversificação estratégica das empresas contábeis, para inserir a consultoria de gestão às Pequenas e Médias Empresas em seu portfólio de atividades, posto que esses serviços estão dentro do escopo da contabilidade gerencial, em forte sinergia com o potencial do contador?

Como proporcionar ganhos de produtividade nas empresas contábeis, e ao mesmo tempo, ganhos de qualidade decisória com informação contábil distribuída nas empresas-cliente? 
FIGURA 12 - PROBLEMA INICIAL DE PESQUISA: SISTEMA DE INFORMAÇÃO CONTÁBIL NÃO INTEGRADO DE FORMA NATURAL, CAUSANDO RETRABALHO E BAIXO APROVEITAMENTO DO POTENCIAL DO CONTADOR

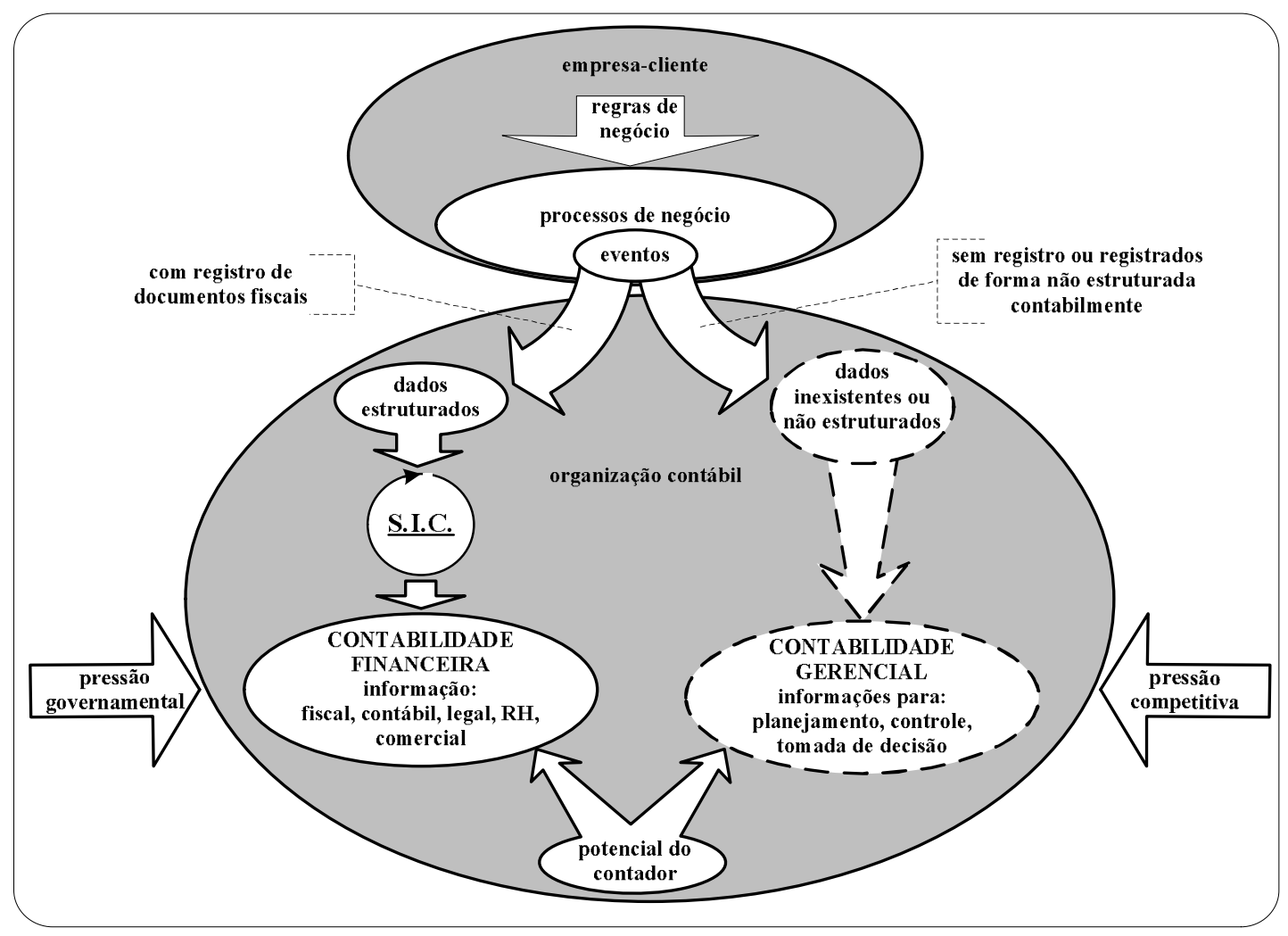

Fonte: Elaborado pelo Autor

\subsubsection{PROBLEMA E QUESTÕES DE PESQUISA: 2ª ITERAÇÃO}

Os sistemas de informações contábeis utilizados pelas empresas contábeis são constituídos dentro da característica de sistema particular da área contábil, e não como parte de um sistema da empresa-cliente. Na conclusão sobre os pontos desfavoráveis dessa visão e sobre a postura do contador com relação aos sistemas de informações contábeis, Riccio (1989, pg.132-133) relaciona vários problemas decorrentes, dos quais destacamos:

(i) o plano de contas é fechado aos demais usuários; (ii) as outras pessoas da empresa não entendem o que é e como é obtida a informação contábil, bem como sua validade; (iii) o sistema não fornece informações detalhadas sobre as transações; (iv) o sistema não processa transações em seu detalhe menor, mas sim por resumo; (v) alguns dados não são capturados pelo sistema e são tratados de maneira não contábil; (vi) sistemas paralelos são construídos gerando informações impossíveis de serem agregadas; (vii) sistemas paralelos incompatíveis entre si aumentam o custo da informação ou induzem desorganização; (viii) os sistemas não refletem, em tempo real, as transações ocorridas na empresa; (ix) as áreas contábeis não conseguem ligar os ciclos contábeis aos processos empresariais; (x) aumentam os erros e as fraudes, pois a segurança e o 
controle desaparecem; e por último, (xi) resultam informações redundantes, desintegradas e retrabalho.

Da visão escriturária do sistema de informações contábeis, não integrados de forma natural e inconsistente, surgiram a terceira e a quarta questões de pesquisa, evidenciadas a partir do seguinte problema:

Problema: O uso do Sistema de informação contábil não integrada de forma natural pelas empresas contábeis gera um continuo re-trabalho, contribuindo para a visão da contabilidade nessas empresas como um processo de escrituração, limitando o potencial do contador.

Quais são as características necessárias a um sistema de informação contábil integrado que apóie de maneira eficaz as operações de uma empresa contábil?

Estas características estão presentes em um sistema empresarial IntegradoSistema Empresarial Integrado - ERP? Elas possibilitam ao mesmo tempo informatizar a empresa-cliente?

FIGURA 13 - IDENTIFICAÇÃO DE OPORTUNIDADES SURGIDAS DA ATUALIZAÇÃO TECNOLOGICA ATRAVÉS DA ADOÇÃO DE UM SISTEMA EMPRESARIAL INTEGRADOSISTEMA EMPRESARIAL INTEGRADO - ERP

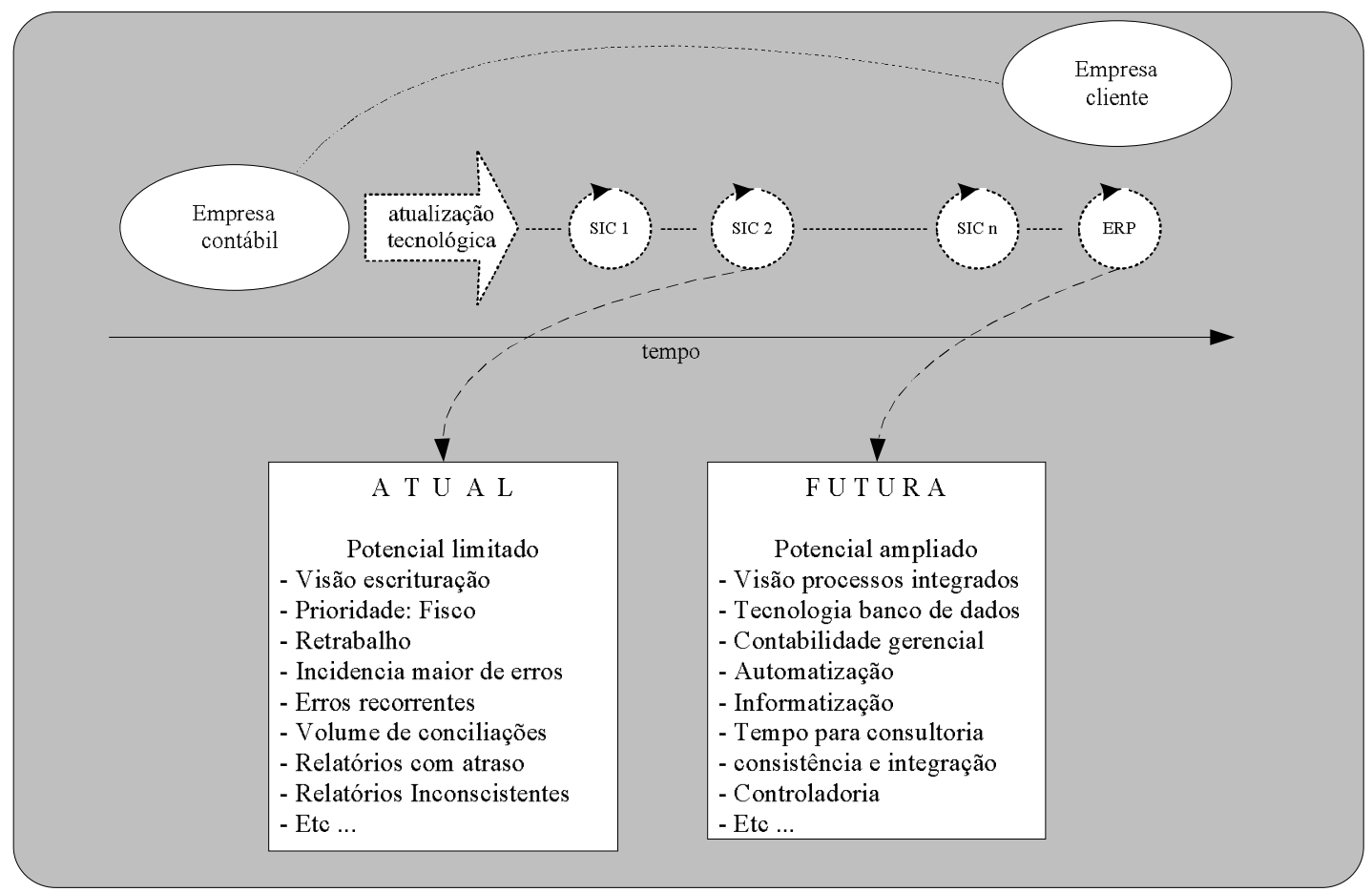

Fonte: Elaborado pelo Autor 


\subsubsection{PROBLEMA E QUESTÕES DE PESQUISA: $3^{\text {a }}$ ITERAÇÃO}

A influência do uso da tecnologia de informação, representada principalmente pela implantação dos sistemas de gestão empresarial integrados baseados na filosofia ERP, tem provocado profundas transformações na área de atuação do contador e na contabilidade (Riccio, 2001; Peleias e Parisi, 2001; Caglio, 2001); com reflexos no seu papel e importância para as organizações. Esses mesmos fatores estarão provocando mudanças na atuação das empresas contábeis.

Para a área contábil, especificamente em controladoria Peleias \& Parisi (2001, pg.11) destacam as vantagens, enfatizando a participação decisiva na implementação: “(i) no diagnóstico da situação atual; (ii) no desenho detalhado da situação atual; (iii) no desenho da situação futura desejada; e (iv) na prototipação ou modelagem". Eles destacam ainda a mudança organizacional necessária e a atuação do contador após a implementação. Os benefícios que justificam a implementação e utilização destes sistemas nas empresas contábeis e nas empresas-cliente serão evidenciados ao longo da pesquisa, no próximo capítulo no item onde se discute a tecnologia para a situação desejada.

A par dos benefícios inerentes decorrentes da implementação de um sistema empresarial integradoSistema Empresarial Integrado - ERP, tanto para a empresa contábil quanto para as empresas-cliente, quais as abordagens de implementação e que condições serão necessárias para iniciá-las?

Um projeto de sistema empresarial integradoSistema Empresarial Integrado ERP é certamente uma viagem de descobrimentos, sendo que torna-se de vital importância que as empresas tenham definido perfeitamente o que são e em que ponto estão antes de se lançarem a um projeto deste âmbito, mapeando os processos existentes para que as oportunidades de melhoria possam ser detectadas.

Para iniciar a viagem de descobrimentos, que representa um sistema empresarial integradoSistema Empresarial Integrado - ERP, faz-se necessário entender que as organizações têm características comuns (procedimentos, políticas, cultura) e ao mesmo tempo são muito diferentes, pois seus processos empresariais têm características únicas, surgindo daí a quinta questão de pesquisa, evidenciada a partir do seguinte problema: 
Problema: Implementação do sistema empresarial integradoSistema Empresarial Integrado - ERP, de maneira a maximizar o aproveitamento do seu potencial.

Por que os dirigentes da empresa contábil "Conjel" decidiram-se pelo sistema "XXX" para suportar suas operações?

Como implementar um sistema empresarial integradoSistema Empresarial Integrado - ERP numa empresa contábil?

Qual o impacto da implementação do sistema empresarial integradoSistema Empresarial Integrado - ERP nas dimensões Estrutura, Processos e Pessoas da empresa contábil?

\subsubsection{PROBLEMA E QUESTÕES DE PESQUISA: 4 ${ }^{\text {a ITERAÇÃO }}$}

As potencialidades oferecidas atualmente pelas tecnologias da informação implicam em que não seja mais possível encarar os sistemas de informação apenas na perspectiva ultrapassada de meros sistemas de suporte aos processos do negócio.

Neste sentido, o sistema empresarial integradoSistema Empresarial Integrado ERP pode ser implantado por razões técnicas, ou visando ao aperfeiçoamento da estratégia e da competitividade (Davenport, 2000). Uma implementação estratégica tem por objetivo maximizar o potencial positivo das mudanças e o valor dos negócios.

$\mathrm{Na}$ verdade, quando você pensa em mudar uma ampla gama de processos, melhorar a maneira pela qual se relaciona com os clientes e fornecedores, criar uma nova cultural organizacional e modificar o procedimento da maioria dos funcionários, isto representa algo que vai tomar realmente muito tempo.

Davenport (2002, pg.13) é enfático quando diz: "Sou um pesquisador e consultor que trabalha sempre no cruzamento dos sistemas de informação com o comportamento e a mudança organizacionais, (...)" "os sistemas de informações são inúteis a menos que proporcionem melhores informações ou melhores métodos de se fazer negócios ". O que é realmente importante - e difícil - com relação a esses sistemas é a drástica mudança que eles representam para um negócio. Uma implementação bem sucedida envolve: mudança tecnológica, mudança nos negócios, na cultura e na estrutura organizacional, no comportamento dos trabalhadores e até mesmo nas estratégias de negócios. 
As dimensões tecnologia, estrutura e comportamento (indivíduos e funções), são vistas de forma integrada, isto é, uma mudança em uma dessas dimensões afeta as demais.

A implementação de novos sistemas de informação é freqüentemente mais difícil do que o previsto, devido às mudanças das necessidades organizacionais (Laudon \& Laudon, 2001). Como os sistemas de informação potencialmente mudam importantes dimensões organizacionais, incluindo a estrutura, a cultura, os relacionamentos de poder e as atividades de trabalho (processos), há freqüentemente resistência considerável aos novos sistemas.

Confirmando a mútua influencia entre tecnologia, estrutura, processos e pessoas, Walton (1998) esclarece que a implementação de tecnologia de informação avançada deve incluir a administração de mudança organizacional, existindo uma conexão imutável entre elas - a implementação da tecnologia de informação e a mudança organizacional.

Pelas considerações levantadas até este ponto, as questões de pesquisa são assim definidas, evidenciadas a partir do seguinte problema central de pesquisa:

Problema: Administração da mudança organizacional requerida em virtude do alinhamento das estratégias de tecnologia, de negócios e de organização numa empresa contábil.

Qual o tipo de mudança organizacional e em que ordem de magnitude ela deve acontecer?

Qual o modelo de gestão da mudança e qual abordagem utilizar para a sua efetivação?

Essas mudanças podem contribuir para melhorar o entendimento do papel, da utilidade e da atuação da contabilidade como instrumento de gestão?

Os sistemas empresariais integrados - ERP podem oferecer novas oportunidades para que o conhecimento contábil seja distribuído nas organizações?

Neste capítulo buscou-se definir a empresa contábil com base em várias abordagens (visões) teóricas permitindo o refinamento dos problemas e questões de pesquisa. 
O próximo capítulo objetiva, ainda dentro da revisão bibliográfica, definir quais dimensões organizacionais sofrem mudanças em função da tecnológia representada pela implementação de um sistema empresarial integradoSistema Empresarial Integrado - ERP, e como essas dimensões permitem comparar a situação atual (o que é) com a situação desejada (o que deveria ser) a empresa contábil, conforme a figura 7 do item 1.7.6 - desenho da pesquisa: liga o problema inicial ao referencial teórico, mostrando a abordagem utilizada para identificar as unidades de análise. 


\section{CAPÍTULO III - A DIMENSÕES DA MUDANÇA ORGANIZACIONAL}

Este capítulo tem o objetivo de refletir sobre o papel da tecnologia de informação na indução de mudanças organizacionais em larga escala, necessária para implementar um sistema empresarial integradoSistema Empresarial Integrado - ERP numa empresa contábil, procurando encontrar na revisão da literatura indicações sobre os caminhos desta mudança, e que vão emergindo ao longo do texto. O processo de mudança que fundamenta a abordagem utilizada em conformidade com a figura 7 do item 1.7.6 - desenho da pesquisa: liga o problema inicial ao referencial teórico, mostrando a abordagem utilizada para identificar as unidades de análise.

O assunto divide-se em 03 partes: (i) Começa traçando uma relação da mútua dependência entre as estratégias de TI e a organização, isto é, uma mudança na tecnologia traz alterações nos demais níveis (dimensões) da organização: estratégia, estrutura, processos e pessoas; (ii) Analisando-se as 05 dimensões procura-se descrever a situação atual da empresa contábil ( $o$ que é), através da forma como ela está organizada; (iii) Então a partir daí discute-se, também através das 05 dimensões, a situação futura (desejada) da empresa contábil estudada (o que deveria ser), proporcionando o entendimento, através da comparação entre os elementos, o processo de mudança necessário.

\section{O PROCESSO DE MUDANÇA NAS ORGANIZAÇÕES}

As organizações de hoje enfrentam um ambiente cada vez mais dinâmico e mutante. A tecnologia está mudando o trabalho das pessoas e seu comportamento no ambiente de trabalho, e em muitos casos, essas novas tecnologias estão tornando muitas funções obsoletas e reduzindo a sobrevida de muitas habilidades - técnicas, administrativas e gerenciais (Robbins, 2002). Essas evidências podem ser percebidas na profissão contábil e terão reflexos nas empresas contábeis, principalmente em função dos sistemas de informação contábil integrado. 


\subsection{A TECNOLOGIA E AS MUDANÇAS ORGANIZACIONAIS}

As mudanças organizacionais e tecnológicas que as empresas estão enfrentando podem ser consideradas como uma mudança de paradigma, isto é, uma mudança de modelo que faz pensar em algo profundo - um divisor de águas.

O processo de mudança organizacional que vem ocorrendo nas demais empresas também deverá chegar nas empresas contábeis, em função da aplicação do sistema empresarial integradoSistema Empresarial Integrado - ERP. Apesar do tema mudança ser amplamente explorado em diversos livros e revistas especializadas, não há um corpo coerente de idéias para gerir estas mudanças, existe um universo teórico e prático multifacetado com enfoques e abordagens totalmente diferentes e muitas vezes incoerentes entre si.

Para superar essas dificuldades inerentes à pesquisa, conforme descrito e comentado no seu desenho no primeiro capítulo, decidiu-se por desenvolver uma abordagem que possibilitasse, mediante a revisão da literatura teórica a comparação entre o estado presente (atual) e o estado futuro (desejado) da empresa contábil.

Esta abordagem permitiu identificar o comportamento dos objetos no estado de transição (mudança), como reflexo da revolução que as tecnologias da informação e comunicação estão provocando na competição empresarial dessas empresas, influenciadas ainda pelas profundas transformações na missão e no trabalho do contador.

\subsubsection{O RELACIONAMENTO ENTRE A TIECNOLOGIA DE INFORMAÇÃO E A ORGANIZAÇÃO}

A introdução dos sistemas de informação cria no ambiente organizacional resistência considerável, em função do potencial de mudanças que eles trazem à estrutura, à cultura, às políticas e ao trabalho desta organização (Laudon \& Laudon, 2001, pg.64). Há vários modos para se visualizar a resistência organizacional. Leavitt (1965) usou uma forma de diamante para ilustrar a característica de interrelacionamento e ajuste mútuo da tecnologia e da organização, concluindo que as mudanças na tecnologia são absorvidas, desviadas ou derrotadas pela disposição das tarefas, estruturas e pessoas das organizações. 
No seu modelo, citado por diversos pesquisadores (Laudon \& Laudon, 2001; Robbins, 2002; Galliers, 1999), com adaptação, o único modo para trazer mudanças é mudar a tecnologia, as tarefas, a estrutura e as pessoas simultaneamente, conforme demonstrado e comentando na figura 3 no primeiro capítulo.

As mudanças que devem ocorrer nas dimensões organizacionais (arquitetura) das empresas contábeis, de acordo com o triângulo estratégico proposto por Walton (1998), inferem que a mudança no domínio tecnologia provocará mudanças nos demais domínios, e como resultado possível da mudança teremos a organização orientada para o comprometimento, na definição do autor citado.

Walton (1998, pg.61) sobre a mútua influência entre as estratégias de negócios, estratégia de TI e estratégia de organização comenta que:

(...) desde o estudo inicial de Alfred Chandler sobre estratégia e estrutura ganhamos progressivamente mais conhecimento sobre como a estrutura organizacional, os sistemas e as habilidades podem se compor para suportar uma estratégia de negócios escolhida e, de modo contrário, como a estrutura existente e outros aspectos estabelecidos de uma organização podem restringir ou moldar a estratégia de negócios.

$\mathrm{O}$ autor enfatiza que há uma mutua dependência entre as dimensões organizacionais que influenciam e são reciprocamente influenciadas pela tecnologia.

Além disso, atualmente a informação exerce um papel cada vez mais importante nas organizações, constituindo-se como elemento integrador das diversas atividades e processos organizacionais, tanto no que se refere aos seus níveis operacional, gerencial e estratégico, como na sua relação com o seu ambiente.

Neste sentido, parte-se do princípio que existe uma interdependência entre informação e organização, sendo as empresas contábeis o elo de ligação dessa interdependência para a empresa-cliente, participando ativamente da definição da arquitetura tecnológica de informação, pois o sistema de informação contábil tem os mesmos limites do sistema empresa.

\subsubsection{O REFERENCIAL TEÓRICO SOBRE MUDANÇA}

Para compreender as mudanças necessárias que deverão ocorrer nas empresas contábeis em função da implementação de um sistema empresarial integradoSistema Empresarial Integrado - ERP, neste estudo utilizar-se-á uma adaptação do referencial teórico sobre mudança organizacional com base no modelo (framework) desenvolvido no MIT, fundamentado nos estudos realizados por: (i) Alfred Chandler (1962), apud 
Walton (1998, pg.61), nos comentários sobre o triângulo estratégico - demonstrando a conexão entre estratégias de negócios, de TI e de organização; e (ii) Lavitt (1965), apud (Laudon \& Laudon; 2001), no qual conclui-se que o melhor modo de entender as mudanças na tecnologia e na organização consiste em analisá-las nas dimensões empresariais a seguir, compreendendo os seus múltiplos reflexos ocorrendo simultaneamente e concomitantemente em cada dimensão.

FIGURA 14 - A MUDANÇA ORGANIZACIONAL E SEUS MÚTIPLOS REFLEXOS NAS SUAS 5 DIMENSÕES

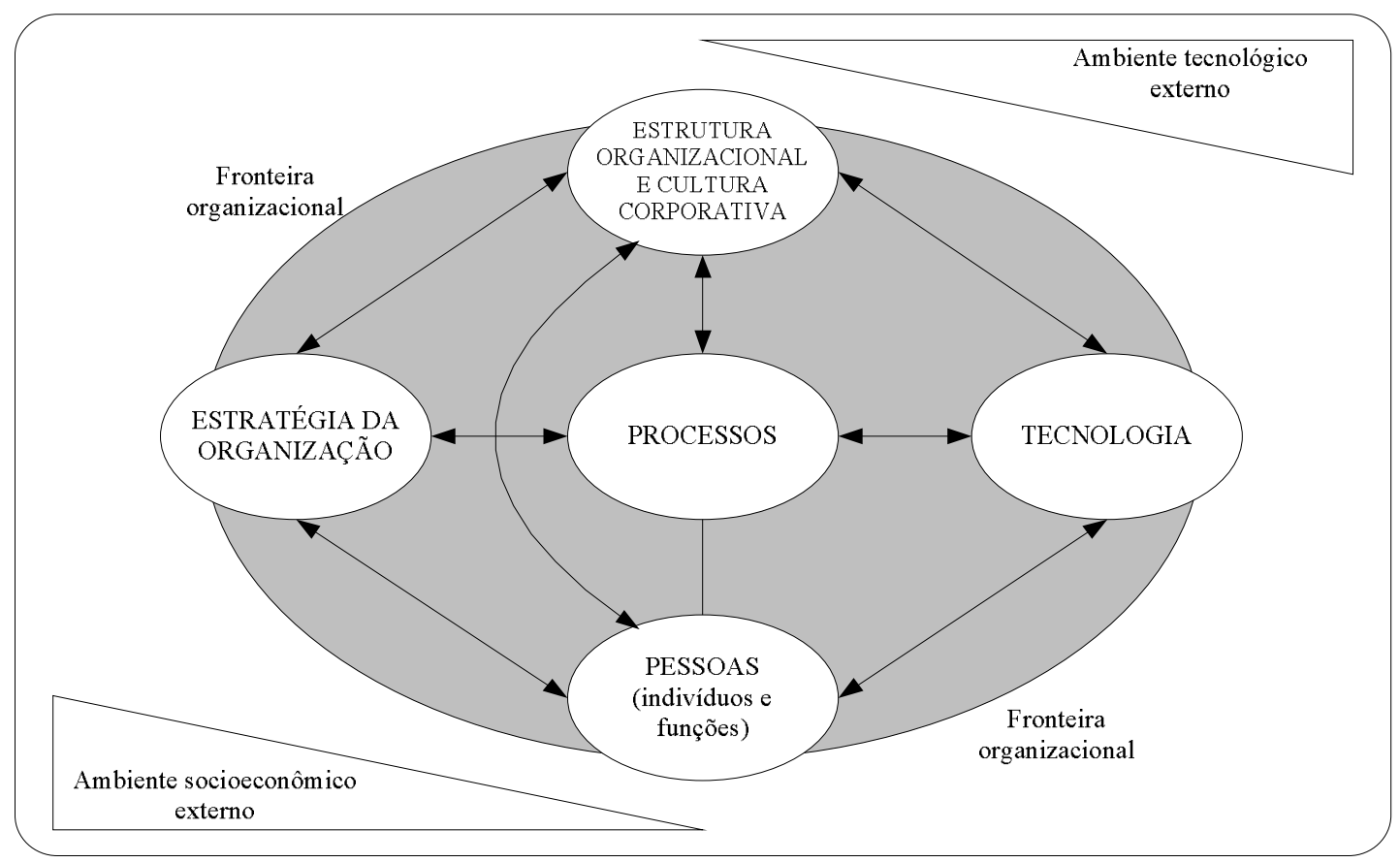

Modelo desenvolvido pelo MIT $^{1}$, fundamentado nos estudos realizados por: Alfred Chandler [1962] apud Walton [1998, pg.61]

\footnotetext{
${ }^{1}$ Instituto de Tecnologia de Massachusetts-EUA por Rockart e Scott e Morton [1984], no desenvolvimento de um programa de pesquisa intitulado “The Management in the 1990's”.
} 


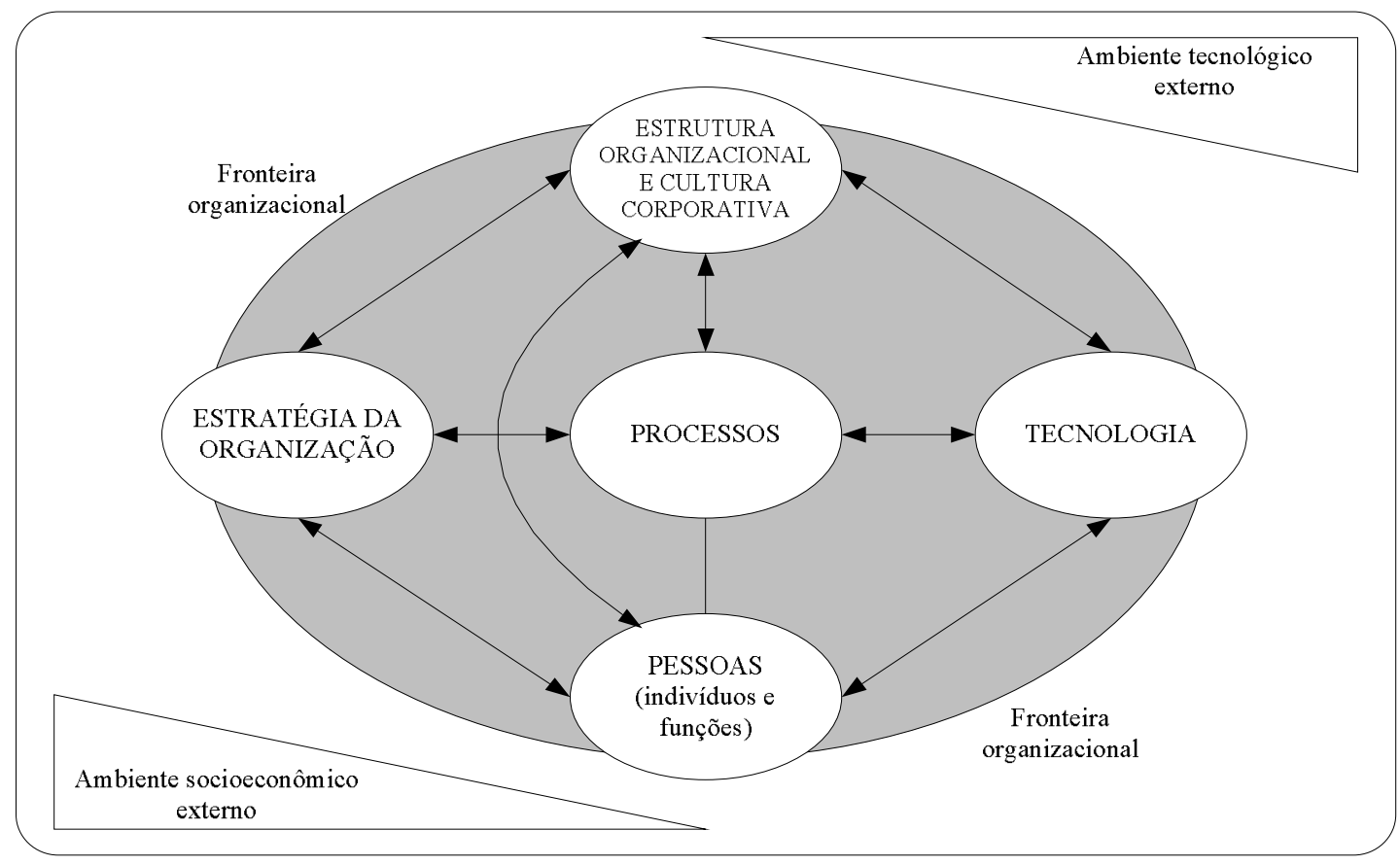

Modelo desenvolvido no mit*, fundamentado nos estudos realizados por: Alfred Chandler (1962) apud Walton (1998, pg.61)

As mudanças que deverão ocorrer na empresa contábil são apresentadas na figura acima, onde se destacam cinco dimensões da organização (estratégia, estrutura, processos, tecnologia e pessoas - indivíduos e seus papéis), um ambiente interno e um externo, além de se identificarem os limites da organização em um sistema aberto (Silva, 1997 apud Lima, 2001).

A relação entre estratégia e estrutura foi, e continua sendo, objeto de muitos estudos organizacionais, conforme comentários de Walton (1998) sobre Alfred Chandler, como um dos precursores nesta linha. Este autor enfatiza o aspecto determinante da estratégia sobre a estrutura e dá origem a uma abordagem chamada contingencial. Em outras palavras, uma mudança na tecnologia traz conseqüências para a estrutura e para a estratégia da organização. Em que nível ocorrem, é o que este trabalho pretende mostrar.

* Instituto de Tecnologia de Massachusetts-EUA por Rockart e Scott e Morton (1984), no desenvolvimento de um programa de pesquisa intitulado "The Management in the 1990's". 
A competitividade da empresa contábil está diretamente relacionada com a sua capacidade de atrelar a sua arquitetura organizacional com a sua arquitetura tecnológica, permitindo, assim o desenvolvimento de suas competências essenciais qual sejam - gerir o sistema de informação contábil integrado, obtendo vantagem competitiva para si e para a empresa-cliente, otimizando suas economias de escala e de escopo. A estratégia tecnológica poderá trazer como benefício para ambas, empresa contábil e empresa-cliente: (i) elevar a produtividade e a qualidade; (ii) modernização e expansão das atividades; (iii) alianças estratégicas visando enfrentar rupturas tecnológicas; e (iv) redução do custo total de propriedade do ambiente tecnológico.

\subsubsection{A ADMINISTRAÇÃO DA MUDANÇA ORGANIZACIONAL E SUAS VARIÁVEIS}

A administração da mudança organizacional deve ser vista como o equilíbrio de um sistema constituído por cinco variáveis interativas dentro da organização pessoas, processos (tarefas), tecnologia, estrutura e estratégia. Uma mudança em qualquer uma delas vai repercutir nas outras. Essa perspectiva é episódica, uma vez que trata a mudança organizacional essencialmente como um esforço de sustentação do equilíbrio. Uma mudança em uma variável inicia uma cadeia de eventos que, se adequadamente administrada, exige ajustes nas demais variáveis para obter um novo estado de equilíbrio.

Numa síntese, a organização, internamente, é estruturada em diversificados sistemas, que podem ser resumidos a três, para efeito de análise: o tecnológico, o social e o gerencial. Pela interdependência existente, uma mudança em qualquer um dos sistemas inevitavelmente afetará os demais (Cury, 2000). No caso que estamos estudando, por exemplo: uma nova tecnologia (tecnológico), para poder ser utilizado plenamente, poderá exigir novos tipos de recursos humanos (social) e novos arranjos estruturais (arquitetura) e / ou redefinições de processos e métodos de trabalho (gerencial). Neste sentido, discutiremos a missão da empresa contábil, ampliando o seu escopo passando a representar o papel de agente de mudança nas empresas-cliente. 


\subsubsection{DEFINIÇÃO DAS DIMENSÕES ORGANIZACIONAIS}

A partir do campo teórico apresentado nesta pesquisa, tornou-se necessária a definição de determinados conceitos que são utilizados na proposição da mudança organizacional, principalmente relacionados às dimensões da organização conforme a figura anterior. Estes conceitos apresentados a seguir, estão definidos com relação às necessidades de mudança, com o fim específico de entender as dimensões estudadas, com base na seguinte pergunta (Robbins, 2002, pg.529-530): o que se pretende mudar?

(i) Mudar a estratégia envolve uma análise crítica de diferentes alternativas de caminhos para alcançar metas, de acordo com a missão. A estratégia pode ser entendida como os meios ou caminhos escolhidos para alcançar posições futuras favoráveis, em relação a outros competidores em determinado mercado. Ela é ação relacionada com objetivos e desafios e com modos de persegui-los, que afetam a empresa como um todo, representando a definição do caminho mais adequado a ser seguido pela empresa para alcançar uma situação desejada (objetivo, desafio, meta).

(ii) Mudar a estrutura envolve alterações nas relações de autoridade, mecanismos de coordenação, replanejamento do trabalho ou modificar qualquer outra variável estrutural. A estrutura de uma organização se define pela forma como as tarefas são divididas, agrupadas ou coordenadas. A necessidade de mudança pode também introduzir modificações importantes no modelo estrutural vigente. Talvez isso inclua a mudança de uma estrutura simples para uma baseada no trabalho em equipe, ou a criação de um modelo matricial;

(iii) Mudar a organização do trabalho da visão funcional para a visão de processos, entendidos como uma ordenação específica de atividades de trabalho no âmbito de tempo e lugar, com um começo, um fim e inputs e outputs claramente definidos, em outras palavras, um processo é uma estrutura para a ação, ou seja, os processos podem ser entendidos como a maneira pela qual se supõe que determinado trabalho deva ser conduzido em uma organização.

A estrutura e os processos podem assumir uma relação muito semelhante ao que se observa entre hardware e software e, portanto, pode-se dizer que as estruturas viabilizam e conformam o desenvolvimento dos processos. Os processos são uma espécie de mecanismo de coordenação lateral, complementar à hierárquica, baseada no fluxo informacional, e que na realidade criam uma estrutura para o desenvolvimento da comunicação e da criação de conhecimento, e o autor continua:.

(iv) Mudar a Tecnologia engloba modificações na maneira pela qual o trabalho é processado e nos equipamentos utilizados. As principais mudanças tecnológicas envolvem a introdução de novos equipamentos, ferramentas ou métodos, além da automatização e da informatização.

(v) Mudar as pessoas se refere à modificação de atitudes, habilidades, expectativas, percepções e / ou comportamento dos funcionários, por meio de processos de comunicação, tomadas de decisão e solução de problemas. 


\subsection{O AMBIENTE ORGANIZACIONAL - SITUAÇÃO ATUAL}

A situação atual - o que é uma empresa contábil - pretende discutir e mostrar, através da revisão bibliográfica existente, os fundamentos teóricos de como é a arquitetura organizacional dessas empresas nas respectivas dimensões apresentadas na figura anterior.

\subsubsection{ESTRATÉGIA}

A existência das empresas contábeis no Brasil está diretamente relacionada com a pressão governamental, no sentido de gerir sua máquina tributária arrecadadora, nos níveis federal, estadual e municipal, junto a empresas menores ${ }^{* 1}$, acrescida das necessidades de registros legais para a existência destes empreendimentos, nos diversos órgãos reguladores.

A ingerência do sistema fiscal sobre a contabilidade, e o modesto desenvolvimento da cultura contábil no Brasil, devido à inoperância, até um passado recente, de nossas associações de contabilistas, são patentes (Schmidt, 2000). Este panorama, aliado às nossas raízes de cultura empresarial portuguesa, levou o segmento empresarial dos pequenos negócios a entender a contabilidade como "um mal necessário" e o profissional de contabilidade como "o guarda-livros"*2, representante do fisco junto às empresas.

Os relatórios contábeis levantados nas situações acima, com base em documentos fiscais, não espelham a realidade econômica destas empresas, pois o

\footnotetext{
* Como não há uma definição única na literatura sobre os parâmetros para enquadramento das empresas entre pequenas, médias e grandes, consideramos aquelas que buscam a terceirização de serviços relacionados à contabilidade, gestão fiscal e de pessoal, objetivando agilidade nas respostas e eficácia na administração destes custos.
}

\footnotetext{
* Guarda-livros - denominação conferida aos profissionais habilitados aos serviços de contabilidade, de acordo com os decretos $\mathrm{n}^{\mathrm{o}}$. 20.158, de 30 de Junho de 1931, e 21.033, de 8 de Fevereiro de 1932; posteriormente através da lei $\mathrm{n}^{\circ}$. 3.384 de 28 de Abril de 1958, passaram a integrar a categoria profissional de Técnicos em contabilidade.

${ }^{2}$ Guarda-livros - denominação conferida aos profissionais habilitados aos serviços de contabilidade, de acordo com os decretos $\mathrm{n}^{\circ}$. 20.158, de 30 de Junho de 1931, e 21.033, de 8 de Fevereiro de 1932; posteriormente através da lei $\mathrm{n}^{\circ}$. 3.384 de 28 de Abril de 1958, passaram a integrar a categoria profissional de Técnicos em contabilidade.
} 
empresário sabe que, quanto mais documentos fiscais emitir, maiores serão os seus custos com impostos, e menores serão suas chances de sobreviver neste mercado cada dia mais competitivo. Nas discussões acadêmicas (Kassai \& Kassai, 2001) a conclusão é no sentido de entender o processo de sonegação de impostos como estratégias de preços, obedecendo às forças de mercado.

\subsubsection{MISSÃO DA EMPRESA CONTÁBIL}

A evidência empírica discutida anteriormente nos leva a inferir a possibilidade de que parte das estratégias empresarias, das empresas contábeis, estão relacionadas diretamente com a capacidade de gerir, através de relacionamento pessoal e político, as estratégias de preços e impostos de suas empresas-cliente junto ao fisco, minimizando os riscos decorrentes deste procedimento.

Devemos destacar, conforme salientado por Thomé (2001), que a confiança do cliente na empresa contábil é a base desta relação empresarial, e a influência desta relação, nas palavras dele "carnal", pode ser verificada na amplitude dos serviços prestados, o que torna difícil testar sua qualidade e limites.

Neste sentido, observa-se que o ponto de julgamento sobre a competência profissional (qualidade) estará sendo medido, por tratar-se de serviço intangível, justamente na capacidade de gerir este contato, ou seja, no exato momento que a empresa-cliente necessita da informação e na confiança que ele percebe na resposta obtida visando solucionar seu problema. Além do que, a negociação da participação do cliente no processo de serviço da empresa contábil é fator decisivo para as questões de qualidade e produtividade, o que poderá ser observado com precisão nas discussões sobre o mapeamento dos processos na empresa contábil e nas mudanças que devem ocorrer visando implantar uma empresa orientada a processos.

Apesar desses limites, a missão das empresas contábeis, descritas no seu subsistema institucional, é produzir informações de caráter econômico, financeiro e patrimonial a respeito do desempenho das empresas, para toda a sociedade. Porém, a pergunta que se faz é: como? se os principais aspectos desses eventos reais que ocorrem não são capturados em nenhum sistema.

A realidade pode mostrar que grande parte destes gestores, limita-se, nestes casos, a gerir com base nas informações advindas do controle financeiro das entradas e 
saídas de caixa. Os índices de mortalidade dessas empresas contribuem para essa percepção, o que é evidenciado por pesquisas realizadas pelo SEBRAE nacional.

Deste conflito entre o ideal e o real é que vivem as empresas contábeis, como pode ser observado no seu planejamento estratégico, pois deparam-se com algumas ameaças, resumidas por Figueiredo e Fabri (2000, pg.57) nos seguintes pontos:

(i) Grande número de concorrentes de baixa qualificação, oferecendo preços extremamente menores do que aqueles oferecidos pelas organizações mais estruturadas;

(ii)A falta de conhecimento, por parte dos usuários dos serviços contábeis, do valor da contabilidade, para o bom desempenho de seus negócios;

(iii)As constantes mudanças na legislação tributária;

(iv)A baixa qualidade da formação acadêmica dos profissionais de contabilidade.

Os autores citados, em oposição às ameaças, descrevem como oportunidades de mercado:

(i) a legislação que protege e dá exclusividades aos profissionais de contabilidade;

(ii) o sistema nacional de registro e fiscalização por meio dos conselhos; e

(iii) o grande número de empresas existentes no país, que necessitam de serviços de contabilidade.

Nota-se que as oportunidades comentadas estão muito vinculadas à regulamentação da profissão, não tocando na questão central do problema das empresas contábeis, que é a própria maneira de entender a contabilidade como sistema de informações, utilizando a tecnologia para levar o conhecimento contábil à realidade do seu mercado de atuação. Estas contradições do modelo atual de atuação e sua visão serão tratadas a seguir.

\subsubsection{FORÇAS ANTAGÔNICAS MOLDANDO OS RELACIONAMENTOS}

Os atores envolvidos nesta atividade, contabilistas (contadores e técnicos) como empresários do ramo contábil, seus clientes e o fisco, envolveram-se ou foram envolvidos pelo poder de duas forças antagônicas, que ao mesmo tempo: (i) impulsionam o crescimento das atividades das empresas contábeis em termos de 
volume e complexidade burocrática ${ }^{1}$, pois a cada dia essas obrigações são mais volumosas e seus prazos de execução mais curtos; (ii) limitam e banalizam o saber contábil e o desenvolvimento da contabilidade, como sistema de informações para os demais usuários - sejam eles internos e externos.

\subsection{IMPULSO AO CRESCIMENTO}

A primeira destas forças contrárias impulsiona o crescimento das atividades das empresas contábeis em termos de volume de serviços e complexidade burocrática. Decorre da crescente informatização da máquina arrecadadora do estado em todos os níveis e pela integração dos diversos sistemas de controle de pagamento dos tributos, vinculados a informações acessórias quase que diárias (semanais, decendiais, quinzenais, mensais, trimestrais e anuais), buscando cruzar a origem dos débitos, suas bases e procedimentos de cálculo com os recolhimentos efetivos - e os contribuintes a eles obrigados, sejam pessoas jurídicas ou físicas a elas relacionadas.

$\mathrm{O}$ atual sistema impõe custos administrativos elevados para as empresas e para o governo, pois a legislação, além de ampla, é de difícil interpretação, composta por impostos em cascata, contribuições sociais que funcionam como impostos, alíquotas elevadas, incentivos e isenções; cada esfera da administração com suas regras e prazos, o que provoca evasão e sonegação fiscais. Esta situação é reconhecida por todas as entidades representativas das categorias profissionais e empresarias, que reclamam uma urgente reforma tributária, como condição principal para o país ganhar competitividade e voltar a crescer.

Como conseqüência desta força temos a queda da eficácia dos serviços contábeis na visão da empresa-cliente, pois esse trabalho não agrega valor aos seus negócios e, tomando a maior parte do tempo do profissional, distancia-o da realidade diária do seu cliente.

Thomé (2001, pg.33) usa uma figura de linguagem para explicar o fato, comparando os serviços prestados pelas empresas contábeis com um iceberg:

\footnotetext{
${ }^{1}$ No sentido de "burocratização", adotado como forma negativa do Modelo de burocracia de Weber, significando, no entendimento popular do termo, emperramento, demora nas decisões, excesso de papéis, desperdício, ineficácia, enfim, ênfase na forma e nas regras, em detrimento dos objetivos, dos resultados.
} 
Nossa empresa-cliente enxerga apenas a parte que está fora da água, ou seja, o cliente "vê" apenas algumas guias, algumas folhas de salários e encargos sociais e algumas folhas de balancete contábil do mês - aquilo que está fora da água; porém, existe todo um conjunto de dados e informações não estruturadas que são coletados, classificados, registrados, sumarizados e remetidos aos órgãos dos vários níveis do poder público, pelos quais a empresa contábil tem responsabilidade até sua prescrição legal qüinqüenal, e em alguns casos, como as informações trabalhistas e previdenciárias, pode chegar a 30 anos.

\subsection{LIMITAÇÃO E BANALIZAÇÃO DO SABER-CONTÁBIL}

O reflexo da segunda força acima evidenciada cria uma limitação à aplicação do conhecimento contábil e sua evolução, levanta a chamada "banalização" do saber contábil tradicional, atraindo mais pessoas com o título necessário somente a responder por estes serviços rotineiros de "despachante de guias", pelo excesso de informações fiscais não estruturadas que requer processamento, impedindo os profissionais organizados em empresas contábeis de observar e se adequar, em termos de conhecimento e eficácia operacional, às mudanças ambientais decorrentes da modernização da nossa economia, principalmente em função da utilização da tecnologia de informação aplicada aos negócios.

Neste sentido, um fenômeno atinge diretamente a profissão contábil nos países ditos desenvolvidos, bem como no Brasil. De acordo com Pádula (1996, pg.1):

a profissão contábil encontra-se fortemente ameaçada pelas ditas "profissões da informação" (coleta, tratamento, análise e difusão), decorrentes, essencialmente, da própria evolução da tecnologia de informação que introduz uma banalização do saberfazer contábil. Essa banalização refere-se à automatização da principal competência da profissão, qual seja, o domínio da informação econômico-financeira, sua coleta e sua formalização, seu processamento e sua utilização analítica.

Essas ocorrências têm limitado a realização do potencial do contabilista junto à sociedade como gestor dos sistemas de informação das empresas-cliente, também limitadas por essas necessidades não atendidas.

Como conseqüência desta segunda força, temos: (i) a sub-utilização do potencial do contador, como gestor do sistema de informação da empresa-cliente; (ii) a utilização dos sistemas de informação contábil de forma não integrada com objetivo único de gerar dados para alimentar os sistemas fiscais; (iii) queda do valor dos serviços no mercado, pois o trabalho torna-se um autentico re-processar dados fiscais, exigindo pouca ou nenhuma especialização dos executores e de utilidade prática duvidosa, tanto em termos de qualidade quanto em termos de fidelidade de representação do patrimônio da entidade. 
Em resumo, as forças antagônicas discutidas acima, produzem no contabilista e no empresário da empresa-cliente a falsa sensação que quanto mais dados dos processos reais estiverem organizados e estruturados na forma contábil, maior será o risco fiscal e conseqüentemente ambos priorizam a desinformação como estratégia não explicitada do seu relacionamento.

Apesar desta realidade existir, as entidades de classe tem lutado para mudar esta visão, enfatizando que a sonegação é um entrave na valorização das empresas contábeis. Neste aspecto Thomé (2001, pg.132) esclarece que quanto menor for o nível de sonegação, maior será a utilidade dos serviços prestados pelos escritórios, contrariamente ao que pensam e dizem algumas autoridades.

\subsubsection{ESTRUTURA}

Sobre a organização do trabalho nos escritórios, Andreoni (2001, pg.27) esclarece a visão dominante nas organizações:

No que diz respeito ao trabalho nos escritórios, podemos, sem sombra de dúvida, afirmar que os princípios da Escola Clássica de administração foram os guias-mestre sobre os quais foram concebidos e desenvolvidos os equipamentos responsáveis pela sua constante automação, das máquinas de escrever e endereçar, das máquinas de somar e calcular até aos modernos computadores.

A mecanização e a automação dos escritórios se desenvolveram na visão da escola clássica de organização do trabalho, ou seja, baseadas na divisão, fragmentação e rotinização do trabalho.

\subsubsection{REGULAMENTAÇÃO PROFISSIONAL}

As empresas contábeis são normalmente constituídas sob forma de sociedade civil com fins lucrativos (sociedade por quotas de responsabilidade limitada) ou empresas individuais. Estas empresas são regidas pelas mesmas regras de registro aplicáveis às demais empresas nacionais. Uma característica especial é que elas devem promover sua inscrição e registro junto ao Conselho Regional de Contabilidade, de acordo com o art. 16 da resolução CFC n 496-79 de 05 de outubro de 1979, para poderem exercer as atividades que são prerrogativas do contabilista, conforme preceitua o decreto-lei $n^{\circ} .9 .295$ de 27 de maio de 1946:

Art. 15 - Os indivíduos, firmas, sociedades, associações, companhias e empresas em geral, e suas filiais que exerçam ou explorem, sob qualquer forma, serviços técnicos contábeis, ou a seu cargo tiverem alguma secção que a tal se destine, somente poderão executar os respectivos serviços, depois de provarem, perante os Conselhos de 
Contabilidade, que os encarregados da parte técnica são exclusivamente profissionais habilitados e registrados na forma da lei.

Note-se que os conselhos regionais exigem que os sócios sejam profissionais habilitados na profissão com registro no conselho (CRC), conforme estabelece a resolução CFC n $\mathrm{n}^{\mathrm{o}}$ 680-90, caracterizando, portanto, aspectos de sociedade de profissionais, semelhante aos moldes das sociedades de advocacia e auditoria.

Porém, diferentemente de outras categorias profissionais, os contadores deverão possuir uma sociedade formalizada e registrada, ou, se for o caso, de atuarem isoladamente como profissional liberal, na condição de escritórios individuais.

Considerando o patrimônio o objeto fundamental da contabilidade, e esta como ciência humana aplicada, o Conselho Federal de Contabilidade, através da resolução CFC $n^{\circ} 560-83$ de 28 de Outubro de 1983, elencou as atividades compreendidas na contabilidade, constituindo prerrogativa, sem exceção, dos contadores e dos técnicos em contabilidade legalmente habilitados, no seu artigo $3^{\circ}$ enumeradas em 48 itens, dos quais destacamos os itens de número 39, 40 e 41, que tratam da organização e operação dos sistemas de controle interno, patrimonial, materiais, matérias-primas, mercadorias e produtos semi-fabricados e prontos, bem como dos serviços em andamento.

Ainda na citada resolução, no artigo $5^{\circ}$, tratando das atividades compartilhadas - aquelas cujo exercício é prerrogativa também de outras profissões - entre outras, elencaram-se 19 atividades, das quais pode-se destacar a elaboração de planos de organização ou reorganização (item 4) e processamento de dados (item 15).

Nota-se que parte das regulamentações existentes objetivaram criar uma "reserva de mercado" para os profissionais de contabilidade, principalmente decorrentes da responsabilidade técnica pelos serviços prestados às suas empresascliente. Ficam claras, porém, a amplitude e multidisciplinariedade de conhecimentos que podem ser aplicados e desenvolvidos pelo contador na sua atuação delimitada pelos regulamentos, muitos indo além dos aspectos de escrituração regular, que normalmente são desenvolvidos por esse segmento empresarial.

\subsubsection{A ARQUITETURA ORGANIZACIONAL}

Um dos maiores problemas das empresas contábeis é que elas não são projetadas no nascimento, mas vão apenas crescendo, normalmente mantendo a 
estrutura visualizada pelo fundador, via de regra, contabilista com formação eminentemente técnica.

Das adaptações necessárias à sobrevivência, durante a fase inicial, de rápido crescimento, e da fase de maturidade do negócio, de profissionalização da gestão, é que se originam muito dos males verificados nas estruturas organizacionais assim desenvolvidas.

Modernamente, fala-se em arquitetura organizacional como a arte de modelar o espaço organizacional para satisfazer necessidades e aspirações humanas, resultando em um processo através do qual a autoridade é distribuída, as atividades são especificadas desde os níveis mais baixos até a alta administração e um sistema de comunicação é delineado, permitindo que as pessoas realizem as atividades e exerçam a autoridade que lhes compete para o atingimento dos objetivos organizacionais. Para este fim é preciso:

1) Especialização do trabalho: No modelo tradicional das empresas contábeis a essência da especialização do trabalho é praticada na íntegra, uma vez que cada atividade é dividida em um certo número de etapas, cada qual sendo realizada por um indivíduo. Cada profissional se especializa em realizar parte de uma atividade, em vez de fazer a atividade inteira, levando-os a trabalhar abaixo do seu nível de competência, pois as tarefas mais complexas e especializadas são normalmente realizadas pelos sócios-proprietários. A este respeito Robbins (2002, pg.403) esclarece:

Durante boa parte da primeira metade do século XX, a especialização do trabalho foi vista como uma fonte inesgotável de aumento da produtividade, porém, a partir da década de 60 ficaram evidentes as deseconomias humanas decorrentes da especialização - que surgiram como tédio, fadiga, estresse, baixa produtividade, perda da qualidade, aumento do absenteísmo e da rotatividade - superando muito as suas vantagens econômicas. A produtividade poderia ser aumentada por meio da ampliação do escopo das tarefas, principalmente em serviços que exigem grande capacidade de interpretação e conhecimento especializado.

2) Departamentalização: A base segundo a qual as tarefas são agrupadas é chamada de departamentalização por Robbins (2001, pg.403) que esclarece:

A departamentalização funcional busca a economia de escala ao juntar as pessoas com habilidades e orientações comuns em uma mesma unidade. Esta visão funcional e fragmentada dos processos, dificulta o trabalho em equipe e cria barreiras para o desenvolvimento do conhecimento do profissional, levando-o a estagnação.

As empresas contábeis têm suas tarefas agrupadas pelos departamentos funcionais. Com o crescimento das organizações, o trabalho pessoal dos sócios vai gradualmente sendo substituído por mão-de-obra contratada (Thomé; 2001, pg.12), 
passando o contabilista à função de empresário. Surge então a necessidade da departamentalização na visão funcional. Neste contexto, a área funcional de maior especialização é a de consultoria, normalmente atendida pelos sócios principais e encarregados dos departamentos: Contábil, Fiscal, Pessoal e Expediente.

Figueiredo e Fabri (2000, pg.131) apresentam um organograma de departamentalização de uma empresa contábil reconhecida pelo mercado como modelo, fornecendo uma visão do que parece ser a realidade nestas empresas, justificando que o modelo da organização formal seja planejada de maneira que permita o melhor resultado operacional e o alcance dos objetivos estratégicos.

Constata-se a visão tradicional (vertical) dessas organizações, o que favorece a fragmentação dos processos e a consolidação de estruturas altamente especializadas e funcionais que são insensíveis a grandes mudanças no ambiente externo - o mercado consumidor. A forma como o trabalho é realmente realizado não é transparente, dificultando a avaliação do desempenho organizacional, e conseqüentemente do setor.

Para Cury (2000, pg.307) esta visão vertical, tradicional, é muito restritiva, porque: (i) Não evidencia como se agrega valor aos produtos ou serviços destinados aos clientes; (ii) As funções são muito mais importantes que os clientes e os fornecedores; e (iii) As principais responsabilidades se perdem na lacuna entre os departamentos funcionais.

Logicamente, a excessiva especialização neste tipo de estrutura torna o trabalho enfadonho, repetitivo, monótono, gerando quase sempre muita dispersão, desatenção e acomodação entre os empregados, o que poderia explicar, em parte, a baixa valorização da profissão contábil no seu principal mercado de atuação. (VG)

3) Cadeia de comando: A cadeia de comando é uma linha única de autoridade que vai do topo da organização até o escalão mais baixo, determinando quem se reporta a quem na organização. No caso das empresas contábeis, no topo encontram-se os sócios que detém de forma direta a autoridade - posição administrativa para dar ordens e esperar que elas sejam obedecidas - e a unidade de comando, preservando a conceito de linha única de autoridade. 
Os avanços da tecnologia de informação e a tendência de autonomia dos funcionários diminuem a relevância dos conceitos discutidos no parágrafo anterior, pois na visão de Arantes (1998, pg.220):

a organização reflete a missão, os propósitos, os princípios empresariais e os planos, e por isso deve ser mutável, ou seja, deve adaptar-se aos novos estágios de evolução da empresa e considerar os novos objetivos, metas, políticas e estratégias.

4) Amplitude de controle: A amplitude de controle vai determinar o número de escalões de chefia que a organização terá. É através da amplitude de controle que podemos responder quantos funcionários um administrador consegue dirigir com eficiência (Robbins; 2002, pg.406). A questão das empresas contábeis tem sido enfocada no sentido de amplitudes maiores, pois gera menos níveis hierárquicos, levando a redução de custos, corte de excessos, agilização no processo decisório, aumento da flexibilidade, aproximação dos clientes e autonomia dos funcionários, o que exige investimento pesado em treinamento e trabalho em equipe.

Neste sentido, verifica-se a tendência nas empresas contábil na formação de células de trabalho, o que possibilita todos os ganhos citados anteriormente, decorrentes da quase que eliminação dos níveis hierárquicos, o que só será possível na arquitetura organizacional desenhada na visão de processos, e não funcional.

5) Centralização e descentralização: Os termos delegação e descentralização referem-se ao grau de autoridade para tomar decisões e para Arantes (1998, pg.243) tem o mesmo significado, comentando que:

Podemos diferenciar a centralização, que se refere ao grau em que o processo decisório está concentrado nos níveis gerenciais superiores, da descentralização, onde, contrariamente, a autoridade para tomar decisões é ampliada para a participação dos escalões inferiores, chegando até os níveis de supervisão direta das operações.

As empresas de serviços contábeis caracterizam-se pela centralização dos processos decisórios na cúpula diretiva, formada pelos sócios fundadores. Os esforços deveriam ser no sentido da descentralização, o que as tornaria mais flexíveis e responsivas. Observa-se na prática que a descentralização é muitas vezes confundida com a subdivisão ou agrupamento de funções (Arantes; 1998, pg.244). O que acontece na realidade é que a execução das funções é descentralizada, mas a autoridade para tomar decisões é centralizada.

Esta evidência decorre provavelmente da forma como as empresas contábeis são geridas e por quem o são, profissionais com largo conhecimento, experiência e 
habilidades técnicas na área contábil, porém, via de regra, sem os conhecimentos necessários para as atividades administrativas.

6) Formalização: Observa-se nas empresas contábeis a tendência da formalização baixa, pois como os processos não são estruturados, a execução interna acaba se adaptando à estrutura da empresa-cliente, que por tratarem-se de várias empresas de culturas e tamanhos diferentes tornam muito difícil a padronização dos procedimentos. Neste sentido Robbins (2002, pg.403) comenta:

A formalização refere-se ao grau em que as tarefas dentro da organização são padronizadas. A padronização restringe a autonomia do funcionário e sua criatividade, embora garanta que o resultado final do trabalho seja consistente e uniforme. Em contrapartida, quando a formalização é baixa, os comportamentos são relativamente não programados e os empregados têm uma boa dose de liberdade para decidir sobre o trabalho.

Por outro lado, a possível causa das poucas mudanças ocorridas nos processos de trabalho das empresas contábeis é a padronização dos processos fiscais pelos órgãos reguladores, que elimina a necessidade destes profissionais buscarem alternativas para a evolução do seu trabalho. Ou seja, a entrada (input) dos processos recebe dados e informações não estruturadas; e a saída (output) exige dados, informações e documentos totalmente padronizados (inflexíveis), nos quais os responsáveis pelos processos (empresas contábeis) não exercem influência no aspecto de estruturação.

\subsubsection{O MODELO DE GESTÃO}

O modelo de gestão das empresas contábeis, via de regra, segue a estruturação das organizações baseada na hierarquia, herança da chamada administração científica. Neste modelo dá-se prioridade à escala hierárquica do maior para o menor poder decisório. Uma característica importante neste modelo convencional e observado nas empresas contábeis é o afunilamento, isto é, na base da estrutura organizacional encontra-se um número proporcionalmente maior de unidades que nos níveis superiores, e à medida que subimos rumo ao topo, nota-se a diminuição do número de unidades e de pessoas. Esta configuração favorece a concentração de poder nas mãos de poucos e com justificada razão, pois nesse número menor de unidades estariam concentradas as pessoas com maiores competências. 


\subsubsection{PROCESSOS}

Tradicionalmente, as empresas contábeis não têm seus processos estruturados e mapeados, em casos casos a um roteiro de atividades advindos de programas de qualidade. Observa-se que os processos são descritos como "serviços de contabilidade" (Thomé; 2001,pg.62), ou objetivam atender ao "processo de terceirização dos serviços contábeis das empresas-cliente" (Figueiredo \& Fabri; 2000, pg.44), e classificados como "produtos das empresas contábeis", divididos por rotina em serviços contábeis, serviços especializados e atos constitutivos societários, entendidos na visão funcional (departamentos), de acordo com as tarefas executadas, assim descritas:

(1) Serviços de consultoria: consiste em orientar e aconselhar as empresas-cliente em todo e qualquer assunto relacionado à sua atividade empresarial, principalmente questões tributárias e legais, ou indicando, quando for o caso, outro especialista. Resumidamente, esta consultoria poderia ser definida como a capacidade do contador de transformar sua experiência em conselhos úteis aos seus clientes, o que exige postura ética e profissional, além de boa formação profissional (multidisciplinar), facilidade de expressão e poder de síntese. Saídas: orientação na constituição e na fase pré-operacional, durante sua atividade e no encerramento da empresa;

(2) Serviços de contabilidade: representando os lançamentos no sistema de contabilidade através dos documentos fornecidos pelo cliente, ou transferidos por arquivo magnético gerado nos controles internos das empresas-cliente. Saídas: Livro diário, razão, caixa, demonstrações financeiras, declarações fiscais, contabilidade gerencial (por meio da escrituração), livro razão, livro caixa, arquivo e guarda dos documentos contábeis e responsabilidade técnica.

(3) Administração de pessoal: representando a gestão dos vínculos empregatícios da empresa-cliente, esses serviços podem ser divididos em quatro fases distintas: por ocasião da admissão do funcionário; durante a permanência do vínculo empregatício; em razão do seu desligamento; e por fim, a elaboração de relatórios e informações impostas pela complexa legislação que rege as relações trabalhistas. Saídas: Folha de salários, rescisão, guias de recolhimento, informações para o seguro social, política de salários e relacionamento com os sindicatos.

(4) Escrituração fiscal: representada pela escrituração dos documentos fiscais (notas fiscais de entrada e saída), visando apuração dos impostos e contribuições nos diversos níveis. A integração do programa de escrituração fiscal com o programa de escrituração contábil é importante, pois elimina dupla entrada de dados, economizando tempo e evitando erros. Saídas: Livros de entradas, saídas, apuração do ICMS, IPI, ISSQN; guias de recolhimento de tributos; informações e declarações fiscais.

(5) Serviços de expediente (departamento comercial): representando os serviços de legalização de uma nova empresa, cancelamento de uma empresa que encerrou suas atividades, alterações contratuais, registro de livros e obtenção de certidões, incluindo os relacionamentos externos juntos aos diversos órgãos públicos. Saídas: Registro de empresas, negativas, alterações contratuais, cadastros, contratos, CNPJ, inscrição estadual, alvarás, etc.

\subsubsection{CARACTERÍSTICAS DAS EMPRESAS CONTÁBEIS}

Atender aos aspectos fiscais e tributários voltados às necessidades do usuário fisco, respondendo pelas empresas-cliente junto aos órgãos reguladores 
governamentais em todos os níveis, tem representado a missão das empresas contábeis, e moldam as práticas tradicionais no seu mercado de atuação, impondo modelo uniforme dadas às características das atividades desenvolvidas.

Para melhor compreender algumas práticas e comportamentos, as atividades a seguir relacionadas evidenciam a essência de algumas práticas atuais da profissão contábil junto às organizações, Pádula (1996, pg.33) citando um estudo sobre a profissão contábil na França:

(i) A empresa contábil está colocada em posição intermediária entre o poder público e as empresas-cliente, devido, principalmente, as regulamentações fiscal e social;

(ii) O contabilista está se tornando cada vez mais dono de empresa (gestor), em decorrência da profissionalização dos escritórios de contabilidade;

(iii) $\mathrm{O}$ aumento da produtividade, resultado da utilização da informática, tem beneficiado mais o poder público do que os clientes das empresas contábeis;

(iv) $\mathrm{O}$ contador, em geral, recusa-se a avançar além do limite restrito da apuração contábil para fins tributários;

(v) Decorrente desse modelo e das forças citadas anteriormente, a parte consultoria da profissão tem se limitado a aspectos fiscais, sociais e jurídicos, alguns em parceria com outras profissões;

(vi) Finalmente, os esforços das empresas contábeis estão mais voltados a moldar os clientes segundo as orientações do poder público, do que atender às necessidades gerenciais de seus clientes.

Confirmando as limitações impostas à atuação das empresas contábeis no Brasil, por uma estrutura fiscal complexa e por exigências burocráticas desconexas que acabam por moldar sua atuação, já comentadas no tópico anterior, Kassai (1996) em sua pesquisa "as empresas de pequeno porte e a contabilidade" diz que o papel do contador é visto associado a um "mal necessário" pelos gestores das empresas-cliente, dissociado do papel profissional desempenhado junto às empresas maiores, nas quais é responsável pela estruturação do sistema de informações de apoio a decisão.

\subsubsection{AS PRÁTICAS ATUAIS NAS EMPRESAS CONTÁBEIS}

Os documentos hábeis que retratam a realidade das operações praticadas são encaminhados para a contabilidade para serem escriturados. Escriturar é o ato de registrar as operações exercidas e comprovadas pela empresa que ocorreram no decorrer de um período. (Guia IOB de contabilidade - vol 1 pg.1 orientação n ${ }^{\circ}$. 1-F)

Tradicionalmente, a escrituração é vista como um dos alicerces, junto com as demonstrações contábeis e a análise contábil, que fornecem o controle do patrimônio de uma entidade por meio de um sistema próprio de controle: a contabilidade, com o 
objetivo de fornecer informações palpáveis aos tomadores de decisão: os administradores.

A visão exposta acima, traduzida do Guia IOB de contabilidade, uma das principais fontes de informação utilizadas pelas empresas contábeis no país, enfatiza que:

(...) a escrituração tem a função principal de relatar o passado da empresa, sem qualquer preocupação com o poder da informação sobre o que ocorrerá no futuro do negócio, um dos pontos mais importantes da informação contábil, e pergunta: a quem interessa informação passada? E responde taxativamente: "o maior usuário de relatos pretéritos chama-se fisco" (pg. 2 - orientação 1-F)

\subsubsection{TECNOLOGIA}

O termo tecnologia, na atualidade, é muito abrangente, e seu significado alargou-se, sendo abordado sob vários enfoques, visando finalidades diferentes. Etimologicamente, tecnologia provém de técnica, cujo vocábulo latino techné quer dizer arte ou habilidade, mostrando por derivação que tecnologia é uma atividade voltada para a prática (Oliveira; 2002, pg.191)

Observa-se o uso generalizado do termo tanto como técnica, como organização e gerenciamento, comércio de aparelhos etc. A tecnologia é o conhecimento científico transformado em técnica que, por sua vez, irá ampliar a possibilidade de produção de novos conhecimentos científicos, conforme Oliveira (2002, pg.191), que conclui sobre seus objetivos:

O principal objetivo da tecnologia é aumentar a eficiência da atividade humana em todas as esferas, incluindo a produção. Poderíamos dizer que a tecnologia envolve um conjunto organizado e sistematizado de diferentes conhecimentos, científicos, empíricos, e até intuitivos, voltados para um processo de aplicação na produção e na comercialização de bens e serviços.

\subsubsection{TECNOLOGIA DE INFORMAÇÃO (TI)}

No que se refere ao uso da tecnologia de informação nas empresas contábeis, apesar da pouca bibliografia publicada, as referências encontradas reportam-se ao tema como informática, o que pode espelhar a visão fragmentada praticada pelo segmento.

Thomé (2001, pg.131) trata o assunto como informática, nos seguintes termos:

A popularização dos programas, sistemas e equipamentos de informática veio facilitar sobremaneira a atividade das empresas de contabilidade, tornando-se a mais importante das ferramentas na execução dos serviços. As atividades mecânicas e cansativas como levantamento de balancetes, por exemplo, hoje são executas pelo computador, permitindo que o profissional dedique seu tempo a tarefas mais importantes e tecnicamente mais complexas. É difícil imaginar qual seria a estrutura 
necessária - instalações, equipamentos e mão-de-obra - para uma empresa contábil média atender 150 clientes, sem os recursos da informática. (...) o advento da informática foi extremamente benéfico para a nossa profissão e para as nossas empresas.

Pode-se observar o destaque dado à importância da informática para as necessidades diárias. Porém, fica entendido que a tecnologia tem sido vista no âmbito interno de automatização das atividades, principalmente com o objetivo de sumarização de relatórios. É claro que a informática, neste ponto, representou um avanço considerável em relação ao processo contábil manual ou mecanizado, onde os fechamentos tornavam-se demorados e muitas vezes traumáticos. Quem não conhece a aflição de um estudante que não consegue "fechar" um balancete contábil?

Já Figueiredo \& Fabri (2000, pg.105) tratam o tema tecnologia como "automação da empresa contábil", resumido nos seguintes termos:

(...) a grande vantagem da automação nas empresas de serviços contábeis é que tarefas rotineiras e não especializadas poderão ser executadas por estagiários, estudantes de cursos de contabilidade, ou funcionários de nível inferior, liberando o contador para tarefas estratégicas, de supervisão e controle, e de sugestões para o gerenciamento das organizações dos clientes. Houve três fases dentro do processo de automação: a fase zero ou fase primitiva, que foi a fase manual, em que o profissional desenvolvia a contabilidade da empresa sem nenhuma utilização de máquinas.

Entende-se nesse ponto, da descrição da evolução da automação nas empresas contábeis, que surge a necessidade de mecanizar o processo de escrituração contábil para fins de sumarização em relatórios legais. Apesar dos autores falarem em três fases, na realidade são quatro, pois além da fase zero temos ainda:

Na primeira fase, com o surgimento da máquina de escrever, a contabilidade começou a ser mecanizada, mas não eletronicamente, apenas datilografada. Na segunda fase, surgiram as máquinas dirigidas para o uso da contabilidade, com programas em placas eletrônicas Eprom, que davam condições de registrar nos sistemas contábeis e de pessoal. Nessas máquinas, eram acoplados teclados com números e tipos semelhantes a uma máquina de escrever. Os modelos mais conhecidos eram Audit - CEF 243 Olivetti, e BA 1000 - Sharp. Para a operacionalização, eram utilizadas fichas tríplices ou cardex carbonadas, para posteriormente serem transcritas para os livros por meio de gelatinas próprias.

É importante esclarecer neste ponto da história evolutiva, que a evolução observada é no ato de mecanização da escrituração, com avanços significativos na fase de produção dos relatórios para fins de sumarização. E os autores Figueiredo \& Fabri (2000, pg.106) continuam:

A terceira fase foi a que deu grande impulso ao desenvolvimento com o surgimento dos microcomputadores. (...) tendo como conseqüência sistemas de software mais desenvolvidos, práticos, automatizados e adequados à execução da contabilidade. (...) Com a integração dos sistemas contábeis, fiscal e trabalhista, pode-se, com uma única operação, registrar automática e integralmente todos esses sistemas, inclusive os 
sistemas de controle de estoque e custos. (...) A fase atual é a de interligação com os clientes em via direta, podendo os dados dos documentos já serem digitados nas empresas de origem e cabendo ao profissional de contabilidade o tratamento adequado dos dados transmitidos e a geração de informações requeridas.

Conclui-se, através do relato da evolução dos sistemas nas empresas contábeis que, apesar da reconhecida evolução, a preocupação central continua sendo com a sumarização e produção dos relatórios contábeis, ou seja, com o processo de escrituração com base no que Sorter (1969) rotulou como sendo a "teoria do valor", isto é, a contabilidade vista simplesmente como esquemas para a organização, classificação e agregação de dados financeiros, através de um plano de contas e seus procedimentos de partida dobrada.

O surgimento da tecnologia de banco de dados possibilitou a correção dos tipos de fraquezas identificados no modelo de contabilidade tradicional, relatados por McCarthy (1982) nos seguintes termos:

(i) suas dimensões são limitadas;

(ii) seus esquemas de classificação não são sempre apropriados;

(iii) seu nível de agregação das informações armazenadas é muito alto;

(iv) seu grau de integração com outras áreas funcionais da empresa é muito restrito.

Um aspecto importante a ser levado em consideração, citado por (Figueiredo \& Fabri, 2000), é a responsabilidade do contador pela veracidade dos dados que apóiam as informações contábeis das empresas-cliente, isto é, a assinatura do contador é que dá credibilidade as informações.

Neste sentido, pode-se inferir que a simples integração entre sistemas financeiros da empresa-cliente (contas a pagar-receber-caixa-faturamento) com o sistema de informação contábil na empresa contábil, proposto pelos autores, não resolve os problemas relativos a informações gerenciais com as características qualitativas necessárias, bem como, colocam em risco os aspectos da responsabilidade profissional no que tange a retratar fielmente o patrimônio da empresa-cliente. A resposta para esta questão à pesquisa visa encontrar. 


\subsubsection{OS SISTEMAS DE INFORMAÇÕES CONTÁBEIS}

Um sistema de informação contábil pode ser visto como um conjunto de cinco componentes que interagem entre si: (1) equipamentos, (2) programas aplicativos, (3) dados, (4) pessoas e (5) procedimentos.

$\mathrm{Na}$ empresa contábil esses sistemas são vistos de forma não integrada, fragmentada, e a explicação para isso pode ser entendida a seguir, explicada pela dificuldade que alguns profissionais de contabilidade e informática tem em ver a interligação existente e natural entre os ciclos contábeis e os processos de negócios, entedendo-os como duas entidades totalmente separadas e independentes.

\subsection{PROCESSAMENTO TRADICIONAL DE ARQUIVO INDEXADO}

Nas empresas contábeis o processamento das informações começou numa pequena escala, automatizando uma aplicação de cada vez, através da compra de um pacote de software aplicativo, isto é, um conjunto de programas preescritos e precodificados que estão comercialmente disponíveis para venda ou aluguel (Laudon \& Laudon; 2001, pg.267).

Estes pacotes tornaram-se comuns a todas as empresas contábeis, pois atendem, através de funções universais com procedimentos padronizados, às suas principais áreas funcionais, desenvolvidos separadamente: Contabilidade, Livros Fiscais, Recursos Humanos (folha de pagamento), Financeiro e Societário. Cada área adquiriu ou desenvolveu seus próprios sistemas e arquivos de dados

Nos meios acadêmicos e empresariais ligados a empresas contábeis no Brasil, discute-se que parte dos avanços conquistados pela classe contábil, como pioneira no uso da informática em seu ambiente de trabalho, foi perdido em função da demora na evolução do ambiente de arquivos tradicional, utilizando o método de acesso seqüencial indexado (ISAM - indexed sequential access method), baseado em um índice de campos chaves para localizar registros individuais, para a filosofia de ambiente de banco de dados. 


\subsection{O AMBIENTE DE ARQUIVOS TRADICIONAL (PROBLEMAS)}

Na maioria dos casos, as empresas contábeis desenvolveram ou adquiriram de software-houses os sistemas construídos com a visão fragmentada dos processos, no modelo de arquivos indexados, dentro da visão da atividade contábil como uma atividade de escrituração, ou seja, que registra os eventos retratados por documentos fiscais para fins de sumarização.

Como este processo continua por mais de dez anos, a organização fica sobrecarregada com vários programas e aplicações, que ninguém sabe o que fazem, que dados usam e quem está usando os dados (Laudon \& Laudon; 2001, pg.158). Os problemas resultantes são a redundância de dados, a dependência de dados de programa, a inflexibilidade, a segurança precária de dados e a inabilidade para compartilhar dados entre as aplicações.

Esta visão "escriturária" no uso dos sistemas contábeis e auxiliares representa um típico trabalho de re-processo, pois sua fonte são dados não estruturados em termos de sistema, o que obriga que, a cada documento emitido na empresa-cliente, o "escriturário" proceda a sua leitura visual, capturando e registrando os impactos tributários dos eventos. Neste sentido, nota-se que a informática utilizada pelos contadores nos escritórios pouco contribuiu na mudança da visão mecanizada do processo contábil, iniciada no Brasil nos primeiros anos da década de 70 .

Este conceito problemático requer o armazenamento de dados separados, como também, sua coleta e produção de relatórios, o que provoca duplicação e falta de integridade dos dados e conseqüentemente ineficiência. Nesta visão, o contador é o registrador das transações ocorridas nas empresas, sumarizando dados e produzindo relatórios de contabilidade financeira e legal.

É provável que a natureza do processamento de transações venha a mudar, à medida que as empresas passem a usar cada vez mais tecnologias como a Internet, programação orientada para objeto e tecnologia de banco de dados (Moscove., Simkin , Bagranoff, 2002). 


\subsubsection{PESSOAS}

Os recursos humanos, em qualquer empresa de serviços, revestem-se de extrema importância, pois a qualidade do serviço oferecido depende da cultura, dos conhecimentos e das habilidades de quem os oferece (Figueiredo \& Fabri; 2000, pg.85).

Thomé (2001), tratando da área de pessoal como mão-de-obra, enfatiza a importância de especialistas por área, denominados de chefes ou encarregados de departamentos, destacando as áreas de consultoria e contábil como as mais importantes. É importante salientar, novamente, que a visão funcional com especialistas é dominante nas empresas contábeis, decorrente provavelmente da diversidade de clientes atendidos, e seus múltiplos negócios e características.

Com relação à estabilidade no emprego e plano de carreira são poucas as empresas contábeis que os oferecem, sendo na visão de Figueiredo \& Fabri (2000) essas políticas imprescindíveis para aquelas organizações que queiram crescer, inclusive propondo que a política de Recursos Humanos envolva gestão participativa e participação nos lucros.

Os autores citados, entretanto, alertam para o fato de que como se trata de empresa de serviços, onde o capital intelectual é preponderante e intrínseco a pessoas, deve existir uma relação de vantagens mútuas, sob o risco de o empregado tornar-se um concorrente. Esta parece ser uma preocupação dominante no mercado.

Sobre a motivação para o trabalho, destacam Figueiredo \& Fabri (2000) que alguns pontos importantes que poderão ser considerados pelo gestor, além do treinamento e formação necessária, visando o maior envolvimento do profissional com o trabalho:

- Reconhecer nas pessoas habilidades diferenciadas;

- Identificar as preferências pessoais e os objetivos de cada um;

- Conferir autonomia na realização das tarefas a elas pertinentes, para que haja identificação com o trabalho;

- Feedback - dar informação, individualmente, a respeito do resultado final do trabalho feito.

A contabilidade é quase sempre em trabalho muito envolvente, que exige determinação e comprometimento para sua boa realização, e em função dos múltiplos conhecimentos que exige somente o trabalho em equipe é que trará a diferença. 


\subsubsection{ESTADO ATUAL: AS EMPRESAS CONTÁBEIS COMO MÁQUINAS}

Utilizando-se a abordagem proposta por Morgan (1996) e comentadas no capítulo anterior, a metáfora que melhor explicaria o funcionamento das empresas contábeis no estado atual poderia ser: organizações como máquinas. Existem forças e limitações da metáfora da máquina, sendo as forças caracterizadas de modo muito simples (Morgan; 1996,pg.37):

Os enfoques mecanicistas da organização funcionam bem somente sob condições nas quais as máquinas operam bem, ou seja: (a) quando existe uma tarefa contínua a ser desempenhada; (b) quando o ambiente é suficientemente estável para assegurar que os produtos oferecidos sejam os apropriados; (c) quando se quer produzir sempre exatamente o mesmo produto; (d) quando a precisão é a meta; e (e) quando as partes humanas da "máquina"são submissas e comportam-se como foi planejado que façam.

Como o principal exemplo do enfoque mecanicista implantado com sucesso são as redes de franquia, entre elas a cadeia de hambúrgueres McDonald's. Por outro lado, o autor (pg.38) esclarece as limitações deste enfoque nos seguintes termos:

(...) apesar desses sucessos, enfoques mecanicistas da organização quase sempre têm severas limitações. Em particular, elas podem: (a) criar formas organizacionais que tenham grande dificuldade em se adaptar as circunstâncias de mudança; (b) desembocar num tipo de burocracia sem significado e indesejável; (c) ter conseqüências imprevisíveis e indesejáveis à medida que os interesses daqueles que trabalham na organização ganhem precedência sobre os objetivos que foram planejados para serem atingidos pela organização; (d) ter um efeito desumanizante sobre os empregados, especialmente sobre aqueles posicionados em níveis mais baixos da hierarquia organizacional.

\subsection{O AMBIENTE ORGANIZACIONAL - SITUAÇÃO DESEJADA}

A situação desejada - o que deveria ser uma empresa contábil - procura discutir e mostrar uma visão de futuro para essas organizações, considerando a revisão bibliográfica efetuada e os fundamentos teóricos de como deveria ser a arquitetura organizacional dessas empresas nas respectivas dimensões, para que as forças que impulsionam as mudanças sejam plenamente aproveitadas, principalmente o potencial oferecido pelo sistema empresarial integradoSistema Empresarial Integrado - ERP.

\subsubsection{ESTRATÉGIA}

A aplicação da tecnologia de informação (TI) aos negócios está provocando mudanças profundas na contabilidade e no campo de atuação do contador, profissional 
cuja principal competência é o domínio da informação econômico-financeira: coleta, formalização, processamento e utilização analítica de tal informação.

As questões tecnológicas para as empresas, principalmente as empresas contábeis, estão inseridas nas suas questões estratégicas, ou seja, as discussões sobre estratégicas tecnológicas nessas empresas envolvem as discussões sobre suas estratégias de atuação.

A estratégia de negócios define a maneira através da qual as empresas competem em um determinado segmento, denominada de estratégia competitiva (Porter; 1996, pg.39), tratando de como ser diferente, de escolher diferentes conjuntos de atividades para fornecer um único mix de valor ao cliente.

Num nível inferior, este autor (1989; pg.164) define como parte da estratégia competitiva da empresa a estratégia tecnológica, devendo ambas ser consistentes entre si e reforçadas pelas suas outras atividades de valor, de tal forma que as tecnologias a serem desenvolvidas devam ser aquelas que mais contribuam para o sucesso competitivo da estratégia global da empresa.

A atividade contábil encontra-se na atualidade fortemente ameaçada pelas ditas profissão da informação (coleta, tratamento, análise e difusão). Apesar da profissão ser protegida legalmente, a ameaça provém da evolução das tecnologias da informação, que torna cada vez menos relevante o saber-fazer contábil (Pádula; 1996, pg.29), principalmente na forma de escrituração, como aplicado pelas empresas contábeis.

\subsubsection{VANTAGEM COMPETITIVA}

As empresas contábeis, cientes das transformações que estão ocorrendo na economia brasileira e da importância de sua atuação junto às empresas-cliente, de menor porte, mas de fundamental importância para a economia - pela capacidade de gerar empregos, agilidade e adaptação às mudanças no ambiente - devem adotar uma postura proativa diante da ameaça identificada, superando-a e obtendo certas vantagens competitivas, concentrando suas ações em duas frentes (Pádula; 1996,pg.30):

(i) Diversificação estratégica, para inserir a consultoria em gestão às pequenas e médias empresas (PMEs) em seu portfólio de atividades, prestação de serviços que apresenta forte sinergia com as práticas tradicionais da profissão;

(ii) Capacitação para o uso da informática e para o apoio ao PMEs em seu processo de informatização, através da implementação de sistema empresarial integrado. 
Uma terceira frente, não evidenciada pelo autor citado é a contabilidade gerencial, descrita em detalhes mais adiante.

A consultoria de gestão, como prolongamento de suas intervenções tradicionais de caráter fiscal, exigirá por um lado, esforços que deverão ser dirigidos concretamente para as condições de realização das intervenções, no sentido de desenvolver novos produtos e serviços a serem oferecidos, metodologias e ferramentas de apóio a intervenção organizacional; e por outro, evolução (comportamental, organizacional, informática) da profissão para melhor adaptação ao ambiente de consultoria, evidenciado nos seguintes pontos:

(1) A evolução comportamental do contador no sentido de trabalhar em equipe multidisciplinar, aplicando o saber, saber-fazer e o fazer-saber ${ }^{1}$ necessários a identificar as expectativas dos gestores e satisfazer as necessidades suas e dos demais usuários.

(2) A evolução organizacional da empresa contábil no sentido de estruturar suas operações com a visão de processos, agregando valor aos serviços entregues as empresas-cliente e desempenhando papel relevante no desenvolvimento destas, por sua posição de fonte de informação para o gestor, não somente como conselheiro obrigatório, mas também como conselheiro escolhido (Pádula; 1996, pg.31).

(3) A evolução na utilização da informática ou especificamente na utilização do sistema de informação contábil (SIC) integrado mudando sua visão do processo contábil como ato de "escrituração" para modelagem de dados, concentrando-se nos eventos de negócios, no momento da sua ocorrência.

Para possibilitar a atuação nestas frentes, as expectativas dos dirigentes das empresas-cliente devem ser identificadas no sentido de satisfazer suas necessidades, o que possibilitará a melhoria.

\footnotetext{
${ }^{1}$ Entendido como a necessidade de tornar a informação contábil distribuída a todos os níveis da empresa, melhorando e agilizando o processo de tomada de decisão, contribuindo para que o usuário compreenda melhor a linguagem dos negócios.
} 


\subsubsection{CONTABILIDADE GERENCIAL}

A contabilidade gerencial é o processo de identificar, mensurar, reportar e analisar informações sobre eventos econômicos das empresas (Atkinson et al.,2001), e como processo, ela visa produzir informação operacional e financeira para funcionários e administradores, direcionada pelas necessidades informacionais dos indivíduos internos da empresa.

Neste sentido, o seu produto, "a informação contábil gerencial", é uma das fontes informacionais primárias para a tomada e decisão e controle nas empresas., cujo escopo, de acordo com Atkinson et al. (2001), em anos recentes foi ampliando-se para incluir informações operacionais ou físicas (não financeiras), tais como qualidade e tempo de processamento, tanto quanto informações mais subjetivas como mensurar o nível de satisfação dos clientes, capacitação dos funcionários e desempenho de produtos e serviços.

No contexto competitivo atual, os contadores gerenciais estão se tornando parte do time executivo, participando da formulação das estratégias empresariais, pois a informação contábil gerencial participa de várias funções organizacionais diferentes, em função da demanda pela informação ser diferente dependendo do nível onde ocorre, dentre as quais destacam-se (Atkinson et al.; 2001, pg.45):

- Controle operacional: processo de fornecimento de feedback aos funcionários e seus
gerentes, sobre a eficiência de atividades sendo executadas.
- Custeio do produto: Processo de avaliação e designação dos custos das atividades
executadas no projeto e fabricação de produtos individuais (e serviços para empresas
não industriais).
- Custeio de Cliente: Processo de designar os custos de marketing, de vendas, de
distribuição e administrativos aos clientes individuais, para calcular o custo de atender
cada um deles.
- Controle administrativo: Processo de fornecer informações sobre o desempenho de
gerentes e de unidades operacionais.
- Controle estratégico: Processo de fornecer informação sobre o desempenho
competitivo completo da unidade de negócios, tanto do ponto de vista financeiro
quanto do ponto de vista dos clientes.

A contabilidade gerencial, como definida pelo Instituto de Contadores Gerenciais apud Atkinson at al. (2001, pg.05), para fins deste trabalho pode ser entendida resumidamente como:

(...) um processo de melhoria continua, que adiciona valor, de planejamento, desenvolvimento, mensuração e operação de sistemas de informações não financeiras e financeiras que guiam as ações da administração, motiva, dá suporte e cria valores culturais necessários para se alcançar os objetivos estratégicos, táticos e operacionais de uma organização. 


\subsection{O SISTEMA DE CONTROLE GERENCIAL}

Os sistemas de controle gerencial auxiliam a administração a conduzir a organização na direção de seus objetivos estratégicos. Para esse fim, a congruência de objetivos deve ser atingida, isto é, os objetivos individuais do pessoal da organização devem ser, na medida do possível, consistentes com o objetivo dela. Em outras palavras, as pessoas (gestores principalmente) têm objetivos pessoais, e o problema central do controle é induzi-los a atuar de maneira que, ao procurarem atingir seus objetivos pessoais, auxiliem o alcance dos objetivos da organização.

Desta forma, na visão de Antony \& Govindarajan (2002) pode-se definir $o$ controle gerencial como sendo o processo intermediário dos três processos de planejamento e controle. É limitado, por um lado, pela formulação da estratégia, a qual é essencialmente assistemática, e, por outro, pelo controle das tarefas, o qual pode ser altamente estruturado. Os parâmetros de gerenciamento e os critérios para julgamento das decisões gerenciais são a eficiência e a eficácia.

No nível mais detalhado o controle gerencial pode ser entendido como o processo pelo qual os executivos influenciam outros membros da organização, para que obedeçam às estratégias adotadas (Antony \& Govindarajan, 2002:34), através das seguintes atividades:

(1) planejar o que a organização deve fazer; (2) coordenar as atividades de várias partes da organização; (3) comunicar a informação; (4) avaliar a informação; (5) decidir se deve ser tomada uma decisão, ou que decisão tomar; e (6) influenciar as pessoas para que alterem seu comportamento.

A ligação do controle gerencial, com o controle das tarefas - processo que visa assegurar que as tarefas sejam cumpridas eficaz e eficientemente - e com a contabilidade gerencial pode ser obtida através de um sistema único integrado, adaptado para qualquer dos propósitos delineados anteriormente. Neste sentido, a contabilidade gerencial, na visão de Antony \& Govindarajan (2002:42), orientada para obtenção de informações úteis a gestão, pode ser vista em três divisões:

(i) contabilidade de custo total que apura o custo total da produção, dos processos, dos serviços e outros custos (preço-estoque-lucatividade-decisões de curto e longo prazo); (ii) contabilidade diferencial que estima os custos que existiriam sob condições alternativas; e (iii) o controle gerencial (contabilidade por área de responsabilidade), cuja definição e escopo foi apresentada nesta seção. 
Conclui-se que a contabilidade gerencial engloba, entre outras informações, todo o processo de controle gerencial, isto é, a contabilidade gerencial contém os chamados sistemas de informações gerenciais.

\subsubsection{ESTRUTURA}

Um ambiente empresarial em constante mudança, sendo esta a única certeza no futuro: vai mudar e mudará, trouxe consigo a necessidade das empresas desenvolverem uma estrutura organizacional mais ágil e capaz de reagir a tais mudanças para garantir sua sobrevivência e ampliar sua competitividade, daí a importância do sistema organizacional.

O sistema organizacional vai definir a estrutura organizacional que está diretamente relacionada com a estratégia da empresa. Uma organização pode expressar o processo ou a função de organizar, aquela que se encarrega de projetar a estrutura organizacional e de potencializar que se realizem as atividades de forma efetiva, incorporando medidas de eficiência e eficácia em relação aos objetivos pretendidos.

\subsubsection{SISTEMA ORGANIZACIONAL E SEUS OBJETIVOS}

De acordo com Pereira, in Catelli (2001, pg.56), o Sistema Organizacional "refere-se à organização formal da empresa, ou seja, à forma como são agrupadas suas diversas atividades em departamentos (departamentalização), aos níveis hierárquicos, às definições de amplitude e responsabilidade, ao grau de descentralização das decisões e à delegação de autoridade".

Já Arantes (1998, pg.93) esclarece que a função do subsistema de organização (referindo-se ao sistema organizacional) é a de "dotar a administração de instrumentos que permitam a subdivisão da tarefa empresarial em funções específicas, e a designação de pessoas qualificadas para assumir as responsabilidades, permitindo que a complexa tarefa empresarial seja compartilhada de forma clara entre as pessoas que integram a empresa".

O objetivo do sistema organizacional é o de assegurar que a distribuição da tarefa empresarial seja feita de forma eficaz, em direção aos resultados, e eficiente, otimizando recursos, tempo, custos, etc., de maneira coordenada (na opinião de Arantes; 1998, pg.93), enfatizando que a organização constitui um verdadeiro desafio 
para os gestores, ao exigir que a subdivisão da tarefa empresarial seja feita sem perder a sinergia do esforço conjunto, concebendo um modelo organizacional que consiga distribuir a tarefa empresarial preservando sua unidade e sua orientação aos resultados.

Neste sentido, de acordo com Buwditch \& Buono (1997, pg.175) a maioria dos teóricos organizacionais atualmente defende uma teoria contingencial do projeto organizacional, ou seja, que o modo como uma organização deve ser montada depende de seu ambiente, particularmente nas dimensões mercado e tecnologia. Daí conclui-se que uma estrutura eficaz é aquela que se ajusta aos seus requisitos ambientais.

A Teoria da Contingência assenta-se epistemologicamente nos fundamentos do funcionalismo sociológico, que entende a estrutura social a partir das funções a serem desempenhadas para o bem-estar da sociedade.

Esta teoria utilizou as premissas básicas da Teoria de Sistemas no que se refere aos aspectos de interdependência e natureza orgânica das organizações, bem como a consideração das organizações como sistemas abertos e adaptativos que interagem dinamicamente com o ambiente, ou seja, clientes, fornecedores, concorrentes, entre outros.

Porém, enquanto a Teoria de Sistemas preconiza uma estruturação organizacional que se reproduz em toda a organização como um conjunto de subsistemas funcionalmente inter-relacionados, a Teoria da Contingência sustenta que é preciso levar em conta o processo de coordenação interdepartamental em função das diferentes formas estratégicas e estruturais contingenciadas pelo ambiente e que podem ocasionar conflitos na organização.

\subsubsection{ORGANIZAÇÃO ORIENTADA A PROJETOS (ADHOCRACIA)}

As organizações executam trabalho, que envolve serviços continuados e / ou projetos, embora possa haver superposição entre os dois. Serviços continuados e projetos, apesar de possuírem muitas características comuns, diferem principalmente porque enquanto os primeiros são contínuos e repetitivos, os projetos são temporários e únicos. 


\subsection{O QUE É UM PROJETO?}

Nesta etapa do trabalho nosso interesse é discutir a gerência de projetos, e para tanto iniciamos conceituando projeto, conforme $\mathrm{PMI}^{* 1}$

Um projeto é um empreendimento temporário com o objetivo de criar um produto ou serviço único. Temporário significa que cada projeto tem um começo e um fim bem definidos. Único significa que o produto ou serviço produzido é de alguma forma diferente de todos os outros produtos ou serviços semelhantes.

As organizações orientadas a projeto são aquelas cujas operações consistem, basicamente, de projetos e se enquadram em duas categorias: (i) organizações cujas receitas se originam primariamente do desenvolvimento de projetos para terceiros, como, por exemplo, empresa de engenharia e consultores; e (ii) organizações que adotam o modelo de gerência por projeto, isto é, uma abordagem organizacional para gerenciamento dos processos operacionais contínuos, tratando muitos aspectos dos serviços continuados como projetos, objetivando aplicar a eles os conceitos de gerência de projetos.

Para muitas organizações, projetos são meio de responder a requisitos que não podem ser atendidos através dos limites normais de operação da organização.

Os projetos são desenvolvidos em todos os níveis da organização, envolvendo uma ou mais pessoas, e em muitos casos podem atravessar as fronteiras organizacionais, sendo meio pelos quais as estratégias empresariais são implementadas, podendo citar-se, como exemplo de projetos: "implementar uma mudança organizacional ao nível de estrutura, de pessoas ou de estilo gerencial”; ou ainda, “implementar um Ssistema Eempresarial Iintegrado - ERP”.

A gestão de projetos é baseada na formação de equipes temporárias e pluridisciplinares. Trata-se de um grupo de trabalho constituído por profissionais provenientes de diferentes setores da empresa que tem um projeto a desenvolver. No universo de conhecimento gerência de projetos é uma denominação que representa todo o somatório de conhecimento dentro da profissão de gerência de projetos.

\footnotetext{
* Project Management Institute Headquarters, através do PMBOK 2000 - disponibilizado pelo PMI MG em Janeiro de 2002 no endereço www.pmimg.org.br.

${ }^{1}$ Project Management Institute Headquarters, através do PMBOK 2000 - disponibilizado pelo PMI MG em Janeiro de 2002 no endereço www.pmimg.org.br
} 
Numa visão semelhante, porém com outro enfoque, Maximiano (2002, pg.26) define que um projeto é: “(i) Um empreendimento temporário ou uma seqüência de atividades com começo, meio e fins programados; (ii) que tem por objetivo fornecer um produto singular; (iii) dentro de restrições orçamentárias".

\subsection{ABORDAGEM DE PROJETO}

Definido o que é projeto, agora torna-se necessário entender quando utilizar esta abordagem, já que nem todos os empreendimentos temporários são projetos, e também que nem todas as atividades finitas precisam ser administradas como tal, pois podem ser geridos como encomenda ou ordem de serviço, necessário se faz elencar alguns critérios para identificá-los e diferenciá-los dessas outras abordagens.

Usar uma abordagem de projeto, de acordo com Maximiano (2002, pg.34) significa:

Decidir que uma atividade é projeto. Em essência, é projeto uma atividade que se decide administrar como tal, podendo ser usados os critérios e indicadores relacionados a seguir, e desde que as respostas as questões enunciadas sejam afirmativas, isto é, sim: (I) A atividade tem começo, meio e fim programados? (ii) A atividade é diferente das atividades de rotina? (iii) A solução do problema envolve muitas variáveis? (iv) A solução do problema é desconhecida? (v) A solução deve ser apresentada dentro de um prazo definido? (vi) A solução do problema requer competências e recursos multidisciplinares? (vii) A solução do problema é importante para a organização/ (viii) A solução do problema ou atividade envolve um cliente importante da organização? Se a resposta for sim, aplique uma abordagem de projeto: Designar um gerente de projeto e uma equipe de projeto para cuidar dessa atividade; Preparar e executar um plano de projeto.

$\mathrm{O}$ gerente do projeto, a equipe de projeto e o plano de projeto são as três ferramentas básicas da administração de projetos.

Como os projetos possuem um caráter único, a eles está associado um certo grau de incerteza. As organizações que desenvolvem projetos usualmente dividem-nos em várias fases visando um melhor controle gerencial e uma ligação mais adequada de cada projeto aos seus processos operacionais contínuos. Este conjunto de fases é conhecido como ciclo de vida do projeto.

O ciclo de vida do projeto serve para definir o início e o fim de um projeto, determinando os procedimentos de transição para o ambiente de operação, e pode ser usado para ligar o projeto aos processos operacionais contínuos da organização executora. 
Os ciclos de vida dos projetos geralmente definem: (i) o trabalho técnico que deve ser realizado em cada fase; (ii) quem deve estar envolvido em cada fase. As descrições do ciclo de vida do projeto podem ser genéricas ou detalhadas, apresentando as seguintes características comuns: (a) o custo e a quantidade de pessoas integrantes varia ao longo da sua execução; (b) a probabilidade de sucesso vai aumentando à medida que o projeto caminha em direção ao seu término; (c) a capacidade das partes envolvidas de influenciar as características finais do produto (ou serviço) do projeto e o seu custo final, é alta no início e vai se reduzindo com o andamento do projeto.

\subsection{TIPO ORGANIZACIONAL ADHOCRACIA}

Adhocracia é um tipo de estrutura montado de forma a ser flexível e capaz de se adaptar a ambientes em mudança acelerada. Como forma orgânica de organização seu principal mecanismo de coordenação é o ajuste mútuo. Este tipo organizacional, Adhocracia, pode ser descrito como a organização de "força-tarefa" que precisa reagir rapidamente a ambientes variáveis. É caracterizada por forças-tarefas multidisciplinares formadas em base temporária, papéis de ligação e integração, e estruturas matriciais (Bowditch \& Buono, 1997). Oferece flexibilidade, pouca formalização, e a tomada de decisões é descentralizada, o que permite amplas capacidades de adaptação.

Cada grupo de projeto tem integrantes das diversas áreas funcionais, mas seu enfoque principal é aquele projeto específico. Freqüentemente um membro da organização tem dois chefes, seu gerente funcional e seu gerente de projeto. Há pessoas com conhecimentos específicos das diversas funções num grupo ou equipe de projeto.

A adhocracia, portanto, permite a integração direta em ambientes turbulentos, onde haja muitas informações a serem processadas.

\subsection{EQUIPES MULTIFUNCIONAIS AUTO-GERENCIÁVEIS}

A adoção das equipes multifuncionais para realização dos trabalhos contábeis é fundamental para o sucesso destas organizações e de seus clientes, na medida em que as tarefas se tornam mais complexas, e habilidades mais diversificadas são necessárias à concretização de um serviço de qualidade. 
Uma equipe de trabalho gera uma sinergia positiva por meio do esforço coordenado. $\mathrm{O}$ uso extensivo das equipes gera o potencial para uma organização aumentar seus resultados sem precisar aumentar as entradas. As equipes de solução de problemas, formadas por grupos de 05 funcionários, que se reúnem algumas horas por semana para discutir formas de melhorar a qualidade, a eficiência e o ambiente de trabalho (Hobbins; 2002, pg.251), porém, não conseguem envolver os funcionários nas decisões e nos processos relacionados com o trabalho. Surgem então as equipes de trabalho auto-gerenciáveis que realizam trabalhos muito relacionados ou interdependentes e assumem muitas responsabilidades de seus antigos supervisores.

Como setor de serviços especializados, isto é, seu produto final tem conteúdo tecnológico e de conhecimento, com recursos humanos altamente especializados, as equipes auto-gerenciáveis induzem à intensa ênfase estratégica na formação e especialização de sua mão-de-obra (Tachizawa \& Scaico, 1997). Seu produto, de altíssimo conteúdo tecnológico e de elevado grau de agregação de conhecimentos especializados, sinaliza a adoção de verdadeiro banco de dados de talentos e a necessidade de armazenar os conhecimentos produzidos para poderem ser reutilizados. Organizacionalmente, acompanha sua estratégia corporativa, que exige uma postura pró-ativa e de gerenciamento interno por projetos, ou de configuração matricial (Tachizawa \& Scaico; 1997, pg.80).

\subsubsection{O MODELO DE GESTÃO}

O envolvimento dos funcionários tornou-se um termo genérico que cobre grande variedade de técnicas, entre elas gestão participativa, democracia no ambiente de trabalho, autonomia (empowerment), etc.

A busca pelo envolvimento dos funcionários, que tem por objetivo estimular um crescente comprometimento das pessoas com o sucesso da organização, são fundamentais para gerar o comprometimento com as novas tecnologias.

\subsection{GESTÃO PARTICIPATIVA}

A principal característica comum a todos os programas de gestão participativa é a utilização do processo decisório coletivo, isto é, os subordinados realmente compartilham um grau significativo de poder decisório com seus superiores. 
A gestão participativa pode ser descrita como um processo no qual os subordinados compartilham um grau significativo de poder de decisão (Robbins; 2002, pg.188). Como técnica de gestão, a gerência participativa tem como um dos aspectos centrais a idéia de participação nos processos de solução de problemas e na tomada de decisões coletivas na organização, e sobre as vantagens decorrentes do modelo o autor comenta:

O raciocínio subjacente em que se baseia esta abordagem é que a participação pode aumentar o conhecimento sobre as atividades organizacionais, a sensação de controle pessoal e confiança por parte da gerência, percepções de satisfação no trabalho e compromisso com a organização, o desempenho e a aceitação das mudanças.

Alguns teóricos defendem que a participação tem efeitos morais (Bowditch \& Buono; 1997, pg.224) e que quando bem desenvolvida e implementada pode aumentar significativamente a produtividade. Neste contexto, a participação é vista muito mais do que simplesmente mais uma ferramenta gerencial. De acordo com esse autor (pg.225) a participação deve ser usada para: “(i) permitir que indivíduos competentes contribuam para decisão; (ii) tratar de abordagens ou pontos de vista conflitantes; ou (iii) obter novas fontes de conhecimento e experiência".

Por outro lado, a gerência participativa (chamada abordagem de envolvimento) tem maior probabilidade de ser eficaz quando: (i) há um grande nível de interdependência entre cargos diferentes; e (ii) o ambiente da organização é dinâmico. Assim, o modelo de envolvimento de um funcionário é mais adequado a trabalhos de tecnologia complexa, como no caso em estudo, a implementação de sistema empresarial integradoSistema Empresarial Integrado - ERP.

\subsection{CONSOLIDAÇÃO DO ESPÍRITO DE EQUIPE}

Embora os benefícios desta abordagem sejam vários, desde uma maior disposição para aceitar a mudança, um bom trabalho em equipe, a melhor qualidade das decisões gerenciais até um maior comprometimento com a organização por parte de todos, há diversas barreiras, características de cada ambiente, que precisam ser vencidas (Bowditch \& Buono; 1997, pg.226), classificadas pelo autor em Barreiras: “(i) da organização, relacionadas a valores e filosofia organizacional; (ii) dos gerentes, hábitos e percepções gerenciais; (iii) dos subordinados, relativas a competência e conhecimento; e (iv) da situação, relativas a tarefas e tempo". 
Um dos componentes essenciais da gerência participativa é fazer com que os empregados colaborem e trabalhem juntos em diversos projetos da organização, principalmente em períodos de mudança. Sejam eles formais ou informais, permanentes ou temporários, esses grupos de trabalho precisam ser capazes de funcionar em conjunto de maneira eficiente e eficaz. Um caminho para facilitar a colaboração e a cooperação entre os membros de um grupo, na opinião de Bowditch \& Buono (1997) é através da consolidação do espírito de equipe ("team building"), um processo através do qual um grupo de pessoas analisa e avalia suas interações com o intuito de melhorar o processo através do qual seus integrantes trabalham em conjunto.

Há quatro categorias principais de metas dos objetivos essenciais das atividades de consolidação do espírito de grupo, sendo que cada uma delas deve ser vista sob a perspectiva do líder da equipe (ou membros individuais), de terceiros (ou do agente de mudança) e dos resultados possíveis (Bowditch \& Buono; 1997, pg.228):

(i) estabelecer diversas metas e / ou prioridades para o grupo; (ii) analisar ou alocar a maneira como o trabalho é realizado; (iii) examinar o modo como o grupo trabalha (seus processos, como normas, tomada de decisões e padrões de comunicação); e (iv) examinar as relações entre as pessoas que estão efetivamente realizando o trabalho.

Em resumo, o espírito de equipe é obtido através de um processo no qual os integrantes do grupo podem (i) desenvolver uma compreensão da natureza da dinâmica do grupo e do trabalho eficaz em equipe, com ênfase especial na relação entre processo e conteúdo; e (ii) aprender a aplicar diversos princípios e habilidades de processos grupais para uma maior eficácia da equipe.

Projetar a estrutura de uma organização é mais do que dar nomes, organizar e preencher os quadros do organograma. Embora relacionamentos hierárquicos claros sejam administrativamente essenciais, a obtenção de produtos e serviços para os clientes exige uma estrutura organizacional que focalize a natureza e o fluxo do trabalho. Para esse fim, a primeira providência é decidir qual trabalho deve ser feito. $\mathrm{O}$ próximo passo é compreender como o trabalho é feito atualmente e projetar como ele deve ser executado. Depois, e somente então, um organograma útil pode ser criado, ou seja, a forma (estrutura) vem depois da função (processos). 
Também se pode dizer que, na medida em que se suportam esses processos, necessita-se do apoio de um conjunto de princípios e de normas de organização. Estes parâmetros relacionam-se com o "desenho" da estrutura organizacional. À função organizar integra-se uma série de aspectos que darão lugar aos correspondentes processos organizacionais ou formas de se realizarem as "rotinas".

O uso adequado dos instrumentos de gestão depende fortemente da compreensão correta e clara sobre os conceitos que the servem de suporte, e a falta desta compreensão é que leva à aplicação isolada e inadequada dos instrumentos e à prática de modelos de gestão desintegrados.

\subsubsection{PROCESSOS}

Nos estudos organizacionais do final da década de 80 , surgiu a idéia de "processo", com o objetivo de maximizar o valor ao cliente. Porém, o termo tem sido empregado sob diferentes conotações, como diversas concepções - organização e métodos ( $\mathrm{O} \& \mathrm{M})$, análise de sistemas ou sobre organizações, podendo, também, referir-se a atividades e / ou tarefas, o que pode causar certa confusão.

Processo pode ser definido como uma série de tarefas ou etapas que recebem insumos (materiais, informações, pessoas, máquinas, métodos) e geram produtos (produto físico, informação, serviço), com valor agregado, usado para fins específicos por seu receptor. Portanto, generalizando esta definição, qualquer tipo de trabalho que uma empresa estiver realizando, na visão de Cury (2000, pg.303), deve integrar um processo.

O termo processo está intimamente ligado ao movimento de reengenharia. Apesar de não se orgulhar muito da forma pela qual muitas empresas fizeram suas respectivas reengenharias, Davenport (2002, pg.132) reafirma sua definição anterior de 1993, da qual gosta muito, definindo:

"Um processo é, portanto, uma ordenação específica de atividades de trabalho no âmbito de tempo e lugar, com um começo, um fim e inputs e outputs claramente definidos: uma estrutura para a ação. Em termos menos formais, os processos podem ser definidos como a maneira pela qual se supõe que determinado trabalho deva ser conduzido em uma organização, (...) o que torna claro que os processos são uma abstração, pois ninguém faz o trabalho o tempo todo exatamente como especificado no projeto do processo".

Existe o projeto do processo e depois vem sua implantação, que pode ser vista como a tentativa de colocar os projetos em prática. 


\subsubsection{ORIGEM DA ABORDAGEM PROCESSOS}

Em meados dos anos 70, a IBM despertou para a necessidade de uma abordagem de planejamento de sistemas, que visualizasse as diversas áreas da empresa de forma integrada, com base nas necessidades do negócio e não de áreas isoladas. Lançou, então, a metodologia BSP - Business System Planning, uma abordagem do planejamento de sistemas voltada para o negócio empresarial e orientada para a alta administração. Existem várias técnicas, descritas na literatura, que derivaram desta abordagem inicial da IBM, tal como o PROPLAN - Programa de Planejamento e o APX - Account Planning Extended . (Cury, 2000).

De acordo com esse autor (pg.304) o APX foi desenvolvido localmente pela IBM do Brasil, em 1976, e tinha como objetivo principal identificar as necessidades de informação da organização-cliente em estudo e estabelecer um plano de desenvolvimento de aplicações e um plano de apoio orientados para satisfação daquelas necessidades.

O APX fundamentava-se em quatro conceitos fundamentais (Cury; 2002, pg.304):

Sistema de informações: é o mecanismo responsável pela coleta, processamento e fornecimento das informações necessárias à administração de uma organização, em todos os seus níveis; Planejar um sistema de informações: significa definir o sistema e traçar um plano para o seu desenvolvimento e implantação; Devido à dinâmica das organizações, sistemas de informações devem ser definidos e desenvolvidos para atender não às necessidades de órgãos ou setores - uma vez que esses podem mudar mas às necessidades dos processos das organizações; Ciclo de vida (movimento) de cada recurso da empresa: planejamento, aquisição, desenvolvimento, uso e extração, permeados por controles e registros; e O conceito de processo como espinha dorsal do APX: Processo representa um grupo lógico de atividades necessárias ao funcionamento da empresa, independentemente dos órgãos executores. Uma vez conhecidos os processos de uma organização, será através das necessidades de informações de cada processo que deverão ser definidos e desenvolvidos os sistemas.

\subsubsection{A VISÃO HORIZONTAL DA ORGANIZAÇÃO}

A estrutura organizacional permite a realização dos fluxos de trabalho através dos processos até que o serviço esteja disponível ao cliente. Para mudar-se a estrutura de modo que o cliente perceba o resultado final, deve-se entender o trabalho e o modo como este flui através dos processos da empresa contábil. O entendimento dos processos constitui-se em uma parte vital da mudança planejada. 
Os estudos organizacionais evoluíram para a visão de sistemas de uma organização, respondendo eficientemente à nova realidade de forte concorrência e de expectativas em mutação dos clientes. Contrariamente às organizações funcionais (verticais), as empresas contábeis modernas deverão ser estruturadas na visão sistêmica (horizontal), que retrata um novo enfoque, exigido pela dinâmica da sociedade atual, forçando-as a melhorar seu desempenho. Para tanto, em princípio, de acordo com Cury (2000, pg.311) devem:

Incluir os ingredientes não evidenciados no organograma - o cliente, o produto e o fluxo de trabalho; Permitir ver a forma como o trabalho é realmente feito por processos, que cortam as fronteiras organizacionais; Mostrar os relacionamentos internos entre cliente e fornecedor, por meio dos quais são produzidos produtos e serviços.

Sob o ponto de vista estrutural, a representação da ação organizacional é feita pelas atividades e processos organizacionais. A descrição das atividades e a sua integração aos processos organizacionais constituem, em parte, um método de análise do comportamento e ação organizacional.

O modelo prescritivo do posto de trabalho, descrito através dos princípios da divisão em tarefas, está sendo substituído, ao longo das últimas décadas, por uma nova concepção de organização do trabalho. Para atender às demandas de um ambiente turbulento, caracterizado pela sua complexidade e dinâmica, as definições associadas ao trabalho evoluíram para um modelo baseado em competências.

\subsubsection{GESTÃO POR PROCESSOS E AS INTERFACES FUNCIONAIS}

Uma das formas modernas de otimizar o sistema empresa é organizá-la por processos, preconizando alguns autores que as empresas nada mais são que um grande conjunto de processos empresariais (Gonçalves, 2000). Esta abordagem decorre da Teoria da Contingência Estrutural, que destaca que não se atinge a eficácia organizacional seguindo um determinado e exclusivo modelo organizacional, ou seja, que não existe uma estrutura organizacional única, que seja eficaz para todas as organizações.

As maiores oportunidades de melhoria do desempenho das empresas estão nas interfaces funcionais, isto é, naqueles pontos em que o bastão é passado de um departamento - ou área funcional qualquer - para outro. 
Sob o ponto de vista dos elementos estratégicos e da configuração organizacional, no sentido da institucionalização do gerenciamento por processos, Tachizawa \& Scaico (1997, pg.82), com relação às empresas de serviços especializados, comentam:

A institucionalização do gerenciamento do processo exige a coexistência pacífica das dimensões vertical (por área funcional) e horizontal de uma organização. Na maioria dos casos, uma estrutura organizacional puramente horizontal (organizada somente em torno dos processos) não é prática, podendo ser mais eficaz quando o pessoal de diferentes funções for agrupado em unidades organizacionais.

Nessas empresas, suas características permitem a criação de verdadeira organização virtual, com a conformação de um núcleo interno de pessoal permanente, associado a equipes externas de pessoal sub-contratado por projetos. (Tachizawa \& Scaico, 1997)

Um processo é repetido de maneira recorrente dentro da empresa. Um critério utilizado para organizar as operações em partes menores constitui o processo. Na visão de Arantes (1998, pg.232) “o critério de organizar por processo é utilizado para reagrupar as partes menores de uma operação no sentido de garantir a coordenação e promover a agilidade e a qualidade, citando como exemplo desse critério o conceito de células".

A um processo se associam: um desempenho (performance), uma organização, uma co-responsabilidade e uma responsabilidade local. A integração das atividades deve ser entendida dentro da realização da estratégia corporativa e identificar horizontalmente a conexão do cliente na rede de atividades. Para a coordenação destas atividades, é necessária a complementação lógica da gestão por processos.

Nesta última década (1990) surgem metodologias de reestruturação organizacionais que visam à contínua melhoria dos esforços despendidos com o negócio. Um novo enfoque chamado melhoria dos processos empresariais (BPR) vem sendo considerado como inovador. Esta metodologia refere-se a uma inovação total na estrutura organizacional e na forma de conduzir o negócio: as dimensões tecnológicas, humanas e estruturais da organização serão mudadas.

\subsubsection{PROJETO E ANÁLISE DE PROCESSOS DE SERVIÇOS}

O projeto de processos de serviços, no âmbito da gestão de operações, está relacionado aos processos operacionais. Os processos operacionais também podem ser 
chamados de processos de transformação, devido à transformação das entradas em saídas As entradas podem ser divididas em recursos transformados e recursos transformadores. Os recursos transformados (materiais, informações e consumidores) são aqueles onde o valor é agregado, mudando de estado durante o processo; enquanto os recursos transformadores (instalações e pessoal) são aqueles que agem sobre os recursos transformados, agregando-lhes valor. As saídas de um processo operacional podem ser bens ou serviços.

A participação do cliente nos processos de serviços contradiz a idéia concebida nos sistemas de manufatura de que as entradas de um sistema de produção deveriam vir apenas de fornecedores externos. Neste sentido Santos (2000, pg.29) esclarece:

\begin{abstract}
Nos sistemas de produção de serviços, os clientes também podem representar entradas para o sistema, participando do início ao fim do processo. As saídas do sistema de operações de serviços representam o resultado do serviço. No entanto, devido à participação do cliente, o serviço também acontece nas interações cliente / empresa ocorridas durante o processo. Assim, a prestação do serviço poderia ser dividida em duas dimensões: o processo e o resultado. A compreensão do conceito de processos leva ao entendimento de sua função no sistema de operações de serviços.
\end{abstract}

FIGURA 15 - A FUNÇAO DOS PROCESSOS NO SISTEMA DE OPERAÇÕES DE SERVIÇOS

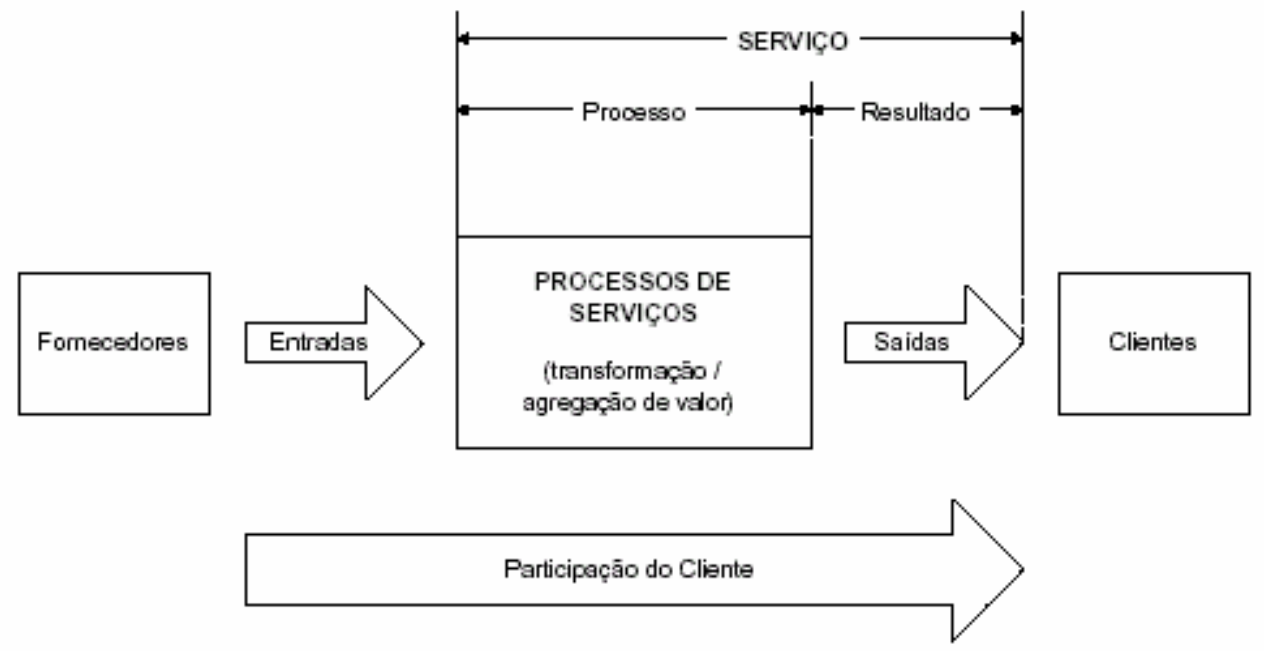

Fonte: Santos (2000, pg..30)

Os recursos transformados definem a natureza do fluxo ao longo do processo, que pode ser de três tipos: fluxo de materiais, fluxo de informações e fluxo de clientes. Confirmando que em grande parte das vezes, o fluxo de clientes é predominante nas operações de serviços, o autor estabelece a diferença entre as operações da seguinte forma, destacando a importância do cliente no processo de serviços (pg.30):

O fluxo de clientes diferencia as operações de serviços das operações de manufatura, pois está diretamente relacionado com a participação do cliente no processo. Devido às particularidades das operações de serviços, considera-se que o foco deste trabalho está 
especificamente no fluxo de clientes ao longo dos processos de serviços e em suas implicações no projeto e análise de processos. (...) no projeto de serviços a sobreposição entre produto e processo nas operações de serviços é maior que nas operações de manufatura e alguns autores chegam a declarar que, em serviços, $o$ processo é o produto. O fato é que o cliente de serviços faz parte do processo de transformação, o que torna difícil a separação entre projeto do produto e projeto do processo. Até mesmo os processos que não envolvem o cliente (processos de retaguarda) se sobrepõem ao "produto", pois dão suporte direto aos processos em que o cliente participa (processos de linha de frente). Assim, o projeto do processo assume uma importância primordial no projeto de serviços, pois é ele que vai determinar a natureza das interações (momentos da verdade) na produção do serviço.

OEste autor pesquisou diversas técnicas (conjunto de procedimentos precisamente descritos para realizar uma tarefa) utilizadas para o projeto e análise de processos de serviços. Através de um elenco de requisitos necessários que deverá ter uma técnica para descrever processos de serviços, Santos (2000, pg.60) elencou 05 requisitos, demonstrado ana figura seguirnte e comparou com as técnicas estudadas, concluindo que com relação as 09 técnicas estudadas, O IDEF3 adaptado atende completamente a quatro requisitos e parcialmente a 1 requisito necessários para projetar e analisar processos de serviços.

TABELA 3 - COMPARAÇÃO DE TÉCNICAS PARA ANALISAR PROCESSOS DE SERVIÇOS

\begin{tabular}{|c|c|c|c|c|c|}
\hline \multirow[b]{2}{*}{ Técnica } & \multicolumn{5}{|c|}{ Requisitos propostos } \\
\hline & $\begin{array}{l}\text { 1. Adequaçäo tanto } \\
\text { para o projeto } \\
\text { quanto para a } \\
\text { analise de processos } \\
\text { de servipos }\end{array}$ & $\begin{array}{l}\text { 2. Descriçás da } \\
\text { expenéencia de } \\
\text { servió do ponto de } \\
\text { vista do cliente }\end{array}$ & $\begin{array}{l}\text { 3. Representaçäo } \\
\text { gráfica beseada em } \\
\text { diagramas }\end{array}$ & 4. Facilidade de uso & $\begin{array}{l}\text { 5. Suporte para a } \\
\text { avaliaçao de } \\
\text { desempento do } \\
\text { processo }\end{array}$ \\
\hline Fluxograma tradiciond & $\bullet$ & 0 & $\bullet$ & $\bullet$ & 0 \\
\hline Service blueprint & $\bullet$ & 0 & $\bullet$ & $\bullet$ & 0 \\
\hline Mapa do serviço & $\bullet$ & 0 & $\bullet$ & $\bullet$ & 0 \\
\hline $\begin{array}{l}\text { Estrutura de processamento de } \\
\text { clientes }\end{array}$ & $\bullet$ & $\mathbf{0}$ & $\bullet$ & $\bullet$ & 0 \\
\hline IDEF $\varnothing$ & $\bullet$ & 0 & $\bullet$ & o & $\mathbf{0}$ \\
\hline Walk-through-audt & 0 & o & 0 & $\bullet$ & $\bullet$ \\
\hline Análise da transaçäo de servico & 0 & $\bullet$ & 0 & $\bullet$ & $\bullet$ \\
\hline IDEF3 adsptado & $\bullet$ & $\bullet$ & $\bullet$ & $\bullet$ & $\mathbf{0}$ \\
\hline $\begin{array}{l}\text { Linguagem de representação para } \\
\text { projeto de processos de serviocs }\end{array}$ & $\bullet$ & $\bullet$ & $\bullet$ & 0 & $\bullet$ \\
\hline - Atende ao requisiti & o & Atende parcialmente & ao requisito & O Nāo atende & 10 requisito \\
\hline
\end{tabular}

Fonte: Santos (2000, pg.61)

O mapeamento do processo do ponto de vista do cliente pode ser feito por uma adaptação do $I D E F 3$, proposta por Tseng et al. (1999) apud Santos (2000). O IDEF3 é mais um integrante da família de técnicas IDEF, desenvolvida pela Força Aérea dos 
Estados Unidos. Os autor citado e outros fizeram algumas simplificações e adaptações para o caso específico das operações de serviços, uma vez que o IDEF3, assim como o IDEF0, foi concebido inicialmente para operações industriais.

Existem dois tipos de diagrama no IDEF3: o diagrama de fluxo de processo e a rede de transição de estado de objeto. Tseng et al. (1999) apud Santos (2000) consideraram somente o diagrama de fluxo de processo e então fizeram algumas modificações. Ao adaptar a técnica, os autores procuraram identificar as atividades em que o cliente participa do processo, dando o nome de "unidades de atuação do cliente" (modificando o nome "unidades de comportamento" do IDEF3 original). Cada unidade atuação do cliente (UAC) é representada por um retângulo preenchido com o nome e número da unidade. O diagrama do IDEF3 adaptado é então elaborado a partir das unidades de atuação do cliente, que correspondem aos momentos da verdade do processo.

Assim, o diagrama mostra somente as atividades de linha de frente. As UAC's obedecem ao mesmo princípio de decomposição hierárquica do IDEF0, podendo ser decompostas de acordo com o nível de detalhamento requerido. A descrição da experiência do cliente começa com um diagrama simples, que abrange todas as atividades do processo no mais alto nível de abstração.

Utilizou-se ao longo da pesquisa uma técnica mista para mapear os processos da empresa contábil, pois as técnicas apresentadas e discutidas devem ser adaptadas ao meio ambiente onde ela irá ser utilizada.

\subsubsection{RELAÇÃO ENTRE OS (SEI) ERPS E OS PROCESSOS}

Existe uma forte dependência entre a implantação de sistema empresarial integradoSistema Empresarial Integrado - ERP com sucesso e a necessidade da implantação da gestão por processos, através do seu redesenho. Comentando a relação entre SEIs e processo, Davenport (2000, pg.133) indaga sobre quais são os atributos dos SEIs que os tornam compatíveis com uma orientação por processo. São vários, a saber:

Os sistemas de gestão proporcionam uma estrutura de trabalho semelhante àquela do processo do pensamento; o fluxo de atividades e informações ao longo da organização é orquestrado pelo sistema;

Os sistemas de gestão são integrados e estabelecem a plena ligação entre as mais variadas funções e sub-processos de negócios; 
Os módulos dos SGEs. correspondem mais ou menos ao modo pelo qual as organizações subdividem seu trabalho entre grandes processos;

Os sistemas de gestão permitem que o desempenho dos processos seja mensurado (especialmente em termos de tempo e de custo) à medida que vão sendo realizados;

Os sistemas de gestão ligam o projeto e a implementação do processo mediante funcionalidades (templates) que orientam uma organização a projetar processos de melhores práticas, para as quais o suporte de sistemas de informações está disponível quando da implantação do sistema resultante;

A documentação dos SGEs e da configuração específica dos sistemas escolhidos por uma empresa exige um determinado nível de conhecimento sobre os processos comerciais dessa empresa; esse nível de disciplina não é muito presente nas empresas antes da implantação de um SGE.

O gerenciamento de processos é muito mais do que os sistemas de informação orientados a processos, esclarecendo o autor citando as conclusões de Michael Hammer sobre a pós-reengenharia, pois inclui: "o gerenciamento e estilos de liderança orientados a processos, as estruturas de avaliação e compensação orientadas a processos, as estruturas organizacionais que refletem a propriedade $e$ o gerenciamento de processos, e muitas outras facetas".

\subsection{MODELAGEM DE PROCESSO}

Uma das formas de aperfeiçoar a compatibilização entre uma empresa e seu SGE ocorre pela utilização da modelagem dos processos e pelas ferramentas de modelagem. Davenport (2000, pg.146) esclarece que a idéia motriz da modelagem é a de que os projetos de processos podem ser criados e manejados a um nível mais alto e de visão mais geral pela utilização de modelos gráficos e interfaces de software interativas. Você projeta o processo ilustrando a maneira pela qual pretende ver o trabalho e a informação fluindo ao longo da organização.

A modelagem de processos pode ser igualmente vista como um veículo para a gestão do conhecimento do processo. A idéia é que o fluxo do processo e a adaptação do projeto do processo ao ERP representam uma forma de conhecimento que deveria ser captada, salva e reutilizada.

\subsection{REDESENHO DE PROCESSO}

A abordagem redesenho de processo faz a ligação entre a melhoria contínua (visão japonesa) e a reengenharia de negócios em escala total (visão americana), representando, assim, na opinião de Cury (2000, pg.317):

(...) a melhor abordagem para a intervenção nas empresas brasileiras, sendo vista como uma estrada intermediária entre os dois extremos, pois nossa cultura empresarial não possui os formidáveis recursos de tecnologia de informação das empresas norteamericanas e nem alguns dos valores próprios da cultura industrial japonesa. 
Entre as diversas metodologias existentes para redesenho de processos, optamos pela estrutura proposta por Ballé e citada por Cury (2000, pg.320), integrada de seis passos, e resumida a seguir, como uma estrutura simplificada para o redesenho de processos:

(i)Encomendar o produto: É o passo inicial: significa colocar-se no lugar do cliente, interno ou externo, para adequada compreensão do que esperar como resultado final, bem como da agregação de valor do processo;

(ii)Esboçar o processo: $\quad \mathrm{O}$ processo deve ser esboçado no seu nível mais alto, para obter-se uma noção da seqüência de atividades envolvidas, e também das pessoas a serem envolvidas na atividade de redesenho;

(iii)Mapear os fluxos de trabalho: $\mathrm{O}$ mapeamento ocorre através da representação de cada tarefa que compõe uma atividade, em elementos que possam ser reposicionados ou reorganizados. Estes elementos devem ser colocados em seqüência, de maneira a visualizar o fluxo atual de trabalho do processo;

(iv)Redesenhar o processo: Tomando como filosofia geral a simplificação, o redesenho visa eliminar retrabalho, reduzir as interfaces e automatizar tarefas;

(v)Verificar e testar: Compreende a validação das propostas de redesenho, envolvendo executores, fornecedores e clientes dos processos em questão;

(vi)Implementar e padronizar: Após a implementação do novo processo, deverá ser realizada uma avaliação pelo ponto de vista dos clientes, que pode evidenciar problemas não previstos anteriormente. Aspectos decorrentes desta avaliação podem ser incorporados ao processo, que poderá então ser concluído.

\subsection{ESTRATÉGIAS E SISTEMAS DE INFORMAÇÃO}

Os sistemas e processos inerentes à organização somente fazem sentido se contribuírem, direta ou indiretamente, à implementação das estratégias definidas para a empresa, que no nível de processo, de acordo com Tachizawa \& Scaico (1997, pg.84) devem observar:

(a) objetivos: identificar os processos mais críticos à estratégia e estabelecer objetivos que descrevam o desempenho exigidos neles;

(b) projeto: autorizar as equipes interfuncionais a encontrarem as interfaces e linhas de interação, internas e externas à empresa, que estejam em redundância, ou faltando em demasia quanto aos processos atuais, e a criarem processos que os aperfeiçoem;

(c) gerenciamento: estabelecer objetivos nas junções críticas do processo, monitorar e aperfeiçoar continuamente o desempenho do processo.

As empresas do setor de serviços especializados têm a possibilidade de implementação de softwares de automação de escritórios, comunicação de dados, ferramentas de produtividade pessoal, cad-cam e editoração eletrônica.

\subsubsection{TECNOLOGIA}

O termo tecnologia já esta devidamente definido na seção 3.2.4 deste trabalho, entendido como uma atividade voltada para a prática, cujo principal objetivo é aumentar a eficiência da atividade humana em todas as esferas. 


\subsubsection{TECNOLOGIA E SISTEMA DE INFORMAÇÃO}

Como entendida neste trabalho a tecnologia afeta virtualmente todos os aspectos da contabilidade e maneira como os contadores atuam. Juntando a tecnologia com a informação, Walton (1998, pg.24) define que:

A tecnologia de informação (TI) abrange uma gama de produtos de hardware e software que proliferam rapidamente, com a capacidade de coletar, armazenar, processar e acessar números e imagens, para o controle de equipamentos e processos de trabalho, e para conectar pessoas, funções e escritórios tanto dentro quanto entre as organizações. (...) A TI de escritório inclui o processamento de textos, arquivamento automático, sistemas de processamento de transações, conferência eletrônica, (...) sistemas de suporte a decisões e sistemas especialistas.

A autor conclui dizendo que a lista tem o objetivo de fornecer uma idéia da diversidade da TI nas organizações.

Numa visão técnica de sistemas, Laudon \& Laudon (1999) utilizando uma abordagem técnica de informática definem os sistemas de informação como "um conjunto de componentes inter-relacionados que coletam (ou recuperam), processam, armazenam e distribuem informação com a finalidade de dar suporte à tomada de decisões e controle em uma organização", auxiliando gestores e trabalhadores a analisar problemas e visualizar soluções em um ambiente dinâmico.

\subsubsection{COMO OS SISTEMAS DE INFORMAÇÃO AFETAM AS ORGANIZAÇÕES}

As organizações adotam sistemas de informação para se tornarem mais eficientes, para economizarem dinheiro e para reduzirem a força de trabalho (Laudon \& Laudon; 2001). Eles se tornaram de vital importância simplesmente para se manter no negócio e podem ser, até mesmo, uma fonte de vantagem competitiva. De acordo com esses autores (pg.61) duas teorias (abordagem) explicam essa relação:

ABORDAGEM ECONÔMICA (...): A TI pode ser vista como um fator de produção que pode ser um livre substituto para capital e trabalho, pois sua aplicação deveria resultar em uma redução do número de gerentes médios e de trabalhadores de escritório na medida em que ela substitui seus trabalhos. A TI também ajuda as empresas a diminuir em tamanho porque ela pode reduzir os custos de transação. De acordo com a teoria de custos de transação, empresas e indivíduos buscam economizar em custos de transações mais do que fazem com os custos de produção. A TI também pode reduzir os custos administrativos internos. De acordo com a Teoria dos agentes a empresa é vista como "nexos de contratos" entre indivíduos com interesses particulares em vez de como uma entidade unificada, de maximização dos lucros. Um diretor (proprietário) emprega "agentes" (empregados) para executar trabalho de seus interesses. Todavia, os agentes necessitam de constante supervisão e 
gerenciamento, pois de outra forma eles tenderiam a seguir seus próprios interesses em vez daqueles dos proprietários.

ABORDAGEM COMPORTAMENTAL (...): As teorias comportamentais desde sociologia, psicologia e ciência política são mais úteis para descrever o comportamento individual das empresas. As pesquisas comportamentais encontram pouca evidências de que os sistemas de informação automaticamente transformam as organizações, embora possam ser os instrumentos de realização desta meta. Em vez disso, pesquisadores observam um relacionamento intrinsecamente coreografado em que organizações e TI influenciam-se mutuamente.

O entendimento desses autores confirma a visão de Walton (1998) através do triangulotriângulo estratégico.

Esses pesquisadores teorizam que a TI poderia mudar a hierarquia da tomada de decisão nas organizações baixando os custos de obtenção da informação. A TI poderia trazer informação diretamente de unidades operacionais para os gerentes seniores, eliminando desse modo os gerentes médios e seus funcionários de apoio.

Nas sociedades pós-industriais, a autoridade se baseia cada vez mais em conhecimento e competência, e não em mera posição formal. Conseqüentemente, a forma das organizações deveria ser "enxugada", visto que os trabalhadores profissionais tendem a se auto-gerenciarem; e a tomada de decisão deveria se tornar mais descentralizada, na medida em que conhecimento e informação se tornam mais comuns por toda a parte (Drucker, 1988).

Após apresentar uma visão geral da TI e seu relacionamento com a organização, passa-se a desenvolver o principal objetivo deste tópico, que é apresentar um entendimento da relação existente entre o sistema empresarial integradoSistema Empresarial Integrado - ERP e o sistema de informações contábeis integrados, como a principal ferramenta tecnológica para uma empresa, inclusive suprindo as necessidades das empresas contábeis e das suas empresas-cliente. A aplicação desses sistemas integrados pelas empresas contábeis pode trazer uma série de mudanças na missão dessas empresas e na sua forma de atuar.

\subsubsection{SISTEMA DE INFORMAÇÃO CONTÁBIL}

De acordo com MOSCOVE, SIMKIN, BAGRANOFF (2002, pg.24) o sistema de informações contábeis (SIC) "é o subsistema de informações dentro de uma organização que acumula informações de vários subsistemas da entidade e comunicaas ao subsistema de processamento de informações". Os SICs. hoje trabalham tanto com dados e informações financeiras quanto com não financeiras. 
Um sistema de informação contábil é uma estrutura unificada dentro de uma entidade, tal como uma firma, que emprega recursos físicos e outros componentes para transformar dados econômicos em informação contábil, com o propósito de satisfazer as necessidades de informação de vários usuários.

As três características principais dos sistemas de informação contábil são: (1) Apoiar as operações do dia-dia - para que possa operar no dia-dia, uma empresa realiza um número de eventos chamados transações. As transações contábeis incluem eventos ou transações que representam trocas que tenham valor econômico; (2) Apoiar a tomada de decisão por tomadores de decisão internos - um propósito igualmente importante é fornecer informação para a tomada de decisão; (3) Cumprir obrigações relacionadas à administração - toda empresa deve preencher suas obrigações legais.

O foco dos sistemas de informações contábeis nos processos empresariais permite que as organizações repensem totalmente esses processos, fazendo a reconstrução desses processos desde a base tornado-os eficazes, pois com a visão sistêmica da contabilidade. Ora, "na era da informação os sistemas de informação contábil estão menos preocupados com a contabilização das transações - que ocorre naturalmente, e mais preocupados com os eventos de negócios”. (MOSCOVE, SIMKIN, BAGRANOFF, 2002).

Neste sentido, os autores concluem que o Sistema de informação contábil é:

(...) um sistema de informações que cobre a empresa toda, concentrando seu foco nos processos de negócios, ligando a visão tradicional dos sistemas de informações gerenciais com a contabilidade e utilizando-se da TI em todos os seus aspectos, integrando suas funções em um grande e indivisível banco de dados que permite aos usuários internos ou externos obter as informações que necessitam dentro do seu modelo de decisão.

Na visão de RICCIO (1989, pg.14), “(...) Sistema de Informação é um conjunto de subsistemas que atuam coordenadamente para, com o seu produto, permitirem às Organizações o cumprimento de seus objetivos principais". O autor esclarece seu conceito explicando que o termo "Sistema" traz dentro de si o conceito de conjunto, de processo, de grupos de elementos, sendo portanto um exercício de lógica pois contém uma noção que é mais "percebida" do que "vista". 


\subsubsection{SISTEMAS EMPRESARIAIS INTEGRADOS (SEI) - ERP}

Os Sistemas Empresariais Integrados - ERP (Enterprise Resources Planning), como definidos por Davenport (2002, pg.18) "são pacotes aplicativos de computador que dão suporte à maioria das necessidades de informação de uma empresa". A denominação ERP é um reflexo da origem desse sistema na área de produção - trata-se de uma modificação de MRP - (planejamento de recursos de manufatura), mas, esses sistemas transcenderam de tal maneira as suas origens que a denominação de ERP talvez tenha deixado de ser adequada, porém é utilizado neste trabalho pois é o nome comercialmente consagrado.

Por tanto, neste trabalho usaremos expressão Sistema Empresarial IntegradoSistema Empresarial Integrado (SEI) - ERP como sinônimo de sistema de gestão empresarial integrado e SICi como Sistema de Informação Contábil Integrado. A sigla ERP está sendo mantida, pois, foi consagrada pelo mercado como sinônimo de sistema integrado, apesar da concordância existente com a posição de Davenport (2002) expressa no parágrafo precedente.

O SEI pode constituir o único sistema de informação de negócios indispensável a uma empresa, pois proporciona informação em um formato que todos - e não apenas os tecnólogos - têm condições de entender. Podem ser vistos, de acordo com Riccio (2001) "como uma evolução natural das soluções oferecidas pela tecnologia de informação para os problemas de controle e gestão de uma empresa”.

\subsection{INTEGRAÇÃO: NOÇÃO CHAVE DO SISTEMA ERP} ADVINDA DA CONTABILIDADE

De acordo com Colangelo Filho (2001, pg.17) não há uma definição precisa e inquestionável do que seja um "sistema ERP". Para ele, representa um software aplicativo que permite às empresas:

\footnotetext{
Automatizar e integrar parcela substancial de seus processos de negócios, abrangendo finanças, controles, logística (suprimento, fabricação e venda) e recursos humanos; Compartilhar dados e uniformizar processos de negócios; Produzir e utilizar informações em tempo real.
}

Este autor esclarece que a noção chave dessa definição é integração, isto é, o intercâmbio de dados ocorre de maneira natural. Este procedimento chama-se de integração original, que ocorre quando os módulos ou sistemas de um conjunto ou 
pacote são concebidos segundo um mesmo módulo conceitual e tecnológico. Apesar da maioria dos autores não citar nem evidenciar a origem de tal noção chave, conforme Riccio (2001, pg.55) concluiu através de sua pesquisa sobre o surgimento do $\mathrm{SAP}^{1}$, deve-se ao sistema de informações contábeis e sua lógica sistêmica essa capacidade de sincronismo e integração.

Sobre o módulo contábil, o autor (pg.66) comenta:

(...) a centralização e convergência de transações dos demais sistemas para o sistema de informações contábeis, obedece à sua característica natural a de ser um sistema consolidador. Essa característica é denominada natural pois é inerente ao modelo contábil. Significa que para qualquer evento que ocorra na empresa e que gere uma alteração no patrimônio, deve existir um registro correspondente nas contas respectivas, indicando pelo método da partida dupla, a conta de origem e a de destino. Assim, em qualquer ponto no espaço e no tempo em que ocorrer o evento, o registro contábil deve ser feito. Essa forma de registro confere à contabilidade uma característica explícita de instrumento de controle único para toda a empresa e que por essa razão é uniformizador, centralizador e consolidador.

O SEI são geralmente dividido em módulos - que se comunicam e atualizam uma mesma base de dados central e são adquiridos na forma de um pacote de software comercial. De acordo com Laudon \& Laudon (2001, pg.16) o software ERP “modela e automatiza muitos processos básicos, como o preenchimento de um pedido ou a programação de uma remessa, com o objetivo de integrar a informação em toda a empresa e eliminar ligações complexas e caras entre sistemas de computador em áreas diferentes de negócio".

Resgatou-se essa definição destes autores, que tem uma visão eminentemente técnica da área de informática, pois denota uma grande preocupação com a questão de "ligações complexas e caras" entre sistemas, evidenciando o que ocorre no mercado quando os sistemas empresariais integrados são desenhados e desenvolvidos sem um profundo conhecimento da área contábil, ou sem a participação de um profissional desta área.

Uma vez definido o que seja ERP, agora serão abordados os seus benefícios para as organizações.

\footnotetext{
${ }^{1}$ SAP ( Systeme, Anwendungen und Produkte in Datenverarbeitung) companhia Alemã que lançou o R/2 em 1978, considerado o primeiro ERP a ser lançado (Riccio; 2001 pg.63)
} 


\subsection{BENFÍCIOS ADVINDOS DA IMPLEMENTAÇÃO DE UM ERP COM SUCESSO}

São muitas, e variadas, as maneiras pelas quais uma organização pode beneficiar-se com os ERPs. De acordo com Davenport (2002, pg.76) os benefícios podem ser agrupados em três categorias diferentes:

(i) ECONOMIAS A PARTIR DE NOVAS ABORDAGENS DO TRABALHO: Automação de tarefas antes realizadas por humanos; Racionalização de dados, ou seja, não precisar mais equiparar e agregar definições e valores diferentes para a mesma unidade ou informação; Mudança de processos, considerados a parte central dos benefícios que justificariam, por si só, sua adoção; Mudanças organizacionais; Enxugamento de recursos ociosos. (ii) ECONOMIAS A PARTIR DO DESMANTELAMENTO DE SISTEMAS LEGADOS: Necessidade de mudanças obrigatórias e constantes nos sistemas atuais; Upgrades nos sistemas legados e do suporte a vários sistemas; Não ser mais necessário construir sistemas inteiros específicos; (iii) ECONOMIAS A PARTIR DA MELHORIA DO RENDIMENTO: Aperfeiçoamento dos serviços aos clientes; Facilidade de expansão e crescimento; Melhores decisões.

\subsubsection{BENEFÍCIOS DA IMPLEMENTAÇÃO DE UM ERP NAPARA A EMPRESA CONTÁBIL}

A implantação e utilização de sistemas empresariais integrados - ERP pela empresa contábil com benefícios para a empresa cliente, objeto do presente estudo, requer a mudança na arquitetura organizacional da empresa contábil, proporcionando ganhos significativos de produtividade e diversificação da atividade do contador organizado em empresa.

Apesar da forma de atuação ser diferente entre os contadores que atuam em uma organização única e aqueles que atuam na empresa contábil, muito mais em função do tamanho do negócio do que propriamente em termos de missão e responsabilidades, para os profissionais e a área contábil - e neste caso para a empresa contábil, é possível apontar as seguintes vantagens ao se utilizar um sistema integrado, de acordo com Peleias \& Parisi (2001, pg.5):

(i) propiciar a descentralização da execução dos registros contábeis, pois estas ferramentas contabilizam automaticamente a maioria das transações que afetam o patrimônio e os resultados de uma empresa; (ii) permitir a ampla utilização do conceito de razão ou sistema auxiliar (contas a receber, contas a pagar, imobilizado, estoques), com a segurança de que os valores registrados nos vários módulos componentes do sistema estão perfeitamente correspondidos na contabilidade geral; (iii) possibilitar que a empresa tenha a contabilidade de custos perfeitamente integrada e coordenada com a contabilidade geral. Alguns sistemas integrados incorporam o conceito de custo padrão, e prevêem formas de tratar as variações resultantes da comparação real x padrão, possibilitando a plena utilização dos padrões para avaliação 
da eficiência operacional e otimização das atividades empresariais, ao mesmo tempo em que permitem atender às determinações fiscais que regulamentam a utilização dos custos padrão; (iv) contemplar os aspectos de controle interno e de natureza fiscaltributária inerentes às etapas e fases componentes dos ciclos de transações. Na medida que a empresa utiliza uma ferramenta de informática desta natureza, a realização de todas as suas atividades passa por uma avaliação se as mesmas serão ou não executadas através do sistema integrado. Esta abordagem leva à necessidade de considerar todos os aspectos relativos à execução operacional, notadamente os contábeis, fiscais e de controle interno; (v) permitem reduzir os prazos de fechamento mensal e de obtenção das demonstrações contábeis. Ao diminuir o tempo dispendido no registro e processamento de informações para elaboração das demonstrações contábeis, o contabilista pode atuar de forma mais próxima aos gestores de todas as áreas da empresa. É uma excelente oportunidade para se conhecer a "intimidade" dos negócios, e identificar o mais claramente possível os diversos modelos de decisão utilizados pelos gestores das várias áreas da empresa, para que se possa fornecer as melhores informações a serem utilizadas como subsídio aos vários processos decisórios.. Em alguns sistemas, assim que você realiza uma transação, o razão é automaticamente atualizado. Consequentemente, os contadores gerenciais dispendem menos tempo preparando relatórios e mais tempo analisando e interpretando informações. Desta forma, muitos contadores gerenciais estão se transferindo dos departamentos de contabilidade para o coração da empresa - os departamentos de operação e de produção. Os contadores gerenciais do novo milênio trabalham em equipes, interagindo de forma pessoal com todos os níveis da organização, e assessoram a alta administração.

Os referidos autores, no mesmo artigo (pg.7) relacionam um conjunto de fatores que demonstram a importância da participação do contador (nesse caso a empresa contábil) deve participar ativamente do projeto de implantação e de mudança organizacional decorrentes da adoção do ERP:

(a) a atividade contábil possui estreito relacionamento com todas as áreas nas quais ocorrem decisões que afetam o patrimônio e os resultados da empresa, e o contabilista é um profissional que precisa deter a visão integrada dos negócios e das atividades. Este relacionamento pode ser demonstrado pelo fato de que os aspectos contábeis, fiscais e de controle interno inerentes às diversas atividades realizadas na empresa devem ser reconhecidos e considerados na origem das transações; (b) existem aspectos de natureza fiscal e tributária relativos às transações de compras e vendas, que precisam sem claramente identificados e tratados, para que a empresa não incorra em contingências fiscais ou fique exposta a sanções por parte dos órgãos fiscalizadores, nas esferas federal, estadual ou municipal; (c) os sistemas integrados permitem efetuar os registros contábeis e fiscais das transações que afetam o patrimônio e os resultados de uma empresa. Para tanto é necessário considerar os requisitos para que estes registros sejam feitos de forma adequada, no momento em que as parametrizações estiverem sendo realizadas; (d) é preciso considerar os aspectos de controle interno incorporados à ferramenta de informática e aqueles que precisam existir no ambiente externo ao sistema, para que as transações sejam realizadas com adequado grau de segurança e salvaguarda ao patrimônio da empresa; (e) por força de suas atividades, o contabilista possui conhecimento sobre os negócios e atividades da empresa, e pode trazer contribuições significativas para o sucesso do projeto. Também é uma excelente ocasião para se conhecer melhor a "intimidade" dos negócios, permitindo novas contribuições e o aumento da qualificação profissional do contabilista.

Durante a pesquisa em muitos momentos o grupo se perguntou por que implantar um ERP na empresa contábil? E quais os benefícios efetivos para a empresa cliente? Ora, em resumo, os benefícios para a empresa contábil serão, no mínimo, os 
mesmos que os benefícios da área contábil das grandes empresas, resumidos acima e ainda, tanto para esta como para a empresa cliente, os relacionados por Riccio (2001, pg.56-57) citando pesquisa de Kale (2000) no estudo sobre as empresas que aplicaram o ERP da empresa SAP, agrupados em:

GERAIS - AQUELES QUE ATUAM SOBRE O SISTEMA EMPRESA: 1. Transforma a empresa em uma empresa "informatio-driver", ou seja, guiada pela informação; 2. A empresa é percebida como uma empresa global - um único sistema; 3. Reflete e reproduz a natureza integrada de uma empresa, favorecendo o MBC; 4. Reproduz uma empresa orientada a processos; 5. Viabiliza a empresa em tempo real; 6. Posiciona a estratégia de TI como parte da estratégia global da empresa; 7. Representa um avanço nas tecnologias de melhoria do desempenho empresarial.; 8. Representa um novo modelo para implementação de sistemas computadorizados; 9. Cria um ambiente totalmente voltado aos usuários do sistema.

ESPECÍFICOS - ONDE SE DESTACAM A AÇÃO MAIS PONTUAL DOS ERPS: 1. Reconcilia e otimiza os objetivos conflitantes das diferentes divisões da empresa; 2. Padroniza os processos das empresas, aumentando sua eficiência; 3. Provê a habilidade de conhecer e implementar melhores práticas globais; 4. Provoca a mudança de uma empresa orientada a funções para uma empresa voltada a trabalho em equipe, inter-funcional, orientada a processo, mais flexível, fortemente integrada; 5. Provê um instrumento que abrange várias alternativas em programas e metodologias de melhoria de processos incluindo inovação, melhoria de processos, processos de negócio. Comtém todas as facilidades para implementação do Balanced Scorecard; 6 . Provê um instrumento para melhoria da qualidade e padronização de esforços, incluindo controle de qualidade, análise de qualidade e Total Quality Management TQM; 7. Oferece meios para mensuração de benefícios gerados para a organização monitorando o ROI - Retorno sobre Investimento por meio de vários parâmetros, monetários e não monetários; 8. É orientado a processos e, portanto, um instrumento poderoso para a implementação do ABM - Activity Based Managent, seja para custos, orçamento, eficiência ou qualidade; 9. Implementa práticas do tipo "best in class"melhores práticas - e oferece meios para a execução de "benchmarking"; 10. Permite a criação de dados em tempo real, durante a transação, diretamente pelos responsáveis pelas atividades; 11. Permite que os envolvidos no controle operacional acessem os dados necessários para decisões rotineiras oferecendo a cada um um maior conhecimento e domínio sobre as atividades; 12. Integra todos os dados da empresa em um único banco de dados, garantindo a integração entre os sistemas e todos os usuários; 13. Dá acesso online a dados corretos e atualizados, sejam financeiros, de vendas, logística, produção, recursos humanos, etc; 14. Cria um abrangente conjunto de dados detalhados, atualizados, consistentes e completos, que podem ser utilizados eficazmente no sistema de informações gerenciais da empresa; 15. Reduz drasticamente os custos de manutenção de sistemas.

Os benefícios da implementação dependem ainda das mudanças nos sistemas técnicos e sociais e da abordagem utilizada na implementação. Entre os fatores que levam uma empresa a implantar um ERP podem ser destacados os fatores na dimensão negócios (estratégico e operacional), legislação (adequação as normas tributárias e legais) e tecnológicos (mudanças no ambiente de TI). Na empresa contábil sem o uso de sistema integrado as empresas clientes, grande parte do esforço empreendimento refere-se ao registro de transações recorrentes e repetitivas, partindo da premissa 
verdadeira que grande parte dos processos empresariais são recorrentes, isto é, repetem-se mensalmente em aproximadamente $95 \%$ dos casos.

Sobre as influências dos ERPs na contabilidade Riccio (2001) conclui que o contador passa a controlar todo o processo de parametrização e de decisão sobre a estrutura de contabilização da empresa, passando adicionalmente, o conhecimento contábil a ser distribuído por todos os setores expandindo a contabilidade e o domínio do seu conhecimento.

Destaque-se que o ERP para a empresa contábil pode propiciar uma nova arquitetura tecnológica, observada e desenvolvida ao longo da pesquisa e discutida nos seus resultados no capítulo $\mathrm{V}$, e que esta arquitetura pode propiciar vantagens em termos de custo de propriedade (TCO) para a empresa cliente, principalmente porque a empresa contábil estará interagindo (on-line) com a empresa cliente e possibilita trabalhar com multi-empresas.

\subsection{LIMITAÇÕES NA ADOÇÃO DA SOLUÇÃO ERP}

Geralmente a literatura da maior destaque aos benefícios relativos a implementação de uma solução ERP do que nas dificuldades que as empresas terão que enfrentar. Essas dificuldades estão relacionadas principalmente com as questões inerentes aos processos de mudanças tecnológicas e organizacionais e seus impactos sobre as pessoas. É nítido que continua a ver-se a implementação de um ERP como um fim em si mesmo, como uma panacéia que resolve todos os problemas da organização, não se dedicando o tempo e o esforço suficientes para, num primeiro momento, analisar e avaliar as implicações estratégicas e operacionais da implementação do sistema e, posteriormente, lançar efetivas ações de otimização de processos e de integração organizacional, que venham, estas sim, a demonstrarem-se como verdadeiramente geradoras de vantagens competitivas.

Entre as regras fundamentais que não devem ser negligenciadas, destacam-se: (i) Investir tempo, recursos e esforços no Planejamento (anteprojeto, projeto e Implementação); (ii) Contratar os mais experientes consultores, neste caso, da empresa contábil; (iii) Envolver os gestores da empresa-cliente no projeto e sua equipe; (iv) Integrar a tecnologia com a estratégia de negócios; (v) Preparar a organização para a implementação e para a mudança efetiva, gerindo adequadamente esse processo 
crítico; (vi) Criar métricas que permitam avaliar o desempenho e não se esquecer que o objetivo final é aumentar lucros e participação de mercado, em resumo, o crescimento da empresa.

As limitações para adoção do ERP são mais relacionadas com o processo de implementação, pois requer a administração do processo de mudança que vai refletir numa alteração de toda a arquitetura organizacional. Neste sentido, o processo crítico é lidar com as resistências das pessoas às mudanças. Não há dúvidas que as pessoas possuem uma resistência "inata" à mudança, e que esta pode se manifestar de diversas formas. Em geral os autores consideram as greves e redução da produtividade formas explícitas de resistência à mudança. Já o aumento do absenteísmo, solicitações de transferências, resignações, perda da motivação do trabalho, "erros mentais" e impontualidade no trabalho são considerados, por outros autores, indicações de resistência implícita. Tratar de resistência é importante, pois mesmo informalmente ela guia o comportamento e influencia as ações tomadas pelos gestores e analistas de sistemas envolvidos na implementação do ERP.

De forma explicita Souza \& Zwicker (1999) relatam algumas problemas que podem ser observados na adoção de tais sistemas, mas que podem ser entendidos, de outra forma, como oportunidade para melhorias, destacando-se os seguintes: (i) Dependência do fornecedor pois a empresa não detém o conhecimento sobre o pacote; (ii) necessidade de customização do sistema e adequação dos processos empresariais a nova tecnologia; (iii) mudança cultural para a visão de processos; (iv) necessidade de consultoria interna e externa; (v) mudança cultural do "dono da informação" para o responsável pela informação; e talvez o que poderia ser o mais grave, porém, as equipes de TI tem solução para isso e o mesmo ocorreria com sistemas legados que é (vi) se o sistema falhar toda a empresa pode parar.

\subsubsection{OPÇÃO DECISIVA NA IMPLEMENTAÇÃO DO SEI - ERP}

As potencialidades oferecidas atualmente pelas tecnologias da informação implicam que não mais seja possível encarar os sistemas de informação apenas na perspectiva ultrapassada de meros sistemas de suporte aos processos do negócio.

Neste sentido, sistema empresarial integradoSistema Empresarial Integrado ERP pode ser implantado por razões técnicas ou visando ao aperfeiçoamento da 
estratégia e da competitividade (Davenport, 2000). Uma implementação estratégica tem por objetivo maximizar o potencial positivo das mudanças e o valor dos negócios.

Na verdade, quando você pensa em mudar uma ampla gama de processos, melhorar a maneira pela qual se relaciona com os clientes e fornecedores, criar uma nova cultura organizacional e modificar o procedimento da maioria dos funcionários, isto representa algo que vai tomar realmente muito tempo.

Davenport (2002, pg.13) é enfático quando diz:

Sou um pesquisador e consultor que trabalha sempre no cruzamento dos sistemas de informação com o comportamento e a mudança organizacionais, (...) os sistemas de informações são inúteis a menos que proporcionem melhores informações ou melhores métodos de se fazer negócios. O que é realmente importante - e difícil - com relação a esses sistemas é a drástica mudança que eles representam para um negócio. Uma implementação bem sucedida envolve: mudança tecnológica, mudança nos negócios, na cultura e na estrutura organizacional, no comportamento dos trabalhadores e até mesmo nas estratégias de negócios.

Walton entende que a estruturação da informação e os sistemas de informações são tão importantes que a TI é fator determinante na competitividade da empresa, já que, além de sua utilização como elemento-chave na administração dos recursos, a política de TI equipara-se, em nível estratégico, com o papel da definição dos negócios e da própria organização. O Autor coloca a TI no que ele denomina de "triângulo estratégico". O Triângulo estratégico é composto por: estratégia de negócios, estratégia da organização e estratégia de TI. Na visão de Walton, cada uma das estratégias influi nas demais, de forma inter-relacionada.

WALTON (1998, pg.14) propôs uma teoria sobre a eficácia do processo de implementação de tecnologia de informação. Sua teoria se apóia essencialmente na segmentação do processo de implementação em três fases:

criação do contexto para TI, desenho do sistema TI e introdução, operação e difusão. E depende crucialmente de: (i) gestão adequada: promover o alinhamento entre as estratégias de negócios, tecnologia e organização; (ii) alto comprometimento organizacional, suporte dos líderes e aceitação do sistema; e (iii) forte competência, no geral, e domínio da TI pelos usuários, em particular.

Em resumo, a conexão entre a implementação da tecnologia de informação e mudança organizacional é imutável. 


\subsubsection{METODOLOGIA DE IMPLANTAÇÃO SEIISTEMAS EMPRESARIAIS INTEGRADOS - ERP}

Os sistemas empresariais integrados - ERP podem ser vistos como um grande sistema de informações, englobando o sistema de informações contábeis. O ERP tem o potencial necessário para ser um grande sistema de informações da empresa contábil com possibilidade de adequação a variáveis tanto internas quanto externas atendendo às características de um sistema por feedback de terceira ordem citado por $\mathrm{Wu}$ (1983) apud Pereira (2002, pg.97) pois auxilia os gestores em todas as fases do processo decisório.

Sua implantação com sucesso pode seguir o modelo do ciclo de vida de um sistema que é um plano detalhado identificado todas as tarefas relevantes e a quem cada uma será designada - indivíduos, grupos internos ou externos a empresa. Essa metodologia segue a lógica da administração de projetos e como tal deve ser encarado, sendo que para cada tarefa é necessário definir as datas de inicio e fim, a ordem de execução e os limites do projeto como um todo, sendo organizadas e categorizadas numa seqüência lógica de execução.

Percebe-se que não existe um padrão universal para as fases do ciclo de vida. Utilizaremos neste trabalho a abordagem proposta por Walton (1998) que resume fielmente todo o processo de desenvolvimento e implementação de um sistema de informações. As três fases propostas por ele podem ser comparadas com o ciclo de vida tradicional, descrito por Turba et al (2001, pg.605) apud Pereira (2002)que considera que o ciclo de vida de um sistema pode ser desenhado em oito fases de acordo com a figura seguinte16:

Seguindo-se a teoria proposta por Walton $(1998,15)$, e que embasa esta pesquisa, pode-se dizer que a primeira fase de Walton (criação de um contexto de TI) pode ser desmembrada nas duas primeiras etapas do ciclo de vida da figura acima; a segunda fase (desenho de um sistema de TI) pode ser relacionada às etapas 3 (análise lógica e projeto) e 4 (aquisição ou desenvolvimento); e a terceira fase (instalação do sistema de TI para utilização) é aquela onde se inicia a implementação (etapa 5 em diante) e posterior operação. Observa-se que os conceitos estão alinhados com o 
objetivo de garantir que a implementação de uma nova tecnologia de informações obtenha o sucesso esperado do projeto quando do seu planejamento.

\section{FIGURA 16 - CICLO DE VIDA DE SISTEMAS}

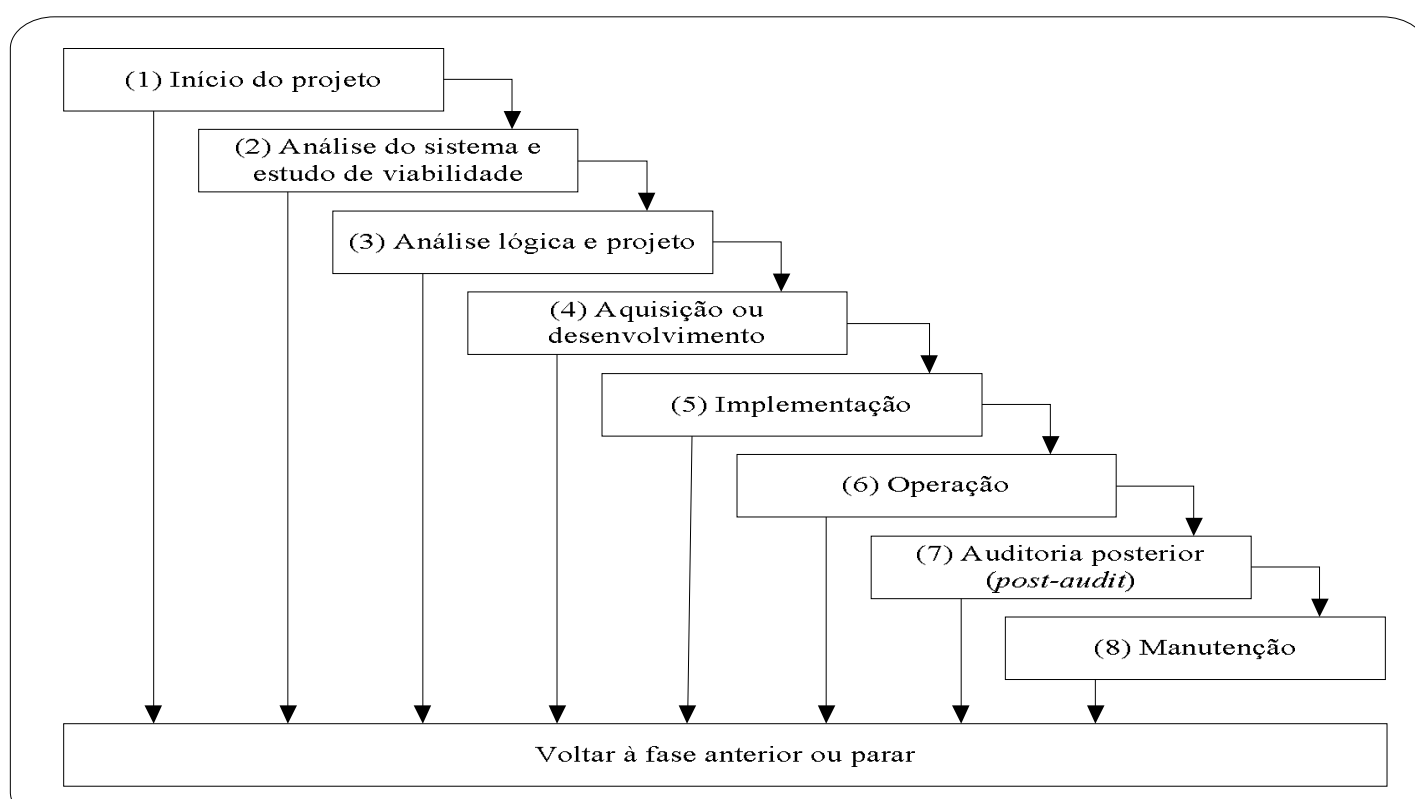

Fonte: Turba et al (2001, p.605) apud Pereira (2002)

Seguindo-se a teoria proposta por Walton (1998, pg.15), e que embasa esta pesquisa, pode-se dizer que a primeira fase de Walton (criação de um contexto de TI) pode ser desmembrada nas duas primeiras etapas do ciclo de vida da figura acima; a segunda fase (desenho de um sistema de TI) pode ser relacionada às etapas 3 (análise lógica e projeto) e 4 (aquisição ou desenvolvimento); e a terceira fase (instalação do sistema de TI para utilização) é aquela onde se inicia a implementação (etapa 5 em diante) e posterior operação. Observa-se que os conceitos estão alinhados com o objetivo de garantir que a implementação de uma nova tecnologia de informações obtenha o sucesso esperado do projeto quando do seu planejamento.

Walton (1998) propôs uma teoria a respeito da integração da TI e a organização concluindo que a eficácia da implementação depende crucialmente de: (i) gestão adequada, isto é, um alinhamento entre as estratégias de negócios, tecnologia e organização; (ii) alto comprometimento organizacional, suporte dos lideres e aceitação do sistema; (iii) forte competência, em geral, e domínio dos usuários, em particular, concluindo que esses ingredientes adquirem crescente especificidade à medida que a 
implementação progride e que o comprometimento e a competência necessitam ser convertidos em aceitação e domínio pelos usuários. Eis aí uma condição crucial para o sucesso na implementação dos sistemas empresariais integrados - ERP que foram encontradas por esta pesquisa e que estão sendo analisados como contribuição ao corpo de conhecimentos no capítulo VI.

Todas essas fases serão detalhadas no projeto de mudança organizacional impulsionada pela implementação da tecnologia de sistema ERP.

\subsubsection{PESSOAS E A ORGANIZAÇÃO QUE APRENDE}

Aquilo que a TQM representou nos anos 80, e a reengenharia no início da década de 90, corresponde hoje à organização que aprende. Este conceito se tornou o principal foco de interesse dos administradores e dos cientistas organizacionais que buscam por novas formas de responder com sucesso a um mundo de mudanças e interdependência.

Uma organização que aprende é aquela que desenvolve uma capacidade de mudar e se adaptar continuamente (Robbins, 2002). Da mesma forma que as pessoas, as organizações também podem aprender, o autor comenta (pg.545):

Muitas organizações se engajam naquilo que costuma ser chamado de aprendizado em circuito simples. Quando ocorrem erros, o processo de correção se baseia nas rotinas prévias e nas políticas vigentes. Em contraste, as organizações que aprendem utilizam o aprendizado de circuito duplo. Quando um erro é detectado, ele é corrigido de maneira que envolva modificações nos objetivos, nas políticas e nas rotinas padronizadas da organização.

Como a mudança de segunda ordem, isto é - uma modificação multidimensional, multinível, descontínua e radical, envolvendo a redefinição das convicções sobre a organização e o mundo no qual ela se insere, - "o aprendizado em circuito duplo desafia convicções e normas profundamente arraigadas dentro da organização” (Robbins; 2002, pg.545).

\subsubsection{CARACTERÍSTICAS: A ORGANIZAÇÃO QUE APRENDE}

Uma organização que aprende possui cinco características básicas, definidas por Peter Senge no livro a quinta disciplina (1990), e apresentadas por Robbins (2002, pg.546) a seguir:

Existe uma visão compartilhada, com a qual todos concordam; As pessoas abrem mão de suas velhas idéias e rotinas padronizadas que utilizam para solucionar problemas ou realizar seu trabalho; As pessoas pensam em todos os processos, atividades, funções 
organizacionais e interações com o ambiente como parte de um sistema de interrelacionamentos; As pessoas se comunicam abertamente (vertical e horizontalmente), sem medo de críticas ou punições. As pessoas sublimam seus interesses pessoais e de seus departamentos fragmentados em prol do trabalho conjunto para alcançar a visão compartilhada da organização.

Essa é uma organização onde as pessoas abrem mão de suas velhas idéias, aprendem a ser abertas uma com as outras, compreendem como sua organização realmente funciona, formam um plano ou visão com a qual todos concordam e depois trabalham em conjunto para conquistar essa visão. Essas cinco disciplinas são programas permanentes de estudo e prática que levam ao aprendizado organizacional e contínuo das pessoas, resumidas nos seguintes aspectos (Senge et al, 2000):

A primeira disciplina é o dominio pessoal. Significa aprender a expandir as capacidades pessoais para obter os resultados desejados e criar um ambiente empresarial que estimule todos os participantes a alcançar as metas escolhidas.

A segunda disciplina, modelos mentais, consiste em refletir, esclarecer continuamente e melhorar a imagem que cada um tem do mundo, a fim de verificar como moldar atos e decisões. A terceira disciplina, visão compartilhada, é estimular o engajamento do grupo em relação ao futuro que se procura criar, e elaborar os princípios e as diretrizes que permitirão que esse futuro seja alcançado. A quarta disciplina, aprendizado em equipe, está em transformar as aptidões coletivas ligadas a pensamento e comunicação, de maneira que grupos de pessoas possam desenvolver inteligência e capacidades maiores do que a soma dos talentos individuais. E finalmente a quinta disciplina, pensamento sistêmico, é criar uma forma de analisar e uma linguagem para descrever e compreender as forças e inter-relações que modelam o comportamento dos sistemas. É essa quinta disciplina que permite mudar os sistemas com maior eficácia e agir mais de acordo com os processos do mundo natural e econômico.

Como mudar uma organização para transformá-la em um aprendiz permanente? Pergunta Robbins (2002, pg.546) e responde:

(i) estabelecer uma estratégia: os gestores precisam explicitar seu compromisso com a mudança, a inovação e a melhoria contínua; (ii) Replanejar a estrutura da organização: adoção de equipes multifuncionais; (iii) Remodelar a cultura da organização: assumir riscos, abertura e crescimento. Os gestores estabelecem o tom da cultura organizacional tanto pelo que dizem (estratégias) como pelo que fazem (comportamento).

Até este ponto da pesquisa identificou-se o que deveria ser feito para administrar uma mudança organizacional planejada visando implementar um sistema empresarial integradoSistema Empresarial Integrado ERP maximizando seu potencial.

Nesse ponto foi encontrado o que fazer?, mas, e o como fazer? Isso eliminava virtualmente a possibilidade de usar uma abordagem de intervenção que não pesquisa, e que basicamente deixou duas alternativas à escolha: (i) pesquisa experimental, que é caracterizada através de controle artificial (laboratório); e (ii) Pesquisa-ação, que é por sua natureza de baixo controle artificial, porém, é uma proposta de pesquisa mais aberta (com característica de diagnóstico e de consultoria), para tentar clarear uma 
situação complexa - sair da situação atual para a situação desejada, e encaminhar possíveis - ações de mudança, especialmente nestas situações criticas.

O processo de mudança é sempre um momento crítico, e a pesquisa-ação contribui levando os atores envolvidos a encontrar as respostas aos seus próprios problemas, comprometendo-se com a mudança e aprendendo com ela, possibilitando desenvolver a chamada "organização que aprende".

O capítulo seguinte explica a metodologia utilizada para coletar os dados, esboçando como os resultados serão alcançados e justificando a abordagem utilizada. 


\section{CAPÍTULO IV - MÉTODO DE PESQUISA}

\section{PESQUISA-AÇÃO (PA)}

Este capítulo descreve o método de investigação. Inicialmente define a Pesquisa-ação e suas variantes em função de seus objetivos, formas de participação ou de compromisso que requerem. Na sequiência faz-se uma breve revisão histórica e de evolução da pesquisa-ação, para então descrever a própria metodologia aplicada e de diagnóstico. Em seguida apresenta-se os princípios do método de pesquisa-ação aplicado no contexto organizacional. Finalizando o capítulo descreve-se o roteiro prático de condução da Pesquisa-Ação utilizado neste trabalho num contexto de mudança organizacional.

Saliente-se que o método de investigação utilizado e a abordagem de PesquisaAção (PA) desenvolvida, conforme demonstrado a seguir, deve ser entendida como decorrente das próprias descobertas da pesquisa, já comentado no inicio do trabalho, e em dois sentidos: (i) como paradigma de pesquisa; (ii) como abordagem para administrar a mudança organizacional. Na abordagem utilizada de PA procurou-se desenvolver um modelo que proporcionou enfrentar as limitações da Pesquisa-Ação, e seus pontos fracos, inerentes aos métodos de pesquisa qualitativa. Os comentários sobre as limitações encontradas fazem parte da contribuição do trabalho ao corpo de conhecimento e são comentadas no capítulo VI.

\subsection{INTRODUÇÃO}

Em pesquisa organizacional, a Pesquisa-Ação (PA) é apresentada como um método apropriado para conhecer e intervir nas organizações (Thiollent; 1997, pg.14), principalmente na introdução de sistemas de informação, entendidos como projetos de mudança e aprendizagem organizacional e na sua dupla vertente técnica e social, mais precisamente na abordagem da escola sócio-técnica, que distingue o aspecto social (ou humano) e o aspecto tecnológico.

A pesquisa ação (PA) se refere a uma classe de abordagens de pesquisa, ao invés de um único, monolítico método de pesquisa (Baskerville, 1999). As variadas formas de PA compartilham algumas características comuns, as quais a distinguem de outras abordagens de investigação social. Uma cuidadosa pesquisa na literatura sobre 
PA fornece uma larga concordância de autoridades sobre as principais características comuns:

(i) Uma orientação para ação e mudança; (ii) $\mathrm{O}$ foco em um problema; (iii) Desenvolvimento da teoria e publicação dos resultados da pesquisa; (iv) Um processo "orgânico" envolvendo estágios sistemáticos e algumas vezes iterativos; (v) Colaboração entre o pesquisador e os agentes;

Historicamente, o método de PA tem sido usado de modo explícito em pesquisas relacionadas com as escolas de relações humanas, Desenvolvimento Organizacional (DO), sócio-técnica, psicossociologia, análise institucional e, em certos casos, com perspectiva crítica.

A expressão pesquisa-ação foi lançada por Kurt Lewin ao se referir aos fenômenos de grupos identificados e trabalhados no próprio grupo, com objetivos de pesquisa em psicologia social e dinâmica de grupo. Para ele pesquisa-ação é igual à pesquisa no próprio campo.

Na visão de Thiollent (1997, pg.14), com a pesquisa-ação há produção e uso simultâneo do conhecimento, pois ela consiste essencialmente em acoplar pesquisa e ação em um processo no qual os atores implicados participam, junto com os pesquisadores, para chegarem interativamente a elucidar a realidade em que estão inseridos, identificando problemas coletivos, buscando e experimentando soluções em situação real.

Neste sentindo, a PA tem o duplo e explícito propósito de auxiliar a reflexão, formulação ou implementação da ação; e de desenvolver, enriquecer ou testar quadros de referências teóricos ou modelos relevantes ao fenômeno em estudo.

O objetivo da pesquisa-ação é aprender com a experiência, e aplicar este aprendizado para provocar a mudança. Como a dinâmica de um sistema social é freqüentemente mais aparente em tempos de mudança (Lewin, 1948), aprendizagem e mudança tem influência mútua. Porém, é mais provável que se aprenda na experiência ao agir-se com a intenção. A experiência deve ser buscada com expectativas. Deve-se buscar a experiência não-metódica, e deve-se buscar entendê-la.

O processo de Pesquisa-Ação (PA) não existe de forma totalmente padronizada. Dependendo do quadro organizacional em que se aplica, os procedimentos e a ordenação das etapas podem variar. 
No caso específico das organizações bastante consolidadas, como a empresa contábil objeto deste trabalho, que existe há mais de vinte anos, o trabalho preliminar tem por objetivo o processamento da demanda para superar seus aspectos imediatos ou meramente utilitários, e assim situá-la na perspectiva dos conhecimentos a serem aplicados ou produzidos, consistindo, em etapas subseqüentes, em pesquisar problemas com maior profundidade, propor coletivamente ações, almejando soluções ou mudanças que são também objeto de investigação e avaliação, propiciando a experiência acumulada que forma a base de um possível avanço no conhecimento prático da contabilidade e ampliação do campo de ação do contabilista.

\subsection{OS COMPROMISSOS DA PESQUISA-AÇÃO}

A Pesquisa-Ação (PA) pode variar em função dos seus objetivos, forma de participação e compromisso que requerem. Como cada elemento destes foi tratado nesta pesquisa está sendo relatado a seguir.

\subsubsection{PESQUISA-AÇÃO (PA) EM CONTEXTO PROFISSIONAL}

A Pesquisa-Ação (PA) em contexto profissional, neste trabalho, tem como objetivo entender as mudanças relacionadas com as características culturais e sociais da tecnologia de informação e seu impacto na organização do trabalho e nas pessoas, que desenvolvem a atividade contábil em grupo, tentando clarear uma situação complexa e encaminhar possíveis ações, pois a implantação de um sistema empresarial integradoSistema Empresarial Integrado - ERP trará conseqüências não somente para o entendimento do que seja este trabalho, bem como, proporcionará que este grupo desenvolva-se como multiplicador da aplicação desta tecnologia nas empresas-cliente.

A pesquisa organizacional é um instrumento cuja aplicação não interessa apenas aqueles grupos que dispõem de poder formal (Thiollent, 1997), e neste caso específico ela está estruturada de modo a atender aos interesses dos diversos grupos componentes, inclusive proporcionando o fortalecimento das condições democráticas pois a organização está implantando um modelo de gestão participativa.

\subsubsection{LEGITIMIDADE DA PESQUISA-AÇÃO (PA)}

A pesquisa-ação requer legitimidade dos diferentes atores e convergência de interesses. No caso em estudo, a proposta surgiu dos interesses dos atores na mudança 
organizacional, decorrentes da implantação do sistema empresarial integradoSistema Empresarial Integrado - ERP e do modelo de gestão participativa, ao passo que a pesquisa participante lida com situações de contestação de legitimidade do poder vigente. Apesar das criticas de alguns autores com relação ao uso da PA no contexto organizacional (especialmente no caso do Desenvolvimento Organizacional, DO, e da sócio-técnica), segundo uma visão operacional sem perspectiva crítica ou conscientizadora, no presente estudo foi dada grande importância ao conteúdo político das propostas apresentadas.

\subsubsection{COMPROMISSO PARTICIPATIVO}

A PA torna-se possível e eticamente sustentável, de acordo com Thiollent (1997, pg.23), quando estão reunidas as condições do compromisso participativo, tais como:

(i) a iniciativa de pesquisa parte de uma demanda de pessoas ou grupos que não ocupam as posições de topo de poder; (ii) os objetivos são definidos com autonomia dos atores e com mínima interferência de membros da estrutura organizacional; (iii) todos os grupos sociais implicados no problema escolhido como assunto de pesquisa são chamados a participar do projeto e de sua execução; (iv) todos os grupos têm liberdade de expressão. Medidas são tomadas para evitar censuras ou represálias; (v) todos os grupos são mantidos informados no desenrolar da pesquisa; (vi) as possíveis ações decorrentes da pesquisa são negociadas entre os proponentes e os membros da estrutura formal; (vii) em geral, as equipes internas que promovem a pesquisa são auxiliadas por consultores ou pesquisadores externos.

O compromisso participativo, utilizado neste estudo, é também reavaliável com base na discussão da PAR (Participatory action research) que é definida como forma de PA na qual pesquisadores sociais e profissionais operam como plenos colaboradores com os membros das organizações que estão sendo estudadas ou transformadas e apresenta-se como um processo contínuo de aprendizagem organizacional, uma abordagem de pesquisa na qual são enfatizadas co-aprendizagem, participação e transformação organizacional.

Neste ponto, a pesquisa tomou outro rumo, pois a partir do problema inicial levantado pela organização, que era de um baixo aproveitamento do potencial do contador, ficou claro entre o pesquisador e os atores que o que realmente estava acontecendo era a necessidade de se implantar um processo contínuo de aprendizagem, isto é, o que o paradigma de pesquisa Pesquisa-Ação, enquanto modelo de intervenção organizacional oferecia era exatamente uma metodologia para lidar com aquilo que estava ocorrendo no grupo, mesmo sem uma percepção clara de seus membros a 
princípio, a necessidade de iniciar um processo de transformação para uma organização que aprende.

\subsubsection{ORIENTAÇÃO E INSTRUMENTALIDADE}

É importante na PA a definição do procedimento de caráter interrogativocrítico. É interrogativo no sentido de dar ênfase ao questionamento que se baseia na formulação de perguntas pelos atores acerca da situação na qual estão envolvidos. As respostas são obtidas pela pesquisa. É crítico no sentido de não aceitação das explicações espontâneas que são dadas pelos atores ou pelo senso comum, pois devem ser evidenciados aspectos problemáticos, em geral relacionados com interesses ou conflitos.

Thiollent (1997) adverte que o domínio da linguagem é também significativo na interpretação do que as pessoas estão dizendo ou querem fazer em termos de ação. As correspondentes decisões não se tomam por "decreto", mas em função de deliberações e da conscientização dos atores. Na ocasião da PA, cria-se um espaço de diagnóstico, investigação sem preconceitos, discussão e amadurecimento coletivo de possíveis soluções.

O autor (pg.25) contrapõe o objetivo do conhecimento crítico, isto é, que consiste em coletar informações e desencadear uma argumentação relacionada com os fatos polêmicos da situação investigada, do objetivo do conhecimento instrumental, qual seja:

(...) aquele que corresponde a uma estratégia cognitiva na qual são privilegiados os critérios da "razão prática", tais como eficácia. Na concepção da PA, um grande desafio consiste em desenvolver a instrumentalidade sem excluir o espírito crítico, e isso pressupõe uma teorização das modalidades de conhecimento (conhecer, acreditar, contrapor, etc.) a serem articuladas com as modalidades da ação (querer, fazer, agir, mudar, lutar, etc.), o que deixa em aberto o espaço da crítica e da relativização dos pontos de vista.

\subsubsection{COMPROMISSO COM MELHORIAS E MUDANÇAS}

A PA de mudança organizacional não se limita a descrever uma situação, mas sim trata-se de gerar pequenos acontecimentos que, em certos casos, levam a desencadear-se mudanças no seio da coletividade implicada.

A pesquisa-ação é um tipo de pesquisa organizada de modo participativo, com a colaboração de pesquisadores e de membros ou grupos implicados em determinada 
situação ou prática social, de modo a identificar os problemas, buscar soluções e implementar possíveis ações coletivamente deliberadas.

A colaboração da equipe de pesquisadores e dos membros de um movimento ou de uma instituição é estabelecida a partir de um tipo de "contrato" no qual são definidos os objetivos gerais do projeto e as modalidades de organização e apoio.

\subsubsection{CIENTIFICIDADE E OBJETIVIDADE DA PESQUISA}

$\mathrm{Na}$ pesquisa social, a questão da cientificidade é abordada em função da predominante concepção positivista, que estabelece a necessidade do padrão metodológico das ciências físicas para que ela seja considerada científica. Porém, amplos setores da filosofia da ciência reconhecem, hoje, que o positivismo está em crise, inclusive no que diz respeito às ciências exatas e da natureza.

$\mathrm{Na} \mathrm{PA}$ as regras são diferentes das da metodologia tradicional positivista, quanto à cientificidade e objetividade. Nesta concepção de pesquisa, o ideal de cientificidade e objetividade é visto como busca de imparcialidade para retratar as visões de todos os atores da situação (Thiollent; 1997 pg.30), porém, há consenso para evitar os excessos de subjetividade.

Uma Pesquisa-Ação bem conduzida alcança suficiente rigor científico quando retrata bem a realidade da organização, e equaciona seus problemas sem parcialidade ou complacência, relacionadas com os interesses vigentes. E Thiollent (1997) conclui sobre a Pesquisa-Ação afirmando que "ela é mais exigente e trabalhosa que a pesquisa convencional”.

De forma resumida, o maior objetivo da pesquisa é produzir novas informações, estruturar conhecimentos e delinear ações, e para tanto M.Liu (1997) apud Thiollent (1997) cita quatro elementos que fundamentam sua originalidade:

1) $\mathrm{O}$ encontro de: (i) uma intenção de pesquisa (pesquisadores), (ii) uma vontade de mudar (usuários); 2) Objetivo duplo: (i) Resolver o problema dos usuários, (ii) Fazer progredir os conhecimentos fundamentais; 3) Trabalho conjunto que é aprendizagem mútua entre pesquisadores e usuários; 4) Quadro ético negociado e aceito por todos.

\subsection{CONTEXTO HISTÓRICO}

A PA como empregada atualmente teve origem em dois programas de pesquisa distintos e independentes, baseados em desenvolvimentos da ação no domínio da psicologia social nos anos quarenta, conforme já comentado brevemente. Kurt Lewin 
desenvolveu a PA nas suas investigações sobre a teoria de campo no domínio da psicologia social, no Centro de Pesquisa para a Dinâmica de Grupos da Universidade de Michigan.

\subsubsection{NADA MAIS PRÁTICO QUE UMA BOA TEORIA (KURT LEWIN)}

Os primeiros trabalhos de Lewin debruçaram-se sobre o comportamento individual. Mais tarde, devido a novas responsabilidades profissionais e envolvimento em projetos de "engenharia social", patrocinados pelo governo norte americano, para ajudar a mudar os hábitos alimentares das famílias americanas, ele pôde constatar a importância dos grupos na mudança do comportamento individual.

Conduzindo e participando em vários projetos de mudança organizacional e social, Lewin tentou mostrar que, do ponto de vista da ação, a pesquisa científica era possível e aconselhável. As suas orientações metodológicas assentaram-se, nomeadamente, na importância do contexto social para se compreender o indivíduo, no valor de tentar mudar a realidade para o desenvolvimento da teoria e assumindo que a principal finalidade da teoria é mudar e melhorar situações do mundo real.

Uma das principais mensagens deste trabalho é que é possível melhorar a nossa habilidade de organizar e de resolver problemas organizacionais compreendendo e fazendo os atores envolvidos compreender a ligação existente entre teoria e prática, e reconhecendo a validade do famoso ditado de Kurt Lewin, segundo o qual "não há nada mais prático do que uma boa teoria”. (Morgan, 1996)

Uma perspectiva diferente de PA foi desenvolvida na Inglaterra, depois da segunda guerra mundial, na Clínica de Tavistock, mais tarde Tavistock Institute of Human Relations, em Londres, como uma ajuda para lidar com os problemas sociais e psicológicos resultantes da guerra. O Instituto utilizava esta metodologia para estudar os distúrbios psicológicos e sociais dos veteranos e prisioneiros de guerra. 


\subsubsection{A PA ORGANIZACIONAL E AS CAUSAS DA SUA POUCA DIVULGAÇÃO}

Houve convergência destes dois desenvolvimentos, quando Lewin juntou-se ao Instituto Tavistock, e assim, foram os inspiradores de um vasto conjunto de trabalhos no domínio da PA, embora a adesão à mesma se tenha processado lentamente.

Os motivos apontados para este fato prendem-se com o financiamento dos projetos. No pós-guerra, a maioria dos fundos que financiavam pesquisas eram públicos. Ora, os governantes preferiam as análises quantitativas suportadas em dados, o que conduziu a um declínio das competências em PA. Como conseqüência, estes métodos eram raramente aplicados e muitas vezes considerados de qualidade científica marginal. A maior parte dos trabalhos na segunda metade deste século foram realizados para solucionar problemas organizacionais.

Argyris e Schön foram os principais autores a retomar e desenvolver os conceitos de Pesquisa-ação, tratando-os como uma abordagem científica específica, na qual o investigador gera um novo conhecimento acerca do sistema social e, ao mesmo tempo, esforça-se para mudá-lo.

\subsubsection{A ESPIRAL DE PESQUISA-AÇÃO}

A pesquisa-ação, como descrita por Lewin, ocorre numa espiral de passos compostos de planejamento, ação e avaliação dos resultados da ação. O processo de PA começa com uma idéia geral de que uma melhoria ou mudança em uma área de trabalho do profissional é desejável. Um grupo então é formado para esclarecer a preocupação mútua que havia sido identificada, e em seguida toma a decisão de trabalhar em conjunto, focando suas estratégias de melhoria (ação) no tema de interesse.

$\mathrm{Na}$ espiral de PA, (conforme figura 14 seguinte) os membros do grupo:

(i) desenvolvem um plano de ação com informações críticas para melhorar as práticas atuais. O plano deve ser flexível para permitir adaptação para efeitos imprevistos ou restrições; (ii) Os membros do grupo agem para implementar o plano, o qual deve ser discutido e controlado; (iii) A ação é observada para coletar evidências que permitam uma avaliação completa. A observação deve ser planejada e um diário pode ser utilizado para o propósito de registro. O processo de ação e seus efeitos dentro do contexto da situação devem ser observados individual ou coletivamente; (iv) A Reflexão sobre a ação registrada durante observação normalmente é auxiliada pela discussão entre os membros do grupo. As reflexões podem levar à reconstrução do 
entendimento da situação social e fornecem uma base para planejamento futuro de ações criticamente informadas, assim o ciclo continua. Estes passos são executados de um modo mais cuidadoso, sistemático e rigoroso do que normalmente acontece na prática diária (Hatten, Knapp \& Salonga; 1997).

FIGURA 17 - CICLO BÁSICO DA PA: A ESPIRAL ASCENDENTE EM (LOOP SIMPLES) . RELACIONAMENTO ENTRE O ESCOPO DA PESQUISA E O MODELO GENERALIZADO

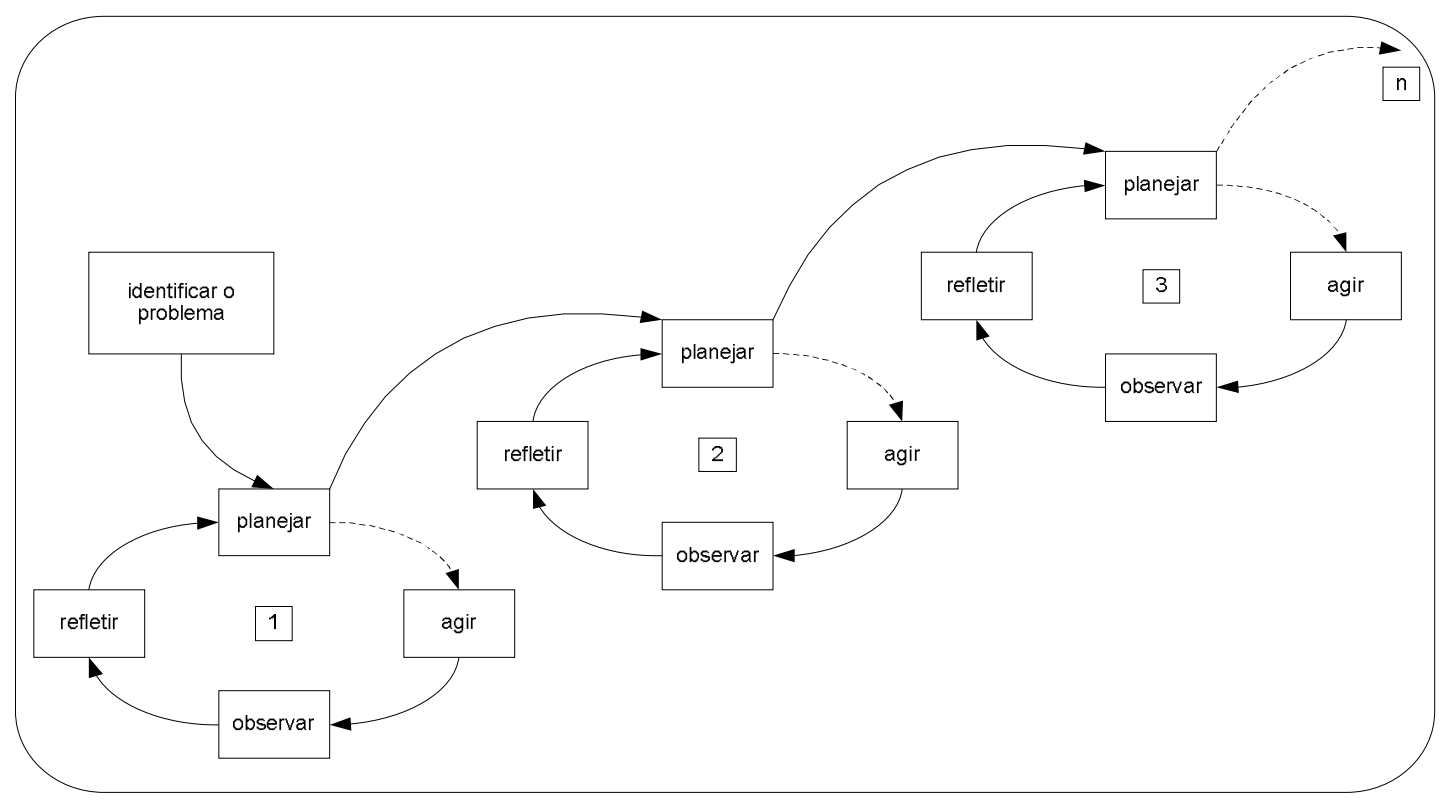

Fonte: Kock, McQueen and Scott (1997, pg.7) Adaptado Pelo Autor

A direção para cima da espiral na Figura 14 indica uma melhoria contínua na prática e um aumento do conhecimento pessoal e profissional.

\subsubsection{AS CINCO PRINCIPAIS CARACTERÍSTICAS DA PESQUISA-AÇÃO}

Há várias características que distinguem a PA de outras formas de pesquisa. As principais podem incluir: colaboração entre o pesquisador e o profissional, solução de problemas práticos, mudança nas práticas existentes, desenvolvimento da teoria, e publicação dos resultados de investigação (Hatten, Knapp \& Salonga; 1997).

Já outros autores vêem a PA como uma classe de abordagens de pesquisa, ao invés de um único, monolítico método de pesquisa (Baskerville, 1999), compartilhando algumas características comuns, as quais distinguem a PA de outras abordagens de investigação social, dentre as quais destacam-se: (i) Uma orientação para ação e mudança; (ii) O foco em um problema; (iii) Um processo "orgânico" envolvendo estágios sistemáticos e algumas vezes iterativos; (iv) Colaboração entre o pesquisador e os agentes. 
Por outro lado, porém, buscando uma visão sintética e única de Pesquisa-Ação (PA), vinculada a tradições européias e norte-americanas, foi definida por (Dubost, 1987:140 apud Thiollent; 1997, pg.35) como segue:

(...) ação deliberada visando à mudança no mundo real, realizada em escala restrita, inserida em um projeto mais geral e submetida a certas disciplinas para obter efeitos de conhecimento e de sentido". E complementa com as suas cinco principais características: “(i) Trata-se de uma experiência (...) que se inscreve no mundo real, em uma história concreta e não apenas no mundo do pensamento; (...) (ii) Esta experiência se desencadeia em escala restrita; essa limitação pode ser o resultado do caráter local ou de aplicação de um princípio de amostragem (...) (iii) como ação deliberada que visa uma mudança efetiva dos grupos e zonas consideradas, ela (pesquisa-ação) define-se pelos objetivos que podem ser fixados quer pelos proponentes do projeto e as instâncias centrais de poder que lhes dão uma posição de autoridade sobre a população considerada, quer pelo conjunto ou sub-conjunto dos indivíduos e grupos implicados no processo, quer ainda por um processo de negociação entre diferentes atores implicados; (iv) Desde seu início, ela é planejada para produzir ensinamentos passíveis de generalização, para guiar ações ulteriores ou evidenciar princípios ou leis; ela tenta dispor de capacidades de antecipação relacionadas com um projeto mais geral que a engloba, situado em outra escala espacial e temporal e cujos aspectos podem ser modificados posteriormente em função dos resultados; (v) ela deve aceitar certas disciplinas, regras ou dispositivos, possibilitando a observação, a coleta de informações cujo processamento condiciona a produção de resultados, o controle e a avaliação dos efeitos.

Como definido anteriormente, a pesquisa-ação como forma de pesquisa pretende ter como saída ou resultado (seu produto) pesquisa e ação, e ela ocorre como um processo cíclico (ou uma espiral), implícita ou explicitamente.

\subsection{METODOLOGIA DE PA APLICADA E DE DIAGNÓSTICO}

Pesquisa-ação é um tipo de pesquisa social com base empírica que é concebida e realizada em estreita associação com uma ação ou com a resolução de um problema coletivo, onde estão envolvidos de modo cooperativo e participativo os pesquisadores e os participantes da situação (Thiolent, 1998). Como forma não tradicional de pesquisa e para a sua compreensão inicial, é importante que se discutam em separado os conceitos de pesquisa, pesquisa social e de ação. A PA é uma proposta que pertence aos métodos de pesquisa social aplicada e, em certos casos, que se aproxima da metodologia de diagnóstico no contexto sócio-organizacional.

\subsubsection{PESQUISA BÁSICA E PESQUISA APLICADA}

Pode-se definir pesquisa como a produção do conhecimento, cujo objetivo fundamental é descobrir respostas para problemas mediante o emprego de procedimentos científicos. Para Gil (1999, pg.42) a pesquisa social pode ser definida 
como o processo que, utilizando a metodologia científica, permite a obtenção de novos conhecimentos no campo social. Já ação pode ser definida como a modificação intencional de uma dada realidade. A ligação dos termos pesquisa e ação realçam as características essenciais desta abordagem, a qual envolve o teste de idéias na prática como um meio de melhoria nas condições sociais e no crescimento do conhecimento.

A pesquisa social voltada para a área organizacional pode ser conduzida de duas maneiras: (a) pesquisa básica do tipo acadêmica e (b) pesquisa aplicada centrada no cliente. A pesquisa aplicada concentra-se em torno dos problemas presentes nas atividades de instituições, organizações, grupos e atores sociais. Ela está empenhada na elaboração de diagnósticos, na identificação de problemas e na busca de soluções. (Thiollent, 1997)

A pesquisa-ação, como descrita por Lewin, ocorre numa espiral de passos compostos de planejamento, ação e avaliação dos resultados da ação. O processo de PA começa com uma idéia geral de que uma melhoria ou mudança em uma área de trabalho do profissional é desejável. Um grupo então é formado para esclarecer a preocupação mútua que havia sido identificada, e em seguida toma decisão de trabalhar em conjunto, focando suas estratégias de melhoria (ação) no tema de interesse.

Em resumo, a pesquisa-ação é uma metodologia que tem dois objetivos: pesquisa e ação. (i) ação para provocar mudança em alguma comunidade, programa ou organização; (ii) pesquisa para aumentar o entendimento por parte do pesquisador ou do cliente, ou de ambos (e freqüentemente alguma comunidade maior).

Há métodos de pesquisa-ação cuja ênfase principal está na ação na realidade, com a pesquisa como um benefício secundário. No extremo, a pesquisa pode levar à forma de aumentar o entendimento direto por parte dos envolvidos, resultando em mudança, levando as partes ao processo de aprendizagem. Nesta pesquisa decidiu-se pelo uso da pesquisa-ação, pois ela permite aumentar o conhecimento por parte dos envolvidos durante a prática, refletindo no melhoramento do processo de mudança.

\subsubsection{METODOLOGIA DE DIAGNÓSTICO E SUA CONCEPÇÃO}

No contexto organizacional, a pesquisa social aplicada é freqüentemente encarada como instrumento de diagnóstico, entendidos na PA como procedimentos 
práticos e adaptados às condições específicas do exercício de uma atividade profissional, isto é, o diagnóstico baseia-se na identificação de problemas, a partir de sintomas cujas variáveis são intuitivamente julgadas relevantes, pelo investigador (Thiollent,1997).

A metodologia de diagnóstico incorpora diversas modalidades de pesquisa e de aprendizagem de tipo participativo ou cooperativo entre especialista e membros da situação objeto da diagnosticação.

\subsubsection{CONCEPÇÃO DE CIÊNCIA VOLTADA PARA A AÇÃO}

A ciência básica e a aplicação de conhecimento, diagnóstico e interação são objeto de preocupação no plano filosófico em que se discute a possibilidade de uma ciência da ação. Thiollent (1997, pg.55) cita que Argyris et al. (1985) têm discutido os limites da Action Research e proposto, em um nível mais elevado, o esboço de uma Action Science. Tal posição se relaciona com o fato de que, na tradição anglo americana, pesquisa-ação se tornou sinônimo de método de pesquisa aplicada, de alcance muito limitado, próximo ao de uma simples técnica de consultoria, voltado para a resolução de problemas de clientes, sem articulação com preocupações de ordem teórica.

A abordagem de Argyris evolui para um corpo teórico que denomina "ciência da ação". Esta "ciência" direciona-se para a pesquisa-participante, buscando o conhecimento útil à ação:

Na ciência da ação procuramos o conhecimento que será útil à ação. O cientista da ação é um interventor que procura ao mesmo tempo promover o aprendizado no sistema-cliente e contribuir para o conhecimento geral. Isso é feito pela criação de condições para o questionamento válido no contexto de deliberação prática por parte dos membros do sistema cliente (Argyris, Putnam e Smith, 1985, pg.36) apud Amatucci (2002).

Os princípios básicos desta ciência incluem preposições empiricamente refutáveis, como critério de demarcação cientifica; conhecimento que possa ser implementado em contextos de ação, e alternativas ao status quo que, ao mesmo tempo, iluminam o que existe e animam mudanças fundamentais, à luz de valores livremente escolhidos pelos atores sociais.

A ciência-ação é uma abordagem criada por Argyris que evoluiu para um corpo teórico direcionado para a pesquisa participante, buscando conhecimento útil à ação, 
isto é, o conhecimento que possa ser implementado em contextos de ação no qual o cientista da ação é um interventor que procura, ao mesmo tempo, promover o aprendizado no sistema-cliente e contribuir para o conhecimento geral.

O organismo humano é destinado à ação, e realiza seu destino aprendendo a agir. As organizações, criados pelos homens, não podem comportar-se de forma diferente, desde que tenham-se posto em ação. Já que aprender é um processo que dura a vida toda, Argyris (1992) coloca que o problema da aprendizagem organizacional é que se deve trabalhar as deficiências de aprendizado.

Neste sentido, como referência na área de aprendizagem organizacional ele faz a diferença entre aprendizado de circuito simples (single loop) e de circuito duplo (double loop), onde a principal distinção entre uma organização que aprende, e uma que não, está na reflexão, que ocorre no double loop learning. O double loop é, pois, um feedback (loop) de segunda ordem: uma reflexão sobre o sistema de ação como um todo.

Morgam (1986) entende que, nas organizações, o single loop representa o aprendizado na forma de detecção de erros, enquanto que o double loop significa aprender a aprender, através da reflexão sobre o funcionamento da detecção de erros.

De acordo com as idéias de Argyris, a pesquisa concreta tem um papel reflexivo como meio de explicação do conhecimento prático dos atores na situação investigada. Na visão de Thiollent (1997, pg.56) “a discussão da pesquisa-ação em termos prático-metodológicos e a reflexão filosófica sobre os compromissos da ciência são condições necessárias para alcançar uma visão mais ampla das potencialidades do vínculo entre ciência e ação".

\subsection{PESQUISA-AÇÃO NAS ORGANIZAÇÕES}

Uma característica própria da PA está no fato de pressupor uma concepção da ação. Neste sentido Thiollent (1997, pg.36) esclarece:

Seja como for, na pesquisa-ação os atores deixam de ser simplesmente objeto de observação, de explicação ou de interpretação. Eles tornam-se sujeitos e parte integrante da pesquisa, de sua concepção, de seu desenrolar, de sua redação e de seu acompanhamento. Disso resulta às vezes - nem sempre - a assimilação da pesquisaação com a pesquisa participativa. 


\subsubsection{A ARTICULAÇÃO DA PESQUISA COM A AÇÃO}

Tema central da metodologia pesquisa-ação, a articulação da pesquisa e da ação é concebida de modo diferenciado e em função de uma tipologia das formas de participação. Vista como pesquisa inserida na ação, a pesquisa-ação comporta três aspectos simultâneos (Thiollent; 1997, pg.37):

(a) Pesquisa SOBRE os atores sociais, suas ações, transações, interações; seu objetivo é a explicação; (b) pesquisa PARA dotar de uma prática racional as práticas espontâneas; seu objetivo é a aplicação. (c) Pesquisa POR, ou melhor, PELA ação, isto é, assumida por seus próprios atores (autodiagnóstico e autoprognóstico) tanto em suas concepções como em sua execução e seus acompanhamentos; seu objetivo é a implicação.

Além dos três tipos de pesquisas correspondentes à explicação, aplicação e implicação, complementarmente a PA possui cinco dimensões (Thiollent; 1997, pg.38) a saber:

(i) Contrato, que pode ser informal entre o pesquisador e atores e consiste em definir os objetivos de conhecimento e mudança; (ii) Participação, que varia entre as formas de colaboração, cooperação ou co-gestão; (iii) Mudança, deriva da aplicação de uma teoria, de um processo de cooperação ou de co-gestão; (iv) Discurso, pode ser espontâneo, esclarecido ou engajado; e (v) Ação, que apresenta aspectos individuais, coletivos ou comunitários.

Esclarece o autor, tanto com relação às cinco dimensões da PA discutidas acima, quanto ao que diz respeito à tipologia das modalidades de articulação entre, de um lado, a pesquisa e os autores (pesquisadores) e, de outro lado, a ação e os atores, que existe multiplicidade de configurações a serem escolhidas, elaboradas ou adaptadas em função das situações concretas da investigação e das ações possíveis.

Neste trabalho, o contrato estabelecido foi informal e aberto, pois o pesquisador faz parte da equipe de trabalho, e os objetivos traçados foram a condução do processo de mudança estrutural necessária à implementação de um sistema empresarial integradoSistema Empresarial Integrado - ERP, principalmente com a redefinição dos papéis e responsabilidades, mudança na cultura organizacional em geral e no processo de gestão em particular, focado na visão de processos, objetivando o comprometimento dos atores envolvidos e o engajamento na criação de uma organização que aprende.

A participação foi a co-gestão e a mudança foi desenvolver um processo de cogestão tendo como teoria o Desenvolvimento Organizacional (DO), a abordagem sócio-técnica, a ciência-ação e análise dos seus reflexos nas dimensões da organização 
com base no triangulotriângulo estratégico proposto por Walton (1998), isto é, a conexão entre a estratégia de negócios, estratégia de organização e estratégia de Tecnologia de informação.

Finalmente o discurso foi o espontâneo e a ação apresenta aspectos de mudança individual e coletiva, ou seja, na cultura da organização.

\subsubsection{FORMAS DA PA EM SISTEMAS DE INFORMAÇÃO}

Susman e Evered (1978) apud Baskerville (1999) visualizaram um projeto geral de pesquisa-ação como um processo cíclico conduzido através do que eles se referem como o ciclo da pesquisa-ação, compreendendo cinco estágios: diagnóstico, planejamento da ação, tomada de ação, avaliação e especificação da aprendizagem, assim entendido:

1) O estágio de diagnóstico envolve a identificação e a definição de uma oportunidade
de melhoria ou de um problema geral a ser resolvido na organização-cliente". 2) O
estágio seguinte, planejamento da ação, envolve a consideração de cursos alternativos
de ação para a melhoria ou resolução do problema identificado. 3) O estágio de
tomada de ação envolve a seleção e a implementação de um dos cursos de ação
considerados no estágio anterior. 4) O estágio de avaliação envolve o estudo dos
resultados do curso selecionado de ação. 5) Finalmente, o estágio de especificação do
aprendizado envolve o estudo dos resultados do estágio de avaliação e, baseado neste
estudo, a construção de conhecimento na forma de um modelo descrevendo a situação
sob estudo.

Espera-se inicialmente que este modelo seja apenas descritivo, ao invés de preditivo, uma vez que o profundo envolvimento do pesquisador com o ambiente sendo estudado leva, devido a restrições de tempo, ao estudo de um pequeno número de instâncias de eventos particulares. Contudo, esclarece Baskerville (1999), enquanto o número de estudos de pesquisa-ação realizados de maneira similar cresce, seus modelos descritivos resultantes podem então ser integrados em modelos preditivos e mais gerais, e eventualmente conduzir a "grandes teorias".

A abordagem clássica, não-participativa, à pesquisa-ação, usualmente prescreve que todos os estágios exceto um (o estágio de especificação do aprendizado) sejam realizados em cooperação com a organização-cliente. Abordagens mais recentes da pesquisa-ação, como pesquisa-ação participativa (PAR) trazem o completo envolvimento da organização-cliente também no estágio de especificação do aprendizado.. 


\subsubsection{O ESCOPO DA PESQUISA $E$ O GENERALIZADO - ITERAÇÕES}

Uma das razões pelas quais a pesquisa-ação é vista como preferencialmente conduzida em ciclos é a oportunidade que isto proporciona para o reforço das descobertas de pesquisa, construída nas evidências colhidas de iterações anteriores no ciclo da pesquisa-ação.

Ketchum e Trist (1992) apud Baskerville (1999) vêem a freqüência das iterações no ciclo da pesquisa-ação como parecendo decrescer enquanto aumentam as coincidências entre a concepção do pesquisador (sobre o sistema sócio-técnico, expresso no modelo que compreende as descobertas da pesquisa), e aquilo encontrado como resultado do estágio de especificação de aprendizado em cada ciclo. Isto pode ser obtido pela expansão do escopo da pesquisa, isto é, das áreas da organizaçãocliente envolvidas na pesquisa, e pela generalização dos resultados através da identificação de padrões invariáveis.

\subsubsection{DISTINGUINDO PESQUISA-AÇÃO DE CONSULTORIA}

O processo da pesquisa-ação e os processos típicos de consultoria organizacional contêm semelhanças substanciais em função das principais literaturas sobre ambos se reportarem ao trabalho inicial de Kurt Lewin.

A maioria dos trabalhos acadêmicos sobre gerenciamento de consultoria, de acordo com Baskerville (1999), é parcialmente embasado no processo consultivo Schein (1969). Este autor baseou suas pesquisas fortemente nos conceitos de pesquisaação de Lewin, e os ciclos são muito similares. Contudo, muito da literatura de consultoria descarta o processo iterativo em favor de um processo linear, qual seja, "abordar-diagnosticar-agir-desabordar", o qual Schein também considerou admissível.

Em linhas gerais, Pesquisa-ação e consultoria diferem em cinco pontos-chave (Baskerville, 1999, pg.12):

1) "Motivação: A pesquisa-ação é motivada por seus propósitos científicos, talvez resumida em publicações científicas, enquanto a consultoria é motivada por benefícios comerciais, inclusive lucros e adicional conhecimento proprietário sobre soluções para problemas organizacionais"; 2) "Comprometimento: A pesquisa-ação traz um compromisso com a comunidade de pesquisa para a produção de conhecimento científico, bem como para com o cliente, enquanto numa situação de consultoria, o comprometimento é apenas em relação ao cliente"; 3 ) "Abordagem: Colaboração é essencial em pesquisa-ação devido às suas suposições idiográficas 
(relativo aos procedimentos de investigação que consideram as características originais do objeto de estudo, estudando-o com profundidade) enquanto a consultoria tipicamente valoriza o seu ponto de vista de fora, não pré-concebido, provendo uma perspectiva objetiva aos problemas organizacionais". 4) "Fundamentação das propostas: Na pesquisa-ação, este fundamento é um arcabouço teórico, enquanto que na consultoria espera-se que os consultores sugiram soluções que, na sua experiência, revelaram-se com êxito em situações semelhantes". 5) "Essência da compreensão organizacional: Na pesquisa-ação, esta compreensão da organização está baseada na prática sucessiva de mudanças experimentais iterativas, enquanto que equipes típicas de consultoria desenvolvem uma compreensão através de sua análise crítica independente da situação-problema".

Resumindo, consultores são usualmente pagos para ditar soluções experimentadas e confiáveis baseadas em sua opinião independente. Pesquisadores da PA agem no interesse científico de auxiliar a própria organização a aprender, pela formulação de uma série de soluções experimentais baseadas em uma teoria não testada, em evolução. (Baskerville, 1999).

\subsubsection{PESQUISA-AÇÃO NAS ORGANIZAÇÕES}

Em geral, a pesquisa organizacional é concebida como caso particular da pesquisa social, e no caso específico de PA existe uma longa tradição internacional nas empresas, principalmente aplicada com os objetivos do Desenvolvimento Organizacional (DO) e da Sócio-técnica, no mundo anglo-saxônico (Thiollent, 1997). De acordo com essa tradição, a PA é vista sobretudo como mecanismo de retroalimentação (feedback) dos resultados da investigação para os usuários ou a organização-cliente.

No Brasil existem poucas experiências de PA nas organizações e empresas, devido, segundo Thiollent (1997), a forma de gestão autoritária e pouco participativa das nossas empresas, onde o problema social é visto como questão de disciplina ou polícia.

A PA pode ser relacionada com o planejamento participativo e com a análise sócio-técnica. Neste sentido, ela permite a captação de fenômenos interativos entre as pessoas e os grupos que participam do projeto. Em propostas de mudança, coletivamente negociadas com pressupostos democráticos, como resultado se obtém a condição favorável a uma efetiva realização do projeto. No caso especifico deste trabalho é esse um dos seus objetivos centrais, e além disso, pretende-se desenvolver através da PA uma metodologia participativa de intervenção para mudanças nas empresas. 
Em termos práticos, a PA abre novos caminhos para a pesquisa social em diversos setores de atuação e, em particular, na área organizacional, especificamente na área contábil, para implementar sistema de informação contábil integrado.

Fonte de informação insubstituível, as intervenções em organizações são oportunidades para os pesquisadores terem acesso a informações e problemas que freqüentemente não se encontram diretamente nos estudos e pesquisas tradicionais. A preocupação metodológica em torno da pesquisa organizacional situa-se no âmbito da pesquisa social aplicada e não das propostas gerenciais imediatistas. Conceber e realizar uma pesquisa-ação em organizações pressupõe um investimento teórico e prático de médio ou longo prazo, no intuito de repensar a organização em seus vários níveis.

Com relação à PA e à gestão da qualidade, apesar de reconhecer semelhanças entre os métodos de melhoria de qualidade, da qualidade de vida no trabalho e outras ferramentas utilizadas, inspiradas em antigas técnicas usadas na PA do tipo sóciotécnico, Thiollent (1997, pg.43) vê uma diferença fundamental nas duas visões relativamente aos objetivos e motivos, "que nessas técnicas de gestão da qualidade são unilateralmente definidos, o que não combina com a PA que possui uma abertura participativa, interrogativa e crítica".

\subsubsection{PA E A AÇÃO PRÁTICA NAS EMPRESAS CONTÁBEIS}

Em estudos organizacionais, a Pesquisa-ação (PA) é caracterizada pela intervenção positiva do pesquisador, aplicada à organização do cliente, enquanto coleta dados de campo sobre a organização, avaliando e refletindo sobre os efeitos da intervenção. Esta característica da PA fornece um fundamento particularmente sólido para a decisão para usar PA neste estudo.

Na procura de uma perspectiva organizacional de como conduzir o processo, de maneira a otimizar os resultados, entendeu-se que tratava-se da necessidade de administrar um processo de mudança no ambiente organizacional, para criar as condições técnicas e sociais ideais, visando implementar um sistema empresarial integradoSistema Empresarial Integrado - ERP numa empresa contábil do interior do Brasil. 
Em linhas gerais, não foram encontrados na literatura disponível relatos voltados especificamente para as empresas contábeis, com as suas especificidades de pequena empresa, e os estudos encontrados que se referiam a PA tratavam de forma superficial a questão da metodologia na pesquisa.

Foram encontrados estudos de casos, principalmente relacionados a grandes companhias, que comentavam sobre os sucessos e fracassos na implementação de sistemas, e o que chamou a atenção é que na maioria deles a abordagem é simplesmente técnica, ou seja, com pouco ou nenhum comentário sobre os aspectos sociais, especificamente humano-comportamentais. Este fato induziu a concluir sobre a verdadeira causa do fracasso ou do baixo nível de sucesso: não tratar a intervenção como um processo mais amplo e profundo de mudança, com seus aspectos técnicos e sociais (abordagem sócio-técnica).

Nesse ponto encontramos o que fazer? Mas e o como fazer? Isso eliminava virtualmente a possibilidade de usar uma abordagem de intervenção que não pesquisa, e que basicamente deixou duas alternativas para escolher: (i) pesquisa experimental, que é caracterizada através de controle artificial (laboratório); e (ii) Pesquisa-ação, que é por sua natureza de baixo controle artificial, porém, é uma proposta de pesquisa mais aberta (com característica de diagnóstico e de consultoria), para tentar clarear uma situação complexa - sair da situação atual para a situação desejada, e encontrar os possíveis caminhos - de mudança, especialmente nestas situações criticas, levando os atores envolvidos a encontrar as respostas e ações aos seus próprios problemas, comprometendo-se com a mudança e aprendendo com ela - a organização que aprende.

A utilidade prática da PA é de assessorar os atores, tornando-os capazes de identificar seus problemas e encontrar possíveis soluções, destacando-se algumas questões, que Thiollent (1997, pg. 43) destaca como fundamentais:

(a) adequar o referencial teórico-metodológico aos contextos de atuação dos profissionais da área; (b) estabelecer condições de interdisciplinaridade para favorecer nas pesquisas a participação de sociólogos, psicólogos e outros especialistas; (c) estabelecer um relacionamento adequado com interessados, usuários, membros das organizações e de seus usuários; (d) manter o equilíbrio entre a dimensão crítica ou conscientizadora da pesquisa e seu caráter instrumental (fixação de objetivos realistas, aplicação de métodos e obtenção de resultados tangíveis). 


\subsubsection{PA E O SEU PONTO FORTE: RESOLVER PROBLEMAS CONCRETOS}

As pesquisas organizacionais de orientação positivista recorrem a técnicas quantitativas sofisticadas, porém de pouca relevância para resolver os problemas concretos das organizações, sendo justamente aí o ponto forte da PA - ficar em contato com os problemas reais. Neste sentido, Susman e Evered (1978) apud Thiollent (1997) destacam, como sendo as principais características da PA não contempladas na pesquisa convencional, as seguintes:

(a) Orientação para o futuro. $O$ processo de pesquisa-ação facilita a criação de soluções voltadas para o futuro desejável pelos interessados; (b) Colaboração entre pesquisadores e clientes; (c) Desenvolvimento de sistema: o dispositivo de PA desenvolve a capacidade do sistema de identificar e resolver problemas; (d) Geração de teoria fundamentada na ação: a teoria pode ser corroborada ou revisada por meio da avaliação de sua adequação à ação; (e) Não predeterminação e adaptação situacional: as próprias relações estabelecidas na situação de pesquisa variam e não são totalmente previsíveis.

Thiollent (1997) comenta com relação às tendências de pensamento organizacional, a concepção de Susman e Evered pode ser considerada como pertencente à escola sócio-técnica dos anos 70, agregando a abordagem sistêmica para equacionar os problemas sociais no trabalho e planejar novas formas de organização, em especial, os chamados grupos semi-autônomos.

Neste contexto, o dispositivo de PA é concebido como estrutura de interação clientes / pesquisadores com procedimentos em cinco fases (Thiollent, 1997, pg.44), na forma como está sendo aplicado neste trabalho com os respectivos comentários, bastante clássico nas áreas de tecnologia e organização:

1) Diagnóstico para identificar um problema na organização; 2) Planejamento da ação, considerando as ações alternativas para resolver o problema; 3) Execução das ações, com seleção de um roteiro de ação; 4) Avaliação das conseqüências da ação; 5) Aprendizagem específica e identificação dos ensinamentos da experiência, com retorno ao ponto de partida para evidenciar o conhecimento generalizável adquirido sobre o problema.

A abordagem é deste trabalho é centrada no ciclo da pesquisa-ação proposto por Thiollent (1997) com base no modelo de Susman e Evered (1978), que em linhas gerais é idêntica à abordagem proposta por Baskerville (1999), para uso com sistema de informação, comentado anteriormente, o qual compreende cinco estágios: 
(1) No estágio de Diagnóstico, o pesquisador e a organização cliente identificam e especificam uma oportunidade de melhoria na organização cliente, e a compatibilizam com as metas da pesquisa.

(2) No estágio de Planejamento da Ação, o pesquisador e a organização cliente consideram cursos alternativos de ação para realizar a melhoria identificada, e desenvolvem um plano para implementar um destes cursos alternativos de ação.

(3) No estágio de Tomada da Ação, o pesquisador e a organização cliente implementam o plano desenvolvido.

(4) No estágio de Avaliação, o pesquisador e a organização cliente avaliam os resultados da implementação do plano.

(5) No estágio de Especificação do Aprendizado o pesquisador identifica e descreve as descobertas gerais, baseadas nas informações geradas no estágio anterior.

\subsection{ROTEIRO PRÁTICO DE PA NO CONTEXTO DE MUDANÇA ORGANIZACIONAL}

Como já definido anteriormente neste trabalho, o objetivo da pesquisa-ação é aprender com a experiência, e aplicar este aprendizado para provocar a mudança. Como a dinâmica de um sistema social é freqüentemente mais aparente em tempos de mudança (Lewin, 1948), aprendizagem e mudança tem influência mutua. Porém, é mais provável que aprenda-se na experiência se agir-se com a intenção. Deve-se entrar na experiência com expectativas. Deve-se estar à procura de experiências nãometódicas. Deve-se buscar entendê-las.

\subsubsection{PROCESSO DE MUDANÇA BASEADO NA PA}

Uma das abordagens para administrar a mudança organizacional planejada é através da pesquisa-ação. Robbins (2002, pg.538) refere-se a ela como um processo de mudança baseado na coleta de dados, seguida da seleção de uma ação de mudança com base no que indicam os dados analisados. Sua importância reside em oferecer uma metodologia para a mudança planejada.

O processo da pesquisa-ação consiste em cinco etapas: diagnóstico, análise, feedback, ação e avaliação. Note-se que essas etapas se assemelham ao processo científico (Robbins, 2002). 
O agente de mudança, quase sempre um consultor externo no caso da pesquisaação, começa por levantar informações sobre os problemas, as preocupações e a necessidade de mudanças junto aos membros da organização. Esse diagnóstico é igual àquele feito por um médico para descobrir o que aflige um paciente. Na pesquisa-ação, o agente de mudanças faz perguntas, entrevista funcionários, examina registros e ouve as preocupações de todos.

O diagnóstico é seguido de análise. Quais os problemas que todos parecem compartilhar? Quais os padrões que eles parecem ter? O agente de mudança sintetiza essas informações em questões básicas, áreas de problemas e ações possíveis.

A PA inclui um extensivo envolvimento dos alvos da mudança, isto é, as pessoas envolvidas em qualquer programa de mudança devem estar ativamente envolvidas na identificação do problema e na participação da criação da solução para ele. Assim, a terceira etapa - feedback - determina o compartilhamento, com os funcionários, das descobertas das duas etapas anteriores. Os funcionários, com a ajuda do agente de mudança, desenvolvem planos de ação para a realização de qualquer mudança necessária.

Agora é a vez de entrar em cena a ação. Os funcionários, juntamente com o agente de mudança, realizam ações específicas para corrigir os problemas identificados.

Na opinião de Robbins (2002) a PA oferece, pelo menos, dois benefícios específicos para a organização: (i) seu foco é no problema, o agente de mudança busca objetivamente problemas, e o tipo de problema é que vai determinar o curso da ação de mudança; (ii) a resistência à mudança fica reduzida, pois a PA envolve profundamente os atores. Como os atores participam ativamente da etapa de feedback, o processo de mudança parece seguir sozinho, e passa a existir uma fonte interna de pressão sustentada para que a mudança ocorra de forma natural.

\subsubsection{FASES DA PESQUISA-AÇÃO}

Embora o projeto de PA não tenha forma totalmente predefinida, de acordo com Thiollent (1997, pg.58), considera-se que existem, no mínimo, quatro grandes fases, a saber: 
1) A fase exploratória - detectar os problemas, os atores, as capacidades de ação e os tipos de ação possível; 2) A fase de pesquisa aprofundada - instrumentos de coleta de dados que são discutidos e progressivamente interpretados pelos participantes; 3) A fase de ação - difundir os resultados, definir objetivos alcançáveis por meio de ações concretas, apresentar propostas que poderão ser negociadas entre as partes interessadas; 4) A fase de avaliação: observar, redirecionar o que realmente acontece e resgatar o conhecimento produzido no processo.

No inicio da experiência, estas fases são seqüenciais, mas na prática, existe entre as três últimas um tipo de vaivém ou mesmo de simultaneidade da pesquisa e da ação. No decorrer da PA, ocorre um efeito de aprendizagem, às vezes concebido como conscientização. Os atores e pesquisadores aprendem conjuntamente a identificar e resolver problemas dentro da situação em questão. A aprendizagem é difusa ao longo do processo e não é considerada como uma fase propriamente dita.

\subsubsection{ABORDAGEM DA PESQUISA-AÇÃO UTILIZADA}

Conforme descrito anteriormente, a pesquisa-ação acontece num processo cíclico de cinco fases. A abordagem requer primeiramente o estabelecimento de uma infraestrutura no sistema cliente, isto é, a criação de um ambiente de pesquisa. Então, cinco fases identificáveis são "iteragidas", conforme descrito na seção 4.4.5 através do: 1) diagnóstico, 2) planejamento da ação, 3) execução da ação, 4) avaliação, e 5) especificação do aprendizado.

A infra-estrutura na organização-cliente (sistema-cliente) é a especificação e a concordância que constituem o ambiente de pesquisa. Ela fornece a autoridade, ou sanções, sob as quais os pesquisadores e os profissionais da empresa estudada (pesquisada) podem especificar ações. A infra-estrutura no sistema-cliente também legitima tais ações com a expectativa expressa de que eventualmente estas ações se revelem benéficas para o cliente (ou empresa-estudada). Aspectos encontrados nesta concordância podem incluir as fronteiras do domínio da pesquisa, e a entrada e saída de pesquisadores. A infra-estrutura pode também reconhecer patentemente a acepção dos pesquisadores em disseminar o aprendizado obtido na pesquisa. Esta infraestrutura também deveria definir as responsabilidades mútuas entre os pesquisadores e o cliente. 
FIGURA 18 - O PROCESSO CICLICO DE 05 FASES DA PA (ABORDAGEM UTILIZADA)

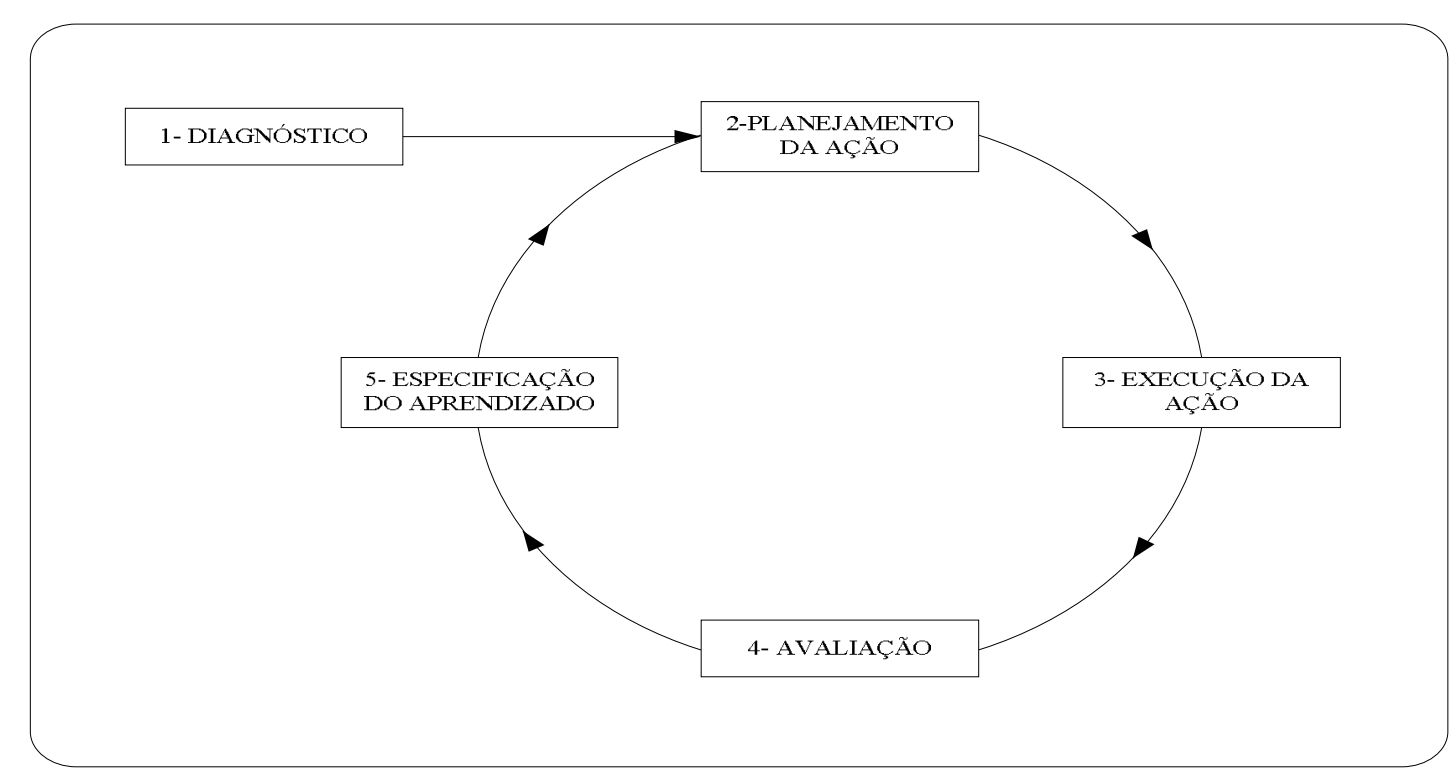

Fonte: Susman e Evered (1978) apud Thiollent (1997) Adaptado Pelo Autor

Por conveniência é útil pensar no profissional como parte de um conjunto de atores orientados à solução de problemas práticos, os quais são essencialmente cientistas organizacionais, ao invés de cientistas acadêmicos.

Um aspecto chave da infra-estrutura é a natureza colaborativa das tarefas. Os cientistas pesquisadores trabalham junto aos profissionais que estão localizados dentro do sistema-cliente. Estes indivíduos fornecem o conhecimento sobre o sujeito sistema e o insight necessário ao entendimento das anomalias em estudo

\subsubsection{DIAGNÓSTICO}

O diagnóstico corresponde à identificação dos problemas primários que são a causa subjacente do desejo de mudança da organização. O diagnóstico envolve autointerpretação do complexo problema organizacional, não através de redução ou simplificação, mas ao invés disto de maneira holística. Este diagnóstico desenvolverá certas suposições teóricas (por exemplo, uma hipótese de trabalho) sobre a natureza da organização e o domínio de seu problema.

\subsubsection{PLANEJAMENTO DA AÇÃO}

Pesquisadores e profissionais então colaboram na próxima atividade, planejamento da ação. Esta atividade especifica as ações organizacionais que deveriam 
remediar ou resolver aqueles problemas primários. A descoberta de ações planejadas é orientada por um esquema teórico, o qual indica, tanto um estado futuro desejado para a organização, como as mudanças que deveriam possibilitar tal estado futuro. O plano estabelece o alvo para a mudança, bem como a abordagem da mudança.

\subsubsection{EXECUÇÃO DA AÇÃO}

A execução de ação então implementa a ação planejada. Os pesquisadores e profissionais colaboram numa intervenção ativa na organização-cliente, implantando a realização de certas mudanças. Várias formas de estratégia de intervenção podem ser adotadas. Por exemplo, a intervenção pode ser diretiva, na qual a pesquisa "direciona" a mudança, ou não-diretiva, na qual busca-se a mudança indiretamente.

Táticas de intervenção podem também ser adotadas, como o recrutamento de lideres informais altamente capacitados e inteligentes, que atuariam como catalisadores de mudança e marcadores do ritmo desta mudança. O processo pode desenhar seus passos com base na psicologia social, no modelo de mudança proposto por Lewin (engajamento, descongelamento, movimento (aprendizagem) e recongelamento).

\subsubsection{AVALIAÇÃO}

Após as ações serem implementadas, os pesquisadores e profissionais colaborativos avaliam os resultados. A avaliação inclui determinar se os efeitos teóricos da ação foram realizados, e se estes efeitos resolveram os problemas. Onde a mudança obteve sucesso, a avaliação deve questionar criticamente se a ação tomada, entre a miríade de ações organizacionais rotineiras e não-rotineiras, foi à única causa do sucesso.

Onde a mudança não obteve sucesso, algum esquema para a próxima iteração do ciclo de pesquisa-ação (incluindo o ajuste de hipóteses) deveria ser estabelecido.

\subsubsection{ESPECIFICAÇÃO DO APRENDIZADO}

Enquanto a atividade de especificação do aprendizado é formalmente tomada por último, ela é usualmente um processo em andamento. $\mathrm{O}$ conhecimento ganho na pesquisa-ação, quer a ação tenha tido sucesso ou não, pode ser direcionado para três âmbitos: 
Primeiro o que Argyris e Schön (1978) chamaram "duplo loop de aprendizado", a reestruturação de normas organizacionais para refletir o novo conhecimento ganho pela organização durante a pesquisa.

Segundo, onde as mudanças não obtiveram sucesso, o conhecimento adicional pode prover fundamentos para a preparação de diagnóstico para futuras intervenções de pesquisa-ação.

Finalmente, o sucesso ou fracasso de modelos teóricos fornece importante conhecimento à comunidade científica, para tratar com futuros parâmetros de pesquisa.

O ciclo da pesquisa-ação pode continuar, quer as ações tenham sucesso ou não, para desenvolver um futuro conhecimento sobre a organização e sobre a validade de modelos teóricos relevantes. Como resultado dos estudos, a organização em si aprende mais sobre sua natureza e ambiente, e a constelação de elementos teóricos da comunidade científica continua a beneficiar e evoluir.

\subsubsection{PROCEDIMENTOS E ESTRATÉGIAS PARA A PA}

Os procedimentos a seguir descritos e utilizados na pesquisa estão baseados em Baskerville (1999) e Thiollent (1997), e envolve passos utilizados em seqüência no processo de PA. Idéias preliminares para esse tipo de objetivo foram sugeridas por Cunningham (1976) apud Thiollent (1997, pg.144) que tentou esquematizar formalmente os procedimentos da PA. 
FIGURA 19 - EXEMPLO DE SEQUÊNCIAS NO PROCESSO DE PESQUISA-AÇÃO

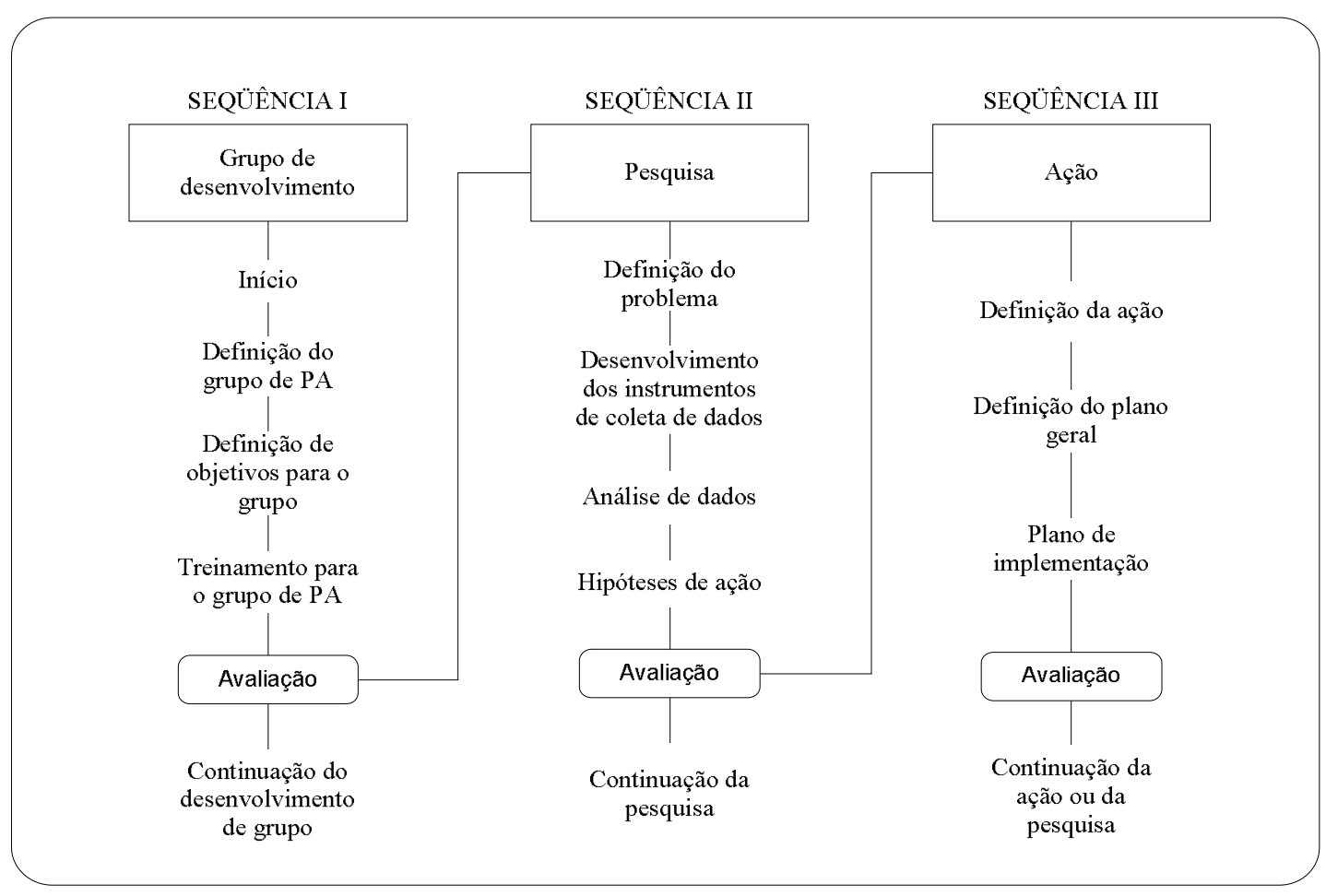

Fonte: Cunningham (1976:218) apud Thiollent (1997, pg.144)

Sete estratégias-chave são sugeridas por Baskerville (1999, pg.15) para condução de pesquisa-ação, e são conhecidas por aprimorar o rigor e a contribuição da pesquisa Cada uma delas está descrita e é comentada a seguir:

\subsubsection{CONDIDERAR A MUDANÇA DE PARADIGMA DE PESQUISA}

Desde que a pesquisa-ação não ocorre na tradicional filosofia positivista da ciência, e tem o domínio de questões de pesquisa ideais, deve-se certificar-se de que a pesquisa-ação é apropriada para a questão de pesquisa, e que seja do interesse de um público que aceite o aprendizado pós-positivista.

\subsubsection{ESTABELECER UMA CONCORDÂNCIA FORMAL A PESQUISA}

Deve-se assegurar aos sujeitos (atores) do estudo dar "consentimento informado", isto é, esclarecer os interesses das partes envolvidas, minimizando a tendenciosidade. Alguns indivíduos (atores), sujeitos da pesquisa, poderiam ver a conduta da pesquisa como uma prática disfarçada de consultoria, anti-ética. A 
concordância sobre consentimento e revelação é apenas parte da infra-estrutura sistema-cliente. O pesquisador deveria também arranjar claramente as garantias que autorizarão a equipe de pesquisa a iniciar a ação dentro da organização, isto é, buscar por consenso o comprometimento dos participantes na deliberação das decisões e na execução das tarefas.

\subsubsection{FORNECER UM ENUNCIADO TEÓRICO DO PROBLEMA}

O esquema teórico deve estar presente como uma premissa, de outra maneira a ação de intervenção não terá validade após o término da pesquisa. O documento de diagnóstico deveria incluir fundamentação teórica explícita. Enquanto a pesquisa progride, o surgimento de teoria deveria ser cuidadosamente registrado nos cadernos de pesquisa.

Neste sentido, com relação ao lugar da teoria na PA no contexto organizacional, Thiollent (1998, pg.55) esclarece que "não é possível desenvolver uma pesquisa independentemente de um quadro teórico de natureza sociológica, tecnológica ou política. (...) o papel da teoria consiste em gerar idéias, hipóteses ou diretrizes para orientar a pesquisa e as interpretações. (...)". Já com relação a importância e o papel das hipóteses na PA o autor (pg.56 e 57) pondera:

A hipótese desempenha um importante papel na organização da pesquisa: a partir de
sua formulação, o pesquisador identifica as informações necessárias, evita a dispersão,
focaliza determinados segmentos do campo de observação, seleciona os dados, etc (...)
Para fins descritivos, a hipótese qualitativa é utilizada para organizar a pesquisa em
torno de possíveis conexões ou implicações não-causais, mas suficientemente precisas
para se estabelecer que X tem algo a ver com Y na situação considerada. Além do
plano descritivo, a hipótese, sob forma de diretriz, é igualmente utilizada no plano
normativo no que toca à orientação da ação, com aspectos estratégicos e táticos. Trata-
se de hipóteses sobre o modo de alcançar determinados objetivos, sobre os meios de
tornar a ação mais eficiente e sobre a avaliação dos possíveis efeitos, desejados ou não.
A formulação deste tipo de hipóteses supõe que critérios (ou normas de decisão, ação e
avaliação) estejam claramente definidos e evidenciados entre os pesquisadores e
participantes. A verificação de tais hipóteses se dá exclusivamente na prática. (...) Uma
hipótese é definida como "tentativa de resposta operativa à questão contida no objeto".
As hipóteses são selecionadas em função da possibilidade de comprovação e de sua
pertinência com relação à ação. Cada hipótese é verificada a partir de indicadores
definidos como "elementos observáveis e mensuráveis escolhidos em função de sua
capacidade de verificação da hipótese". (...) 4.6.4.4 PLANEJAR MÉTODOS DE COLETA DE DADOS

A pesquisa-ação é empírica, embora os dados coletados sejam tipicamente qualitativos e interpretativos. Os dados podem ser coletados através de observações gravadas em fitas de áudio, entrevistas, experimentos de ação, e casos escritos pelos 
participantes. Experimentos de ação exigem discussões com os sujeitos envolvidos na ação, durante a própria tomada de ação; enquanto casos escritos pelos participantes são as recordações, escritas posteriormente, do sujeito seguindo a tomada de ação. Pesquisadores ou equipes de pesquisa podem também manter diários estruturados. Devem ser desenhadas e especificadas cuidadosa e claramente as técnicas de coleta de dados, quando estiver sendo ajustada a infra-estrutura de pesquisa, e deve-se retornar a este assunto quando se estiver planejando as ações.

\subsubsection{MANTER A COLABORAÇÃO E O APRENDIZADO DOS ATORES}

A pesquisa-ação requer uma cuidadosa preservação da colaboração com os sujeitos. Particularmente na pesquisa-ação participativa, os sujeitos deterão conhecimento chave de ambos os aspectos, teóricos e práticos, os quais são críticos para a descoberta de aspectos da teoria sob teste. Deve ser evitado o domínio das fases de diagnóstico e planejamento (por exemplo, assumir o papel impositivo do consultor externo).

\subsubsection{PROMOVER ITERAÇÕES}

Pesquisa-ação é também tipicamente cíclica. Ações fracassadas (em termos da situação-problema imediata) são tão importantes quanto, e talvez mais importantes do que, as ações com sucesso. A ação deveria continuar até que a situação-problema imediata seja relevada. As ações que relevam um problema imediato são evidências poderosas da efetividade prática de uma teoria subjacente.

\subsubsection{GENERALIZAR ADEQUADAMENTE}

A generalidade de teorias desenvolvidas na ação é fundamentada em generalizações dedutivas. Este tipo de generabilidade é compartilhado com experimentos de laboratório. Enunciados gerais não podem ser feitos com base no número de observações (uma noção estatística), mas ao invés disto, sobre um exemplo representativo de uma observação. Generalizações devem ser temperadas com uma interpretação da extensão de cenários similares aos quais espera-se que a teoria possa ser aplicada. 


\subsection{TÉCNICAS DE PESQUISA APLICADA AO CASO ESTUDADO}

Nesta pesquisa-ação foram utilizados vários instrumentos para a coleta de dados, mas o principal foi a observação participante. Para coleta de dados em pesquisaação, Gil (2002, pg.46) esclarece que a tendência é a adotar preferencialmente procedimentos flexíveis, isto é, ao longo do processo de pesquisa os objetos são constantemente redefinidos, com base nas decisões dos seminários e reuniões, nas quais foram utilizados a observação participante, análise de conteúdo, sociodrama, entrevistas, questionários e dinâmicas de grupo.

\subsubsection{OBSERVAÇÃO PARTICIPANTE}

A observação participante, ou observação ativa, consiste na participação real do conhecimento na vida da comunidade, do grupo ou de uma situação determinada. $\mathrm{O}$ observador assume, pelo menos até certo ponto, o papel de membro de um grupo. De acordo com Gil (1999) pode se definir observação participante "como a técnica pela qual se chega a conhecimento da vida de um grupo a partir do interior dele mesmo".

Ainda de acordo com este autor (1999, pg.113) a observação participante pode assumir duas formas distintas:

(a) natural, quando o observador pertence à mesma comunidade ou grupo que investiga (que é especificamente o caso desta pesquisa: o observador é membro do grupo); e (b) artificial, quando o observador se integra ao grupo com o objetivo de realizar uma investigação.

A observação participante, na qual o observador tem papel ativo no grupo em estudo, fornece certas oportunidades incomuns para a coleta de dados. Yin (2001, pg.116) destaca as seguintes vantagens:

(i) sua habilidade de conseguir permissão para participar de eventos ou grupos que são, de outro modo, inacessíveis à investigação científica - em alguns tipos de pesquisa não há outra forma de coletar evidências; (ii) capacidade de se perceber a realidade do ponto de vista de alguém de dentro do grupo, e não do ponto de vista externo - de valor inestimável para produzir um retrato "acurado" do fenômeno pesquisado; (iii) surgem outras oportunidades porque pode-se ter a capacidade de manipular eventos menos importantes - por exemplo uma reunião de grupo. Este autor cita como os maiores problemas aqueles relacionados com possíveis pontos de vista tendenciosos que possam ser produzidos. Já foi tratado, noutra parte deste trabalho, dos "antídotos" para este problema.

A observação participante apresenta, em relação às outras modalidades de observação, vantagens que são destacadas a seguir (Gil; 1999 pg.114): 
a) facilita o rápido acesso a dados sobre situações habituais em que os membros das comunidades se encontram envolvidos; b) possibilita o acesso a dados que a comunidade ou grupo considera de domínio privado; c) possibilita captar as palavras de esclarecimento que acompanham o comportamento dos observados. Com relação às desvantagens este autor cita as restrições determinadas pela assunção de papéis pelo pesquisador.

\subsubsection{DINÂMICA DE GRUPO E SEMINÁRIOS}

A dinâmica de grupo constitui um campo de pesquisa voltado para o estudo da natureza do grupo, para leis que regem seu desenvolvimento e para as relações indivíduo-grupo, grupo-grupo e grupo-instituições (Minicucci, 2002).

Os estudos pioneiros de Kurt Lewin e de seus discípulos, sobre campo, praticamente marcaram o aparecimento desta disciplina. A partir de seus estudos, especialistas em dinâmica de grupo vêm empregando grande variedade de métodos de pesquisa. Possibilitou-se, dessa forma, que a vida em grupo fosse trazida para o laboratório e submetida a experimentação controlada.

Isso tem levado a uma grande variedade de tratamentos e de abordagens teóricas, que refletem filosofias, escolas de pensamento e teorias sociais pertinentes a cada orientação de pesquisa, dentre as quais pode-se destacar: (i) a teoria de campo criada por Lewin - propõe que o comportamento é o produto de um campo de determinantes interdependentes conhecido como espaço de vida; e (ii) teoria sociométrica criada por Moreno, estuda essencialmente as escolhas interpessoais que ligam o grupo às pessoas.

Na opinião de Thiollent (1998, pg.58) de importância fundamental para a PA organizacional, o papel do seminário consiste em examinar, discutir e tomar decisões acerca do processo de investigação. O seminário centraliza todas as informações coletadas e discute as interpretações. Suas reuniões dão lugar a "atas". Os seminários têm como tarefas principais (pg.59):

(1) Definir o tema e equacionar os problemas para os quais a pesquisa foi solicitada; (2) Elaborar a problemática na qual serão tratados os problemas e as correspondentes hipóteses de pesquisa; (3) Constituir os grupos de estudos e equipes de pesquisa. Coordenar suas atividades; (4) Centralizar as informações provenientes das diversas fontes e grupos; (5) Elaborar as interpretações; (6) Buscar soluções e definir diretrizes de ação; (7) Acompanhar e avaliar as ações; (8) Divulgar os resultados pelos canais apropriados.

Dentro do funcionamento normal do seminário, Thiollent (1998, pg.60) define o papel dos pesquisadores que consiste em: 
(1) Colocar a disposição dos participantes os conhecimentos de ordem teórica ou prática para facilitar a discussão dos problemas; (2) Elaborar as atas das reuniões, elaborar os registros de informação coletada e os relatórios de síntese; (3) Em estreita colaboração com os demais participantes, conceber e aplicar, no desenvolvimento do projeto, modalidades de ação; (4) Participar numa reflexão global para eventuais generalizações e discussão dos resultados no quadro mais abrangente das ciências sociais ou de outras disciplinas implicadas no problema.

Os principais assuntos debatidos em cada sessão são descritos sob forma de atas e analisados em seguida. As atas e relatórios são concebidos e arquivados de modo adequado a uma fácil consulta por parte de qualquer participante.

\subsubsection{QUESTIONÁRIO}

Pode-se definir questionário como a técnica de investigação composta por um número mais ou menos elevado de questões apresentadas por escrito às pessoas, tendo por objetivo o conhecimento de opiniões e expectativas (Gil, 1999)

Os questionários nesta pesquisa foram propostos por escrito aos respondentes, e na maioria das vezes utilizando-se de ferramentas como o e-mail para fazer a comunicação entre o pesquisador e os agentes entrevistados, neste caso, designados como questionários auto-aplicados.

As principais vantagens dos questionários com relação às entrevistas, de acordo com Gil (1999) podem ser:

a) possibilita atingir grande número de pessoas, mesmo que estejam dispersas numa área geográfica muito extensa; b) implica menores gastos com pessoal, pois não exige treinamento de pesquisadores; c) garante o anonimato das respostas; d) permite que as pessoas o respondam no momento em que julgarem mais conveniente; e e) não expõe os pesquisados à influência das opiniões e do aspecto pessoal do entrevistado.

As desvantagens relacionadas por este autor foram eliminadas, pois com o uso do e-mail todas as dúvidas com relação às questões de pesquisa eram amplamente debatidas e esclarecidas.

\subsubsection{DIÁRIO E REGISTRO DE ATIVIDADES}

Consistem em anotações e registros importantes, principalmente as falas das pessoas envolvidas no processo, e as atas das reuniões realizadas. Em cada uma das reuniões realizadas durante a pesquisa o processo era assim encaminhado:

(i) discussão da ordem do dia dos assuntos a serem debatidos, o que gerava um documento para todos os participantes poderem preparar-se para os debates; 
(ii) os temas-problema eram divididos por dimensão organizacional e discutidos em pequenos grupos de 05 membros (equipe menor);

(iii) após as reuniões os temas e decisões aprovados são colocados em ata e publicados;

(iv) em cada reunião 03 pesquisas de avaliação são efetuadas e o feedback é retornado na próxima reunião. Todos os documentos são, também, disponibilizados em arquivo na rede (texto e fotos) com acesso ilimitado para consulta.

\subsubsection{INFORMANTE-CHAVE}

Foi criado uma equipe com um representante de cada área funcional da empresa (líder) e da cúpula diretiva, que acompanha o projeto como uma atividade e papel distintos das atividades diárias, junto com o pesquisador. Este grupo foi escolhido como "lideres da mudança", composto de 10 pessoas. Houve, também, um registro das interações com esse grupo, com o mesmo modelo de registro das reuniões com o grupo maior.

\subsubsection{O ESTUDO DE CASO}

\subsubsection{POPULAÇÃO}

A população desta pesquisa foi composta por todos os setores da empresa contábil diretamente envolvidas, ou seja, todos os funcionários, sócios e parceiros de serviço permanente, num total de 32 pessoas.

\subsubsection{NÍVEL E UNIDADE DE ANÁLISE}

Nível de análise: Mudança organizacional nas dimensões Estratégia, estrutura, processos, tecnologia e pessoas.

Unidade de análise: Os processos da empresa contábil pesquisada. É importante esclarecer que como o paradigma de pesquisa escolhido foi a pesquisaação, com as suas características peculiares já devidamente relatadas, as unidades de análise, ao longo do processo de pesquisa e por suas próprias características, foram sendo alteradas. Analisou-se as mudanças na medida em que foram ocorrendo no nível individual, de grupo e da organização. 
Entretanto, visando possibilitar a replicação da pesquisa em outras organizações similares em termos de tamanho e complexidade, o pesquisador focou no mapeamento e análise dos processos empresariais, contemplando o próprio desenho da pesquisa que relata a situação atual (o que é) e a situação futura (o que deverá ser), pois com este limite foi possível materializar os resultados da pesquisa.

Um ponto importante a observar é que o processo de mudança - objeto da pesquisa não se encerra com ela. A pesquisa concentrou-se em analisar os fatos no período de 12 meses, ou seja, esta pesquisa relata e analisa as mudanças ocorridas e provocadas pela própria intervenção do pesquisador no período entre 01 de Janeiro a 31 de Dezembro de 2002.

\subsubsection{COLETA DE DADOS}

A coleta de dados é efetuada por grupos de observação e pesquisadores sob controle do seminário central. Sejam quais forem as técnicas utilizadas, os grupos de observação compostos por pesquisadores e de participantes comuns procuram a informação que é julgada necessária para o andamento da pesquisa, respondendo a solicitações do seminário central. É claro que os grupos podem fornecer outras informações que não estavam previstas, o que permite aumentar a riqueza das descrições. Todas as informações coletadas pelos diversos grupos de observação e pesquisadores de campo são transferidas ao seminário central, onde são discutidas, analisadas, interpretadas, etc. Com relação a aplicação de questionários Thiollent (1998, pg.65) é da opinião que:

Na pesquisa-ação nem sempre são aplicados questionários codificados, pois, quando a população é de pequena dimensão e sua estruturação em grupos permite a fácil realização de discussões, é possível obter informações principalmente de modo coletivo, sem administração de questionários individuais.

\subsection{PROBLEMÁTICA DA MUDANÇA}

O tema da mudança é central em qualquer proposta de pesquisa interveniente na realidade organizacional. Como elementos de uma problemática de mudança, no contexto considerado, destacam-se na visão de Thiollent (1997, pg.106) quatros aspectos:

(1) A concepção de vários tipos de mudanças em contexto organizacional (as ações propõem mudanças qualitativas, com alteração de regras ou de estrutura); (2) A diferenciação da capacidade de mudança em função dos atores implicados (as mudanças propostas atingiram todos os níveis hierárquicos); (3) $\mathrm{O}$ alcance das ações 
ou propostas (mudanças de regras da organização no funcionamento da estrutura, nos processos gerenciais, nos mecanismos de avaliação de resultados e de desempenho); (4) O encaminhamento da mudança pela base e pelo topo (o ideal consiste na busca de equilíbrio entre um encaminhamento que venha de baixo e, simultaneamente, esteja estimulado por uma parte do topo).

\subsubsection{RELAÇÃO ENTRE LINGUAGEM E AÇÃO}

No processo de PA em organização, em que interagem vários atores cujo "peso" é muito diferente em termos de poder, prestígio ou visão, a linguagem enquanto instrumento de comunicação e de decisão - exerce importante papel (Thiollent: 1997).

A oposição (ou descontinuidade) entre uma situação real, hoje existente, e uma situação ideal a ser alcançada amanhã desempenha função importante não somente na formulação de perguntas "propositivas" para captar as sugestões dos respondentes, mas também na fase de ação propriamente dita. Qualquer ação pressupõe que o ideal a ser realizado seja diferente do presente vivenciado (Thiollent: 1997).

\subsubsection{COMO FAZER ACONTECER?}

Como fazer acontecer? Esta é uma pergunta que se coloca quando alguém pensa no problema da relação entre linguagem e ação (Thiollent; 1997 pg.116).

A dificuldade de passar da linguagem para a ação é um tema que está sempre presente no decurso da PA. No tocante aos problemas de organização e às possíveis soluções, existe nítida separação entre o pensar (ou falar) e o agir. Até mesmo as pessoas que estão sensibilizadas ao problema não conseguem estabelecer permanentemente uma relação entre o que elas dizem e fazem.

Em geral, uma mudança em larga escala e, portanto cultural pressupõe mudanças no uso da linguagem. Mudando as palavras ou suas definições, é possível introduzir pequenas mudanças nos modos de encarar as relações e os problemas da organização.

A elaboração de um projeto de $\mathrm{PA}$ em organizações não é um procedimento de percurso predeterminado. À luz dos princípios de metodologia geral, cada passo da investigação e o desencadeamento da ação requer a geração de novas idéias, em parte sugeridas pelos pesquisadores e em parte expressadas pelos demais participantes.

O capítulo seguinte apresenta os resultados da aplicação destes métodos na pesquisa e as conclusões sobre as questões e os problemas de pesquisa. 


\section{CAPÍTULO V - RESUMO DAS CONCLUSÕES}

Este capítulo apresenta os resultados e as conclusões sobre os problemas e questões de pesquisa. Inicialmente descreve-se em detalhes cada uma das repetições da pesquisa, estruturada na forma do processo cíclico de 05 fases da pesquisa-ação, refletindo nas seções principais essas fases (1-diagnóstico, 2- planejamento da ação, 3- execução da ação, 4- avaliação, e 5- especificação do aprendizado) conforme discutido e desenvolvido no capítulo anterior através das figuras 19 e 20 .

Em cada uma das repetições efetuadas, de acordo com a mudança efetiva na dimensão organizacional estuda, é feita a especificação do aprendizado de maneira geral e em seguida apresentado um quadro com a avaliação das principais variáveis envolvidas que foram observadas e avaliadas pelo pesquisador quanto a qualidade da aplicação nos diferentes níveis deficiente, regular e adequada, dependo da profundidade com que a mudança foi implementada e o conhecimento absorvido. $\mathrm{O}$ processo de pesquisa do ponto de vista organizacional foi administrado como um projeto.

\section{ANÁLISE DOS DADOS COLETADOS}

Ao longo da pesquisa houve uma interação muito forte entre os membros do cliente (empresa pesquisada) e o pesquisador, até porque a mudança é um processo contínuo que foi se construindo durante ao longo do trabalho. $\mathrm{O}$ pesquisador procurou relatar as conclusões do grupo, na medida do possível, respeitando a linguagem utilizada pelos atores envolvidos, e em muitos casos as conclusões (planejamento das ações) e decisões (especificação das ações) foram relatadas na forma que foram sendo compreendidas e estão descritas na pesquisa, identificadas no texto ou no desenho pelas letras maiúsculas VG (voz do grupo) no fim do parágrafo e o (conteúdo sublinhado), diferenciando-se assim dos relatos das conclusões do próprio pesquisador. Em muitos casos a compreensão e a aplicação da teoria no caso estudado veio das discussões dos atores envolvidos com a orientação do pesquisador, como por exemplo, as conclusões sobre a avaliação e escolha do sistema integrado a ser utilizado. O próprio Thiollent (1997, pg.37) esclarece que existe uma relação muito forte ligando a articulação da pesquisa com a ação. Tema central da metodologia pesquisa-ação, a 
articulação da pesquisa e da ação é concebida de modo diferenciado e em função de uma tipologia das formas de participação. Os resultados da aplicação destes métodos na pesquisa e as conclusões sobre as questões e os problemas de pesquisa estão relatados a seguir, porém, comenta-se antes a forma como o processo foi sendo administrado.

\subsection{ADMINISTRAÇÃO DA MUDANÇA E OS PROCESSOS DE GERÊNCIA DO PROJETO}

A mudança organizacional decorrente da mudança na arquitetura tecnológica e organizacional, requer, para sua administração eficaz a utilização da abordagem gestão de projetos, objetivando atingir tanto o sistema técnico quanto o sistema social na empresa contábil.

A administração de um projeto abrange dois problemas principais: (i) a administração do projeto em si, como sistema de recursos e atividades que procuram fornecer um produto (no caso pesquisa a implementação de um sistema empresarial integradoSistema Empresarial Integrado - ERP) dentro de um prazo; (ii) a administração do projeto dentro de um contexto organizacional.

Este caso é o que foi aplicado para apoiar o estudo, definido quando do contrato estabelecido com o pesquisador. O projeto é um empreendimento que exige consenso, formação e coordenação de equipes, divisão de responsabilidades, apoio da alta administração e coordenação de fornecedores internos e externos, ou seja, os problemas são os inerentes a administração de um sistema temporário dentro de outro, permanente, a estrutura organizacional da empresa contábil que disponibiliza os recursos. Assim como os produtos, os projetos também apresentam um Ciclo de Vida. Os projetos sempre apresentam um início e um fim determinados. Entre este início e o final do projeto ele sofre todo um desenvolvimento, uma estruturação, uma implantação e, finalmente, uma conclusão.

O objetivo da Gestão de Projetos é o de alcançar controle adequado do projeto de modo a assegurar sua conclusão no prazo e no orçamento determinados, obtendo a especificação estipulada. O trinômio custo, prazo e especificação sempre estão presente nos projetos conforme sua própria definição. Qualquer alteração em um deles afeta um ou os outros dois parâmetros. Os dois pontos pontos-chave, que sempre 
devem estar presentes na Gestão de Projetos, estão relacionados à escolha e presença do gestor do projeto, bem como com o relacionamento cooperativo que deve existir, desde o início, entre os profissionais que vão atuar no projeto. Estes pontos-chave são: responsabilidade unificada em um elemento e planejamento e controle unificado.

O início do projeto deve ser marcado pela definição de três elementos: o patrocinador (sócios da empresa contábil), o gerente do projeto e a equipe básica. Tanto a pirâmide hierárquica - que estabelece o poder - quanto a funcional - que estabelece conhecimentos específicos - tendem a conviver numa organização. Um procedimento importante é destacarmos a necessária interação (patrocinador, gestor do projeto e equipe básica) para a definição do norte para o projeto.

O controle dos processos e atividades de um projeto são fundamentais para o seu sucesso, e para facilitar o atingimento deste objetivo foi necessária à utilização de um sistema apropriado denominado comercialmente de Project da Microsoft.

Administrar um projeto significa planejar, organizar, executar e controlar as fases de seu ciclo de vida. Esses processos da administração de um projeto podem ser chamados processos do projeto, conforme descritos na figura seguinte, e são necessários para o projeto todo e para cada fase do seu ciclo de vida. Em termos práticos para administrar um projeto faz-se necessário: (i) preparar o projeto (conceber o produto e fazer a estimativa do tempo e dos recursos necessários); (ii) Mobilizar os recursos; (iii) Realizar as atividades; (iv) Encerrar o projeto.

Observou-se desde o inicio dos trabalhos que o prazo do projeto iria muito além do tempo relatado na pesquisa, estimado inicialmente em 36 (trinta e seis) meses, em função de dois fatores principais: (i) que a equipe do projeto fazia parte do quadro funcional da empresa contábil, isto é, a equipe de projeto teria papéis um funcional e outro ligado ao projeto; (ii) Muitas das ferramentas necessárias ao desenvolvimento do projeto (metodologias-sistemas-técnicas) teriam que ser incorporadas pelo grupo e pela equipa da empresa contábil através de treinamento ou cursos montados internamente, como, por exemplo, o curso de administração de projetos. 
TABELA 4 - PROCESSOS PRINCIPAIS DE GERENCIA DE PROJETO

\begin{tabular}{|c|c|c|c|}
\hline \multicolumn{2}{|c|}{ PROCESSOS E ATIVIDADES SUBORDINADAS } & \multicolumn{2}{|c|}{$\begin{array}{l}\text { PROCESSOS E ATIVIDADES } \\
\text { SUBORDINADAS }\end{array}$} \\
\hline Processo & Atividade & Processo & Atividade \\
\hline Iniciar & 1. Inicio & & \\
\hline Planejar & 1. Planejar Escopo & Executar & 1. Planejar execuções \\
\hline & 2. Definir Escopo & & 2. Verificar Escopo \\
\hline & 3. Definir Atividade & & 3. Garantir Qualidade \\
\hline & 4. Seqüenciar Atividade & & 4. Desenvolver time \\
\hline & 5. Estimar duraçào da atividade & & 5. Distribuir informaçào \\
\hline & 6. Desenvolver Plano & & 6. Propostas \\
\hline & 7. Planejar Recursos & & 7. Selecionar fontes \\
\hline & 8. Estimar custos & & 8. Administrar Contratos \\
\hline & 9. Orçar custos & & \\
\hline & 10. Desenvolver plano do projeto & & \\
\hline Controlar & 1. Planejar qualidade & Controlar & 1. Controle de mudanças global \\
\hline & 2. Planejamento organizacional & & $\begin{array}{l}\text { 2. Controle de mudança de } \\
\text { escopo }\end{array}$ \\
\hline & 3. Aquisiçăo de Staff & & 3. Controle de plano \\
\hline & 4. Identificação de risco & & 4. Controle de Custo \\
\hline & 5. Quantificaçào de risco & & 5. Controle de Qualidade \\
\hline & $\begin{array}{l}\text { 6. Desenvolvimento da resposta ao } \\
\text { risco }\end{array}$ & & 6. Reportar Performance \\
\hline & 7. Planejamento de aquisiçào & & 7. Controle de resposta ao risco \\
\hline & 8. Planejamento de propostas & & \\
\hline & & & \\
\hline & & Fechar & 1. Encerrar contrato \\
\hline & & & 2. Fechamento administrativo \\
\hline & & & \\
\hline
\end{tabular}

Fonte: Manual PMBOK 2000 - Adaptado pelo Autor

\subsection{CRIAÇÃO DA EQUIPE DE AGENTES DA MUDANÇA}

Seguindo o esquema proposto de procedimentos da PA enunciado no tópico (4.6.4) através da (figura 20) do capítulo anterior, houve a definição do grupo de PA denominada de "equipe promil" com os agentes da mudança composta por um representante (líder) de cada área funcional da empresa e da cúpula diretiva, que acompanha o projeto como uma atividade e papel distintos das atividades diárias, junto com o pesquisador.

O grupo escolhido é composto por 10 pessoas, cujo organograma funcional é apresentado a seguir, liderado por um "gerente do projeto" escolhido entre seus membros e com dedicação exclusiva e papel funcional especificamente voltado ao projeto. 
FIGURA 20 - ORGANOGRAMA FUNCIONAL DA EQUIPE DO PROJETO ORGANIZACIONAL (AGENTES DA MUDANÇA)

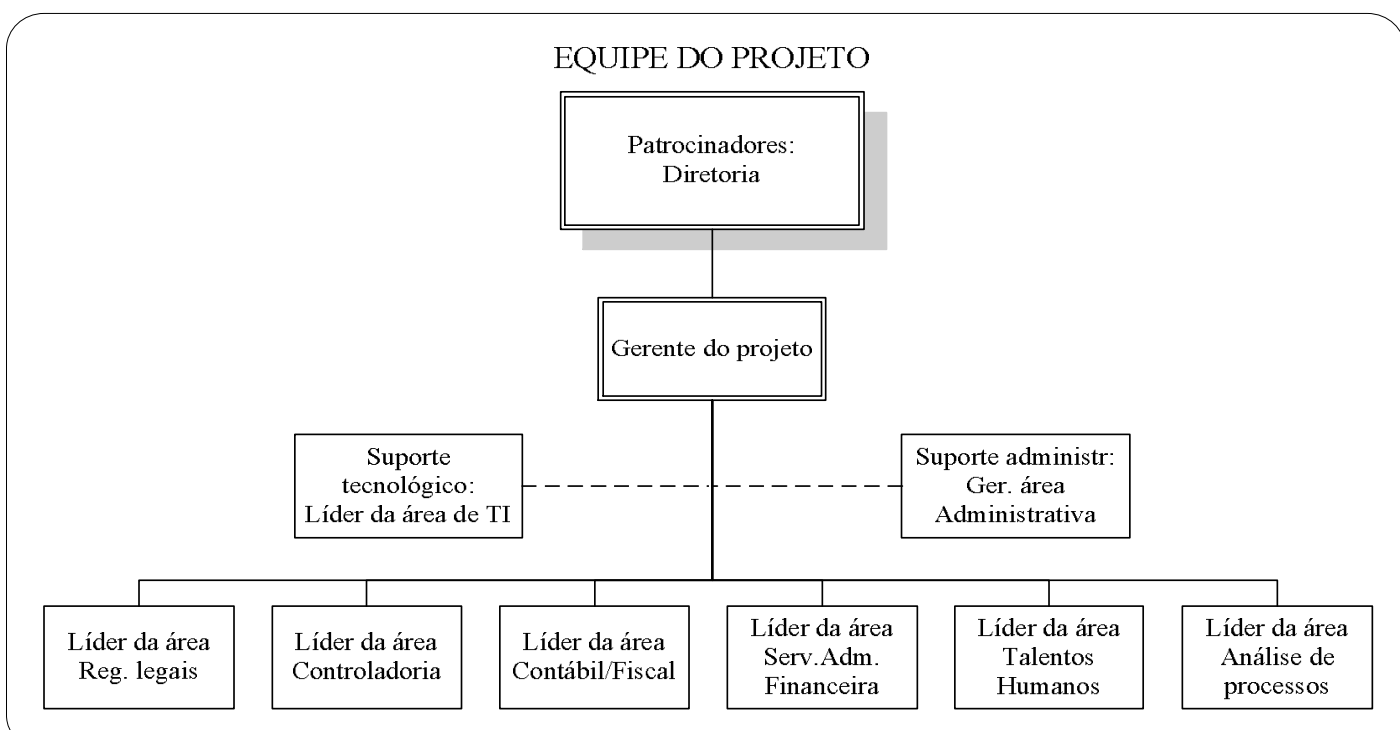

\section{FIGURA 20: ORGANOGRAMA FUNCIONAL DA EQUIPE DO PROJETO ORGANIZACIONAL (AGENTES DA MUDANÇA)}

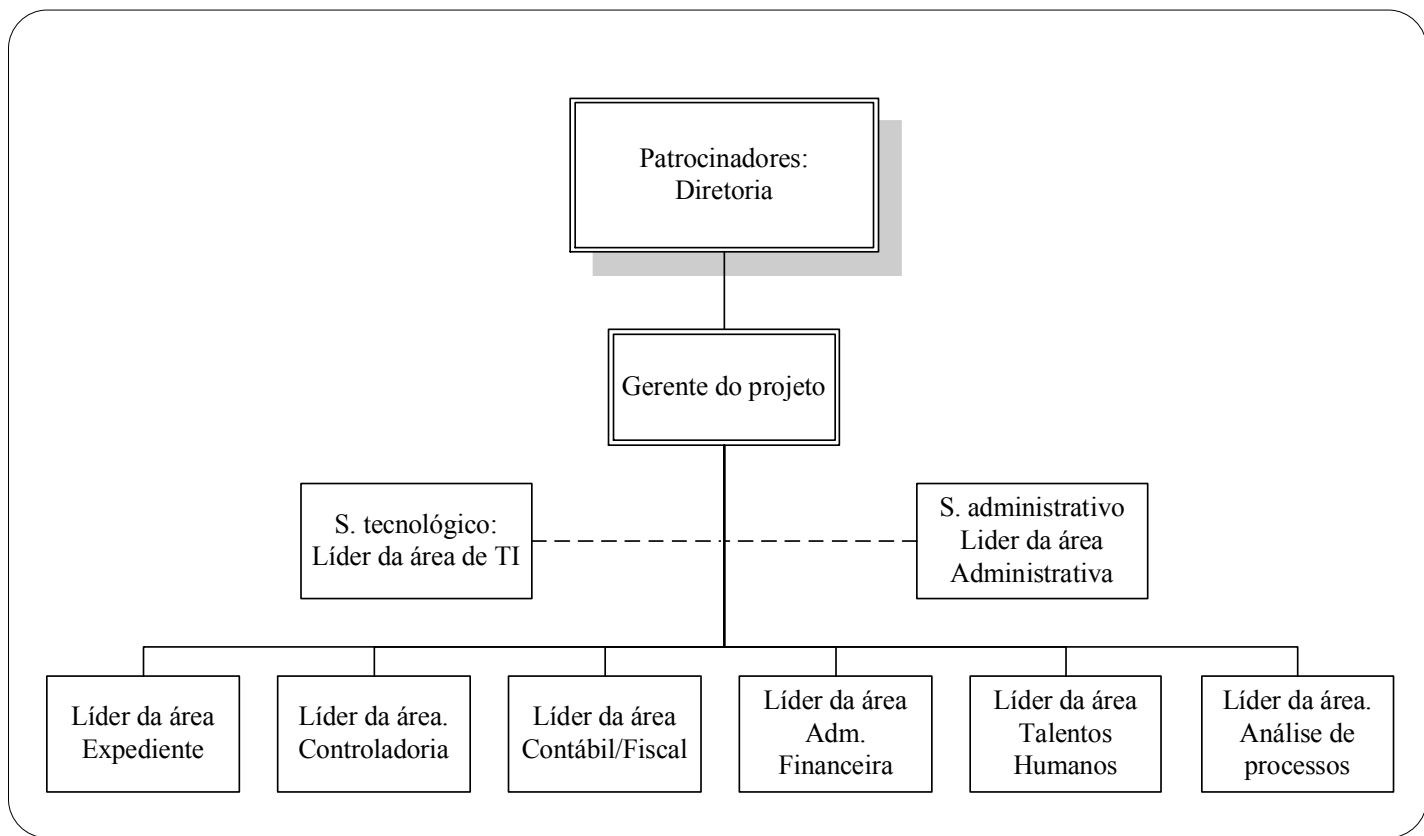

Fonte: Elaborado pelo Autor

Decidiu-se tratar a mudança na abordagem de projeto, tendo como principal objetivo implementar um sistema empresarial integradoSistema Empresarial Integrado (ERP). Este grupo, através do gerente desenvolveu o planejamento do projeto, definindo através do uso de um software específico para gerir projeto toda a sua agenda e etapas a serem cumpridas visando atingir o objetivo principal. 
$\mathrm{Na}$ reunião inicial esta equipe recebeu as principais noções sobre a pesquisaação e discutiu com o pesquisador as fases baseadas na proposta de Thiollent (1997) divididas nas fases exploratória, de pesquisa aprofundada, de ação e avaliação cujas reuniões ocorreram uma vez por semana desde o inicio do projeto, até a sua conclusão.

A empresa toda foi dividida em 05 grupos, cada grupo recebendo a missão, a partir do levantamento de todos os problemas que envolvem a empresa, de apresentar soluções e planejar ações de acordo com as 05 dimensões organizacionais que sofreram alterações em função da mudança na tecnologia.

\subsection{O PROCESSO CICLICO E AS DESCOBERTAS DA PESQUISA}

As descobertas da pesquisa serão evidenciadas utilizando-se o processo cíclico da Pesquisa-Ação, conforme descrito em detalhes no capítulo IV tópico (4.6.3) através da figura (20), de acordo com os problemas e questões de pesquisa evidenciadas no Capítulo II.

No final de cada fase são efetuados os comentários identificando o referencial teórico utilizado, bem como as variáveis de pesquisa identificadas com base na proposta de Saccol, Macadar e Soares (2001) e seu andamento no processo de mudança, de acordo com as dimensões organizacionais propostas no desenho da pesquisa (figura 7 tópico 1.7.6 do cap.ítulo I) e descritas no tópico (3.1.2 do cap.ítulo III)

É importante salientar a preocupação durante todo o processo de pesquisa com o esquema teórico, estando presente como uma premissa para validar a ação de intervenção. Enquanto a pesquisa progrediu o surgimento da teoria foi sendo testada e relatada.

Os problemas de pesquisa que serão tratados a seguir no modelo de PA desenvolvido, para fins deste estudo, foram agrupados e serão tratados nas dimensões organizacionais referentes à administração da mudança vista como o equilíbrio de um sistema constituído de cinco variáveis interativas (estratégia-tecnologia-estruturaprocessos--pessoas) dentro da empresa contábil, sabendo-se que uma mudança em uma variável inicia uma cadeia de eventos que, se adequadamente administrada, exige 
ajustes nas demais variáveis para obter um novo estado de equilíbrio. Esta é uma das descobertas desta pesquisa.

FIGURA 21FIGURA 21 - O PROCESSO CICLICO DE 05 ESTÁGIOS DA PA (ABORDAGEM UTILIZADA PARA DESCREVER AS DESCOBERTAS DE PESQUISA)

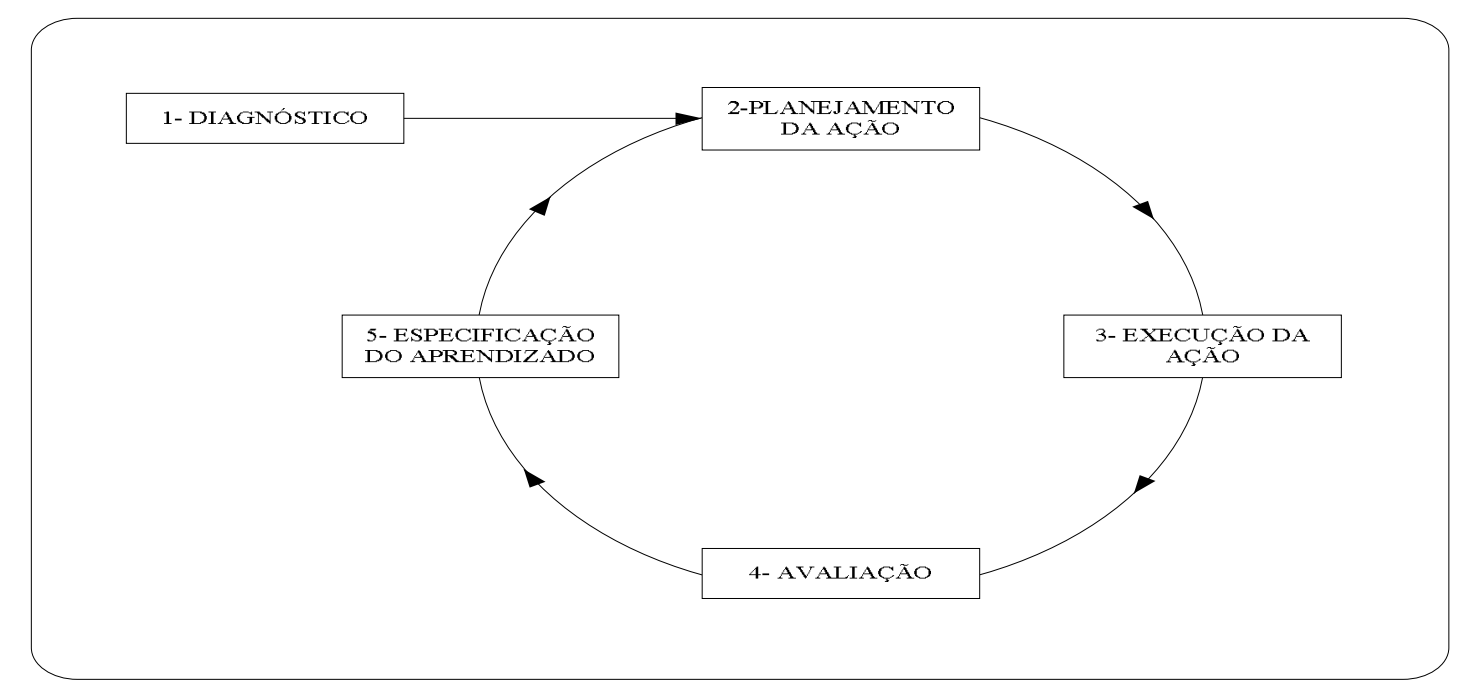

Fonte: Susman e Evered (1978) apud Thiollent (1997) Adaptado Pelo Autor

(1) No estágio de Diagnóstico, o pesquisador e a organização cliente identificam e especificam uma oportunidade de melhoria na organização cliente, e a compatibilizam com as metas da pesquisa.

(2) No estágio de Planejamento da Ação, o pesquisador e a organização cliente consideram cursos alternativos de ação para realizar a melhoria identificada, e desenvolvem um plano para implementar um destes cursos alternativos de ação.

(3) No estágio de Tomada da Ação, o pesquisador e a organização cliente implementam o plano desenvolvido.

(4) No estágio de Avaliação, o pesquisador e a organização cliente avaliam os resultados da implementação do plano.

(5) No estágio de Especificação do Aprendizado o pesquisador identifica e descreve as descobertas gerais, baseadas nas informações geradas no estágio anterior.

\subsubsection{DIMENSÃO ESTRATÉGIA}

Problema na $1^{a}$ Iteração: A inexistência de dados dos eventos de negócios, ou sua existência de forma não estruturada contabilmente - na empresa-cliente, impede a 
diversificação estratégica das empresas contábeis e limita, por um lado, o potencial do contador, e por outro o crescimento e a vida destas empresas.

Quais ações proporcionariam a diversificação estratégica das empresas contábeis, para inserir a consultoria de gestão às Pequenas e Médias Empresas em seu portfólio de atividades, posto que esses serviços estão dentro do escopo da contabilidade gerencial, em forte sinergia com o potencial do contador?

Como proporcionar ganhos de produtividade nas empresas contábeis, e ao mesmo tempo, ganhos de qualidade decisória com informação contábil distribuída na empresa-cliente?

\subsubsection{RESPOSTA E ANÁLISE DO APRENDIZADO APLICANDO OS 05 ESTÁGIOS DE PA}

Implantação de um sistema de informação contábil que integre de forma natural a contabilidade financeira e a contabilidade gerencial, automatizando as transações nas empresas-cliente. Isso contribuiria para o resgate da missão tradicional da contabilidade e proporcionaria o desenvolvimento de novas missões específicas, entre elas, consultoria de gestão.

(1) Diagnóstico: Potencial do contador (empresa contábil) limitado a questões fiscais (contabilidade financeira)

(2) Planejamento da Ação: Consultoria de gestão (diversificação estratégica)

(3) Tomada da Ação: Implantação de sistema de contabilidade Gerencial

(4) Avaliação: O retrabalho continua e os custos da informação gerada são maiores que os benefícios para a empresa-cliente.

(5) Especificação do Aprendizado: A consultoria de gestão só poderá ser implementada trazendo benefícios mensuráveis para a empresa contábil e ganhos no processo de decisão para a empresa-cliente através da implantação de um sistema de informação contábil que integre de forma natural a contabilidade financeira e a contabilidade gerencial, automatizando as transações na empresa-cliente. A figura seguinte mostra de forma clara o processo de aprendizagem que ocorreu decorrente das possibilidades que o sistema empresarial integradoSistema Empresarial Integrado ERP e as oportunidades que surgirão tanto para a empresa contábil quanto a empresa- 
cliente pelo uso dessa tecnologia, e que poderão ser tornadas realidade através das mudanças na visão estratégica da empresa contábil.

FIGURA 22FIGURA 22 - DIVERSIFICAÇÃO ESTRATÉGICA DA EMPRESA CONTÁBIL ATRAVÉS DA CONSULTORIA DE GESTÃO A PME, RESGATANDO A CONTABILIDADE GERENCIAL ATRAVÉS DA IMPLANTAÇÃO DE SISTEMA EMPRESARIAL INTEGRADOSISTEMA EMPRESARIAL INTEGRADO - ERP

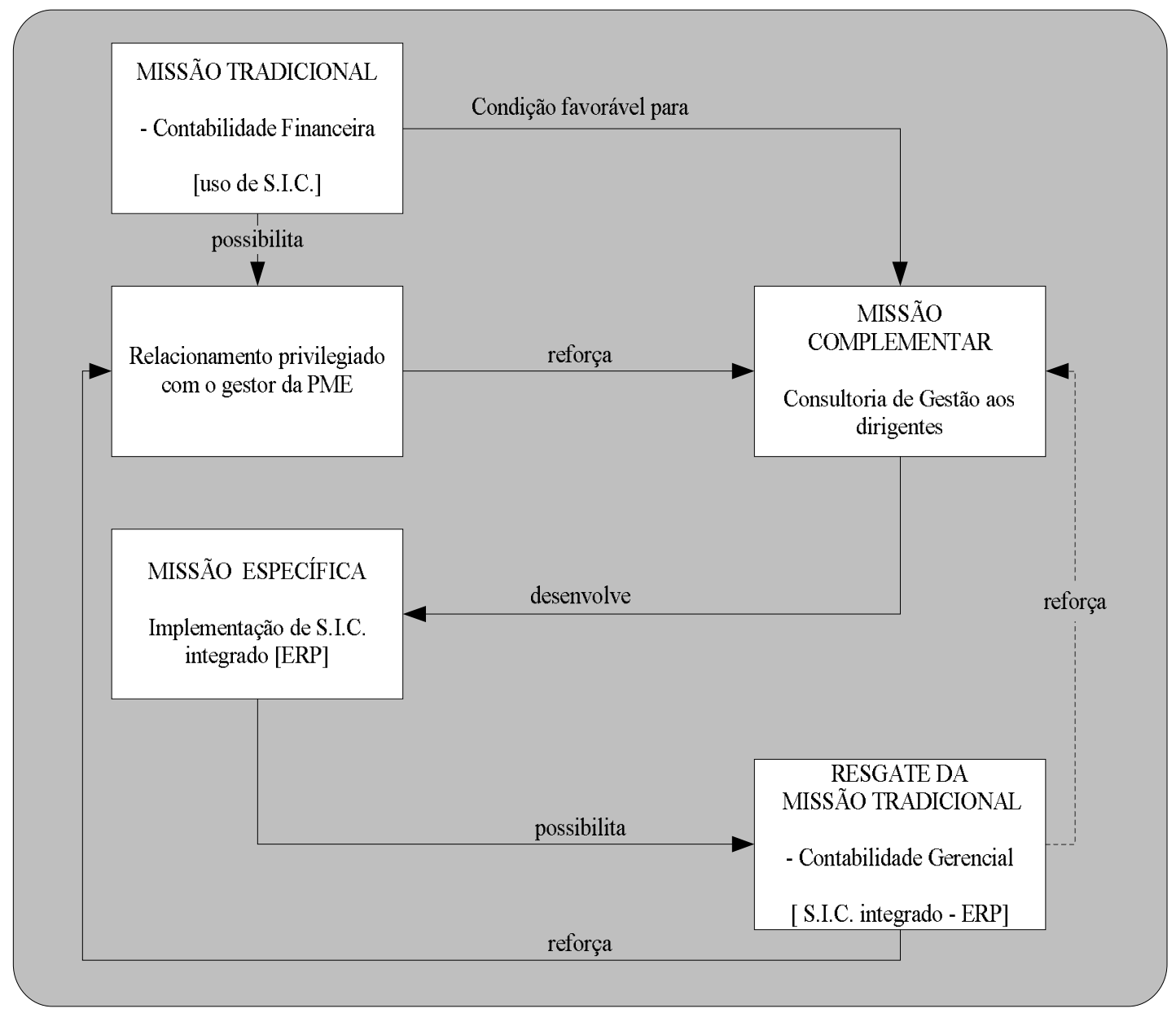

Fonte: Elaborado pelo Autor

\subsubsection{CONCLUSÕES SOBRE AS MUDANÇAS NA DIMENSÃO ESTRATÉGIA}

O esquema acima mostra que a missão tradicional do contador organizado em empresa está limitada pela maneira como o SIC é entendido e utilizado, de forma não integrada aos processos internos tanto da empresa contábil quanto da empresa cliente, porém, essa missão tradicional possibilita um relacionamento privilegiado com o gestor da PME, sendo essa uma condição favorável para o desenvolvimento de missão complementar consubstanciada na consultoria de gestão reforçada pelo relacionamento privilegiado. 
A missão complementar, por sua vez, permite desenvolver a missão especifica de levar a tecnologia a essas empresas, representada pelo sistema empresarial IntegradoSistema Empresarial Integrado - ERP, o que possibilita o resgate da missão tradicional da contabilidade gerencial através da utilização do SIC integrado, reforçando ainda mais o relacionamento privilegiado com esses gestores que passam a entender melhor o seu negócio e aprimoram o processo de decisão pelo uso da informação contábil de forma distribuída, pois contam com uma consultoria de gestão especializada e permanente com visão sistêmica e forte formação na linguagem natural dos negócios.

Referencial teórico: Sistema de informação - Sistema de informação contábil integrado - Contabilidade Gerencial.

\subsubsection{DIMENSÃO TECNOLOGIA}

Problema 2 ${ }^{\text {a }}$ Iteração: O uso do Sistema de informação contábil não integrada de forma natural pelas empresas contábeis gera um continuo retrabalho, contribuindo para a visão da contabilidade nessas empresas como um processo de escrituração, limitando o potencial do contador.

Quais são as características necessárias a um sistema de informação contábil integrado que apóie de maneira eficaz as operações de uma empresa contábil?

Estas características estão presentes em um sistema empresarial IntegradoSistema Empresarial Integrado - ERP? Elas possibilitam ao mesmo tempo informatizar a empresa-cliente?

\subsubsection{RESPOSTA E ANÁLISE DO APRENDIZADO APLICANDO OS O5 ESTÁGIOS DE PA}

A centralização e convergência de transações dos demais sistemas para o sistema de informações contábeis obedecem à sua característica natural a de ser um sistema consolidador. Essa característica é denominada natural, pois é inerente ao modelo contábil, significando que para qualquer evento que ocorra na empresa e que gere uma alteração no patrimônio, deve existir um registro correspondente nas contas respectivas, indicando pelo método da partida dupla, a conta de origem e a de destino. Assim, em qualquer ponto no espaço e no tempo em que ocorrer o evento, o registro 
contábil deve ser feito. Essa forma de registro confere à contabilidade uma característica explícita de instrumento de controle único para toda a empresa e que por essa razão é uniformizador, centralizador e consolidador.

O sistema empresarial integradoSistema Empresarial Integrado - ERP permite desenvolver o entendimento da tecnologia de banco de dados e os benefícios decorrentes desta tecnologia para os negócios e para as informações contábeis com as características acima, contribuindo para o desenvolvimento da visão de processos integrados e oportuniza a aplicação da contabilidade gerencial e o desenvolvimento da controladoria.

(1) Diagnóstico: Sistema de informação contábil não integrado de forma natural contribui para visão da contabilidade como um processo de "escrituração".

(2) Planejamento da Ação: Análise das características de um sistema de informação contábil integrado que suporte as operações da empresa contábil.

(3) Tomada da Ação: Escolha de um sistema empresarial integradoSistema Empresarial Integrado - ERP que ao mesmo tempo apóie as operações da empresa contábil, possibilitando automatizar e informatizar a empresa-cliente.

(4) Avaliação: O sistema empresarial integradoSistema Empresarial Integrado ERP oportuniza a atualização tecnológica da empresa contábil ampliando o seu potencial futuro de atuação.

(5) Especificação do Aprendizado: A atualização tecnológica da empresa contábil através de um sistema empresarial integradoSistema Empresarial Integrado ERP permite desenvolver o entendimento da tecnologia de banco de dados e os benefícios decorrentes desta tecnologia para os negócios e para as informações contábeis; Contribui para o desenvolvimento da visão de processos integrados; Oportuniza a aplicação da contabilidade gerencial e o desenvolvimento da controladoria; Proporciona o desenvolvimento de parcerias com empresas de software e tecnologia.

Referencial teórico: Tecnologia -Tecnologia de informação - Sistema empresarial integradoSistema Empresarial Integrado - ERP - Tecnologia de banco de dados. 


\subsubsection{O PROCESSO DE ESCOLHA DO SEI - ERP PARA A EMPRESA CONTÁBIL}

$\mathrm{Na}$ análise efetuada considerou-se que o sistema deveria atender a todas as necessidades da operação e de informação da empresa contábil, e que os sistemas comparados possuíam as condições mínimas de automatizar e informatizar as empresas-cliente através dos principais módulos existentes nesses tipos de sistema, quais sejam: Comercial, Financeiro, Contábil, Custos e Produção.

A decisão da empresa contábil pelo sistema "D" levou ainda em consideração, além dos requisitos e características comparadas na tabela anterior, o seguinte: (i) o sistema possui um módulo de gerenciamento de projetos, fundamental para a empresa contábil poder gerenciar recursos horas disponíveis por cliente e projeto; (ii) a parceria estabelecida na qual a empresa contábil poderá dispor o sistema ERP aos seus clientes no modelo provedor de serviços de aplicação (ASP - Application Service Provider), com acesso via Internet, reduzindo consideravelmente o custo total de propriedade (TCO) para empresa cliente; (iii) a empresa softhouse possui longa experiência nacional com as empresas contábeis, inclusive a empresa estudada ser cliente dela já por mais de 10 anos. Além das vantagens evidenciadas pelos requisitos da tabela acima, o sistema tem todos os seus processos certificados pelas normas de qualidade (I.S.O. 9000), o que em termos de sistema pode ser considerado um diferencial, especificamente no Brasil. 
TABELA 5 - AVALIAÇÃO DOS REQUISITOS QUANTO A CARACTERÍSTICAS TECNOLÓGICAS E DE NEGÓCIOS DESEJÁVEIS EM UM SISTEMA EMPRESARIAL INTEGRADOSISTEMA EMPRESARIAL INTEGRADO - ERP PARA A EMPRESA CONTÁBIL

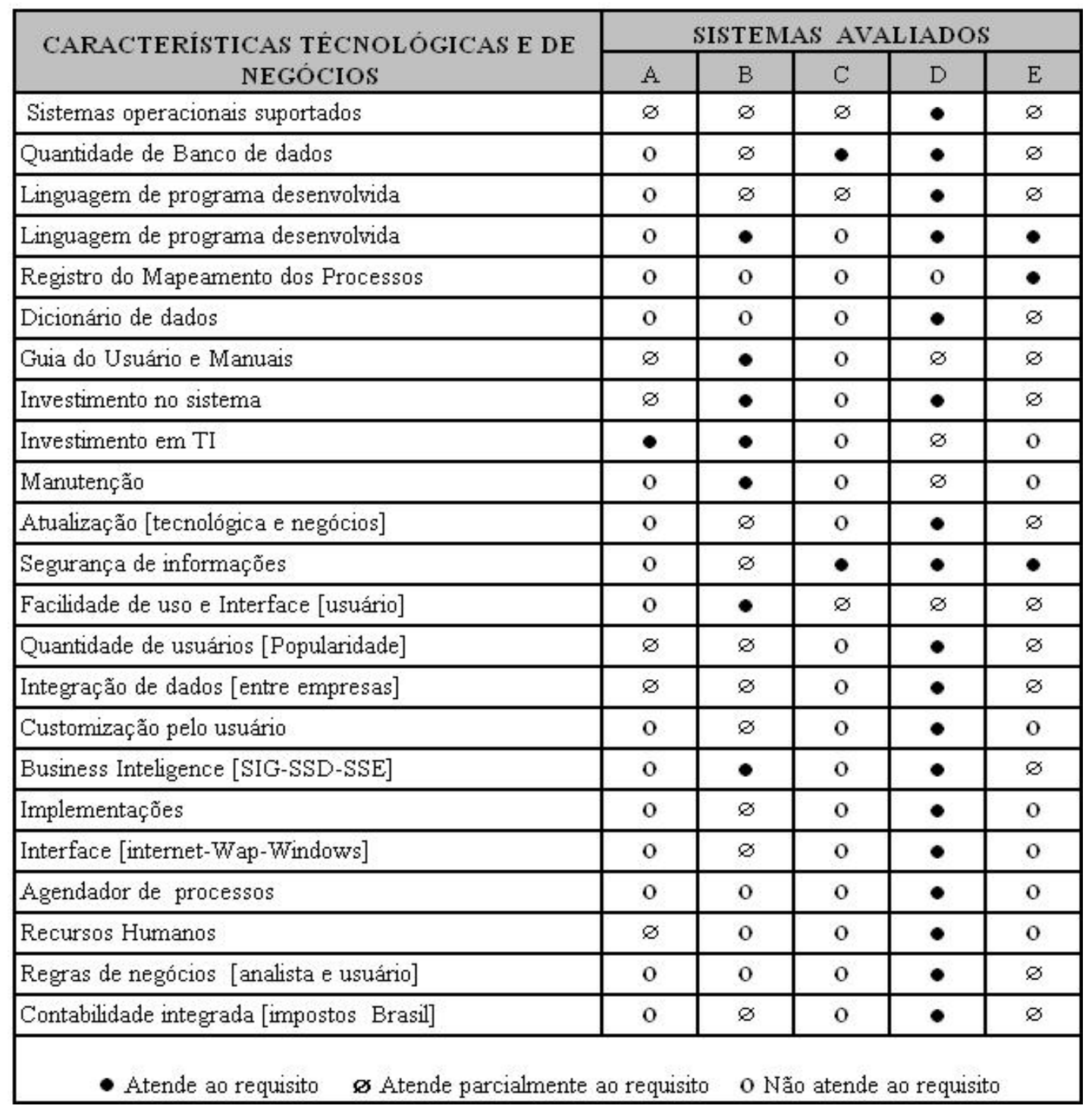

Fonte: Elaborado pelo Autor

(A) Sistemas legados atuais: Contábil-Fiscal-Patrimonial-Pessoal-InventárioFaturamento (origens diversas - Brasil); (B) Sistema de gestão para pequenos negócios (Origem Estados Unidos); (C) Sistema Empresarial IntegradoSistema Empresarial Integrado - ERP (Origem: Rio Grande do Sul-Brasil); (D) Sistema Empresarial IntegradoSistema Empresarial Integrado - ERP (Origem: Santa CatarinaBrasil); (E) Sistema Empresarial IntegradoSistema Empresarial Integrado - ERP (Origem: Goiás - Brasil); 


\subsubsection{CONCLUSÕES SOBRE AS MUDANÇAS NA DIMENSÃO TECNOLOGIA}

A implantação de um Sistema de Informação - ERP provocou uma mudança significativa, principalmente nos processos de trabalho. Para instalação do sistema foi necessária uma atualização de hardware e software aumentando o número de microcomputadores, proporcionando melhoria na qualidade das informações disponíveis. Ficou evidente a necessidade de treinamento continuo e crescente do pessoal envolvido no projeto para conhecer os principais conceitos e modelos propostos pelo sistema. Neste sentido, desenvolveu-se uma agenda de cursos externos e internos visando conhecer com profundidade o sistema, e para otimizar os resultados por toda a empresa os membros da equipe que recebiam treinamento junto a softhouse transforma-se em treinador e repassava os conhecimentos aos demais colaboradores.

O trabalho propiciou desenvolver um modelo de atuação para a empresa contábil no qual está inserido uma nova arquitetura tecnológica que trará benefícios mútuos, tanto para a empresa contábil quanto para a empresa cliente, pois facilitará acesso e treinamento ao uso de tecnologia de ponta com a redução do custo total de propriedade (TCO) para ambas, transformando-se a contábil num provedor de serviços de aplicação (ASP) interagindo ambas no sistema em tempo real com poder de trabalho com multiempresas.

Nesta arquitetura tecnológica a empresa contábil poderá realizar sua missão principal, bem como resgatar a missão tradicional da contabilidade - evidenciado nas conclusões deste trabalho e ainda, atuar como Provedor de Serviços de Aplicação (ASP - Application Service Provider) levando tecnologia de ponta para as empresas cliente com custo total de propriedade (TCO) minimizado. 
Uma percepção do grupo foi a necessidade de desenvolver ferramentas para o registro e disseminação do conhecimento que foi sendo desenvolvido e aplicado, pois, em primeiro lugar vêm as mudanças de know-how, que muda sem que necessariamente se tenha que mudar as ferramentas; o conhecimento humano é fundamental para a mudança tecnológica. Os benefícios do uso da TI são marginais se forem simplesmente impostos nas condições já existentes. Em realidade o processo de mudança é muito mais profundo e poderia chamar-se de uma transformação organizacional decorrente do uso de TI.

\subsubsection{DIMENSÃO ESTRUTURA}

Problema $\mathbf{3}^{\mathbf{a}}$ Iteração: Implementação do sistema empresarial integradoSistema Empresarial Integrado - ERP, de maneira a maximizar o aproveitamento do seu potencial.

Por que os dirigentes da empresa contábil "Conjel Contabilidade" decidiramse pelo sistema "D” para suportar suas operações?

Como implementar um sistema empresarial integradoSistema Empresarial Integrado - ERP numa empresa contábil?

Qual o impacto da implementação do sistema empresarial integradoSistema Empresarial Integrado - ERP nas dimensões Estrutura, Processos e Pessoas da empresa contábil?

\subsubsection{RESPOSTA E ANÁLISE DO APRENDIZADO APLICANDO OS 05 ESTÁGIOS DE PA}

O sistema empresarial integradoSistema Empresarial Integrado - ERP escolhido atende a todas as necessidades da operação e de informação da empresa contábil, e possibilita automatizar e informatizar as empresas-cliente através dos principais módulos existentes: Comercial, Financeiro, Contábil, Custos e Produção. Entre outras características, a parceria estabelecida na qual a empresa contábil poderá dispor o sistema ERP aos seus clientes no modelo provedor de serviços de aplicação (ASP - Application Service Provider), com acesso via Internet, reduz consideravelmente o custo total de propriedade (TCO) para empresa cliente. 
A implantação, como parte do processo de mudanças, está sendo administrada na abordagem projeto, com acordo com o referencial teórico proposto por Walton (1998) e descrito anteriormente. Os impactos são os discutidos ao longo do trabalho, mas envolve principalmente o mapeamento e redesenho dos processos de serviços através da metodologia IDEF3 adaptada, e que está influenciando uma revisão geral nos métodos e processos de trabalho, possibilitando gerir a empresa orientada a processos. O principal impacto observado, neste estágio do projeto é a mudança de entendimento por parte dos usuários do valor efetivo da informação contábil e que ela direciona, através da tecnologia utilizada, a preocupação do contador para a análise e customização das regras de negócio dentro da visão de processo, isto é, o contábil passa a ter como objetivo principal modelar os processos de negócio dentro do sistema ERP.

(1) Diagnóstico: Modelo de gestão centralizado inviabiliza o enfoque organizacional orientado a aprendizagem, necessário para implementar o sistema empresarial integradoSistema Empresarial Integrado - ERP de maneira a maximizar o aproveitamento do seu potencial.

(2) Planejamento da Ação: Implementar a gestão participativa.

(3) Tomada da Ação: Desenho da nova estrutura organizacional, definido novos papéis, funções e responsabilidade conforme organograma funcional aprovado em assembléia.

(4) Avaliação: O processo decisório participativo gerou o envolvimento de todos na identificação dos problemas da empresa e das soluções dos problemas que estão sendo levantados na medida em que o sistema ERP vai sendo customizado e implantado.

(5) Especificação do Aprendizado: A abordagem participativa utilizada aumentou em todos os membros da equipe o conhecimento sobre as atividades organizacionais, contribuindo para a sensação de confiança por parte da gerencia e dos lideres. Destaca-se o surgimento de novos lideres e percebe-se o aumento do grau de satisfação no trabalho e no comprometimento com a empresa, reduzindo as barreiras com relação as mudanças. 
A pesquisa-ação neste ponto foi de importância fundamental, pois contribuiu decisivamente para fazer com que os atores se envolvessem e trabalhassem juntos nos diversos projetos da empresa, advindos principalmente nesse período de mudança da tecnologia.

O espírito de equipe foi sendo obtido através da gestão participativa observado na medida em que os integrantes do grupo foram: (i) desenvolvendo uma compreensão da natureza da dinâmica do grupo e do trabalho eficaz em equipe, com ênfase especial na relação entre processo e conteúdo; e (ii) aprendendo a aplicar diversos princípios e habilidades de processos grupais para uma maior eficácia da equipe.

\subsubsection{CONCLUSÕES SOBRE AS MUDANÇAS NA DIMENSÃO ESTRUTURA}

Assim como a pesquisa propiciou desenvolver uma nova arquitetura tecnológica com seus reflexos nas demais dimensões, observou-se a necessidade do desenvolvimento de uma nova arquitetura organizacional, pois os processos de negócios sofrem profundas alterações pelas mudanças tecnológicas, principalmente quando essa mudança tem como objetivo transforma-se numa nova estratégia de negócios e o sistema empresarial integradoSistema Empresarial Integrado - ERP permite e exige esta abordagem para maximizar seus benefícios.

As mudanças estruturais observadas resumidamente redefinem a maneira pela qual os trabalhos operacionais e de apoio são divididos em tarefas distintas e como é feita a coordenação entre essas tarefas. O sistema auxilia na comunicação entre os setores tornando-o mais rápido e diminui as trocas de informações verbais, que causavam grande perda de produtividade e controle, facilitando os mecanismos de coordenação que teve como resultando uma melhor definição das responsabilidades pela entrega de serviços aos clientes, levando a necessidade de projetar novas funções e papéis principalmente relacionados à operação da nova arquitetura tecnológica (banco de dados, redes, análise, desenho e desenvolvimento de ferramentas de informática), a qualificação do pessoal para gerenciar projetos e principalmente a conscientização da necessidade do trabalho em equipe multifuncionais. 
TABELA 7 - SÍNTESE DAS PRINCIPAIS VARIÁVEIS DE MUDANÇAS ESTRUTURAIS IDENTIFICADAS E O GRAU DE APLICAÇÃO OBSERVADO

\begin{tabular}{|c|c|c|c|c|c|}
\hline \multirow{2}{*}{ VARIAVEIS } & \multirow{2}{*}{ SUBVARIAVEIS } & \multirow{2}{*}{ MUDANÇAS IDENTIFICADAS } & \multicolumn{3}{|c|}{ AVALIAÇÃO } \\
\hline & & & D & $\mathbf{R}$ & A \\
\hline \multirow[t]{2}{*}{$\begin{array}{l}\text { Partes básicas da } \\
\text { Organização }\end{array}$} & \multirow[t]{2}{*}{$\begin{array}{l}\text { Mudanças nas partes básicas: } \\
\text { núcleo operacional, núcleo } \\
\text { estratégico, linha intermediária, } \\
\text { tecnoestrutura e assessorias de } \\
\text { apoio da organização. }\end{array}$} & $\begin{array}{l}\text { Sistema auxilia a comunicação inter e } \\
\text { intra unidades [maior rapidez] }\end{array}$ & & $\sqrt{ }$ & \\
\hline & & $\begin{array}{l}\text { Diminuição da quantidade de consultas } \\
\text { diretas e trocas de informação verbais }\end{array}$ & & & $\sqrt{ }$ \\
\hline \multirow[t]{3}{*}{$\begin{array}{l}\text { Mecanismos de } \\
\text { coordenação }\end{array}$} & \multirow{3}{*}{$\begin{array}{l}\text { Mudanças quanto aos } \\
\text { mecanismos de coordenação: } \\
\text { ajustamento mútuo, supervisão } \\
\text { direta, padronização de } \\
\text { habilidades, de processos de } \\
\text { trabalho e de resultados. }\end{array}$} & $\begin{array}{l}\text { Eliminação de um nível hierárquico [de } \\
\text { natureza tática] }\end{array}$ & & $\sqrt{ }$ & \\
\hline & & $\begin{array}{l}\text { Demissão de pessoas que não tiveram } \\
\text { condições de se adaptar à nova } \\
\text { tecnologia }\end{array}$ & $\sqrt{ }$ & & \\
\hline & & $\begin{array}{l}\text { Acúmulo de funç̧̃es por parte de alguns } \\
\text { cargos }\end{array}$ & & & $\sqrt{ }$ \\
\hline \multirow{4}{*}{$\begin{array}{l}\text { Parâtmetros de } \\
\text { Desenho } \\
\text { (mecanismos } \\
\text { organizacionais } \\
\text { utilizados para } \\
\text { desenhar a } \\
\text { estrutura) }\end{array}$} & \multirow{4}{*}{$\begin{array}{l}\text { Mudanças quanto a: } \\
\text { diferenciação, especialização, } \\
\text { formalização do comportamento, } \\
\text { treinamento e doutrinação, } \\
\text { planejamento e controle, } \\
\text { instrumentos de interligação, } \\
\text { descentralização, divisão em } \\
\text { unidades, tamanho das unidades. }\end{array}$} & $\begin{array}{l}\text { Aumento do nivel de controle sobre o } \\
\text { trabalho }\end{array}$ & & & $\sqrt{ }$ \\
\hline & & $\begin{array}{l}\text { Tendência a um aumento de autonomia } \\
\text { para a realização de tarefas e decisões } \\
\text { rotineiras pelo maior acesso às } \\
\text { informações }\end{array}$ & & & $\sqrt{ }$ \\
\hline & & $\begin{array}{l}\text { Aumento no nivel de formalização das } \\
\text { organizações }\end{array}$ & & $\sqrt{ }$ & \\
\hline & & $\begin{array}{l}\text { Maior padronização dos processos de } \\
\text { trabalho }\end{array}$ & & & $\sqrt{ }$ \\
\hline \multirow{3}{*}{ Avaliação: } & \multicolumn{5}{|c|}{ D [deficiente]: A variável não foi observada [ainda]. } \\
\hline & \multirow{2}{*}{\multicolumn{5}{|c|}{$\begin{array}{l}\text { R [regular]: A variável foi observada mas não foi totalmente resolvida } \\
\text { A [adequada]: A variável foi observada e resolvida }\end{array}$}} \\
\hline & & & & & \\
\hline
\end{tabular}

Fonte: Saccol, Macadar e Soares (2001) Adaptado pelo Autor

As mudanças quanto aos parâmetros de desenho da organização observou-se que a integração e divulgação das informações de forma transparente promoveu e facilitou o planejamento dos trabalhos, aumento o controle sobre o trabalho uma vez que os responsáveis pelas ações (identificadas em termos de saída) são mais facilmente identificados, bem como, facilitando apresentar aos clientes os resultados dos trabalhos de forma rápida e prática, em suma, as informações passaram a estar mais no sistema do que somente na cabeça das pessoas.

Especificamente para a área de prestação de serviços contábeis onde existe uma grande dificuldade no balanceamento dos recursos no processo de trabalho, pois o 
conhecimento e o tempo são fatores chaves o sistema permitiu medir a produtividade fornecendo uma hora padrão para fins de planejamento de preço e avaliação do desempenho. Neste sentido conclui-se que a forma (estrutura) vem depois da função (processos), ou seja, organiza-se o processo para depois se estruturar a forma de realizá-lo.

Referencial teórico: Gestão participativa, escola sócio-técnica, pesquisa-ação.

\subsubsection{DIMENSÃO PROCESSOS}

O mapeamento de processos exige a utilização de ferramentas adequadas para o seu sucesso (por exemplo os sistemas Microsoft Visio, Pro vision, Aris Methods da IDS Scheer, etc) e o entendimento para utilizar essas ferramentas. Além disso, é fundamental entender a metodologia (técnica) por trás destas ferramentas, principalmente as adequadas para mapear os processos de serviços, que possui características específicas, pois os clientes nos sistemas de produção de serviços como no caso da empresa contábil, também podem representar entradas para o sistema, participando do inicio ao fim do processo.

Assim, as saídas do sistema de operações de serviços representam o resultado do serviço, que, em função da participação do cliente também acontece nas interações (cliente / empresa) ocorridas durante o processo.

Esse entendimento só veio ocorrer no final do período de relato dos resultados da pesquisa, o que obrigou o pesquisador e os "atores" da empresa contábil a rever a metodologia que estava sendo usada para mapear os processos atuais, bem como, adaptar as metodologias existentes criando uma técnica específica para redesenhar os processos de negócios futuros. As dificuldades encontradas, neste ponto, devem-se ao fato que a literatura pesquisada trás diversas técnicas, diferentes entre si e com abordagens muitas vezes antagônicas, porém voltada especificamente para a área de manufatura industrial.

O desenvolvimento de uma técnica própria, fundamentada numa metodologia apropriada, é fundamental para que se possa conduzir com sucesso a melhoria dos processos empresariais que serão suportados pela tecnologia de informação que está sendo implantada. Neste sentido, o paradigma da pesquisa-ação proposto neste trabalho confirma sua real e efetiva utilidade, tendo em vista que, mesmo que o 
resultado não tenha sido alcançado totalmente, as diversas iterações no nos cinco estágios de PA levaram o grupo a entender as dificuldades de mapear os processos, ampliando consideravelmente seu conhecimento e compreendendo a sua importância chave na implementação com sucesso de um sistema empresarial integradoSistema Empresarial Integrado - ERP com objetivo de maximizar seu potencial de mudanças nos negócios.

Como mapear os processos de uma empresa contábil?

\subsubsection{RESPOSTA E ANÁLISE DO APRENDIZADO APLICANDO OS 05 ESTÁGIOS DE PA}

(1) Diagnóstico: Avaliação dos processos atuais da empresa contábil

(2) Planejamento da Ação: Mapear os processos atuais, redesenhá-los melhorando-os e considerando as mudanças exigidas pela nova tecnologia, bem como, de acordo com novas linhas estratégicas.

(3) Tomada da Ação: Mapear, analisar, redesenhar e implantar os processos de serviço.

(4) Avaliação: O mapeamento dos processos atuais, em função da inexistência de projeto anterior, tornou-se moroso por dois motivos: (i) o tempo necessário ao mapeamento dos processos foi subestimado no projeto de mudança, em razão da necessidade dos próprios lideres de setor participarem ativamente no mapeamento e isso concorrer com as suas atividades operacionais de rotina; (ii) o entendimento das etapas necessárias, numa seqüência lógica, para atingir uma organização por processos, ou uma organização totalmente orientada à processos.

(5) Especificação do Aprendizado: Uma empresa contábil orientada a processos precisa envolver seus lideres (todos) na definição do que seja um processo, através das seguintes fases: (i) Conscientizar; (ii) Mapear processos; (iii) Selecionar processos essenciais; (iv) melhorar os processos essenciais junto com a tecnologia; (v) redistribuir recursos definindo os donos do processo; (vi) Adotar modelo estrutural rompendo com as principais funções; (vii) Reformular o referencial e os mecanismos de gestão; (viii) Implantar e monitorar a definição do negócio. 


\subsubsection{CONCLUSÕES SOBRE AS MUDANÇAS NA DIMENSÃO PROCESSOS}

Entre as principais conclusões desta pesquisa está a necessidade de criar e desenvolver a empresa contábil orientada a processos, para que se obtenha de forma precisa os benefícios da nova arquitetura tecnológica e organizacional decorrentes do processo de mudança disparado pela tecnologia. $\mathrm{Na}$ visão da pós-reengenharia, Michael Hammer (2002) relaciona as facetas de uma empresa orientada a processos, condição essencial para que os projetos de implantação de sistema de informações integrados tenham êxito, dividindo-as em características essenciais e habilitadores comentadas a seguir, permitindo focalizar as mudanças de visão que deverão ocorrer na gestão e nas pessoas da empresa pesquisada, e que foram utilizadas como um roteiro na criação do ambiente organizacional necessário ao projeto de mudança estudado.

Como características essenciais temos:

Modelo: Um modelo em termos de empresa orientada a processos é aquele que descreve os processos de negócio da organização e seus principais sub-processos, identifica seus inputs, outputs e relacionamentos primários. O modelo provê o vocabulário básico necessário em uma empresa orientada a processos, bem como, fornece uma visualização geral da empresa sendo expresso de maneira clara e simples para que seja compreensível e legível por todos os agentes envolvidos, mesmo para aqueles que não estão acostumados a pensar em processos.

Donos do processo: Gerentes com responsabilidade geral pelos processos e suas performances, com a capacidade e a motivação necessária para executá-los sem precisarem ser vigiados. Nesse sentido, os administradores devem prover o desenho do processo que deve ser executado e as ferramentas e recursos necessários para executálo, sendo o papel do dono do processo criar e manter o desenho do processo atualizado, provê àqueles que o executam a capabilidade de suporte que eles requerem (como um sistema), medindo a performance do processo e tomando ações corretivas quando necessário e representando o processo no centro de decisões da empresa.

Desenhos: Especificações precisas sobre como os processos devem ser executados para se produzir o output desejado. Um desenho identifica exatamente 
quais atividades devem ser executadas, por quem e em que ordem. $\mathrm{O}$ desenho formal de um processo permite que todos no processo saibam o que deve ser feito e como o seu trabalho se relaciona com o das outras pessoas ou áreas. O desenho do processo também favorece a realização de esforços de melhoria organizacionais, tanto incrementais quanto radicais, fundamentais para a empresa contábil que tem como característica, nos seus processos, a participação do cliente com informações durante todo o trabalho.

Medidas: Métricas da performance do processo que provêem uma quantificação holística ponta-a-ponta das saídas dos processos, focadas nos resultados que mais importam ao cliente. Não existe compromisso com processos se não existe um compromisso igual com sua medida. Nas mãos certas, as medidas fornecem um esquema básico para o processo de trabalho e permite que todos vejam como os processos estão sendo executados e como os esforços de melhorias estão progredindo. Também é importante disseminar as informações resultantes da medição dos processos, pois estas informações encorajam as pessoas a se importarem mais com os indicadores do processo. Quando a performance do negócio é discutida em termos de processos, as pessoas captam rapidamente a mensagem de que os processos são realmente importantes.

Equipes: Trabalho orientado a processos é o trabalho baseado em times. Todas as pessoas envolvidas na execução de um processo devem reconhecer que seus esforços individuais podem ser úteis somente quando integrados com os esforços de seus colegas. Os times devem ser mapeados e estabelecidos como as unidades básicas de trabalho da organização.

Liderança: Uma empresa orientada a processos é tão fundamentalmente diferente de uma empresa tradicional que ela nunca poderá existir, nem operar como deveria, sem o compromisso absoluto e irrestrito dos executivos do posto mais alto na organização. Eles devem compreender a fundo o imperativo do processo e devem ser enérgicos e determinados no planejamento, na implementação e na comunicação das novas maneiras de se administrar o negócio.

Como características habilitadoras, o autor cita: (i) Conscientização sobre os Processos, isto é, como a empresa cria e entrega valor aos clientes, compreendendo a diferença entre trabalhar orientado a processos e trabalhar orientado a tarefas; (ii) 
Integração, criação de mecanismos que assegurem que todos os processos da organização trabalhem juntos e que a fragmentação funcional não seja substituída pela fragmentação dos processos; (iii) Coaching $^{l}$, atenção administrativa para se desenvolver pessoas através da educação do planejamento de carreira e da orientação pessoal, pois a performance de uma empresa orientada a processos depende altamente da capacidade de sua equipe; (iv) Cultura: Sistema de valores que encoraja os comportamentos que o trabalho orientado a processos demanda, em outras palavras, o trabalho orientado a processos requer que indivíduos assumam responsabilidades pessoais pelos resultados, valorizem o trabalho em equipe e façam dos clientes sua prioridade número um. (v) Tecnologia de Informação, sistemas de computador orientados a processos que suportam a integração de todas as atividades de um processo através da comunicação e do compartilhamento de dados; (vi) Instalações, ambientes de trabalho que reforçam o trabalho em equipe e o trabalho orientado a processos. O layout do local de trabalho deve dar vazão ao fluxo natural de um processo, ao invés de institucionalizar os limites funcionais; Sistemas de Recursos Humanos, modelos de carreira e sistemas de compensação apropriados para pessoas focadas em processos. Os executores dos processos precisam de modelos para crescimento profissional que não sejam baseados nos limites funcionais e nas promoções hierárquicas.A carreira de quem trabalha em uma empresa orientada a processos se baseia no crescimento profissional e no aprendizado de novas habilidades e disciplinas. Semelhantemente, basear parte das compensações na performance dos processos leva a organização a obter objetivos compartilhados e alinhado em torno das saídas dos processos, reforçando conseqüentemente sua importância. Os processos são uma dimensão efetiva para a compensação, ficando entre a performance da empresa (que é o mais importante, mas sobre o qual o indivíduo possui menor influência) e a performance pessoal (a qual as pessoas podem controlar, mas que são de pouca conseqüência); (vii) Sistemas de gestão: Orçamento, planejamento e sistemas financeiros que estão alinhados em torno dos processos. Isto assegura que a tomada de decisão na organização, assim como os trabalhos, estão baseados em processos.

${ }^{1}$ É usado para designar a orientação baseada na experiência que leva ao desenvolvimento das pessoas na organização 
As características essenciais e habilitadoras descritas acima proporcionaram uma direção segura no processo de mudança na medida em que os processos da empresa contábil foram sendo mapeados, discutidos e melhorados, e neste período a equipe do projeto recebia treinamento sobre as características do sistema ERP e discutia sua customização, planejando adequadamente ações de ajustes nos processos ao sistema, e/ou vice-e-versa.

Referencial teórico: IDEF3, APX-IBM, reengenharia de processos de negócios.

\subsubsection{DIMENSÃO PESSOAS}

Problema $4^{\text {a }}$ Iteração: Administração da mudança organizacional requerida em virtude do alinhamento das estratégias de tecnologia, de negócios e de organização numa empresa contábil.

Qual o tipo de mudança organizacional e em que ordem de magnitude ela deve acontecer?

Qual o modelo de gestão da mudança e qual abordagem utilizar para a sua efetivação?

Essas mudanças podem contribuir para melhorar o entendimento do papel, da utilidade e da atuação da contabilidade como instrumento de gestão?

Os sistemas empresariais integrados - ERP podem oferecer novas oportunidades para que o conhecimento contábil seja distribuído nas organizações?

\subsubsection{RESPOSTA E ANÁLISE DO APRENDIZADO APLICANDO OS O5 ESTÁGIOS DE PA}

A administração dessa mudança é um processo crítico e só pode ser consolidado a médio e longo prazo, isto é, em dois ou três anos, embora as melhorias, mesmo que graduais, podem se fazer sentir a cada momento, principalmente com a utilização da pesquisa-ação que contribui para a construção de um clima de comprometimento e aprendizado. A utilização dessa tecnologia, com sucesso visando maximizar o seu potencial, requer o desenvolvimento de um modelo de mudança organizacional de larga escala, através da alteração no caráter da organização que mudará significativamente seu desempenho. 
O modelo de gestão deve ser participativo com a abordagem projeto e levantando-se em consideração os benefícios para o sistema social dentro do que prega a escola sócio-técnica.

O contador passa a ter um papel central no gerenciamento das informações da empresa, sendo sua participação no projeto de implantação e mudança crucial para o seu sucesso. As oportunidades que esses sistemas oferecem para a empresa contábil já foram devidamente comentadas e analisadas quando da discussão da dimensão estratégia.

(1) Diagnóstico: Criação de uma organização que aprende

(2) Planejamento da Ação: Desenvolver a capacidade de mudar e se adaptar continuamente através da conscientização da equipe do processo de mudança pelo entendimento das cinco disciplinas: "domínio pessoal, modelos mentais, visão compartilhada, aprendizado em equipe e pensamento sistêmico".

(3) Tomada da Ação: A empresa foi dividida em 05 grupos, onde cada grupo estudou uma disciplina e desenvolveu uma dinâmica repassando o conteúdo da disciplina aos demais membros da empresa.

(4) Avaliação: Os conteúdos das disciplinas foram apresentados e discutidos, levando o grupo ao perfeito entendimento das necessidades de mudança pessoais e que só em grupo é que se aprende, nestes termos: (i) Existe uma visão compartilhada, com a qual todos concordam; (ii) As pessoas abrem mão de suas velhas idéias e rotinas padronizadas que utilizam para solucionar problemas ou realizar seu trabalho; (iii) As pessoas pensam em todos os processos, atividades, funções organizacionais e interações com o ambiente como parte de um sistema de inter-relacionamentos; (iv) As pessoas se comunicam abertamente (vertical e horizontalmente), sem medo de críticas ou punições; (v) As pessoas sublimam seus interesses pessoais e de seus departamentos fragmentados em prol do trabalho conjunto para alcançar a visão compartilhada da organização.

(5) Especificação do Aprendizado: Numa versão preliminar o conteúdo das disciplinas havia sido entregue a cada individuo para que desenvolvesse a explicação para a equipe. Está atividade individual se mostrou ineficaz e serviu de entendimento para a necessidade dos trabalhos em equipe. As dinâmicas apresentadas com os 
conceitos foram surpreendentes, tanto para o pesquisador como para a equipe em geral, pois ficou demonstrada a criatividade dos grupos em utilizar diversos meios para transmitir o entendimento dos conceitos embutidos nas 5 disciplinas.

Ficou claro que a organização que aprende é uma empresa onde as pessoas abrem mão de suas velhas idéias, aprendem a ser abertas uma com as outras, compreendem como sua organização realmente funciona, formam um plano ou visão com a qual todos concordam e depois trabalham em conjunto para conquistar essa visão. As cinco disciplinas são programas permanentes de estudo e prática que levam ao aprendizado organizacional e contínuo das pessoas.

Para transformar a empresa em uma aprendiz permanente é necessário um projeto de mudanças visando: (i) estabelecer uma estratégia: os gestores precisam explicitar seu compromisso com a mudança, a inovação e a melhoria contínua; (ii) Replanejar a estrutura da organização: adoção de equipes multifuncionais; (iii) Remodelar a cultura da organização: assumir riscos, abertura e crescimento. Os gestores estabelecem o tom da cultura organizacional tanto pelo que dizem (estratégias) como pelo que fazem (comportamento).

Nesse ponto foi encontrado o que fazer? Mas e o como fazer? Pesquisa-ação como uma proposta de pesquisa mais aberta (com característica de diagnóstico e de consultoria), para tentar clarear uma situação complexa - sair da situação atual para a situação desejada, e encaminhar possíveis - ações de mudança, especialmente nestas situações criticas.

O processo de mudança é sempre um momento crítico, e a pesquisa-ação contribui levando os atores envolvidos a encontrar as respostas aos seus próprios problemas, comprometendo-se com a mudança e aprendendo com ela, possibilitando desenvolver a chamada "organização que aprende".

\subsubsection{METODOLOGIA TRANSMETH E AS BARREIRAS À MUDANÇA}

A metodologia de transformação organizacional denominada Transmeth tem o objetivo de auxiliar empresas na condução do processo de transformação, procurando minimizar a ocorrência de fatores críticos ou falhas ao longo do tempo, através da utilização de uma série de técnicas já disponíveis na literatura e algumas novas 
ferramentas que considera diversos aspectos vitais para a condução de um processo de mudança.

Neste sentido, está sendo aplicando para avaliar o andamento das mudanças, uma estrutura de classificação e uma relação de falhas a serem consideradas e evitadas ao longo do processo, de acordo com as dimensões mais gerais de gerenciamento chamadas: a) Dimensões de negócios; b) Dimensão Cultural; c) dimensão de recursos; d) dimensão de operação; e que representam barreiras ao processo de mudança, de acordo com a metodologia Transmeth. Se as barreiras foram constantemente monitoradas ao longo do processo, de acordo com as respectivas dimensões e frentes, e a qualidade da aplicação for adequada o processo poderá ser considerado eficaz, e no caso de não se atingir a qualidade da aplicação adequada a barreira terá que ser revista pois apresenta as posições onde o processo não está sendo bem conduzido e compreendido.

Nos anexos está sendo apresentada a avaliação das barreiras feita no final da pesquisa com os respectivos comentários, sobre o seu entendimento, explicando o significado de cada dimensão, frente e barreira a ser avaliada, pelos lideres da mudança, de acordo com a metodologia Transmeth.

\subsubsection{CONCLUSÕES SOBRE AS MUDANÇAS NA DIMENSÃO PESSOAS}

Conclui-se que as mudanças na arquitetura tecnológica e organizacional descritas nesta pesquisa tem como pano de fundo a questão comportamental. É impossível não associar tais mudanças as pessoas que trabalham na empresa contábil, e essas só mudam efetivamente, através da aquisição de novos conhecimentos. Essas mudanças estão relacionadas com as mudanças na cultura organizacional, no grau de motivação dos colaboradores e principalmente mudança nas habilidades e capacidades requeridas das pessoas.

Observou-se a necessidade de aumento na responsabilidade pela realização das atividades e tarefas através do sistema, criatividade na produção de relatórios e visão sistêmica para entender os reflexos de suas ações através do sistema nas informações utilizadas por outras pessoas, tanto interna quanto externamente. $\mathrm{O}$ trabalho tornou-se 
mais autônomo com relação ao processo de decisão, porém, exigindo muito mais discussão e sinergia em equipe.

TABELA 8TABELA 8 - SÍNTESE DAS PRINCIPAIS VARIÁVEIS DE MUDANÇAS COMPORTAMENTAIS IDENTIFICADAS E O GRAU DE APLICAÇÃO OBSERVADO

\begin{tabular}{|c|c|c|c|c|c|}
\hline \multirow{2}{*}{ VARIÁVEIS } & \multirow{2}{*}{ SUBVARIÁVEIS } & \multirow{2}{*}{ MUDANÇAS IDENTIFICADAS } & \multicolumn{3}{|c|}{ AVALIAÇÃO } \\
\hline & & & D & $\mathbf{R}$ & $\mathbf{A}$ \\
\hline \multirow[t]{5}{*}{$\begin{array}{l}\text { Cultura } \\
\text { Organizacional }\end{array}$} & \multirow{5}{*}{$\begin{array}{l}\text { Mudanças quanto a: } \\
\text { conflito e poder, } \\
\text { valores, crenças, } \\
\text { atitudes e visão } \\
\text { compartilhada. }\end{array}$} & $\begin{array}{l}\text { Aumento da responsabilidade na realização de } \\
\text { atividades }\end{array}$ & & & $\sqrt{ }$ \\
\hline & & Preocupação com a veracidade e precisão dos dados & & & $\sqrt{ }$ \\
\hline & & $\begin{array}{l}\text { Maior necessidade das pessoas pensarem na } \\
\text { empresa como um todo, de modo a se voltarem aos } \\
\text { objetivos organizacionais para a execução de suas } \\
\text { atividades }\end{array}$ & & & $\sqrt{ }$ \\
\hline & & $\begin{array}{l}\text { Aumento da visão sobre clientes externos da } \\
\text { organização }\end{array}$ & & $\sqrt{ }$ & \\
\hline & & $\begin{array}{l}\text { Maior conscientização sobre o impacto causado pelo } \\
\text { trabalho de cada individuo sobre os processos como } \\
\text { um todo }\end{array}$ & & & $\sqrt{ }$ \\
\hline Motivação & $\begin{array}{l}\text { Mudanças quanto às } \\
\text { recompensas } \\
\text { intrinsecas e } \\
\text { recompensas } \\
\text { extrinsecas. }\end{array}$ & Maior compreensão dos objetivos do trabalho & & & $\sqrt{ }$ \\
\hline \multirow[t]{4}{*}{$\begin{array}{l}\text { Habilidades e } \\
\text { capacidades }\end{array}$} & \multirow{4}{*}{$\begin{array}{l}\text { Mudanças quanto ao } \\
\text { perfil dos recursos } \\
\text { humanos } \\
\text { conhecimentos, } \\
\text { capacidades e } \\
\text { habilidades), e quanto } \\
\text { à capacidade de }\end{array}$} & $\begin{array}{l}\text { Necessidade de maior disciplina na realização do } \\
\text { trabalho }\end{array}$ & & $\sqrt{ }$ & \\
\hline & & $\begin{array}{l}\text { Necessidade de explorar o sistema exige maior } \\
\text { preparo para pesquisa e análise }\end{array}$ & & & $\sqrt{ }$ \\
\hline & & Valorização da capacidade de trabalhar em grupo & & & $\sqrt{1}$ \\
\hline & & $\begin{array}{l}\text { Necessidade de pessoas mais comprometidas e mais } \\
\text { ágeis }\end{array}$ & & & $\sqrt{ }$ \\
\hline $\begin{array}{l}\text { Resistência à } \\
\text { mudança }\end{array}$ & $\begin{array}{l}\text { Estudo do processo de } \\
\text { mudança: causas da } \\
\text { resistência a } \\
\text { mudanças, estratégia } \\
\text { adotada para vencer a } \\
\text { resistência, agentes de } \\
\text { mudança. }\end{array}$ & **Ver avaliação das Barreiras Transmeth & & & \\
\hline \multirow{3}{*}{ Avaliação: } & \multicolumn{5}{|c|}{ D [deficiente]: A variável não foi observada [ainda]. } \\
\hline & \multicolumn{5}{|c|}{ R [regular]: A variável foi observada mas não foi totalmente resolvida } \\
\hline & \multicolumn{5}{|c|}{ A [adequada]: A variável foi observada e resolvida } \\
\hline
\end{tabular}

Fonte: Saccol, Macadar e Soares (2001) Adaptado pelo Autor.

Aumentaram as exigências relacionadas às habilidades e atitudes das pessoas, passou a existir uma maior necessidade de disciplina na realização do trabalho por parte dos colaboradores que utilizam o sistema, uma vez que ele exige que todas as movimentações físicas sejam documentadas, bem como, os processos e procedimentos tem sido devidamente discutidos, estruturados os procedimentos e desenhados. Da mesma forma, a necessidade de explorar o sistema exige maior preparo para pesquisar e analisá-lo, o que faz com que hoje se valorize mais a capacidade analítica dos funcionários. Eles precisam ter mais curiosidade e iniciativa para usufruir das 
funcionalidades do sistema, valorizando a capacidade de trabalhar em grupo, pois, cada alteração no ERP exige um estudo de suas repercussões nas diversas áreas, fazendo com que as pessoas interajam com maior intensidade. Por outro lado, uma vez que aumentou a rapidez dos processos de trabalho, também se exige atualmente que as pessoas sejam mais comprometidas e mais ágeis, pois as informações estão disponíveis em tempo real, de forma que a procrastinação na execução das tarefas não mais é aceita.

Observou-se no inicio do processo que diversas barreiras às mudanças foram sendo levantadas pelas pessoas e somente com o tempo elas foram sendo convencidas dos benefícios que o sistema traria seria de médio e longo prazo, com resultados positivos em termos econômicos e sobre o pessoal, principalmente relacionados com de motivação para o trabalho e realização financeira e profissional. Porém, uma mudança efetiva numa empresa só ocorre à medida que as pessoas mudam, através da aquisição de novos conhecimentos que sejam transformados em competências e habilidades.

O capítulo seguinte discute a contribuição para o corpo do conhecimento delineado nos capítulos anteriores, em outras palavras, o que se compreende agora e que não era compreendido no início da pesquisa. 


\section{CAPÍTULO VI - CONTRIBUIÇÃO AO CORPO DE CONHECIMENTO}

Neste capítulo discute-se a contribuição para o corpo do conhecimento delineado previamente nos capítulos II, III e IV, de acordo com os resultados e as conclusões sobre os problemas e questões de pesquisa relatados no capítulo $\mathrm{V}$, ou seja, o que se compreende agora e que não era compreendido antes, centrando-se nos comentários sobre o estágio de atingimento dos objetivos gerais e específicos da pesquisa, delineados no primeiro capítulo. Essas conclusões serão apresentadas da seguinte forma:

No início comenta-se a relação entre a mudança tecnológica e a necessidade de aprendizagem pelas pessoas, e então especificam-se as questões -chave da implementação eficaz da TI, demonstrando que é imutável a conexão entre a implementação da TI e a mudança organizacional. Após, apresenta-se a visão desenvolvida ao longo da pesquisa, onde conclui-se que trata-se de um processo de transformação organizacional utilizando-se a abordagem sócio-técnica, ou seja, que não põe a TI como ponto central, e sim as pessoas. Na seqüência apresenta-se o modelo de mudança organizacional abrangente que levou à descoberta da Pesquisaação como abordagem para administrar a mudança organizacional, onde são apresentados os fatores principais desta abordagem de pesquisa social, seus pontos fortes e suas limitações. Por último demonstra-se o atingimento dos objetivos propostos no início da pesquisa e apresenta-se a conclusão final com a recomendação para trabalhos futuros.

\section{A RELAÇÃo ENTRE A MUdANÇA TECNOLÓGICA E A} APRENDIZAGEM

As mudanças tecnológicas produzem um conjunto de efeitos organizacionais positivos em termos econômicos e para as pessoas, desde que o processo de mudança seja orientado ao comprometimento. Isso só se atinge na prática através da aprendizagem. Em outras palavras, aprendizagem e mudança são inseparáveis: enquanto aprende, você muda, e a mudança requer aprendizagem, e para isso a pesquisa- ação contribui decisivamente. 
A implantação de uma nova arquitetura de serviços na empresa contábil, com o uso de tecnologia avançada representada pela implantação de um sistema empresarial integradoSistema Empresarial Integrado - ERP é um desafio, e ao mesmo tempo uma oportunidade para a empresa contábil transformar-se num provedor de serviços de aplicação, com a oferta de valor adicionado aos clientes, contribuindo para a diversificação estratégica dessas empresas através do resgate da missão tradicional da contabilidade nas empresas-cliente.

A arquitetura tecnológica resultante requer uma nova arquitetura organizacional, baseada no modelo de gestão participativo, no trabalho em equipes multifuncionais orientadas a projetos e no desenvolvimento da empresa orientada a processos. O resultado é o desenvolvimento do conhecimento e da experiência necessários para que a empresa contábil possa levar a tecnologia de gestão às empresas-cliente, maximizando o potencial positivo provocado por essas mudanças e adequando os investimentos necessários à realidade das pequenas e médias empresas.

\subsection{AS QUESTÕES-CHAVE DA IMPLEMENTAÇÃO EFICAZ DA TI}

A pesquisa indicou, entre as suas principais conclusões, que a implementação de tecnologia de informação avançada deve incluir a administração de mudança organizacional, ou seja, é obrigatória a conexão entre a implementação da tecnologia de informação e a mudança organizacional. Esta conclusão utilizada como premissa por Walton (1998) foi observada neste estudo, favorecendo a conclusão de que a tecnologia e a organização interagem, pelo menos, de sete diferentes maneiras. Em outras palavras, a adoção de um sistema de TI: (i) para ser eficaz, requer novas políticas ou desenhos organizacionais, tais como cargos mais amplos e flexíveis, distribuição de autoridade diferente, novos programas de treinamento e diferentes critérios de seleção; (ii) provoca reações organizacionais não previstas, tais como novas disputas por poder ou status, mudanças nos padrões de comunicação ou controle comportamental generalizado, no caso estudado proporcionou a implantação da gestão participativa; (iii) pode ser elaborado e revisado com a participação dos usuários, e deve contribuir para o comprometimento e aceitação do sistema, levando ao domínio deste pelos usuários, como por exemplo na empresa contábil, onde foi desenvolvida 
uma ferramenta de informática junto ao sistema que permite planejar as atividades para cada cliente, focada nas saídas do processo, onde o profissional consegue ter uma agenda permanente dos serviços realizados e a realizar com indicação dos pontos críticos de controle do processo; (iv) pode criar ou promover novas soluções organizacionais, como por exemplo o desenvolvimento, na empresa contábil, de uma nova arquitetura tecnológica; (v) pode acelerar e refinar a adaptação organizacional a condições de mudança; (vi) as formas organizacionais podem, às vezes, ser consideradas alternativas, no sentido de que cada uma é capaz de desenvolver funções similares, como facilitar certos tipos de comunicação e coordenação entre departamentos, por exemplo, pelo desenvolvimento de um sistema que registra todo o conhecimento produzido, facilitando a troca de conhecimento entre aqueles que já desenvolveram este conhecimento e aqueles que dele necessitam; (vii) pode criar oportunidades para introdução de mudanças organizacionais consideradas desejáveis pela administração, independentemente das necessidades ou potenciais efeitos do sistema, como, por exemplo, focar a atividade contábil na organização dos processos da empresa cliente e no sistema, com resultados efetivos para os processos internos da empresa contábil.. 
FIGURA 23FIGURA 23 - ESTRUTURA RESUMIDA DA TEORIA E DA PRÁTICA PARA IMPLEMENTAÇÃO EFICAZ DA TI

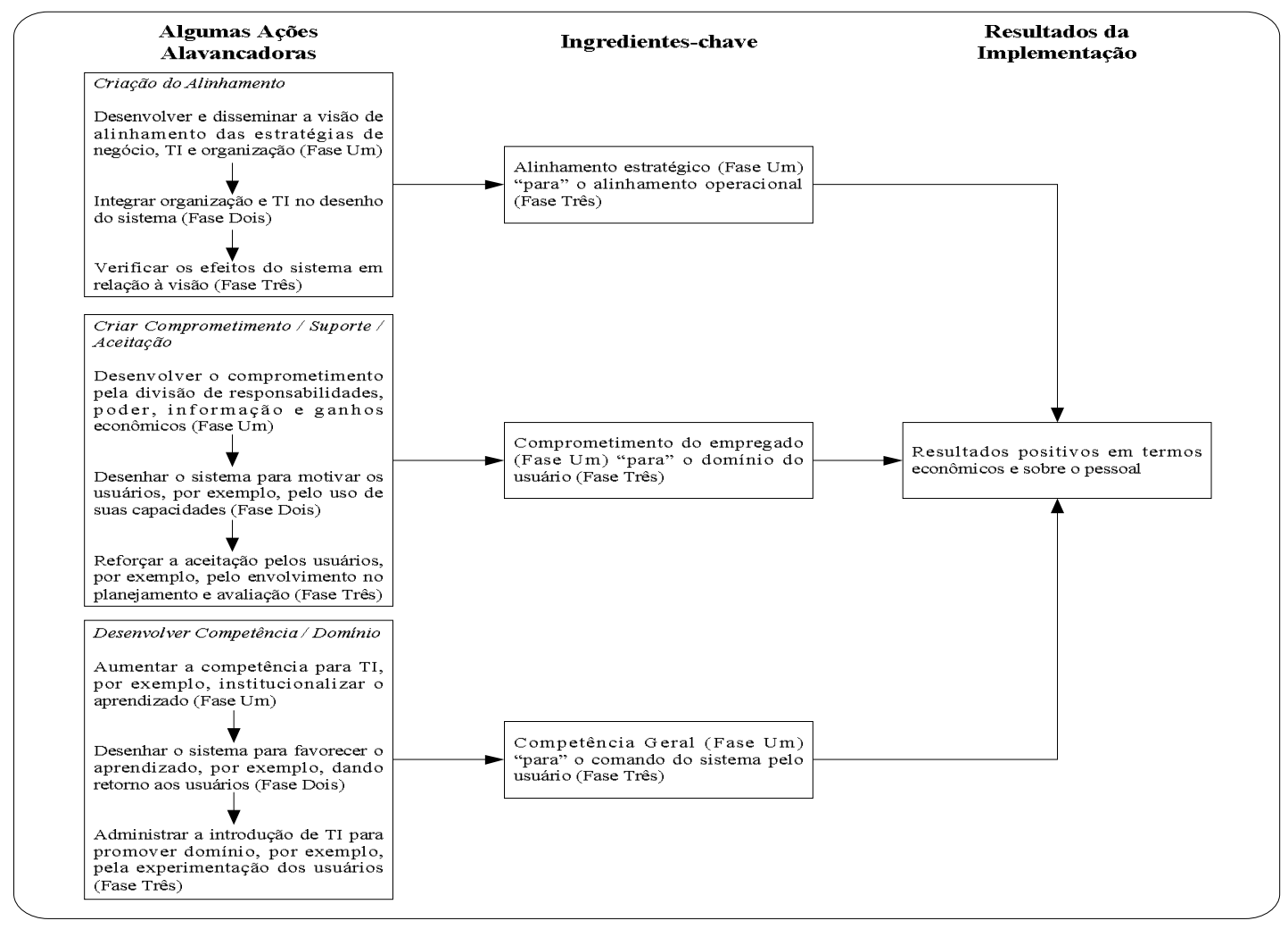

Fonte: Walton (1998, pg.198)

A teoria a respeito da integração da TI e a organização, aplicada nesta pesquisa, foi resumida por Walton (1998) da seguinte maneira: a eficácia da implementação depende crucialmente de (1) gestão adequada; (2) alto comprometimento organizacional, suporte dos líderes e aceitação do sistema; e (3) forte competência, em geral, e domínio dos usuários, em particular. Durante a implementação percebeu-se que o cuidado com a estrutura de alinhamento estratégico da fase Um direciona a atenção para um sistema de TI e a organização integrados na Fase Dois, e então para o alinhamento operacional durante a introdução e difusão - isto pode ser particularmente observado na empresa contábil onde o sistema empresarial integradoSistema Empresarial Integrado - ERP passou a ser parte da estratégia de negócios, permitindo desenvolver a consultoria de gestão, que por sua vez levou à necessidade do desenvolvimento de novos processos de negócios e nova forma de operá-los e gerenciá-los. Similarmente, o comprometimento global e a competência são condições contextuais para o desenvolvimento de sistemas de TI, mas necessitam ser convertidos em aceitação e domínio pelos usuários na Fase Três - neste ponto, a abordagem de 
pesquisa utilizada trouxe resultados significativos em termos de aceitação e domínio do sistema, além do desenvolvimento de conhecimentos práticos decorrentes da forma como o processo de mudança foi conduzido pela própria equipe (atores) da empresa contábil.

A figura anterior, desenvolvida por Walton (1998), propõe algumas ações alavancadoras e os respectivos ingredientes chave que orientam uma implementação eficaz da TI, utilizadas na empresa contábil, com vários pontos que justificam uma discussão adicional, na forma interrogativa, tratados a seguir:

1) Senso de oportunidade em encaminhar assuntos organizacionais - em qual estágio do processo de implementação seria tanto desejável quanto factível efetuar escolhas organizacionais? A pesquisa demonstrou que o desenvolvimento simultâneo da organização e da tecnologia é preferido, desde que o projeto como um todo seja tratado dentro de uma dimensão de mudança organizacional mais ampla. Ou seja, a fase Um do projeto deve envolver o desenvolvimento da nova arquitetura organizacional, onde serão discutidos temas como filosofia organizacional, flexibilidade técnica, resultados iniciais da implementação, clima organizacional, recursos humanos e materiais, entre outros. Deve então iniciar-se a fase Dois, onde será implementado o novo sistema, aproveitando-se na informatização dos processos o uso das melhoras práticas que normalmente os sistemas ERP trazem. Em resumo, quanto maior a folga organizacional disponível para o desenho e a introdução de novos sistemas, mais factível para os planejadores comprometerem-se com o desenvolvimento simultâneo.

2) Administração da Participação - Quais usuários e outros patrocinadores podem ser envolvidos efetivamente e em quais capacidades, e em qual ponto do processo? Todos os usuários devem participar com profundidade em todas as fases do projeto, pois a participação é fator chave no processo e foi enfatizada pela abordagem de pesquisa utilizada - a pesquisa-ação. Uma profunda participação torna mais amplo o escopo do projeto e mais significativas as implicações humanas, contribuindo decisivamente para: (i) melhorar a qualidade do desenho e do planejamento da implantação, pela incorporação do melhor conhecimento sobre as tarefas e a organização das atividades; (ii) gerar o apoio e o domínio por parte dos usuários para 
com o sistema e com o processo de introdução; (iii) incrementar a legitimidade e credibilidade do processo para além do grupo de usuários.

TABELA 9TABELA 9 - RESULTADO DA ANÁLISE DE BARREIRAS AO PROCESSO DE MUDANÇAS

\begin{tabular}{|c|c|c|c|c|c|c|}
\hline \multirow{2}{*}{ Dimensões } & \multirow{2}{*}{ Frentes } & \multirow{2}{*}{\multicolumn{2}{|c|}{ Barreiras }} & \multicolumn{3}{|c|}{ Avaliação } \\
\hline & & & & \multirow[t]{2}{*}{ D } & \multirow[t]{2}{*}{$\mathbf{R}$} & \multirow{2}{*}{ A } \\
\hline \multirow{9}{*}{ Negócios } & \multirow{2}{*}{$\begin{array}{l}\text { Burning } \\
\text { Platform }\end{array}$} & 1 & Não identificação de uma clara burning platform & & & \\
\hline & & 2 & Excesso de complacência & & $\sqrt{ }$ & \\
\hline & Liderança & 3 & Falhar na criação de liderança para o processo & & & $\sqrt{ }$ \\
\hline & Visão & 4 & Falta de uma visão clara para o processo & & $\sqrt{ }$ & \\
\hline & \multirow{3}{*}{ Focalização } & 5 & Falha na focalização de processos e problemas raizes & & & $\sqrt{1}$ \\
\hline & & 6 & F alha na orientação/focalização nas necessidades dos clientes & & $\sqrt{ }$ & \\
\hline & & 7 & Declarar vitória cedo demais & & & $\sqrt{ }$ \\
\hline & \multirow{2}{*}{ Alinhamento } & 8 & Falhar no alinhamento de objetivos & $\sqrt{ }$ & & \\
\hline & & 9 & Falhar na criação de objetivos de curto prazo & & $\sqrt{1}$ & \\
\hline \multirow{11}{*}{ Cultura } & \multirow{3}{*}{$\begin{array}{l}\text { Crenças e } \\
\text { Valores }\end{array}$} & 10 & Subestimar crenças e valores vigentes & $\sqrt{ }$ & & \\
\hline & & 11 & Supervalorizar crenças e valores vigentes & & $\sqrt{ }$ & \\
\hline & & 12 & Negligenciar a ancoragem das mudanças na cultura & $\sqrt{1}$ & & \\
\hline & \multirow{3}{*}{ Comunicação } & 13 & Falhar no processo de comunicação da visão e burning platform & & $\sqrt{1}$ & \\
\hline & & 14 & Negligenciar a comunicação durante o processo de mudança & & & $\sqrt{1}$ \\
\hline & & 15 & Não colher feedback 3600 & & & $\sqrt{ }$ \\
\hline & \multirow{3}{*}{ Motivação } & 16 & Ausência de um claro sistema de compensações e recompensas & $\sqrt{1}$ & & \\
\hline & & 17 & Permitir que obstáculos bloqueiem a visão & & $\sqrt{ }$ & \\
\hline & & 18 & Falta de empowerment aos agentes de mudança e equipe & & $\sqrt{ }$ & \\
\hline & \multirow{2}{*}{ Participação } & 19 & Conduzir a transformação de forma apenas topdown & & $\sqrt{1}$ & \\
\hline & & 20 & Ignorar os receios das pessoas participantes do processo & $\sqrt{ }$ & & \\
\hline \multirow{11}{*}{ Recursos } & \multirow{4}{*}{ Infraestrutura } & 21 & Confundir estrutura de transformação com estrutura operacional & $\sqrt{ }$ & & \\
\hline & & 22 & Falha na adaptação da estrutura organizacional à mudança & & $\sqrt{1}$ & \\
\hline & & 23 & Não criar disponibilidade de tempo na agenda dos participantes & $\sqrt{ }$ & & \\
\hline & & 24 & Falha na alocação de pessoas à equipe de transformação & & & $\sqrt{ }$ \\
\hline & \multirow{2}{*}{ Tecnologia } & 25 & Subestimar a importância de novas tecnologias & & $\sqrt{ }$ & \\
\hline & & 26 & Falha na adequação entre a necessidade e a tecnologia selecionada & & & $\sqrt{1}$ \\
\hline & \multirow{2}{*}{\begin{tabular}{|l} 
Sist. \\
Informação
\end{tabular}} & 27 & Falha na obtenção de dados relevantes para a transformação & $\sqrt{1}$ & & \\
\hline & & 28 & Falha no sistema de divulgação dos resultados da transformação & $\sqrt{1}$ & & \\
\hline & \multirow{3}{*}{$\begin{array}{l}\text { Educ/Treina- } \\
\text { mento }\end{array}$} & 29 & Falta de conhecimento sobre o processo e ferramentas de transformação & $\sqrt{ }$ & & \\
\hline & & 30 & Falha no compartilhamento de conhecimentos & & $\sqrt{1}$ & \\
\hline & & 31 & Falha no treinamento sobre novas tecnologias a serem utilizadas & & & $\sqrt{1}$ \\
\hline \multirow{7}{*}{ Operações } & \multirow{3}{*}{ Planejamento } & 32 & Inexistência de cronograma de transformação com milestones & $\sqrt{1}$ & & \\
\hline & & 33 & Falha na escolha do momento de iniciar a mudança & & & $\sqrt{1}$ \\
\hline & & 34 & Conduzir o processo vagarosamente & & $\sqrt{1}$ & \\
\hline & \multirow{2}{*}{$\begin{array}{l}\text { Ger. de } \\
\text { Processos }\end{array}$} & 35 & Falha na criação de uma visão de processos consensual e clara & $\sqrt{1}$ & & \\
\hline & & 36 & Fragmentação dos processos entre subgrupos durante a transform. & & & $\sqrt{1}$ \\
\hline & Med. & 37 & Falha no estabelecimento de critérios de avaliação da transform. & $\sqrt{ }$ & & \\
\hline & Desempenho & 38 & Não manter aderência dos grupos às medidas de avaliação & $\sqrt{ }$ & & \\
\hline Legenda: & D [deficiente]: & plica & sção falhou em eliminar a barreira e isto comprometeu inteiramente ou parcialmente & resu & & \\
\hline $\begin{array}{l}\text { avaliação } \\
\text { [quslidsde do }\end{array}$ & R [regular]: & Iouve & preocupação em eliminar a barreira, mas esta perdurou e teve algum impacto negativ & nos: & esulta & \\
\hline spliçร̧́์e] & A [adequada]: & & ção teve sucesso em eliminar a barreira ou não foi afetada por esta & & & \\
\hline
\end{tabular}

Fonte: Rentes (2000, pg.100) Adaptado pelo Autor (Os conceitos de análise estão nos apêndices)

3) Avaliação - Como podemos saber se a implantação está indo bem? A avaliação deve incluir critérios múltiplos. Adicionalmente à avaliação dos resultados 
sobre os negócios e índices de desempenho técnico, deve-se avaliar o sistema operacional em termos de ingredientes-chave para a eficácia.

A empresa contábil utilizou, para acompanhar o andamento do processo, a metodologia de transformação organizacional denominada Transmeth, que tem o objetivo de auxiliar empresas na condução do processo de transformação, procurando minimizar a ocorrência de fatores críticos ou falhas ao longo do tempo, através da utilização de uma série de técnicas já disponíveis na literatura e algumas novas ferramentas que consideram diversos aspectos vitais para a condução de um processo de mudança.

A tabela acima demonstra a avaliação da aplicação da técnica no encerramento da pesquisa, ficando claro que o processo de mudança ainda está no começo e que diversas barreiras às mudanças ainda tem que ser eliminadas, por completo ou parcialmente. Essas barreiras estão sendo discutidas a avaliadas pelos atores envolvidos no projeto de mudança ao fim de cada mês. Entre as barreiras às mudanças, a metodologia permitiu identificar a inexistência de cronograma de transformação com milestones, isto é, a falta de uma visão das etapas do processo ao longo do tempo, o que forneceria ritmo ao processo. A falta de um cronograma significa a falta de controle sobre a ocorrência das atividades, levando à falta de planejamento dos recursos a serem empregados. Os milestones são pontos de controle deste cronograma. Eles indicam o cumprimento de objetivos intermediários de curto prazo que são importantes para a motivação dos membros das equipes de transformação. Eles auxiliam também numa avaliação do andamento do projeto, permitindo verificar dificuldades de desenvolvimento e efetuar ações corretivas.

4) Liderança - O que podemos esperar como contribuições das lideranças, e quando elas serão cruciais? A liderança desempenha um importante papel em cada fase do processo de implementação da nova tecnologia, dependendo o sucesso do projeto da liderança vinda do topo da organização, isto é, preferivelmente do executivo chefe denominado como patrocinador do projeto, que envolverá as demais lideranças das áreas operacionais e de apoio, envolvendo-os inicialmente na formulação e comunicação de longo prazo, ou seja, para onde a empresa está indo e como chegará lá. Como exemplo na empresa contábil está a análise da figura 22 no capítulo $\mathrm{V}$ que trata da diversificação estratégica da empresa contábil através da consultoria de gestão 
a empresas-cliente (pme), resgatando a contabilidade gerencial através da implantação de sistema empresarial integradoSistema Empresarial Integrado - ERP. Decorrendo desta visão estratégica a nova arquitetura tecnológica representada pela figura 6 no capítulo I, a empresa contábil poderá realizar sua missão principal, bem como resgatar a missão tradicional da contabilidade, e ainda atuar como Provedor de Serviços de Aplicação (ASP - Application Service Provider), levando tecnologia de ponta para as empresas cliente com custo total de propriedade (TCO) minimizado.

Senso de urgência e uma forte liderança são fatores necessários, mas não são condições suficientes para o processo de mudança. A visão da empresa exerce um papel chave no processo, fornecendo direcionamento, alinhamento de objetivos e inspirando ações de um grande número de pessoas na organização. Da mesma forma que a burning platform, a visão não é óbvia e precisa ser eficientemente comunicada..

Grandes mudanças são normalmente consideradas impossíveis, a não ser que o líder da organização seja um patrocinador ativo do projeto. Mais do que isso, em transformações de sucesso, o presidente, diretores de divisões, gerentes e líderes de processos devem estar comprometidos com o processo de melhoria de performance, possibilitando a criação de um time coeso, que acredite na necessidade da mudança e que consiga liderar e motivar as demais pessoas da empresa nas diversas ações de melhoria. Um indivíduo sozinho normalmente não tem a capacidade de vencer as tradições e a inércia organizacional existente, para realizar mudanças de grande porte em um espaço de tempo razoável. A ausência deste comprometimento é outra falha grave no desenvolvimento da mudança organizacional. Observou-se a necessidade de desenvolver processos de treinamento e desenvolvimento das lideranças na empresa contábil.

\subsection{TRANSFORMAÇÃO ORGANIZACIONAL: A ABORDAGEM SÓCIO-TÉCNICA.}

O gerenciamento da transformação organizacional proposto por este trabalho na empresa contábil, decorrente da implementação da TI, encontra-se na fase inicial, após um ano de debates que levaram a equipe a compreender a profundidade da mudança requerida, o que propiciou alterações constantes no projeto, na medida em que as descobertas foram sendo evidenciadas através da pesquisa-ação. 
Neste sentido, uma abordagem sócio-técnica à formação de estratégia de negócio e à mudança organizacional que incorpore considerações sobre sistemas de informação e aspectos da filosofia de reengenharia de processos de negócios, mas que não ponha a TI como ponto central, nem assuma que a mudança seja necessariamente radical, ajudou a entender melhor os aspectos e as fases dessas mudanças como um processo cíclico, cujo modelo, descrito na figura seguinte, está sendo seguido e foi entendido como a melhor abordagem para encaminhar o processo de forma promissora rumo aos objetivos traçados.

Através da análise do ambiente organizacional chegou-se a conclusão que as necessidades dos clientes da empresa contábil estão relacionadas com o desenvolvimento tecnológico. Criou-se então um clima favorável para a mudança e preparação do respectivo projeto, concluindo-se que a tecnologia a ser adotada poderia servir para a empresa contábil e ao mesmo tempo ser testada sua eficácia internamente, isto é, a implantação do sistema na própria empresa contábil serviu de laboratório para testar-se a sua eficácia em adaptar-se a diferentes realidades e para entender que mudanças organizações sua operação requer, ao mesmo tempo permitindo o treinamento e desenvolvimento de uma equipe de especialistas internos na condução do projeto . Isso propiciou a criação de cenários alternativos futuros - nova arquitetura tecnológica no modelo ASP, que transformou-se numa nova estratégia de negócios, sendo avaliada sua praticabilidade pela parceria desenvolvida com a empresa fornecedora do ERP. 
FIGURA 24FIGURA 24 - O GERENCIAMENTO DA TRANSFORMAÇÃO ORGANIZACIONAL, ATRAVÉS DE UMA ABORDAGEM SÓCIO-TÉCNICA AOS NEGÓCIOS E A FORMAÇÃO DA ESTRATÉGIA DE SISTEMA DE INFORMAÇÃO

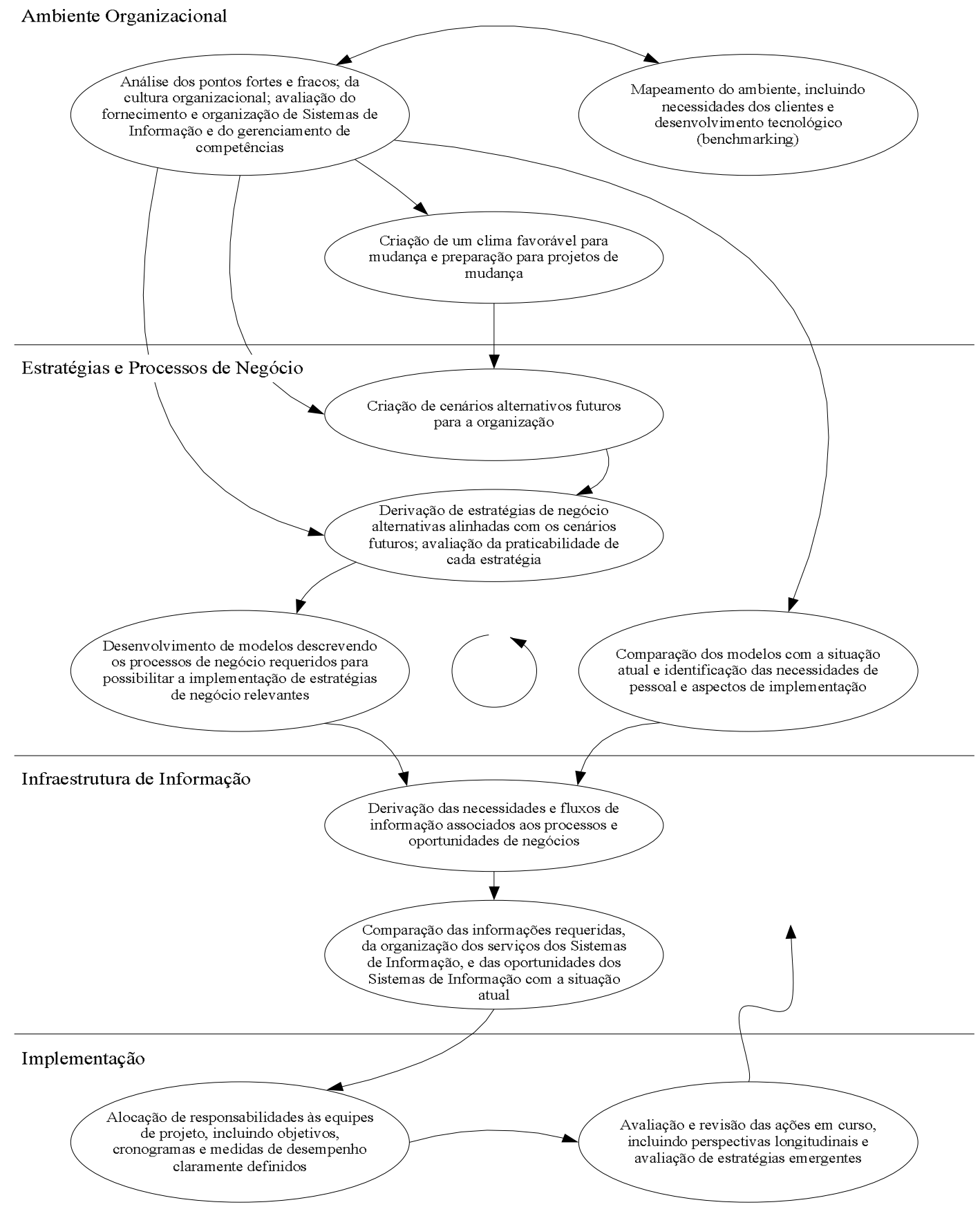

Fonte: Galliers (1998, pg.234)

Os novos processos de negócio foram sendo desenvolvidos para possibilitar implementar as estratégias comparando-se com a situação atual e identificando as necessidades de mudança, principalmente em termos de conhecimento do pessoal. Foi então criada a infra-estrutura tecnológica e de informação. A complexidade de criar novos processos de negócio passou inicialmente pelo mapeamento dos processos 
atuais, onde foram discutidas as regras de entrada - que no caso da empresa contábil tem a participação ativa da empresa cliente com informações, o processamento - com o desenho do sistema para refletí-lo eficazmente, e as saídas dos sistemas, que envolvem serviços entregues à empresa cliente e para o fisco na forma de obrigações tributárias e legais. Isso exigiu o desenho de um novo sistema, integrado ao ERP que permitisse automatizar todo o processo de planejamento e controle das operações de serviços.

Iniciou-se a implementação através da alocação de responsabilidades às equipes de projeto, incluindo objetivos, cronogramas e medidas de desempenho claramente definidos. Isto terá como resultado o desenvolvimento de um modelo descrevendo como implementar essa mesma estratégia tecnológica e de mudança na empresa cliente.

A avaliação das barreiras às mudanças serve como parâmetro balizando se o processo está sendo devidamente conduzido, e fornece o foco das principais ações, que tem que ser revistas e avaliadas para que o objetivo final seja plenamente alcançado. Cada uma das barreiras pode representar uma ou várias ações a serem implementadas.

\subsection{MODELO DE MUDANÇA ORGANIZACIONAL}

\section{ABRANGENTE}

A tecnologia de informação representada principalmente pelo sistema empresarial integradoSistema Empresarial Integrado - ERP traz profundas mudanças no ambiente organizacional, com conseqüências para a vida social dos atores e para a administração das empresas, principalmente das empresas contábeis, que terão de redefinir o seu papel na sociedade. A administração dessa mudança é um processo crítico e só pode ser consolidado a médio e longo prazo, isto é, em dois ou três anos, embora as melhorias, mesmo que graduais, possam se fazer sentir a cada momento, principalmente com a utilização da pesquisa-ação, que contribui para a construção de um clima de comprometimento e aprendizado.

Conclui-se que a utilização dessa tecnologia com sucesso, visando maximizar o seu potencial, requer o desenvolvimento de um modelo de mudança organizacional abrangente, através de alteração no caráter da organização que mudará significativamente seu desempenho, pois: 
(i) modifica os seus aspectos chave, incluindo mudanças no padrão do seu relacionamento com o seu meio ambiente - inputs / processamento / outputs e na própria natureza desses, mudança nos padrões de diferenciação, coordenação e integração, através dos quais os recursos organizacionais são canalizados ou estruturados e mudanças nas práticas da gestão de recursos humanos, notadamente na gestão participativa e;

(ii) modifica o desempenho da organização, na medida que muda a forma de transformar inputs em outputs, a própria natureza dos outputs e sua estrutura e processos, conseqüentemente seu desempenho será alterado.

Para se compreender melhor um modelo de mudança organizacional abrangente é importante entender as três dimensões dessa mudança, através de: (i) profundidade da mudança, que envolve alterações nas crenças e valores dos membros da organização e na maneira pela qual a organização é compreendida e atuada, estando associada a profundas alterações cognitivas e mudanças de paradigma; (ii) penetração da mudança, envolve a maioria dos subsistemas da organização e equipes multidisciplinares como agentes de mudança, exigindo cooperação, coordenação e a construção de um consenso entre os diferentes setores e atores; (iii) tamanho da empresa, pois quanto maior a organização, maior a mudança necessária para alterar o seu caráter e desempenho, o que não é o caso deste estudo. Enfim, por maiores resistências que possam ocorrer quanto às mudanças, observa-se que elas acontecem com freqüência nas organizações, principalmente decorrentes da atualização da tecnologia. Porém, foi observado que a implementação de um sistema empresarial integradoSistema Empresarial Integrado - ERP exige uma mudança abrangente, com reflexos nos seus sistemas técnico e social.

\subsection{PESQUISA-AÇÃO: FATORES PRINCIPAIS, PONTOS FORTES E LIMITAÇÕES.}

Em outras partes deste trabalho comentamos que a abordagem Pesquisa-Ação foi decisiva para os resultados da pesquisa e deve ser entendida como decorrência das próprias descobertas da pesquisa, em dois sentidos: (i) como paradigma de pesquisa; e (ii) como abordagem para administrar a mudança organizacional. O objetivo da 
pesquisa-ação é aprender com a experiência, e aplicar este aprendizado para provocar a mudança. A dinâmica de um sistema social é freqüentemente mais aparente em tempos de mudança, e aprendizagem e mudança tem influência mútua.

O processo de mudança é sempre um momento crítico, e a pesquisa-ação contribui levando os atores envolvidos a encontrar as respostas aos seus próprios problemas, comprometendo-se com a mudança e aprendendo com ela, possibilitando desenvolver a chamada "organização que aprende”.

Fontes de informação insubstituíveis, as intervenções na empresa contábil foram oportunidades únicas para o pesquisador ter acesso a informações e problemas que freqüentemente não estavam aparentes no dia-a-dia. Conceber e realizar a pesquisa-ação nesta empresa, com suas características peculiares, foi um investimento teórico e prático cujos resultados serão mais visíveis a médio ou longo prazo, em termos de mudanças estruturais, porém permitiu repensar a atividade do contador organizado em empresa já a partir do primeiro dia.

Para identificar as forças e limitações da PA nesta pesquisa buscou-se agrupar os resultados em oito categorias, chamadas de fatores principais, identificadas por Waterman et al. (2001), e organizados de acordo com o tema que cada um aborda, discutidos de forma a contrapô-los em aspectos positivos e negativos percebidos ao longo das intervenções. A oposição de aspectos do mesmo fator principal oferece possíveis caminhos para recontextualizar o entendimento do processo de PA e oferecer idéias para o desenvolvimento futuro de outros trabalhos.

Os fatores principais identificados durante o processo de PA são: Participação, Pessoas-chave, Relacionamento pesquisador-participante da PA, Foco na realidade (mundo real), Recursos, Métodos de Pesquisa, Processo e gerenciamento do projeto e Conhecimento.

Mesmo parecendo que existe sobreposição entre os fatores e seus aspectos, o que é comum em pesquisas qualitativas considerando a natureza das análises, as diferenças são suficientes para facilitar o entendimento das conclusões e relatar as discussões que foram encaminhadas ao longo do processo cíclico característico da PA.

As tabelas seguintes apresentam de forma resumida os aspectos percebidos na respectiva categoria descrita como fator principal, de acordo com o modelo proposto 
por Waterman et al. (2001; pg.29-41). Saliente-se que mesmo quando o aspecto não foi observado na pesquisa ora comentada, o contraponto positivo ou negativo percebido reforça o entendimento dos resultados alcançados, representando forças ou limitações da abordagem de pesquisa-ação para trabalhos futuros, devendo desenvolver-se desde seu projeto estratégias para evidenciá-los ou contorná-los, o que permitirá alcançar resultados mais efetivos de mudança.

A participação é o principal e mais importante fator em todas as fases da pesquisa-ação, influenciando o resultado de todos os demais fatores, bem como, sua implementação eficaz. As discussões sobre a participação incluem a definição de quem participa, nível de participação e as várias atividades do projeto. Toda a empresa contábil foi envolvida no projeto, dividida em equipes, cada qual responsabilizada por questões relacionadas com uma das dimensões da mudança, além das próprias lideranças das áreas, que formavam um grupo definido como "equipe do projeto" que alocou parte do tempo destinado às suas atividades operacionais ao projeto. 
A participação direta no projeto de todos os membros do grupo desencadeou um movimento muito grande de interesse pelo seu entendimento e desenvolvimento, o que criou relações de envolvimento com o pesquisador e fez crescer a motivação e a vontade de mudar, próprios do processo de mudança. A participação também foi fundamental como processo educacional e de treinamento, porque propiciou troca de experiências, conhecimentos, idéias e aprendizagem na utilização de novas ferramentas de trabalho em grupo, ligadas a sistemas de informática, que foram pesquisadas, testadas, implantadas e divididas levando os participantes a sentirem-se apoiados nas suas iniciativas.

TABELA 10 - FATOR PRINCIPAL: PARTICIPAÇÃO

\begin{tabular}{|c|c|}
\hline Aspectos Positivos Percebidos & Aspectos Negativos Percebidos \\
\hline Promove compreensão do contexto de estudo. & $\begin{array}{l}\text { Rompe as fronteiras existentes de tomada de } \\
\text { decisão e planejamento estratégico. }\end{array}$ \\
\hline $\begin{array}{c}\text { Permite a identificação de problemas pelos } \\
\text { participantes. }\end{array}$ & Inicia mudanças nos relacionamentos existentes. \\
\hline $\begin{array}{l}\text { Desenvolve inovações e estratégias apropriadas, } \\
\text { relevantes e praticáveis para a mudança, } \\
\text { conduzindo à mudança sustentável. }\end{array}$ & Requer energia para ser mantida. \\
\hline $\begin{array}{l}\text { Faz uso dos recursos de conhecimento e } \\
\text { experiência disponíveis. }\end{array}$ & $\begin{array}{l}\text { Fornece oportunidade para domínio dos projetos } \\
\text { por participantes com mais poder. }\end{array}$ \\
\hline $\begin{array}{c}\text { Fornece oportunidades educacionais através do } \\
\text { compartilhamento de experiência, conhecimento e } \\
\text { idéias. }\end{array}$ & $\begin{array}{c}\text { Encoraja feedback sobre o desempenho de } \\
\text { participantes que possam ser vistos como uma } \\
\text { ameaça. }\end{array}$ \\
\hline $\begin{array}{c}\text { Gera interesse no projeto, superando barreiras } \\
\text { para mudanças. }\end{array}$ & Toma tempo. \\
\hline $\begin{array}{l}\text { Aumenta ou desenvolve a disposição de participar } \\
\text { e mudar. }\end{array}$ & Expõe e cria resistência à mudança. \\
\hline $\begin{array}{l}\text { Promove a posse da mudança, permitindo uma } \\
\text { abordagem rápidaSupera barreiras para mudança. }\end{array}$ & $\begin{array}{c}\text { Cria sentimentos negativos se as mudanças não } \\
\text { são implementadas. }\end{array}$ \\
\hline Promove a posse da mudança. & \\
\hline Permite abordagem rápida de mudança. & \\
\hline $\begin{array}{l}\text { Constrói entendimento, fornece apóio e poupa } \\
\text { tempo. }\end{array}$ & \\
\hline
\end{tabular}

Fonte: Waterman et al. (2001), adaptada pelo Autor.

A participação é o principal e mais importante fator em todas as fases da pesquisa-ação, influenciando o resultado de todos os demais fatores, bem como, sua implementação eficaz. As discussões sobre a participação incluem a definição de quem participa, nível de participação e as várias atividades do projeto. Toda a empresa contábil foi envolvida no projeto, dividida em equipes, cada qual responsabilizada por 
questões relacionadas com uma das dimensões da mudança, além das próprias lideranças das áreas, que formavam um grupo definido como "equipe do projeto" que alocou parte do tempo destinado às suas atividades operacionais ao projeto.

A participação direta no projeto de todos os membros do grupo desencadeou um movimento muito grande de interesse pelo seu entendimento e desenvolvimento, o que criou relações de envolvimento com o pesquisador e fez crescer a motivação e a vontade de mudar, próprios do processo de mudança. A participação também foi fundamental como processo educacional e de treinamento, porque propiciou troca de experiências, conhecimentos, idéias e aprendizagem na utilização de novas ferramentas de trabalho em grupo, ligadas a sistemas de informática, que foram pesquisadas, testadas, implantadas e divididas levando os participantes a sentirem-se apoiados nas suas iniciativas.

As características de heterogeneidade dos grupos e a forma como foi negociada a participação dos seus membros propiciou maior compreensão e envolvimento na identificação e análise dos problemas e nas ações visando resolvê-los, através de estratégias e inovações apropriadas. Enfim, a participação foi fundamental para ultrapassar as barreiras identificadas para a mudança e ajudou a reduzir as principais ameaças ao projeto, definidas na literatura administrativa como "resistências à mudança".

Destaca-se como o aspecto positivo percebido mais relevante da participação a identificação de problemas organizacionais pelos próprios participantes, que desenvolvem estratégias apropriadas, relevantes e praticáveis para a mudança, conduzindo à mudança sustentável, oportunizando um processo de aprendizagem através do compartilhamento de experiência, conhecimento e idéias. Dos aspectos negativos percebidos ligados a este fator destacam-se que a participação requer muita energia para ser mantida e toma muito tempo dos participantes, normalmente ocorrendo uma disputa intensa entre o tempo das atividades operacionais rotineiras e aquele que deve ser investido no projeto, exigindo dedicação extra do pessoal.

Neste aspecto, o ideal é que a equipe ligada diretamente ao projeto, definida como os agentes de mudança, tenha uma agenda diferenciada dos demais membros da organização, conforme pode-se observar pelos aspectos positivos percebidos no fator pessoas-chave da tabela seguinte. 
As pessoas-chave incluem todos aqueles que tem posição formal na organização com poder de comando, ou seja, têm liderança formal e influência nos processos de decisão. As lideranças alocadas ao projeto têm como missão serem os multiplicadores e apoiadores das idéias principais, e devem receber um treinamento especial sobre a abordagem utilizada, compreendendo adequadamente a importância do seu papel no projeto de PA, mesmo muitas vezes agindo através de canais de comunicação informal para discutir e divulgar os objetivos e andamento dos trabalhos.

TABELA 11 - FATOR PRINCIPAL: PESSOAS-CHAVE

\begin{tabular}{|c|c|}
\hline Aspectos Positivos Percebidos & Aspectos Negativos Percebidos \\
\hline $\begin{array}{l}\text { Requer estudo obtendo permissão do grupo para } \\
\text { conduzí-lo. }\end{array}$ & Impor o projeto. \\
\hline $\begin{array}{l}\text { Autoriza acesso ao staff (alta gerência).Obtém } \\
\text { permissão para conduzir o estudo. }\end{array}$ & Opor-se ao projeto. \\
\hline $\begin{array}{l}\text { Liga diferentes agendas, isto é, agenda profissional } \\
\text { e gerencial, ou pontos de vista diferentes (gestão / } \\
\text { operação).Autoriza acesso ao staff (alta gerência). }\end{array}$ & $\begin{array}{l}\text { Não participar, isto é, não transmitir informação, } \\
\text { não completar diários (registro) }\end{array}$ \\
\hline $\begin{array}{l}\text { Fornecer recursos: fundos, materiais, tempo, } \\
\text { assessoria.Liga diferentes agendas, isto é, agenda } \\
\text { profissional e gerencial, ou pontos de vista } \\
\text { diferentes (gestão / operação). }\end{array}$ & $\begin{array}{c}\text { Não participar, resultando em mudanças de pouca } \\
\text { significância. }\end{array}$ \\
\hline $\begin{array}{l}\text { Iniciar ou responsabilizar-se pela prática que é o } \\
\text { foco da mudança. }\end{array}$ & Dominar o projeto. \\
\hline $\begin{array}{l}\text { Fornecer habilidades relevantes à mudança } \\
\text { proposta. }\end{array}$ & Recusar-se a permitir mudanças no poder. \\
\hline $\begin{array}{l}\text { Fornecer recursos: fundos, materiais, tempo, } \\
\text { assessoria. }\end{array}$ & \\
\hline $\begin{array}{l}\text { Sustentar a mudança: alteração da estrutura e da } \\
\text { política organizacional para acomodar inovações, } \\
\text { provisão de recursos, financiamento, pessoal. }\end{array}$ & \\
\hline
\end{tabular}

Fonte: Waterman et al. (2001), adaptada pelo Autor.

Os principais dirigentes devem atuar como patrocinadores do projeto em todos os níveis, para permitir que o poder seja distribuído uniformemente, e a participação do idealizador da organização, com sua visão sobre os objetivos e resultados a serem alcançados, também contribui decisivamente, principalmente para sustentar a mudança através da alteração da estrutura e da política organizacional para acomodar inovações, provisão de recursos, financiamento, pessoal etc. As pessoas-chave devem dedicar-se a 
estudos para responder adequadamente às novas necessidades de conhecimento que vão sendo incorporadas pela organização, pois muitas das questões que vão sendo levantadas exigem fundamentação teórica para o planejamento da ação, como, por exemplo, as técnicas para mapeamento dos processos que exigem, além do conhecimento das ferramentas necessárias ao trabalho, conhecimento sobre os conceitos e metodologias que estão por trás das técnicas. Destacam-se como aspectos negativos principais percebidos, com relação às pessoas-chave, recusar-se a permitir mudanças no poder ou não participar, resultando em mudanças de pouca significância, normalmente decorrentes do querer impor o projeto. Neste sentido, o relacionamento aberto e sincero entre o pesquisador e os participantes, desenvolvido desde a negociação inicial do projeto, é fundamental para reduzir os aspectos negativos percebidos quando o pesquisador tem um papel formal na organização, e discutidos na tabela seguinte. 
TABELA 12 - FATOR PRINCIPAL: RELACIONAMENTO PESQUISADOR-PARTICIPANTE DA PA

\begin{tabular}{|c|c|}
\hline Aspectos Positivos Percebidos & Aspectos Negativos Percebidos \\
\hline \multicolumn{2}{|c|}{ PESQUISADOR COM PAPEL FORMAL NA ORGANIZAÇÃO } \\
\hline $\begin{array}{l}\text { Melhora da compreensão das questões e do } \\
\text { contexto }\end{array}$ & Familiaridade obscurece a compreensão. \\
\hline Aumenta a credibilidade com os participantes. & Compromissos conflitantes podem causar atrasos. \\
\hline Desafia barreiras à mudança. & Os participantes relutam em abrir a informação. \\
\hline Aumenta o comprometimento com o estudo. & $\begin{array}{l}\text { Acesso limitado a informação sensível ou } \\
\text { confidencial. }\end{array}$ \\
\hline \multirow[t]{4}{*}{ Sustenta a mudança. } & Percebido como o "dono" dos dados. \\
\hline & $\begin{array}{l}\text { Poderia gerar sentimento de vulnerabilidade dos } \\
\text { participantes caso o pesquisador seja considerado } \\
\text { como tendo aprovação de fora. }\end{array}$ \\
\hline & Certas alianças podem representar ameaças. \\
\hline & Dependência do pesquisador ou dos participantes. \\
\hline \multicolumn{2}{|c|}{ PESQUISADOR SEM PAPEL FORMAL NA ORGANIZAÇÃO } \\
\hline Traz novas perspectiva para o assunto. & Tem dificuldade na compreensão do contexto. \\
\hline \multirow[t]{3}{*}{ Conduz ao fortalecimento dos participantes. } & $\begin{array}{c}\text { O pesquisador acha dispendioso em termos de } \\
\text { tempo compreender o contexto e estabelecer } \\
\text { credibilidade. }\end{array}$ \\
\hline & $\begin{array}{c}\text { Falta de preocupação com os resultados de longo } \\
\text { prazo, dando a impressão que o pesquisador é que } \\
\text { tem mais a ganhar. }\end{array}$ \\
\hline & Parece ter mais a ganhar (um grau mais alto). \\
\hline
\end{tabular}

Fonte: Waterman et al. (2001), adaptada pelo Autor.

O relacionamento pesquisador-participante na pesquisa-ação envolve o desenvolvimento da interação entre aquele que tem interesse de testar a teoria e aqueles que buscam soluções para problemas práticos. Nesta pesquisa o pesquisador tem um papel formal na direção da empresa contábil pesquisada, o que permitiu desenvolver uma melhor compreensão das questões e do contexto do ambiente estudado, permitindo também aumentar a credibilidade com os participantes no encaminhamento das soluções encontradas, referentes à implantação de uma nova arquitetura tecnológica e organizacional. 
Foram percebidos aspectos positivos em função do pesquisador ter um papel formal, como o aumento do comprometimento de todo o grupo com o estudo, principalmente os lideres escolhidos, e que permitiu sustentar as mudanças planejadas e paulatinamente ir desafiando e eliminado as barreiras à mudança. Em contrapartida a familiaridade do pesquisador com o ambiente de pesquisa e seus problemas obscurece a compreensão das ações, principalmente por compromissos conflitantes que podem causar atrasos na implementação das decisões, o que acabando refletindo-se no lento andamento do projeto e no adiamento da sua conclusão.

Percebeu-se também que, quando o pesquisador não possui um papel formal na organização, os aspectos positivos relatados são poucos, comparativamente, com os aspectos negativos encontrados, concluindo-se que o melhor resultado para o processo de pesquisa-ação ocorre quando o pesquisador compreende com profundidade o contexto social (ambiente organizacional) onde a pesquisa está sendo aplicada, e tem preocupação com os resultados de longo prazo, o que é plenamente aplicável ao caso da empresa contábil estudada.

$\mathrm{O}$ reconhecimento do contexto onde a pesquisa acontece proporciona $\mathrm{o}$ desenvolvimento de habilidades no grupo em identificar problemas concretos e freqüentemente complexos, sendo um dos aspectos mais positivos observados pela abordagem de PA aplicada no contexto da empresa contábil, e por isso altamente recomendável para os processos de implementação de sistema ou mudança tecnológica. Isso elimina parte das críticas que são feitas às pesquisas científicas, principalmente no domínio do conhecimento contábil e de sistemas, que se fundamentam no distanciamento entre o conjunto de conhecimento teórico e o que acontece no mundo real, aquele do dia-a-dia, onde existe efetivamente a necessidade de buscar-se soluções para os problemas existentes, que podem ser distintos ou únicos, dependendo do ambiente, das pessoas envolvidas e da cultura do grupo. 
TABELA 13 - FATOR PRINCIPAL: FOCO NA REALIDADE (MUNDO REAL)

\begin{tabular}{|cc|}
\hline Aspectos Positivos Percebidos & Aspectos Negativos Percebidos \\
\hline Reflete a situação da realidade (mundo real) & Cria conflito e tensão enquanto assuntos complexos \\
são tratados. \\
$\begin{array}{c}\text { Esclarece o contexto e os assuntos, expondo a } \\
\text { ção dos pesquisadores às realidades da prática. }\end{array}$ & Rompe relacionamentos existentes. \\
Aumenta a importância da pesquisa. & Falha em atender expectativas. \\
$\begin{array}{c}\text { Resolve discrepâncias entre assuntos estratégicos e } \\
\text { operacionais. }\end{array}$ & $\begin{array}{c}\text { Dirige a atenção para assuntos que podem ter baixo } \\
\text { significado financeiro ou estratégico. } \\
\text { Requer tempo fora da área operacional para } \\
\text { educação, reflexão e análise. }\end{array}$ \\
Promove a pesquisa orientada ao serviço. & \\
$\begin{array}{l}\text { Expõe a ação dos pesquisadores às realidades da } \\
\text { prática. }\end{array}$ & \\
\hline
\end{tabular}

Fonte: Waterman et al. (2001), adaptada pelo Autor.

$\mathrm{O}$ reconhecimento do contexto onde a pesquisa acontece proporciona o desenvolvimento de habilidades no grupo em identificar problemas concretos e freqüentemente complexos, sendo um dos aspectos mais positivos observados pela abordagem de PA aplicada no contexto da empresa contábil, e por isso altamente recomendável para os processos de implementação de sistema ou mudança tecnológica. Isso elimina parte das críticas que são feitas às pesquisas científicas, principalmente no domínio do conhecimento contábil e de sistemas, que se fundamentam no distanciamento entre o conjunto de conhecimento teórico e o que acontece no mundo real, aquele do dia-a-dia, onde existe efetivamente a necessidade de buscar-se soluções para os problemas existentes, que podem ser distintos ou únicos, dependendo do ambiente, das pessoas envolvidas e da cultura do grupo

Observou-se que a exposição da ação do pesquisador às realidades práticas aumenta a importância da pesquisa, refletindo a situação vivenciada pelos agentes no contexto social num ambiente de pesquisa. Os agentes sentem a necessidade de mudanças relevantes e apropriadas, porém não conseguem implementar ações, pois o contexto parece sempre nebuloso, encontrando-se dificuldades de entender ou antecipar os efeitos e avaliar os resultados entre as alternativas de ação, que muitas vezes podem parecer antagônicas ou concorrentes, se mal interpretadas suas causas e conseqüências. Particularmente no grupo estudado observou-se uma dificuldade muito 
grande em encontrar-se as causas efetivas dos problemas levantados, confundindo-se na maioria das vezes as conseqüências com as causas e vice-e-versa. Para combater essa fraqueza é muito importante treinar o grupo de PA no domínio de ferramentas da qualidade, que são técnicas que utilizamos com a finalidade de definir, mensurar, analisar e propor soluções para os problemas que interferem no bom desempenho dos processos de trabalho, tais como: Diagrama de tendência, Gráficos de dispersão, Diagrama de controle, Folha de verificação, Diagrama de causa e efeito, Histograma, Brainstorming, Fluxograma e Diagrama de Pareto, entre outros.

Um ponto bastante positivo que se destaca é a clarificação entre os assuntos estratégicos e os assuntos operacionais da organização pesquisada. Porém, entre os principais aspectos negativos percebidos está o grupo focar atenção em assuntos que tinham baixo significado financeiro ou estratégico, como por exemplo, terem sido identificados como os maiores e mais sérios problemas os conflitos ditos comportamentais, identificando-se na maioria das vezes comportamentos inadequados nos outros, sem uma auto-reflexão objetiva, o que levou ao desenvolvimento de conflitos e tensão enquanto assuntos complexos eram tratados, dificultando o planejamento e a implantação de ações adequadas.

O processo de PA exige da organização estudada a dedicação de muitos recursos, normalmente bem escassos na empresa contábil, relacionados a: (i) tempo: para a discussão, encaminhamento e avaliação das ações propostas; (ii) pessoal: conhecimento e maturidade para emergir soluções coletivas dos debates e dos problemas identificados, principalmente de ferramentas e métodos adequados para identificar as verdadeiras causas dos problemas e abordá-los de maneira positiva, isto é, apresentando o encaminhamento das soluções possíveis; (iii) Material e dinheiro necessários para a compra de recursos, como por exemplo, audiovisuais e sistemas para expor as ações e avaliar os resultados da sua implementação, software e treinamento. Destaca-se no aspecto cultural a dificuldade dos profissionais contábeis ligados à empresa contábil pesquisada em expor adequadamente suas idéias, por escrito, de forma coerente ou através de fluxogramas, exigindo investimento extra no treinamento desses requisitos. A percepção do pesquisador é que falta ao profissional contábil formação específica para a comunicação escrita, o que pode ser decorrente de 
falhas no processo de ensino ou dos respectivos currículos nas escolas de contabilidade da região.

A PA exige um montante de tempo significativo na resolução de situações controvérsas, quando buscam-se soluções por um processo de participação com princípios democráticos, isto é, quando as deliberações devem ocorrer por consenso.

Um cuidado especial deve ser tomado quanto ao método de coleta de dados, enquanto oposto ao gerenciamento do projeto e implementação da mudança, pois os registros e avaliações devem ser claros e objetivos, e o grupo não pode achar que somente a equipe do projeto é que deve ter acesso às informações e à avaliação dos resultados, em outras palavras, que as informações levantadas e registradas ao longo da pesquisa não signifiquem base para construir julgamento dos participantes que estejam fora do projeto, aqueles que fazem parte da organização estudada, porém, não são membros efetivos com função formal no projeto.

Observou-se que as pessoas gostam de participar de projetos cujos processos estejam desde o início formalmente estabelecidos, e que as mudanças que vão ocorrendo ao longo do projeto, característica peculiar da PA em função da sua natureza cíclica, quanto ao escopo, prazos e implementação são percebidos como falta de foco e falhas no seu gerenciamento. Percebeu-se no projeto em estudo que a utilização da PA como metodologia permitiu ao grupo compreender melhor a natureza e complexidade dos problemas estudados e a flexibilidade permitida pela natureza do processo cíclico de 5 fases da pesquisa-ação (1- diagnóstico, 2- planejamento da ação, 3- execução da ação, 4-avaliação, e 5- especificação do aprendizado) ajudou a encontrar as respostas na medida em que o processo caminhava, permitindo, muitas vezes, redefinir melhor os problemas, e conseqüentemente buscar outros objetivos. 
Como em muitos modelos, a simplicidade aparente da pesquisa-ação desmente sua complexidade. A dificuldade dos atores em compreender o processo no inicio é inerente aos objetivos da pesquisa-ação, pois o conhecimento vai aumentando na medida em que o projeto vai sendo estabelecido e os ciclos vão sendo completados, para que então um quadro mais claro vá sendo delineado. Justamente a natureza flexível da PA ajuda a aumentar a responsabilidade dos participantes, que compreendem sua participação no processo como uma das forças principais do projeto, e necessária ao seu gerenciamento. Em outras palavras, os atores envolvidos são participantes ativos também no gerenciamento do processo, pois lhes são dados mecanismos de feedback que aumentam a sua participação e responsabilidade pelos resultados.

TABELA 14 - FATOR PRINCIPAL: PROCESSO E GERENCIAMENTO DO PROJETO

\begin{tabular}{|c|c|}
\hline Aspectos Positivos Percebidos & Aspectos Negativos Percebidos \\
\hline \multicolumn{2}{|r|}{ COMPREENSÃO E FLEXIBILIDADE } \\
\hline Receptivo a novas idéias. & Deixar o projeto sem estabelecer objetivos e metas. \\
\hline Ajuste à abordagem qualitativa. & $\begin{array}{l}\text { Falta de clareza - dificuldade em obter } \\
\text { financiamento, interesse e suporte. }\end{array}$ \\
\hline Promove projetos orientados aos participantes. & $\begin{array}{l}\text { Encoraja o "seqüestro" do projeto pelos } \\
\text { participantes mais fortes. }\end{array}$ \\
\hline $\begin{array}{c}\text { Encoraja informação emergente que contribua com } \\
\text { o plano estratégico. }\end{array}$ & Esconde o gerenciamento fraco do projeto. \\
\hline $\begin{array}{c}\text { Permite mudanças mais rápidas na pesquisa e } \\
\text { implementação. }\end{array}$ & $\begin{array}{l}\text { Leva a numerosos planos de ação que retalham } \\
\text { projetos complexos. }\end{array}$ \\
\hline \multicolumn{2}{|r|}{ MECANISMOS DE FEEDBACK } \\
\hline $\begin{array}{l}\text { Permite monitoramento simultâneo e aumenta a } \\
\text { participação. }\end{array}$ & Obscurece a avaliação. \\
\hline $\begin{array}{l}\text { Possibilita planejamento, desenvolvimento e } \\
\text { implementação mais efetivos.Aumenta a } \\
\text { participação. }\end{array}$ & $\begin{array}{l}\text { Ameaça os participantes, levando à tensão e } \\
\text { potencialmente reduzindo a participação. }\end{array}$ \\
\hline $\begin{array}{l}\text { Fornece orientação valiosa para o projeto, } \\
\text { aumentando a importância do estudo. }\end{array}$ & Toma tempo. \\
\hline \multicolumn{2}{|l|}{$\begin{array}{l}\text { Possibilita planejamento, desenvolvimento e } \\
\text { implementação mais efetivos. }\end{array}$} \\
\hline \multicolumn{2}{|l|}{ Aumenta a importância do estudo. } \\
\hline \multicolumn{2}{|r|}{ AVALIAÇÃO } \\
\hline $\begin{array}{l}\text { Encoraja concordância sobre o ponto final (do } \\
\text { projeto). }\end{array}$ & $\begin{array}{l}\text { Desestimula a criação de um ponto final (no } \\
\text { projeto). }\end{array}$ \\
\hline Permite a avaliação em qualquer fase do projeto. & \\
\hline
\end{tabular}

Fonte: Waterman et al. (2001), adaptada pelo Autor. 
Como em muitos modelos, a simplicidade aparente da pesquisa-ação desmente sua complexidade. A dificuldade dos atores em compreender o processo no inicio é inerente aos objetivos da pesquisa-ação, pois o conhecimento vai aumentando na medida em que o projeto vai sendo estabelecido e os ciclos vão sendo completados, para que então um quadro mais claro vá sendo delineado. Justamente a natureza flexível da PA ajuda a aumentar a responsabilidade dos participantes, que compreendem sua participação no processo como uma das forças principais do projeto, e necessária ao seu gerenciamento. Em outras palavras, os atores envolvidos são participantes ativos também no gerenciamento do processo, pois lhes são dados mecanismos de feedback que aumentam a sua participação e responsabilidade pelos resultados.

Observou-se entre os principais aspectos positivos do processo e gerenciamento do projeto que a PA promove projetos orientados aos participantes, permitindo mudanças rápidas no próprio projeto, e essenciais para o encaminhamento de mudanças profundas exigidas pela implementação de uma nova tecnologia. Os mecanismos de feedback e avaliação simultâneos que a PA permite aumentam a importância do estudo do ponto de vista da empresa contábil, possibilitando planejamento, desenvolvimento e implementação de ações com resultados mais efetivos e a longo prazo. Destaque-se entre os aspectos negativos percebidos que o gerenciamento do projeto toma muito tempo dos seus líderes, principalmente do gerente e do patrocinador, pois começam a surgir, ao mesmo tempo, numerosos planos de ação que retalham os projetos complexos, como no caso estudado. 
TABELA 15 - FATOR PRINCIPAL: CONHECIMENTO

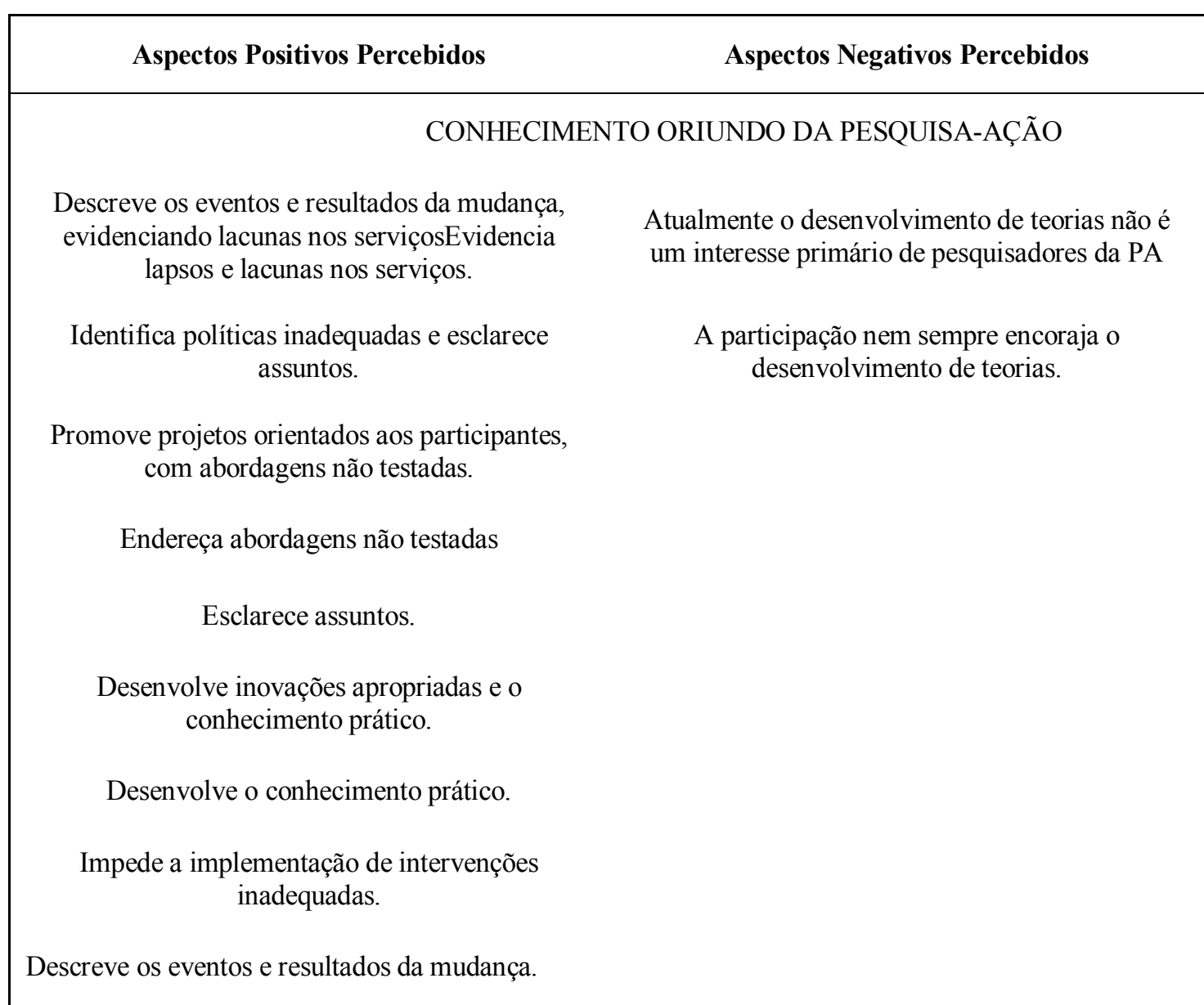

Fonte: Waterman et al. (2001), adaptada pelo Autor.

$\mathrm{O}$ projeto de PA estudado teve como seu grande ponto forte contribuir para o crescimento do conhecimento da equipe da empresa contábil, vindo a cumprir parte dos objetivos gerais desta pesquisa, de discutir a empresa contábil e seus processos. A pesquisa ação foi escolhida especificamente por causa de sua habilidade em produzir conhecimento e contribuir com a teoria.

O conhecimento derivado das fases de identificação de problemas da pesquisa ação tem sido demonstrado como crucial para evidenciar lacunas nos serviços e políticas inadequadas da empresa contábil, destinando abordagens não testadas, esclarecendo assuntos, desenvolvendo inovações apropriadas e impedindo a implementação das inadequadas. Por exemplo, o processo de serviço da empresa contábil tem características peculiares, e que aumentam a complexidade na sua gestão, por exemplo o cliente ver somente a saída do processo, e ao mesmo tempo ele (o 
cliente) participar como fornecedor de informação ao longo de todo o processo, dependendo da qualidade dessa participação o resultado que será entregue.

Ora, no processo de serviço da empresa contábil, depende da qualidade do que o cliente fornece ao processo a qualidade e satisfação do que ele recebe. Isso só foi possível entender devido às discussões cíclicas decorrentes da pesquisa-ação, bem como, decorre dessa constatação que o conhecimento contábil deve ser parte do processo da empresa cliente, caso contrário, os processos da empresa contábil não podem ser melhorados e otimizados seus resultados.

O conhecimento obtido como resultado deste estudo foi focado no desenvolvimento de inovações e na preparação para intervenções de mudança, sendo esta uma característica da maioria das pesquisas com esta abordagem. Mesmo quando os objetivos de mudança não foram alcançados, a PA ajudou a entender com a indicação da teoria porque o objetivo não foi alcançado, e uma nova repetição no processo cíclico indicou o melhor caminho para a ação efetiva de mudança, contribuindo desta forma para a mudança na teoria.

Um ponto forte mostrado pelo estudo de PA foi seu dom de produzir conhecimento principalmente nas fases iniciais de avaliação. $\mathrm{O}$ conhecimento foi sendo utilizado no desenvolvimento do próprio projeto de mudança, isto é, na medida em que se aplicava a teoria, o conhecimento absorvido pelo grupo provocava novas demandas e reorientava o projeto. Os resultados indicam que conhecimento prático foi desenvolvido e aplicado simultaneamente, e mesmo quando os objetivos específicos do processo cíclico não foram atingidos, isso não invalidou a tentativa porque o grupo passou a entender que a ação planejada não traz o resultado esperado. Em outras palavras, a teoria aplicada à realidade da empresa contábil não serve para solucionar as problemas levantados. Em muitos casos, observou-se que as abordagens e ferramentas utilizadas no levantamento da situação inicial é que eram falhos, isto é, confundiu-se, no levantamento dos problemas, os sintomas e suas conseqüências com as verdadeiras causas. Neste sentido, houve a necessidade de se pesquisar métodos e ferramentas que auxiliassem o grupo a melhor identificar, de maneira clara e objetiva, os principais e verdadeiros problemas que a empresa enfrentava.

Percebeu-se que a pesquisa ação pode superar o impasse entre as disciplinas de teoria e prática, porque ela requer um determinado movimento ou "uma exploração 
para trás e para a frente entre a teoria e a prática." Ficou evidente neste trabalho que a principal qualidade da PA, pouco evidenciado em outras abordagens de pesquisa e mesmo em outros trabalhos como PA, é a sua capacidade de gerar diferentes tipos de conhecimento, variando do proposicional ao prático. Estes conhecimentos podem ser aplicados numa variedade de cenários, principalmente ligados à mudança organizacional decorrente do processo de implementação de tecnologia de informação. Observou-se uma dificuldade do grupo em lidar com as abstrações teóricas gerais e seus membros argumentaram ao longo do processo, muitas e repetidas vezes, que "existia muita teoria e pouca prática", percebendo-se uma ansiedade no atingimento dos resultados práticos e tangíveis. Compreendeu-se então que a teoria tradicional aliena os profissionais devido a eles considerarem-na idealizada e inatingível, e então implicitamente criticam suas práticas correntes, talvez mais por incapacidade de abstração e entendimento do que por dificuldade de colocá-las em prática. A vantagem da pesquisa ação é que os profissionais desenvolvem e exploram suas próprias hipóteses, o que serve para aumentar a própria compreensão sobre seu trabalho, bem como a de outros profissionais.

\subsection{ATINGINDO OS OBJETIVOS PROPOSTOS}

A implantação de um sistema empresarial integradoSistema Empresarial Integrado - ERP representa uma mudança tecnológica que afeta praticamente toda a empresa contábil, devendo sua adoção ser tratada como um projeto de mudança organizacional amplo, exigindo principalmente alterações na dimensão estrutura, que permitirão o desenvolvimento de uma nova visão estratégica. Para efetivação desta nova visão será necessária a criação de uma empresa orientada a processos, com reflexos em todas as demais dimensões organizacionais, em especial sobre o sistema social (pessoas) e sobre o modelo de gestão, que deverá ser adequado a esta nova realidade. $\mathrm{O}$ modelo de gestão participativa contém os requisitos necessários e facilita o processo de introdução de novas tecnologias, pois permite a construção do conhecimento durante o processo de mudança.

A mudança na Tecnologia na empresa contábil permite desenvolver uma nova arquitetura que possibilita levar os benefícios da TI, materializados pelos sistemas empresariais integrados - ERP, à empresa cliente, no modelo ASP, com redução 
considerável do custo total de propriedade (TCO), passando a empresa contábil e a empresa cliente a interagir remota e simultaneamente sobre uma mesma base de dados e sistemas, tornando então a informação contábil distribuída.

As economias obtidas por essa forma de atuação podem ser direcionadas a mudanças na arquitetura organizacional de ambas as empresas, com ganhos recíprocos. Neste sentido, a empresa contábil deve desenvolver com profissionais de TI uma área especifica de sistemas, cujos custos serão suportados pelos ganhos de produtividade com a eliminação do processo de retrabalho, característicos da empresa contábil no modelo de atuação tradicional.

A pesquisa mostrou que através de parcerias com empresas de software já é possível a empresa contábil disponibilizar às empresas-cliente um sistema de gestão empresarial integrado - ERP, numa relação custo x benefício atraente e aplicável a pequenas e médias empresas, identificando oportunidades surgidas pela atualização tecnológica, ampliando o potencial do contador organizado em empresa. Para tanto, necessário se faz o desenvolvimento de uma nova arquitetura tecnológica na empresa contábil, passando ela a gerir o sistema de informação contábil da empresa cliente de forma integrada, na visão ampliada.

Buscando construir essa integração via tecnologia, a empresa contábil teve que passar por uma mudança organizacional profunda, através da alteração nas 5 dimensões organizacionais, de acordo com o modelo proposto e desenvolvido ao longo da pesquisa, principalmente criando a empresa orientada a processos. Um modelo em termos de empresa orientada a processos é aquele que descreve os processos de negócio e seus principais sub-processos, identifica seus inputs, outputs e relacionamentos primários, aponta os donos dos processos, líderes com responsabilidade geral pelos processos, suas performances, e dedica atenção especial à participação do cliente ao longo de todo o trabalho, característica peculiar dos projetos de processos de serviço da empresa contábil.

Esses líderes, divididos por área ou setor, realizam este trabalho baseados em times, envolvendo todas as pessoas na execução de um processo e desenvolvendo a compreensão, na equipe, de que seus esforços individuais podem ser úteis somente quando integrados com os esforços de seus pares no grupo, e que eles têm a missão de desenhar os processos com especificações precisas sobre como devem ser executados 
para se produzir o output desejado, através do mapeamento, análise e redesenho, identificando as medidas de performance, automatizando-os através da implementação do sistema escolhido, o que permite desenvolver os conhecimentos e experiências necessários para levar essa mesma tecnologia às empresas-cliente, que, por sua vez, passarão pelo mesmo processo, com a ajuda e intervenção da empresa contábil. ‘

A pesquisa mostrou que a análise dos processos é uma atividade fundamental na adoção de um sistema integrado, e que os casos de insucesso relatados na literatura não destacam esta variável, e na maioria das médias e pequenas empresas essa atividade crucial para o sucesso do projeto não é realizada. Ora, como informatizar e automatizar aquilo que não está devidamente organizado? Ou, em outras palavras, os problemas empresariais atuais na empresa contábil são mais de processos do que de informática, pois eles localizam-se nas interfaces funcionais onde justamente as questões de integração serão superadas pela implantação da visão de processos e pela nova tecnologia. As duas questões estão inter-relacionadas na visão sistêmica, a resolução de uma somente não produz o resultado esperado.

A diversificação estratégica da empresa contábil através da consultoria de gestão pode ser implementada trazendo benefícios mensuráveis para a empresa contábil, com valor adicionado à empresa-cliente através da implantação de um sistema de informação contábil que integre de forma natural a contabilidade financeira e a contabilidade gerencial, automatizando as transações na empresa-cliente.

Percebe-se que as oportunidades estratégicas advindas da adoção da tecnologia representada pelo sistema empresarial integradoSistema Empresarial Integrado - ERP para a empresa contábil são inúmeras e serão obtidas a médio e longo prazo, pois permite aplicar uma característica especial destes sistemas que é a colaboração, isto é, o sistema passa a ser a estrutura mestra da empresa cliente, agregando e gerenciando os dados de todas as transações de maneira precisa e em tempo real, passando a fazer parte da própria estratégia de negócios deste, sendo a empresa contábil a parceria de negócio estratégica na adoção e uso desta tecnologia e sua evolução. Além disso, com essa nova arquitetura tecnológica e organizacional, a empresa contábil participa desenvolvendo um modelo de implementação de sistema empresarial integradoSistema Empresarial Integrado - ERP, pois já conhece a realidade da empresa cliente e sabe os 
caminhos da mudança que deverão ser trilhados, gerando ganhos comuns pelo relacionamento privilegiado que possui com o gestor da empresa cliente.

Conclui-se que o processo de implantação exige uma mudança substancial nas habilidades e competências das pessoas que trabalham na empresa contábil. Destacase, como ponto forte desses profissionais a familiaridade com a visão sistêmica da contabilidade, principalmente de custos, e o forte conhecimento nas questões tributárias, o que facilita a customização do sistema nestas áreas importantes. Por outro lado, observou-se a necessidade desenvolver o espírito de trabalho em equipe, agregando profissionais da área de TI atuando em parceria com o profissional contábil, facilitando o desenvolvimento das questões tecnológicas. Identificou-se ainda, como condições principais, a necessidade de treinamento com as ferramentas aplicadas em programas de qualidade, principalmente voltadas à área de gestão, bem como ser crucial a esses profissionais compreender os conceitos, técnicas e ferramentas ligadas ao mapeamento e análise de processos, além, é claro, de conhecer o sistema em profundidade, recebendo constantes treinamentos operacional e conceitual.

Outra conclusão importante, mas não final e definitiva, é que a informática traz profundas alterações para a profissão contábil, mas em que dimensão isto ocorre, é o que procurou responder a pesquisa. A função contábil é fundamental para o sucesso da operação dos negócios modernos, fornecendo informações relevantes sobre o planejamento, a tomada de decisões e o controle, sejam os negócios grandes, médios ou pequenos, principalmente no Brasil, onde a complexidade tributária requer uma engenharia especial que faz a diferença entre o sucesso ou o fracasso da operação, e, nesse sentido, o contador tem atuação estratégica.

Planejar as operações via sistema exige que os contadores se transformem em consultores de sistema, ajudando a empresa cliente a implantar um sistema de informação, escolher equipamentos e tecnologias de comunicação e fazer a melhoria dos processos de operação para que a ela passe a operar mais eficientemente, o que trará como conseqüência a gestão dos processos contáveis mais eficazes, na empresa contábil. 


\subsection{CONCLUSÃO FINAL E RECOMENDAÇÃO PARA ESTUDOS FUTUROS}

Em uma economia cada vez mais volátil e dinâmica, impulsionada principalmente pelas revoluções tecnológicas, com ciclos de inovação cada vez mais rápidos, a principal fonte de vantagem competitiva são as próprias pessoas da empresa - em particular, a habilidade que elas desenvolvem para antecipar-se as mudanças, adaptar-se a novas circunstâncias e inventar novas práticas. Compreendeu-se que as mudanças tecnológicas exigem mudanças organizacionais, que essas só ocorrem na medida que as pessoas mudam, isto é, na medida que as pessoas desenvolvem novas competências e habilidades, pois isso permitiu, especificamente na empresa contábil, desenvolver a habilidade de se antecipar às mudanças ambientais e inventar novas práticas de negócios.

A informação contábil, tão necessária ao sucesso dos negócios atuais, não pode ficar restrita ao ambiente interno da empresa contábil, que por responsabilidade profissional e por missão pode levar essa principal fonte de vantagem competitiva a empresa-cliente pois a tecnologia já permite isso, e aí sim, tornar a informação contábil distribuída e entendida para produzir melhores decisões.

Um outro ponto muito importante na pesquisa que poderia ser aprofundado em trabalhos futuros está relacionado à questão da melhoria dos processos de serviços contábeis, especificamente através do estudo das metodologias (técnicas) utilizadas em projeto e análise de processos de serviços, identificando qual é mais adequada às características específicas dos serviços contábeis, visando fornecer suporte à melhoria da qualidade. Desta identificação, poderia ser desenvolvido um modelo específico para mapear e melhorar os processos de negócios da empresa contábil, com a análise de ferramentas de informática que auxiliassem a automatização deste trabalho. Conclui-se que o uso eficaz do sistema empresarial integradoSistema Empresarial Integrado ERP, que maximize o seu potencial de mudanças e o valor dos negócios, só se efetiva plenamente quando a empresa é gerida na visão de processos.

A profissão contábil embarcou num projeto para definir o contador do futuro, motivada pela constatação de que a profissão está enfrentando concorrência cada vez 
maior de outros profissionais, e que a tecnologia da informaçãoTecnologia de informação é fator decisivo na definição de como os contadores trabalham. O processo de criar uma visão requer que os profissionais da contabilidade pensem sobre seu futuro e visualizem o futuro que gostariam de ter (Moscove, Simkin, Bagranoff, 1999), e foi neste sentido o desenvolvimento deste trabalho, de criar uma visão sobre o futuro da empresa contábil, mostrando de maneira prática e objetiva como este futuro pode começar a ser construído hoje, pois a evolução da empresa contábil deve acompanhar a evolução da profissão, e para os que desejam as mudanças na empresa contábil, o futuro surge especialmente brilhante. 


\section{ANEXOS}

ANEXO A: ORGANOGRAMA FUNCIONAL: SITUAÇÃO ATUAL (COMO A EMPRESA CONTÁBIL É)

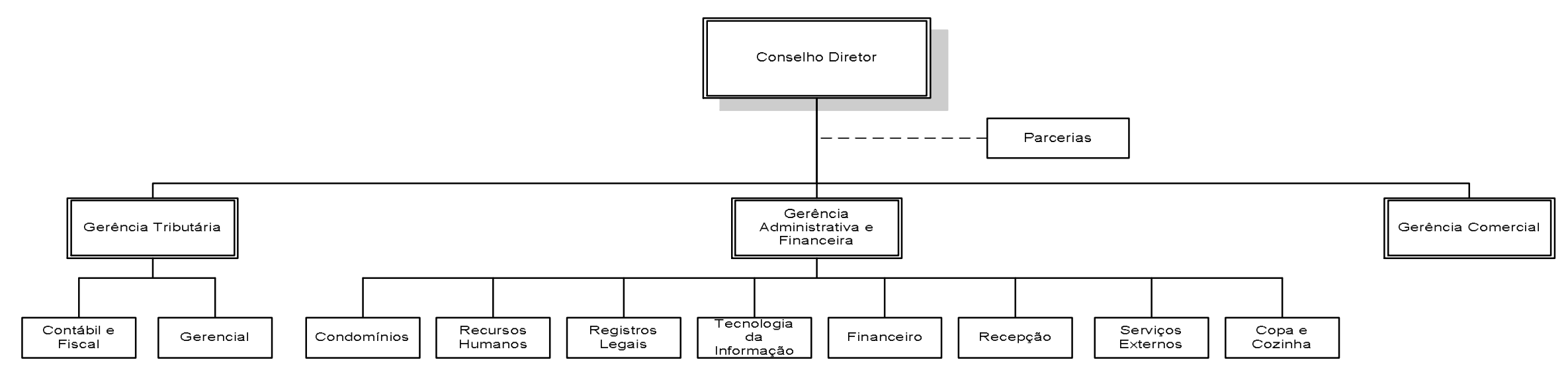

Fonte: Elaborador pelo Autor 
ANEXO B: MAPEAMENTO DOS PROCESSOS: SITUAÇÃO ATUAL (COMO A EMPRESA CONTÁBIL É)

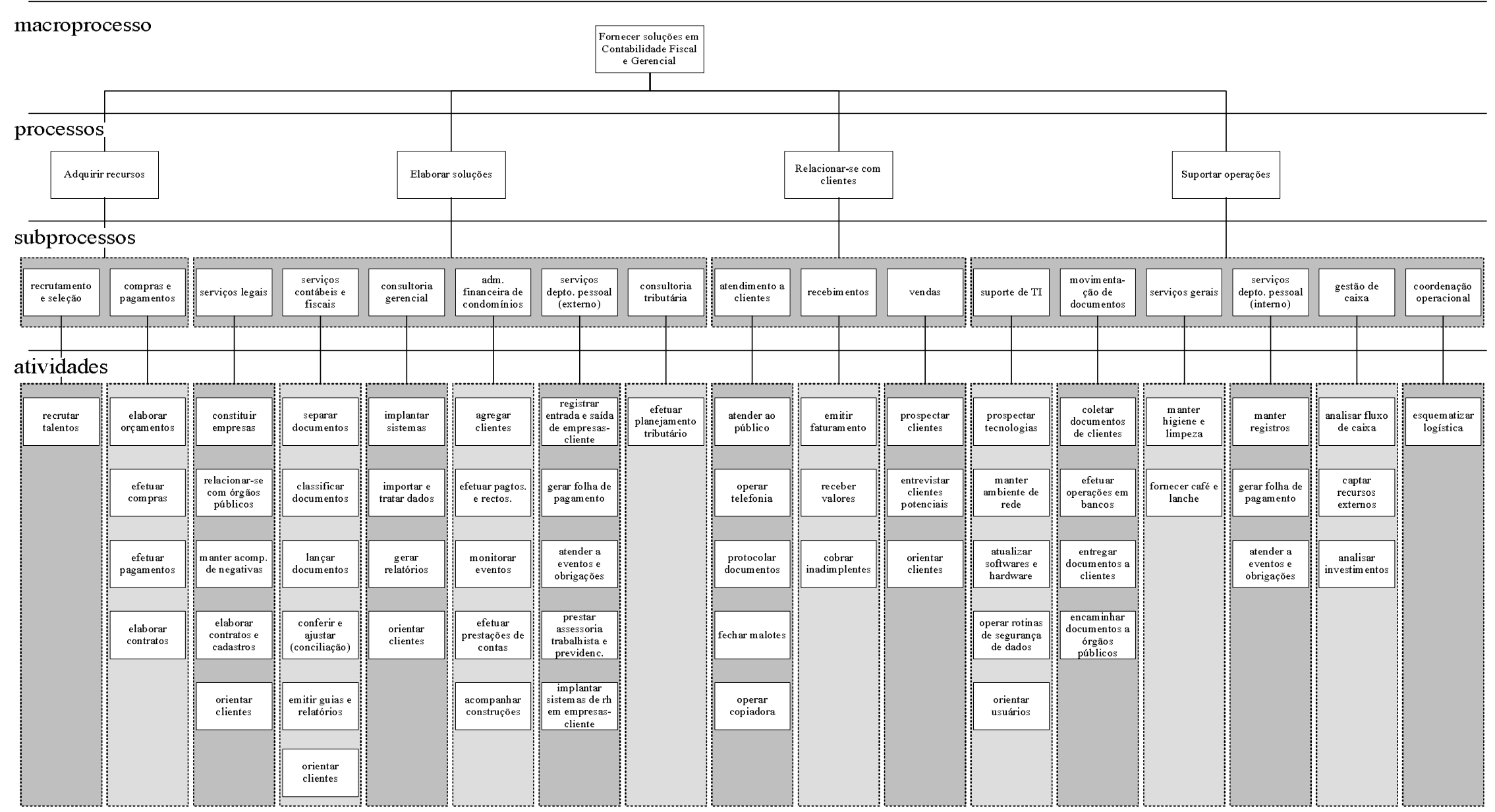


ANEXO C: ORGANOGRAMA PROPOSTO : SITUAÇÃO FUTURA (COMO A EMPRESA CONTÁBIL SERÁ)

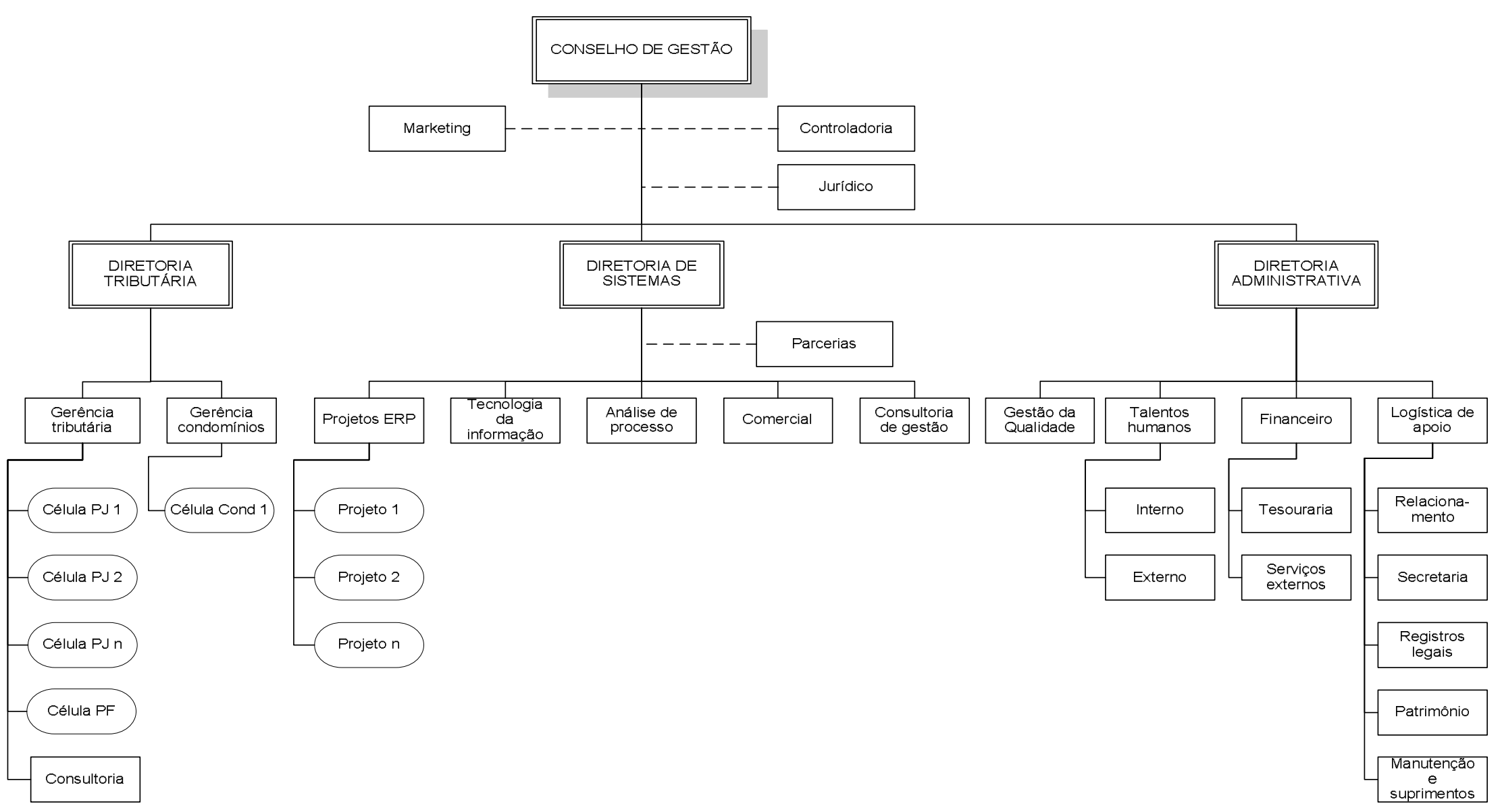

Fonte: Elaborador pelo Autor 


\section{ANEXO D: MAPEAMENTO DOS PROCESSOS: SITUAÇÃO FUTURA (COMO A EMPRESA CONTÁBIL SERÁ)}

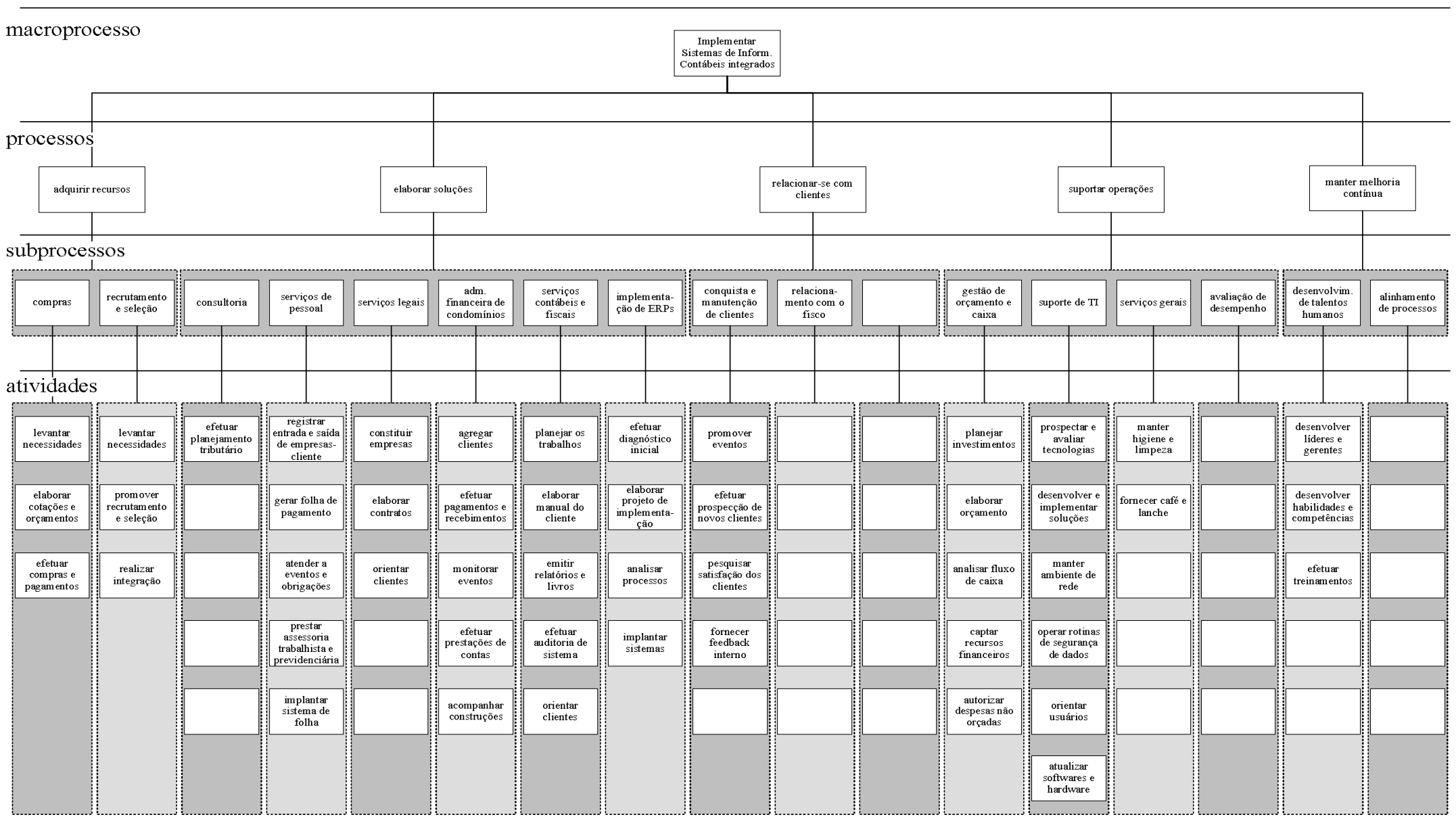

Fonte: Elaborador pelo Autor. (OS ESPAÇOS “EM BRANCO” REPRESENTAM PROCESSOS QUE ESTÃO SENDO REDESENHADOS). 


\section{REFERÊNCIAS}

AGUIAR, M.A.F. Implicações da Pesquisa-ação no Processo de Aprendizagem da Organização. São Paulo, 1982. Tese de Doutorado. IP Instituto de Psicologia, USP. $263 \mathrm{p}$.

ALVES, Rubens. Filosofia da ciência: introdução ao jogo e a suas regras. São Paulo: Editora Loyola, 2000.

AMATUCCI, M. Aprendizado Organizacional: a complexidade para enfrentar a complexidade. Disponível em: <http://www.geocities.com/marcosamatucci / complex.html $>$ Acesso em: 13/11/2002. $18 \mathrm{p}$.

ANDREONI, R. A sócio-técnica moderna no Escritório. São Paulo, 2001. Dissertação de Mestrado. Escola Politécnica: - Engenharia da Produção, USP. 95 p.

ANTONY, R.N.; GOVINDARAJAN, V. Sistemas de Controle Gerencial. 1 ed. São Paulo: Atlas, 2002. 1019 p.

ARANTES, N. Sistemas de Gestão Empresarial: Conceitos Permanentes na Administração de Empresas Válidas. 2 ed. São Paulo: Atlas, 1998. 439 p.

ARAUJO, L.C.G. Tecnologias de Gestão Organizacional. 1 ed. São Paulo: Atlas, 2001. $361 \mathrm{p}$.

ARELlAnO, E. B.; ALBUQUERQUE, L.G. Gestão Participativa - Um Estudo de Caso. IV Semead. São Paulo, Outubro de 1999. 7 p.

ARGYRIS, C. Enfrentando Defesas Empresariais. 1 ed. Rio de Janeiro : Campus, 1992. 204 p..

Ensinando Pessoas Inteligentes a Aprender. in: HARVARD BUSINESS REVIEW BOOK Aprendizado Organizacional. 1 ed. Rio de Janeiro : Campus, 2000. p. 185-203.

. A boa comunicação que impede a aprendizagem in: HARVARD BUSINESS REVIEW Aprendizagem Organizacional. 1 ed. Rio de Janeiro : Campus, 2001. p. 84-104.

ARGYRIS, C., SCHON, D.A. Theory in Practice: Increasing professional effectiveness. San Francisco: Jossey-Bass Inc, 1974.

ARIELA, Caglio. Accountants, from tradition to transition: The impact or enterprise resource planning systems. The European Accounting Review. Acessado no endereço http://papers.ssrn.com em 21/08/2002.

ATKINSON, A.A. et al. Contabilidade Gerencial 1 ed. São Paulo: Atlas, 2000. 812 p.

BASKERVILLE, R. Investigating Information Systems with Action Research. Communications of AIS. Geórgia, v. 2, nº. 19, October, 1999. 32 p.

BEER, M.; EISENSTAT, R.A.; SPECTOR, B. Por que Programas de Mudanças Não Produzem Mudanças in: HAVARD BUSINESS REVIEW BOOK Aprendizado Organizacional - Gestão de pessoas para a Inovação Contínua. 1 ed. Rio de Janeiro : Campus, 2000. p. 229-244. 
BERALDI, L.C.; ESCRIVÃO, E. Impacto da Tecnologia de Informação na gestão de Pequenas Empresas. Revista Ciência e Informação. Brasília, v. 29, nº. 1, Janeiro/Abril, 2000. p.46-50.

BRANDÃO, P. Custo tributário leva 6 bi das empresas. Disponível em:

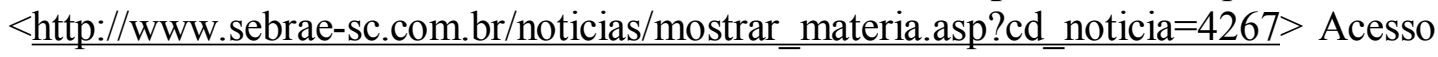
em: $16 / 12 / 2002$.

BUONO, A.F; BOWDITCH, J.L. Elementos do Comportamento Organizacional. 1 ed. São Paulo: Livraria Pioneira Editora, 1997. 305 p.

BUCKHOUT, S., FREY, E.; NEMEC JR. Por um ERP eficaz. HSM Management. Set-Out, p. 30-36. 1999.

CAGLIO, A. Accountants, From Tradition to Transition: The Impact of Enterprise Resource Planning Systems. The European Accounting Review, 2001. Disponível em http://homepages.strath.ac.uk/ cias19/teaching/40428/ERP\%20\&\%20accounting\%20change.pdf.

Acesso em 16/10/2002.

CATELli, A. (ORG.) Controladoria: Uma Abordagem da Gestão Econômica Gecon. 2a . Ed. São Paulo: Atlas, 2001. 570 p.

CHANDLER, A. D. Strategy and Structure: chapters in the History of the American Industrial Enterprise. Cambridge, Mass.: MIT press, 1962. 476 p.

CONSELHO FEDERAL DE CONTABILIDADE. Legislação Básica da Contabilidade: Conselho regional de contabilidade de Santa Catarina. Florianópolis, 1997.

COLANGELO FILHO, L. Implantação de Sistemas ERP - Um enfoque de Longo Prazo. $1^{\mathrm{a}}$ ed. São Paulo: Atlas, 2001. 191 p.

CORNACHIONE, E.B. Contribuição ao Estudo de Arquitetura de Sistemas de Informações de Gestão Econômica. São Paulo-SP, 1999. 301 p. Tese de Doutorado Faculdade de Economia, Administração e Contabilidade, USP.

CRUZ, T. Sistemas, Organização e Métodos. 3 ed. São Paulo: Atlas, 2002. 276 p.

CURY, A. Organização e métodos uma visão Holística. $7^{\mathrm{a}}$ ed. São Paulo: Atlas, 2000. 589 p.

DAVENPORT, T.H. Reengenharia de Processos. 1 ed. Rio de Janeiro: Campus, 1994. $242 \mathrm{p}$

DAVENPORT, T.H. Missão Critica - Obtendo Vantagem Competitiva Com os Sistemas de Gestão Empresarial. 1 ed. Porto Alegre: Bookman, 2002. 293 p.

DAVENPORT, T.H.; PRUSAK, P. Conhecimento Empresarial - Como as Organizações Gerenciam o Seu Capital Intelectual. 6 ed. Rio de Janeiro : Campus, 1998. $237 \mathrm{p}$.

DICK, B. Approching an action research thesis: an overview Action research and evaluation on line (Areol). (03/01/2000 revisado) 1997. Disponível em http://www.scu.edu.au/schools/gcm/ar/arp/phd.html. Acesso em: 24/10/2002. 
(1993) You want to do an action research thesis? Disponível em

http://www.scu.edu.au/schools/gcm/ar/art/arthesis.html. Acesso em: 24/10/2002

. (1998) Occasional pieces on action research methodology. Disponível em: $<$ http://www.scu.edu.au/schools/gcm/ar/arm/op000.html $>$ Acesso em: 05/12/2002.

. (2000) Information sharing through voting. Disponível em:

$<$ http://www.scu.edu.au/schools/gcm/ar/arp/voting.html $>$ Acesso em: 05/12/2002.

DIPBUS, J.B.B. Organisational Culture and Enterprise Resource Planning (ERP) Systems Implementation Australia, 2001. Dissertação de mestrado - School of computing and Information Technology, Griffith University.

DUPAS, G. Impactos sociais e econômicos das novas tecnologias de informação. Impactos Das Novas Tecnologias De Informação: Universidade e Sociedade. São Paulo. Simpósio internacional em 23.09.1999.

EPSTEIN, I. Teoria da Informação. São Paulo: Ed. Ática, 1.986.

FERREIRA, M.C. Manual para apresentação de trabalhos acadêmicos. Curitiba: Faculdade Católica de Administração e Economia, 2000. 76 p.

FIGUEIREDO, S.; FABRI, P.E. Gestão de Empresas Contábeis. 1 ed. São Paulo: Atlas, 2000. $172 \mathrm{p}$.

FREITAS, H; MOSCAROLA, J. Da Observação à Decisão: Métodos de Pesquisa e de Análise Quantitativa e Qualitativa de Dados. Rea Revista eletrônica de administração, Porto Alegre, ano I, v. 1, Janeiro-Junho, 2002. Disponível em: http://www.rae.com.br/artigos/1159.pdf. Acesso em 10/11/2002.

GALLIERS, B. Reflections on BRP, IT and Organizational Change. in: R.D. GALLIERS AND W.R.J. BAETS. Information Tecnology and Organizational transformation: innovation for the 21 st century organization. 1 ed. England: John Wiley \& Sons Ltd, 1998. 10. p. 225-243.

GARRISON, R.H.; NOREEN, E.W. Contabilidade Gerencial. 9 ed. Rio de Janeiro : LTC - Livros técnicos e Científicos Editora, 2001. 643 p.

GIL, A.C. Como Elaborar Projetos de Pesquisa. 4 ed. São Paulo: Atlas, 2002. 175 p. . Métodos e técnicas de Pesquisa Social. 5 ed. São Paulo: Atlas, 1999. 206 p.

GOLDENBERG, M. A arte de pesquisar: como fazer pesquisa qualitativa em ciências sociais. $4^{\mathrm{a}}$ ed. Rio de Janeiro: Record, 2000. 107 p.

HAMMER, M. A empresa orientada a processos. Publicação em Português autorizada para Acttive Software S/A. Disponível em: http://www.acttive.com.br/download.htm. Acesso em 10/11/2002.

HATTEN, R.; KNAPP, D.; SALONGA, R. Action Research: Comparison with the Concepts of "The Reflective Practitioner" an "Quality assurance". Action Research Electronic Reader, p. 19, 1997. Disponível on line http://www.scu.edu.au/schools /gmc/ar/arr/arow/rdr.html. Acesso em: 12/11/2002.

HENDRIKSEN, E.S; VAN BREDA, M.F. Teoria da Contabilidade. 1 ed. São Paulo: Atlas, $1999.550 \mathrm{p}$. 
HOLANDA, V.B. Controladoria Governamental no Contexto do Governo Eletrônico: Uma modelagem utilizando o enfoque sistêmico e a pesquisa-ação na Coordenadoria de Controle Interno da Secretaria da Fazenda do Estado de São Paulo. São Paulo-SP, 2002. 256 p. Tese de Doutorado - Faculdade de Economia, Administração e Contabilidade, USP.

HOLANDA, V.B; RICCIO, E.L. A Utilização da Pesquisa-ação para Perceber e Implementar Sistemas de Informações Empresariais. Asian Pacific Conference on International Accounting Issues, 132001 Rio de Janeiro, São Paulo, v. 1 (trabalhos em português e espanhol), n. FEA/CD 89, p. 16, 2001. CD ROM meio digital. Acesso em: 21/10/2002.

HUNTON, J.E. The reaction of financial analysts to enterprise resource planning (ERP) implementation Plans. Disponível em SSRN acessado no endereço http://papers.ssrn.com. Em 21/08/2002.

IDE, P. A Arte de Pensar. 2 ed. São Paulo: Martins Fontes, 2000. 299 p.

KALAKOTA, R.; ROBINSON, M. E-business estratégias para alcançar o sucesso no mundo digital. Porto Alegre: Bookman, 2002.

KASSAI, José Roberto \& Sílvia. Balanço Perguntado: Solução para as Pequenas Empresas. Anais do VIII Congresso Brasileiro de Custos. São Leopoldo/RS, 2.001.

KASSAI, S. As empresas de Pequeno Porte e a Contabilidade. São Paulo, 1996. 258 p. Dissertação de mestrado - FEA, USP.

KASSAI, Sílvia; KASSAI, José Roberto; NOSSA, Valcemiro. Pequenas Empresas Como é Difícil "Levantar Dinheiro". Anais do VII Congresso Brasileiro de Custos. Recife/PE, 2000.

KOCK JR. N.F. The Three Threats of Action Research: A Discussion of Methodological Antidotes in the Context of an Information Systems Study Action research and evaluation on line (Areol), Philadelphia, PA - USA, 2002. 43 p.

. Reengenharia de Processos PROI: uma metodologia Prática. 1 ed. Petrópolis: Vozes, 1995. 187 p.

. Myths in Organizational Action Research: Reflections on a Study of Computer-Supported Process Redesign Groups. Organizations \& Society, Philadelphia, PA - USA, 1997.

KOCK, N.F., JR.,MCQUEEN, R.J. AND SCOTT, J.L. Can Action Research be Made More Rigorous in a Positivist Sense? The Contribution of an Iterative Approach. Journal of Systems and Information Technology, 1997. V.1, Nr.1, p. 1-24,

KRUGLIANSKAS, I. Tornando a pequena e média empresa competitiva: São Paulo: Editora Iege, 1996.

LAUDON, K.C; LAUDON, J.P. Gerenciamento de Sistemas de Informação. Rio de Janeiro , 2001. 433 p.

LIMA, E.P. Uma Modelagem Organizacional Suportada Por Elementos de Natureza Comportamental. Florianópolis, 2001. 384 p. Tese de doutorado Engenharia da Produção, UFSC. 
MARTINS, A..M. Manual para Elaboração de Monografias e Dissertações. 2 ed. São Paulo: Atlas, 2000. 116 p.

MARTIUS, R.R.; AGUSTIN, J.F. Tecnologia de Informação e Gestão Empresarial. 2a. Ed. Rio de Janeiro: e-papers, 2000. 446 p.

MAZZOTTI, A.J.A. A "revisão da bibliografia" em teses e dissertações: meus tipos inesquecíveis - o retorno in: LUCÍDIO BIANCHETTI E ANA MARIA NETTO MACHADO (org.). A bússola do Escrever - Desafios e Estratégias na Orientação de Teses e Dissertações. 1 ed. Florianópolis: Ed. da UFSC, 2002. p. 25-41.

MAXIMIANO, A.C.A. Administração de Projetos: Como Transformar Idéias em Projetos. $2^{\mathrm{a}}$ ed. São Paulo: Atlas, 2002. 281 p.

MCCARTHY, W.E. The REA Accounting Model: A Generalized Framework for Accounting Systems in a Shared Data Environment. The Accounting Review. Vol. LVII n $n^{\circ} .3,1982$. p.554-578.

MENDES,J.V. e ESCRIVÃO FILHO,E. O sistema integrado de gestão é fator de competitividade para as pequenas e médias empresas? Revista Uniara, n.8, 2000. p.1321.

MINICUCCI, A. Dinâmica de Grupo - Teorias e Sistemas. 5 ed. São Paulo: Atlas, 2002. 313 p.

MORESI, E.A.D. Delineando o Valor do Sistema de Informação de Uma Organização Revista Ciência e Informação. Brasília, v. 29, $\mathrm{n}^{\mathrm{o}}$. 1, Janeiro/Abril, 2000. p.14-24.

MORGAN, G. Imagens da Organização. 1 ed. São Paulo: Atlas, 1996. 421 p.

MOSCOVE, S.A.; SIMKIN, M.G.; BAGRANOFF, N.A. Sistemas de Informações Contábeis. 1 ed. São Paulo: Atlas, 2002. 451 p.

OLIVEIRA, J.F. Sistemas de Informação: Um Enfoque Gerencial Inserido no Contexto Empresarial e Tecnológico. 2 ed. São Paulo: Érica, 2002. 330 p.

PÁDULA, A.D. A utilização da tecnologia da informática como ferramenta estratégica para capitalização do saber-fazer organizacional: o caso de um sistema especialista de apoio a consultoria gerencial em PME. Rea revista eletrônica de administração, Porto Alegre, v. 2, nº. 2, 1996.

Diversificação Estratégica das Atividades dos Profissionais Contábeis. RAUSP revista de administração. São Paulo, v. 31, n. 2, Abril/Junho, 1996. p.29-39. PELEIAS, I.R; PARISI, C. Contribuições e Limitações dos Sistemas Integrados às funções de Controladoria no Novo Cenário de Negócios. Asian Pacific Conference on International Accounting Issues, 13 - 2001 Rio de Janeiro, São Paulo, v. 1 (trabalhos em português e espanhol), FEA/CD 89, p. 20, 2001. CD ROM meio digital. Acesso em: 21/10/2002.

PEREIRA, C.D.S. Sistemas Integrados de Gestão Empresarial - Um estudo de Caso de Implementação de um Sistema ERP em uma Empresa Seguradora Brasileira. São Paulo, 2002. 273 p.. Dissertação de mestrado - FEA, USP.

PEREIRA, J.C.R. Análise de Dados Qualitativos: Estratégias Metodológicas para as Ciências da Saúde, Humanas e Sociais. 3 ed. São Paulo: Editora da USP, 2001. 157 p. 
PERRY, C. (1998) A structured approach to presenting theses. Disponível no endereço http://www.scu.edu.au/schools/gcm/ar/art/cperry.html. Acesso em: $24 / 10 / 2002$.

PORTER, M. Vantagem Competitiva: Criando e Sustentando um Desempenho Superior. 1 ed. Rio de Janeiro: Campus, 1989.

. What is strategy? On competition, Boston, p. 39-74, 1998.

Project Management Institute Headquarters, através do Manual PMBOK 2000 disponibilizado pelo PMI MG em Janeiro de 2002, no endereço www.pmimg.org.br.

RENTES, A.F. TransMeth - Proposta de uma Metodologia para Condução de Processos de Transformação de Empresas. São Carlos - SP, 2000. 229 p. Tese de Livre Docência - Escola de Engenharia de São Carlos, USP.

RICCIO, E.L. Uma Contribuição ao Estudo da Contabilidade Como Sistema de Informação. São Paulo, 1989. 170 P. Tese de Doutorado - FEA-USP.

. Efeitos da Tecnologia de informação na Contabilidade - Estudos de casos na implementação de Sistemas Empresariais Integrados "ERP". São Paulo, 2001. 127 P.(parcial). Tese de Livre Docência - FEA-USP.

. Analysis of the Effects of ERP Systems in Accounting Organization. Asian Pacific Conference on International Accounting Issues, 13 - 2001 Rio de Janeiro, São Paulo, v. 1 (trabalhos em português e espanhol), n. FEA/CD 89, p. 19, 2001. CD ROM meio digital. Acesso em: 21/10/2002.

RICCIO, E.L.; PETERS, M.R.S. Novos Paradigmas para a Função Controladoria. Trabalho apresentado no $17^{\circ}$. Encontro Anual da ANPAD. Salvador, BA: Setembro, 1993.

RIPAMONTI, A. Função Social das Empresas de Serviços Contábeis. Anais do V Congresso Brasileiro de Gestão Estratégica de Custos. Fortaleza, CE: Agosto, 1998. p. 773-790.

ROBBINS, S.P. Comportamento Organizacional, 9 ed. São Paulo: Prentice Hall, 2002. $637 \mathrm{p}$.

SACCOL, A. Z.; MACADAR, M.A.; SOARES, R.O. Organization Change Related to the Use of ERP in Brazilian Enterprises. Anais do $23^{\circ}$. ENANPAD. Foz do Iguaço (PR). Setembro, 1999.

Implantação de pacote de gestão empresarial em médias empresas. Artigo publicado pela KMPress disponível no site http://www.kmpress.com.br, 13 fevereiro 2000. Acessado em 20 de Agosto de 2002.

SALERNO, M.S. Projeto organizacional de Produção Integrada, Flexível e Gestão Democrática: Processos, Grupos, e Espaços de Negociação-comunicação. São Paulo, 1998. 184 p. Tese de Livre Docência - Engenharia da Produção, USP.

SANKARAN, S. Methodology for an organisational action research thesis. Action Research International, Australia, 2001. Disponível no endereço http:/www.scu.edu.au/schools/gcm/ar/ari/p-ssankaran01.html. Acesso em: 24/10/2002. 
SANTOS, L.C. Projeto e Análise de Processos de Serviços: Avaliação de Técnicas e Aplicação em uma Biblioteca. Florianópolis, 2000. 99 p. Dissertação de Mestrado. Engenharia da produção, UFSC.

SCHON, D. The Reflective Practitioner: How Professionals Think in Action. Avebury: Ashgate Publishing Ltda, 1991.

SCHMIDT, P. (ORG). Controladoria Agregando Valor para a Empresa. $1^{\circ} \mathrm{ed}$. Porto Alegre : Bookman, 2002. 262 p.

SCHMIDT, P. História do Pensamento Contábil. $1^{\mathrm{o}}$ ed. Porto Alegre : Bookman, 2000. $231 \mathrm{p}$.

SEBRAE-SP (Serviço Brasileiro de Apoio às Micro e Pequenas Empresas de São Paulo); FIPE (Fundação Instituto de Pesquisas Econômicas). Coordenadores: Marco Aurélio Bedê (SEBRAE-SP); Carlos Roberto Azzoni (FIPE). Sobrevivência e Mortalidade de Empresas Paulistas de 1 a 5 anos. São Paulo, outubro de 2001. Disponível em: http://www.sebraesp.com.br. Acesso em: 29 Setembro/2002.

SEIFFERT, P.Q. Modelo de Reestruturação Organizacional por Processos. Florianópolis, 1998. 145 p. Dissertação de Mestrado. Engenharia da produção, UFSC.

SHAPIRO, Carl, VARIAN, Hal, R. A economia da informação: como os princípios econômicos se aplicam à era da Internet. Tradução de Ricardo Inojosa. Rio de Janeiro: Campus, 1999.

SETZER, V. Dado, informação, conhecimento e competência. DataGramaZero Revista de ciência da informação. Nr. Zero, dez 1999. Disponível em http://www.dgz.org.br em 21/08/2002.

SENGE, P. et al.. A Quinta Disciplina: Caderno de Campo - Estratégias e Ferramentas para Construir uma Organização que Aprende. $1^{\text {a }}$. ed. Rio de Janeiro : Qualitymark, 2000. $541 \mathrm{p}$.

SILVA, J.M. Guia IOB de Contabilidade: O Patrimônio da Empresa e a Contabilidade. atualizável ed. São Paulo: IOB informações Objetivas, 30/11/1992 1992. v. 1. p. 15. Parte 1.

SIRIHAL, A. B.;LOURENÇO, C. A. Conhecimento e Informação: Aspectos Filosóficos e Informacionais. Revista Informação e Sociedade: Estudos, João Pessoa, v. 12 , n. 1, p. 15, 2002. http://www.informacaoesociedade.ufpb.br/1210203.pdf. Acesso em: 15/15/2002.

SORTER, G.H. An "Events"Approach to Basic Accounting Theory. The Accounting Review. Janeiro, 1969 .12-19.

SOUZA, C.A. Sistemas Integrados de Gestão Empresarial: Estudos de Casos de Implementação de Sistemas ERP. São Paulo, 2000. 275 p. Dissertação de Mestrado - Departamento de Administração - FEA, USP.

SOUZA, C.A.; ZWICKER, R. Ciclo de vida de sistemas ERP. Caderno de pesquisas em administração, São Paulo. V. 1, N $11,1^{\circ}$ Trim./2000.

SOUZA, G.W.L. Aplicação de conceitos de Modelagem e Integração de Empresas no Gerenciamento de Projetos de Transformação Organizacional: Uma 
abordagem voltada à construção de sistemas de informação. São Carlos - SP, 1999. 151 p. Dissertação de Mestrado. Escola de Engenharia de São Carlos, USP.

STRINGER, E.T. Action Research - A Handbook for Practitioners. $1^{\text {a }}$. ed. Califórnia: Sage Publications, Inc, 1996. 169 p.

TACHIZAWA, T.; SCAICO, O. Organização Flexível: Qualidade na Gestão por Processos. $1^{\text {a }}$. ed. São Paulo: Atlas, 1997. 335 p.

TAVARES, M.G.P. Cultura Organizacional: Uma Abordagem Antropológica da Mudança. 1a. Ed. Rio de Janeiro: Qualitymark, 1999. 88 p.

THEÓPHILO, C.R. Uma Abordagem Epistemológica da Pesquisa em Contabilidade. São Paulo, 2000. 128 p.. Dissertação de Mestrado - FEA, USP.

THIOLlENT, M. Metodologia da pesquisa ação. $8^{\text {a }}$ ed. São Paulo-SP: Cortez , 1998. $107 \mathrm{p}$.

THIOLLENT, M. Pesquisa-Ação nas organizações. $1^{\text {a }}$. ed. São Paulo: Atlas, 1997. $164 \mathrm{p}$.

THOMÉ, I. Empresas de Serviços Contábeis: Estrutura e funcionamento. $1^{\mathrm{a}}$. ed. São Paulo: Atlas, 2001. 178 p.

UNIVERSIDADE DE SÃO PAULO. Sistema Integrado de Bibliotecas / Centro de Computação de São Carlos. Diretrizes para apresentação de Teses e Dissertações à USP: documento eletrônico ou impresso. - São Paulo: SIBi/USP, 2001. 16 p.

VILELA, D.L. A Contabilidade Gerencial e O Processo de Comunicação: Estudo Sobre a Utilização de Ferramentas de Contabilidade Gerencial Pelas Empresas de Pequeno Porte e Pelos Escritórios de Contabilidade In: congresso brasileiro de contabilidade, XVI., 2000, Goiana-GO. Conselho Federal de Contabilidade, 2000. Acesso em: 11/12/02.

VILLELA, C.S.S. Mapeamento de Processos como Ferramenta de Reestruturação e Aprendizado Organizacional. Florianópolis, 2000. 154 p. Dissertação de Mestrado. Engenharia da produção, UFSC.

WALTON, R.E. Tecnologia de Informação: O uso de TI pelas empresas que obtêm vantagem competitiva. São Paulo: Atlas, 1998.

WILSON, T.D. Recent trends in user studies: action research and qualitative methods. Institut fur Publizistik und Dokumentationwisswnachaft, Berlin, 1980. http://nformationR.net/ir/paper76.html. Acesso em: 21/10/2002.

WATERMAN, H.; et.al. Action Research: a systematic review and guidance for assessment. Health Technol Assess. 2001;5(23)

YIN, R.Y. Estudo de Caso: Planejamento e Métodos. 2a . ed. Porto Alegre - RS: Bookman, 2001. 205 p. 


\section{APÊNDICES}

\section{APÊNDICE 1: VISUALIZAÇÃO DOS PASSOS DA METODOLOGIA}

TRANSMETH

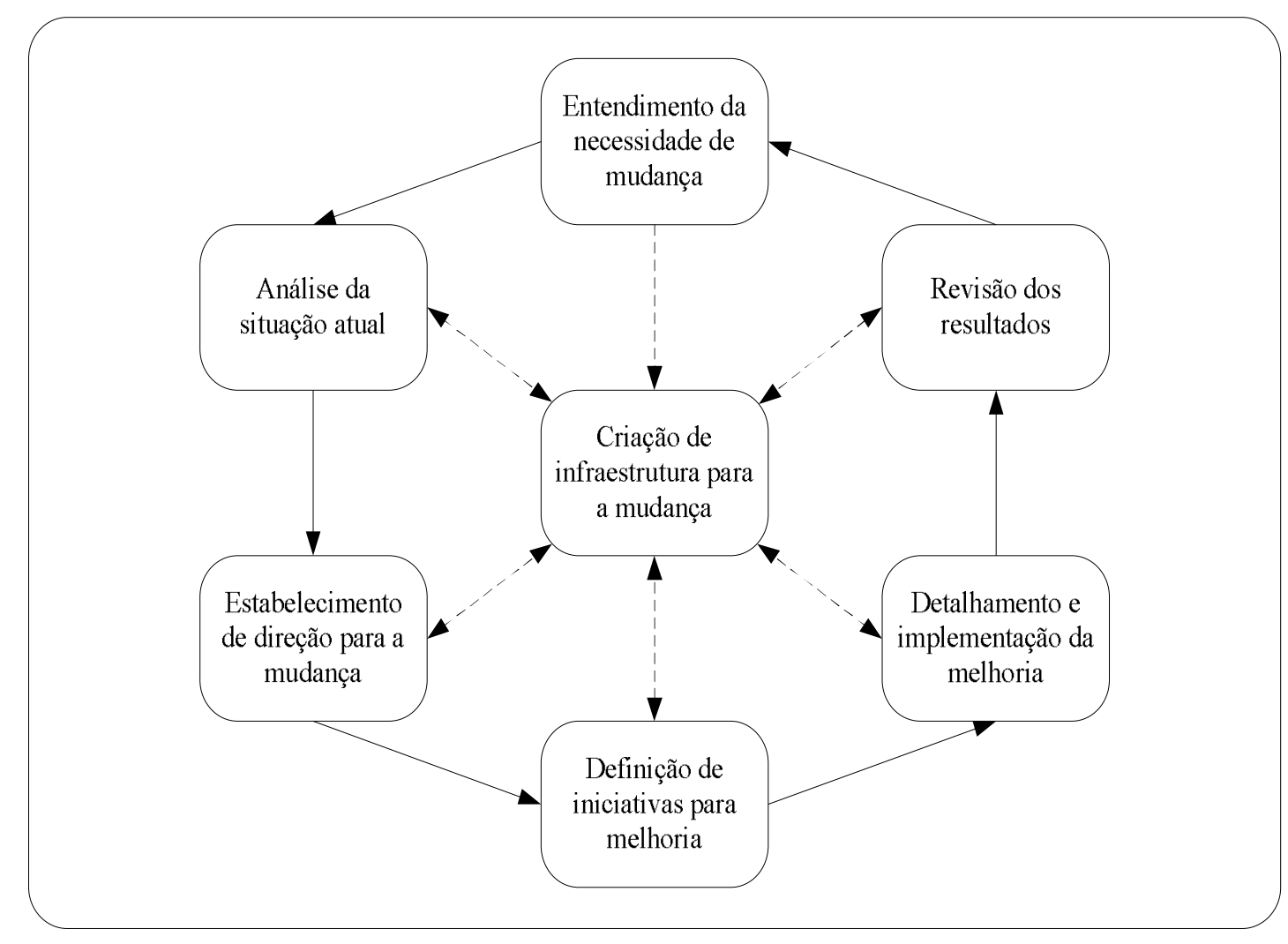

Fonte: Rentes (2000, pg.84) 
APÊNDICE 2: QUESTÕES ASSOCIADAS COM AS ETAPAS DA METODOLOGIA TRANSMETH

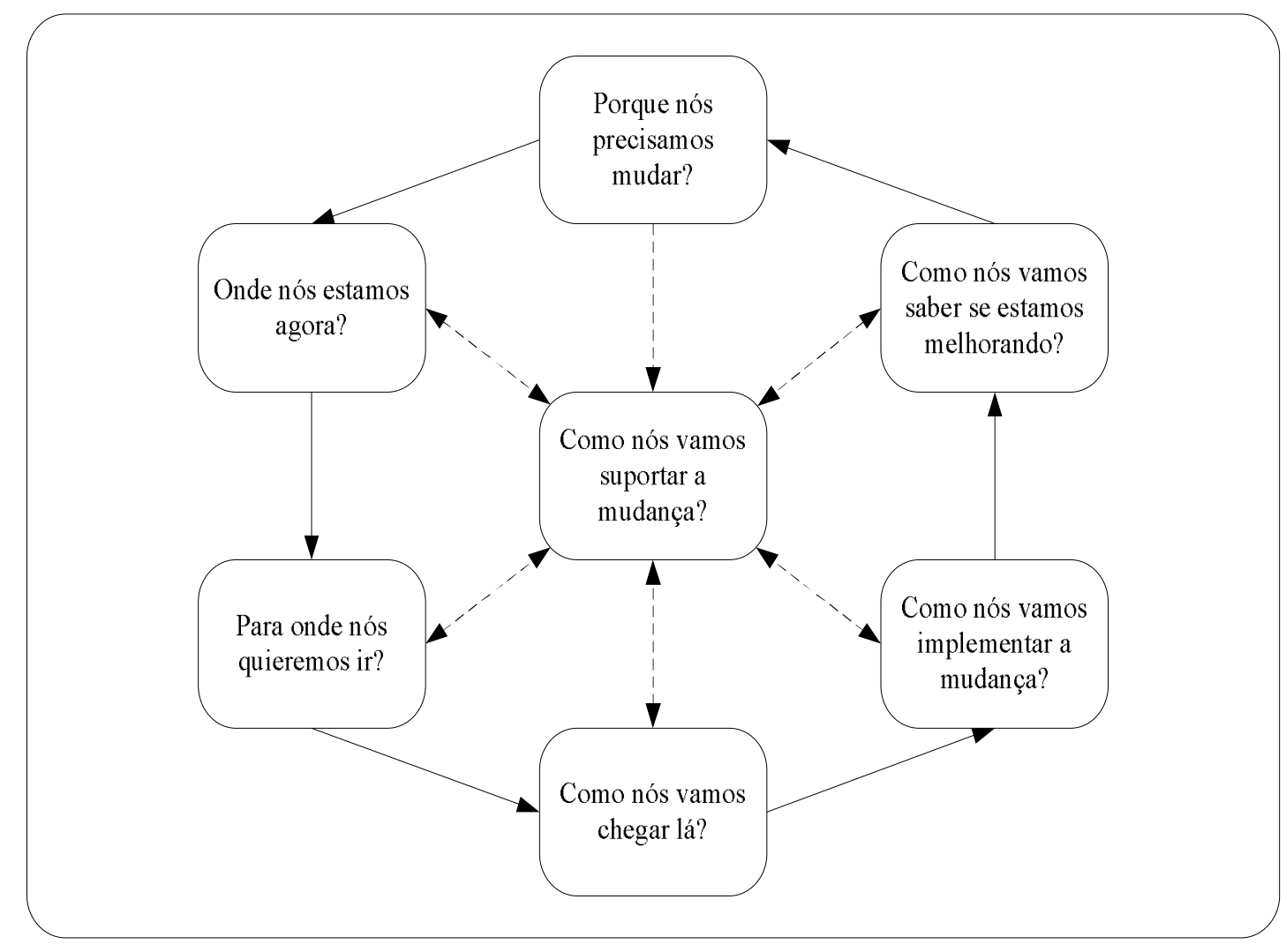

Fonte: Rentes (2000, pg.85) 


\section{APÊNDICE 3: CONCEITOS UTILIZADOS PELA METODOLOGIA TRANSMETH}

\begin{tabular}{|c|c|}
\hline Dimensões & Frentes \\
\hline \multirow{5}{*}{ Negócios } & $\begin{array}{l}\text { Burning Platform: É a mola motora do processo de mudança. É o motivador inicial e a } \\
\text { razão de ser de todo o processo }\end{array}$ \\
\hline & $\begin{array}{l}\text { Lideranca: Diz respeito à qualidade de comando e a capacidade de condução do processo } \\
\text { de transformação }\end{array}$ \\
\hline & $\begin{array}{l}\text { Visão: É uma peça fundamental para a liderança do processo de transformação. Fornece } \\
\text { de forma clara e objetiva a direção a ser perseguida pela organização neste processo de } \\
\text { transformação }\end{array}$ \\
\hline & $\begin{array}{l}\text { Focalização: Garante que o processo de transformação está focado no atingimento da } \\
\text { visão da organização e que esta está utilizando os seus recursos de forma eficaz para } \\
\text { atingir o ponto desejado }\end{array}$ \\
\hline & $\begin{array}{l}\text { Alinhamento: É a capacidade da organização em alinhar os seus esforços e direcionar a } \\
\text { utilização dos seus recursos na perseguição e atingimento de sua visão de transformação. } \\
\text { Trata do desdobramento dos objetivos mais globais da organização para os objetivos das } \\
\text { equipes e individuos }\end{array}$ \\
\hline \multirow{4}{*}{ Cultura } & $\begin{array}{l}\text { Crenças e Valores: São as regras culturais da organização, normalmente não escritas, que } \\
\text { direcionam e estimulam em grande parte o comportamento dos seus membros. São } \\
\text { normas compartilhadas na organização, atitudes, crenças, expectativas, costumes e } \\
\text { pressupostos sobre a organização, que vão sendo estabelecidos a partir de experiências } \\
\text { passadas na empresa }\end{array}$ \\
\hline & $\begin{array}{l}\text { Comunicação: É a transmissão eficaz de informações pertinentes ao processo de } \\
\text { transformação a todos os participantes deste processo, garantido que as decisões e ações }\end{array}$ \\
\hline & $\begin{array}{l}\text { Motivaç̃o: Capacidade das lideranças em motivar os participantes do processo de } \\
\text { desenvolvimento de mudanças e os demais funcionários na implementação das mudanças } \\
\text { propostas }\end{array}$ \\
\hline & $\begin{array}{l}\text { Participacão: Nivel de contribuição das pessoas envolvidas em termos intelectuais e } \\
\text { operacionais no processo de transformação }\end{array}$ \\
\hline \multirow{4}{*}{ Recursos } & $\begin{array}{l}\text { Infraestrutura: Referente ao nivel de qualidade das equipes montadas para atuar no } \\
\text { processo, do espaço fisico, dos recursos materiais e de outros recursos organizacionais } \\
\text { disponiveis para o desenvolvimento da transformação }\end{array}$ \\
\hline & $\begin{array}{l}\text { Tecnologia: Diz respeito ao nivel tecnológico da organização e a sua preparação para a } \\
\text { utilização de novas tecnologias nas soluções a serem propostas no processo de mudança. } \\
\text { Como tecnologia aqui, compreende-se tecnologia de produção, de gerenciamento, de } \\
\text { comunicação, etc. }\end{array}$ \\
\hline & $\begin{array}{l}\text { Sist. Informação: É a eficiência do conjunto de veículos de informação formais utilizado } \\
\text { durante o processo de mudança. Estes veículos podem ser eletrônicos, gráficos, } \\
\text { manuais, etc. }\end{array}$ \\
\hline & $\begin{array}{l}\text { Educação/Treinamento: } \dot{E} \text { a qualidade da estrutura ou recurso de desenvolvimento de } \\
\text { pessoal para atuar no processo de transformação }\end{array}$ \\
\hline \multirow{3}{*}{ Operações } & Planejamento: É a capacidade da organização em planejar as atividades do processo de \\
\hline & $\begin{array}{l}\text { Ger. de Processos: Diz respeito ao nivel de conhecimento e de visualização dos } \\
\text { processos envolvidos na transformação. Outra perspectiva desta barreira é a não } \\
\text { realização de alterações necessárias no sistema de medidas de desempenho da } \\
\text { organização. Este sistema deve coerentemente refletir as mudanças organizacionais } \\
\text { ocorridas/propostas }\end{array}$ \\
\hline & $\begin{array}{l}\text { Med. Desempenho: É a qualidade das métricas a serem empregadas para se medir o } \\
\text { desempenho das equipes e do processo de transformacão propriamente dito }\end{array}$ \\
\hline
\end{tabular}

Fonte: Rentes (2000, pg.85) 


\section{APÊNDICE 4: CONCEITOS UTILIZADOS PELA METODOLOGIA TRANSMETH - BARREIRAS AS MUDANÇAS (BLOQUEIOS)}

\begin{tabular}{|c|}
\hline Barreiras \\
\hline $\begin{array}{l}\text { 1-Não identificação de uma clara burning platform: Um erro comum cometido pelo patrocinador e pela } \\
\text { liderança do processo é achar que a burning platform é óbvia a todos os participantes. Ela não é } \\
\text { necessariamente óbvia e, portanto, deve-se tomar o cuidado de formalizá-la adequadamente. Se a burning } \\
\text { platform não for válida, a empresa estará gastando recursos, estressando seus funcionários e gastando a } \\
\text { credibilidade de seus executivos na perseguição de uma transformação que não é necessária ou que está } \\
\text { orientada em uma direção equivocada. }\end{array}$ \\
\hline $\begin{array}{l}\text { 2-Excesso de complacência: Segundo Kotter, este é o maior dos erros. Ocorre quando a empresa decide } \\
\text { empreender a mudança sem estabelecer um suficientemente forte senso de urgếncia entre os seus } \\
\text { gerentes e funcionários. Além de definir a necessidade de mudança, é necessário também demonstrar a } \\
\text { necessidade da urgência da mudança. A ausência deste cuidado faz com que os associados não dêem } \\
\text { prioridade ao processo de mudança, em relaçäo às suas atividades usuais. Este é um erro fatal, porque } \\
\text { transformaçöes sempre fallham no atingimento de seus objetivos se o nivel de complacência for alto. }\end{array}$ \\
\hline 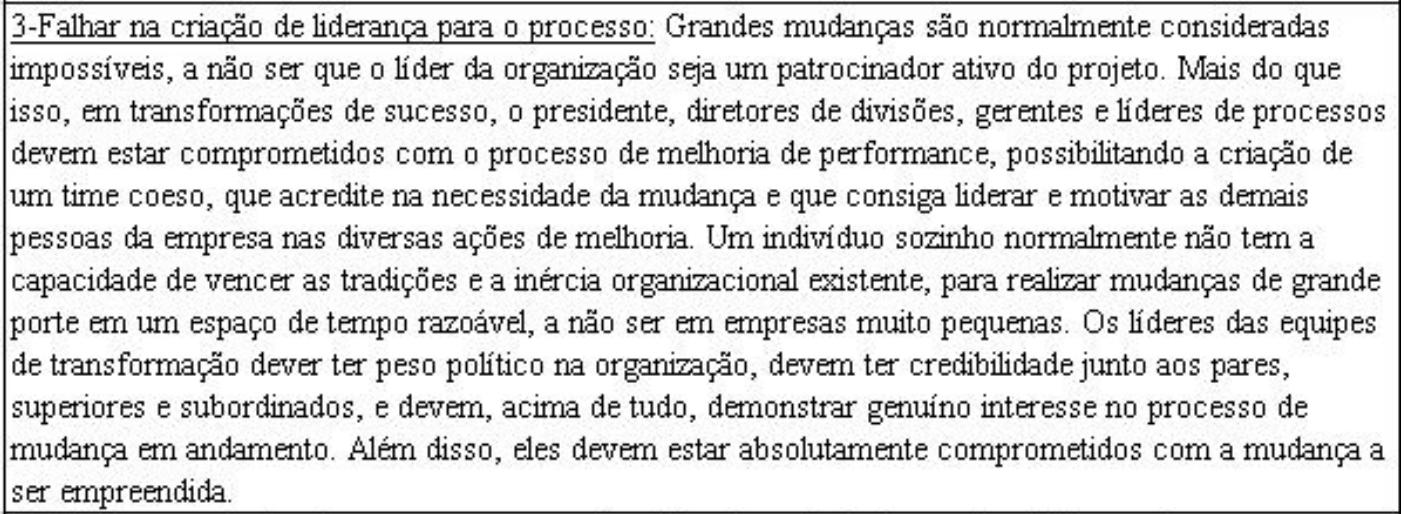 \\
\hline $\begin{array}{l}\text { 4-Falta de uma visão clara para o processo: É a falta de estabelecimento de objetivos claros a serem } \\
\text { atingidos no processo de mudança. Senso de urgência e uma forte liderança são fatores necessários mas } \\
\text { não são condiçöes suficientes para o processo de mudança. A visão da empresa exerce um papel chave } \\
\text { no processo, fornecendo direcionamento, alinhamento de objetivos e inspirando ações de um grande } \\
\text { número de pessoas na organizaçäo. Da mesma forma que a burning platform, a visão não é óbvia e } \\
\text { precisa ser eficientemente comunicada. A falta de uma visäo clara dificulta a integração entre os } \\
\text { elementos participantes, uma vez que cada subgrupo envolvido pode desenvolver a sua própria visão de } \\
\text { onde se quer chegar, fazendo com que o esforço de transformaçäo se dissolva em uma lista de projetos } \\
\text { confusos, incompativeis e devoradores de recursos, orientados em direçőes erradas. }\end{array}$ \\
\hline $\begin{array}{l}\text { 5-Falha na focalizaçäo de processos e problemas raizes: É uma falha associada ao processo de } \\
\text { diagnóstico da organizaçäo. Pode ser decorrente de uma interpretaçäo errônea do ambiente da empresa } \\
\text { que tenha resultado em uma falha de identificaçäo e formulação de burning platform, ou então de falha } \\
\text { no processo de análise da situação atual, resultando em deficiência na identificação de problemas raizes } \\
\text { e processos chaves a serem atacados no processo de transformaçäo. De qualquer forma, é } \\
\text { primariamente associada a erro de focalização e de comunicaçäo no início do processo. }\end{array}$ \\
\hline $\begin{array}{l}\text { 6-Falha na orientaçao/focalização nas necessidades dos clientes: Isto inclui a ocorrência de falthas de } \\
\text { percepçäo tanto das necessidades dos clientes externos quanto das necessidades dos clientes internos da } \\
\text { empresa como um todo. O processo de transformaçäo, em última instância, deve afetar positivamente o } \\
\text { desempenho global da empresa. Para que isso aconteça, o processo dever levar em consideração os } \\
\text { requisitos dos clientes em relação à organizaçăo. }\end{array}$ \\
\hline
\end{tabular}

Fonte: Rentes (2000, pg.28-30) 


\section{CONTINUAÇÃO APÊNDICE 4: CONCEITOS UTILIZADOS PELA METODOLOGIA TRANSMETH - BARREIRAS AS MUDANÇAS (BLOQUEIOS)}

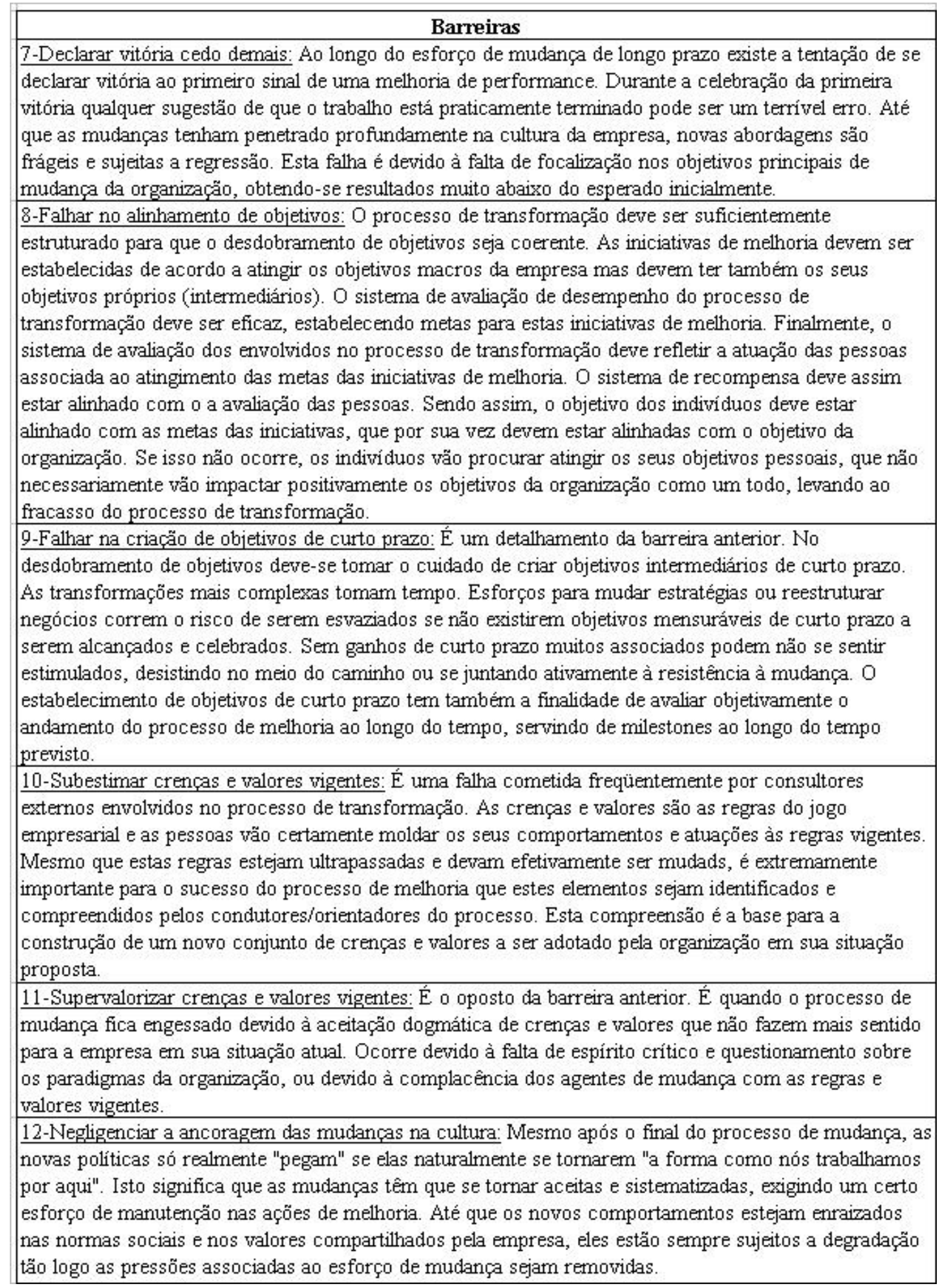

Fonte: Rentes (2000, pg.30-32) 


\section{CONTINUACÃO APÊNDICE 4: CONCEITOS UTILIZADOS PELA METODOLOGIA TRANSMETH - BARREIRAS AS MUDANÇAS (BLOQUEIOS)}

\begin{tabular}{|c|}
\hline Barreiras \\
\hline $\begin{array}{l}\text { 13-Falhar no processo de comunicaçäo da visão e burning platform: Grandes mudanças são } \\
\text { normalmente impossiveis a não ser que a maioria dos funcionários esteja disposta a ajudar, muitas vezes } \\
\text { a ponto de fazer sacrificios de curto prazo. Mesmo que as pessoas näo estejam satisfeitas com a } \\
\text { situação da empresa, elas só vão ter o envolvimento necessário se acharem que esta mudança é } \\
\text { realmente necessária para a organização e que os beneficios em potencial da mudança são atrativos a } \\
\text { nivel pessoal e possiveis de serem atingidos a curto/médio prazo. Para que isso ocorra é necessário que } \\
\text { se efetue um volume muito grande de comunicação confível. Este processo de "captura do coração e } \\
\text { mente dos funcionários" é vital para a motivaçäo durante o processo de transformação. Sendo assim, é } \\
\text { absolutamente importante que a burning platform e a visão de transformaçäo sejam comunicadas } \\
\text { eficazmente. }\end{array}$ \\
\hline $\begin{array}{l}\text { 14-Negligenciar a comunicacão durante o processo de mudança: Além da comunicação da burning } \\
\text { platform e visão, é também igualmente importante manter os participantes da mudança e os demais } \\
\text { membros da organização bem informados sobre o processo em andamento. O desconhecimento das } \\
\text { atividades de transformação em andamento pode acarretar a ocorrência de ações isoladas de } \\
\text { transformação que não estão alinhadas e que são, muitas vezes, contraditórias ao processo como um } \\
\text { todo. }\end{array}$ \\
\hline $\begin{array}{l}\text { 15-Näo colher feedback } 3600 \text { : Colher feedback } 360 \text { o significa a obtençäo de sugestões sobre o } \\
\text { processo de transformação em todos os niveis da empresa. Isto significa comunicar eficazmente o } \\
\text { processo e estimular os demais membros da organizaçäo, em todos os niveis, a encaminhar sugestões, } \\
\text { fornecer novas idéias para o projeto da situaçäo futura, fornecer dados relevantes não considerados } \\
\text { inicialmente, etc. Este procedimento facilita a adesão dos demais membros ao processo de } \\
\text { transformaçăo, conseqüentemente facilitando a sua implementaçäo. }\end{array}$ \\
\hline 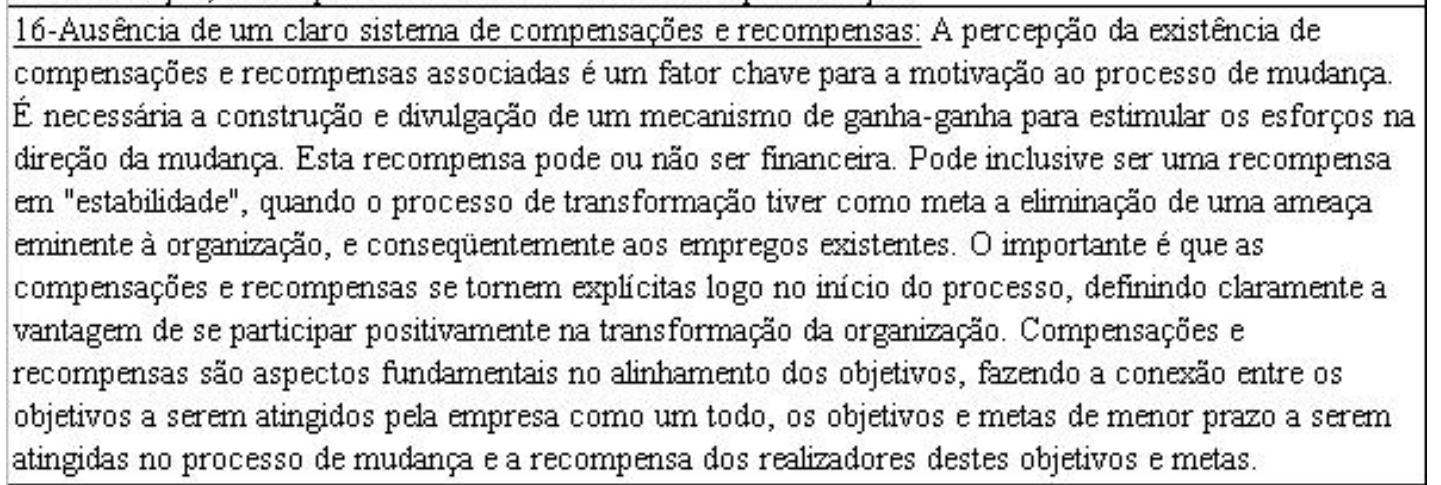 \\
\hline $\begin{array}{l}\text { 17-Permitir que obstáculos bloqueiem a visão: Novas iniciativas freqüentemente falham porque os } \\
\text { empregados, apesar de abraçar a nova visão da empresa, se sentem impotentes para vencer grandes } \\
\text { obstáculos que surgem no caminho do processo de mudança. Ocasionalmente estes obstáculos estão } \\
\text { apenas na mente das pessoas, sendo dogmas associados ao antigo paradigma, e o desafio então é } \\
\text { convencer as pessoas de que não existem barreiras reais e reforçar a capacidade de realização da equipe } \\
\text { e da organizaçăo. Porém, em muitos casos, as barreiras realmente existem, tendo que ser identificadas, } \\
\text { compreendidas e trabalhadas. De qualquer forma, a não percepção dessas barreiras, reais ou } \\
\text { imaginárias, por parte dos agentes de mudança é uma fonte de falhas para o processo de mudança. Este } \\
\text { pode ser, portanto, um erro também associado à falta de focalização. }\end{array}$ \\
\hline
\end{tabular}

Fonte: Rentes (2000, pg.33-35) 


\title{
CONTINUAČ̃O APÊNDICE 4: CONCEITOS UTILIZADOS PELA METODOLOGIA TRANSMETH - BARREIRAS AS MUDANÇAS (BLOQUEIOS)
}

\begin{abstract}
Barreiras
18-Falta de empowerment aos agentes de mudanca e equipe: Um dos maiores obstáculos ao processo de transformação é a percepção do agente ou da equipe condutora da mudança de que ele ou ela não tem poderes suficientes para a condução apropriada do processo. A falta de empowerment para 0 agente de mudança é um erro grave e comum, que pode conduzir ao insucesso do processo de transformaça. Este erro está constantemente associado ao fato de que a estrutura de mudança é considerada uma estrutura de segunda categoria em comparação à estrutura operacional da empresa. Desta forma, os membros do grupo de transformaçäo podem tender a negligenciar a autoridade do agente de mudança, se não existir um claro sinal de empowerment a partir do patrocinador do processo de mudança.
\end{abstract}

19-Conduzir a transformaça de forma apenas topdown: Este é um erro constantemente associado aos métodos de reengenharia. A condução top-down subestima a complexidade dos processos envolvidos, desconsiderando a participação de elementos chaves no processo de transformação e,

conseqüentemente, não aproveitando adequadamente as idéias e perspectivas de pessoas realmente envolvidas no problema em questão. Normalmente a ausência de transparência resultante das transformações top-down acabam também levando à desmotivação, à desinformação e à inserção de receios das pessoas no processo, acabando por tomar o processo de transformação em algo temido e informalmente indesejado pela organizaçäo.

20-Ignorar os receios das pessoas participantes do processo: Esse erro diz respeito à falta de eficácia na comunicação, não apenas no sentido de cima para baixo, envolvendo a comunicação de metas e direções para o processo, mas também no sentido de baixo para cima, envolvendo informações técnicas e operacionais. Os participantes do processo de transformação são pessoas, normalmente inteligentes, que estão vivendo o dia a dia da empresa e tềm uma percepção própria dos problemas. A liderança do processo de transformação deve ter a sensibilidade de entender estes diferentes pontos de vista, acrescentando-os ao conjunto de varíveis que devem ser analisadas na construção das estratégias e da própria visão da empresa.

21-Confundir estrutura de transformaça com estrutura operacional: Normalmente isso ocorre devido à forte cultura de estruturação departamental que ainda perdura em um grande número de empresas. Poucas mudanças são tão "localizadas" a ponto de ocorrer internamente em apenas um departamento ou área. Normalmente as transformações organizacionais afetam diversas áreas e conseqüentemente demandam a atenção e formaça de grupos multifuncionais para o desenvolvimento. Estas estruturas de transformaçäo necessariamente devem ser estruturas paralelas e temporárias em relaçäo à estrutura operacional "oficial" da organizaçäo. Elas são estruturas mais orientadas em termos de processo. Recomenda-se assim estruturas multifuncionais e com representantes de diversos niveis hierárquicos. É o que neste trabalho será chamado de "fatia diagonal da organização", em referência a esta variedade funcional e diversidade hierárquica. Um fator extremamente importante que afeta esta estrutura de transformação é a questão da relação de poder desta em relação à estrutura operacional. Muitas vezes o processo de transformaça corre o risco de sua estrutura näo deter poder suficiente. 22-Falha na adaptaça da estrutura organizacional à mudanç: Grande parte das implementações de mudanças organizacionais de grande porte demanda alterações na estrutura organizacional, em maior ou menor grau. A estrutura organizacional é um elemento extremamente dinâmico nas empresas atuais, devido ao relativamente alto índice de turnover nos niveis gerenciais e à necessidade de se adaptar às transformaçöes. Esta barreira diz respeito às situaçöes onde as mudanças demandam alteraçōes na estrutura organizacional e estas alteraçōes não são feitas adequadamente, devido à inércia organizacional ou a falha na constatação da necessidade de alteração.

Fonte: Rentes (2000, pg.34-37) 


\section{CONTINUAÇÃO APÊNDICE 4: CONCEITOS UTILIZADOS PELA METODOLOGIA TRANSMETH - BARREIRAS AS MUDANÇAS (BLOQUEIOS)}

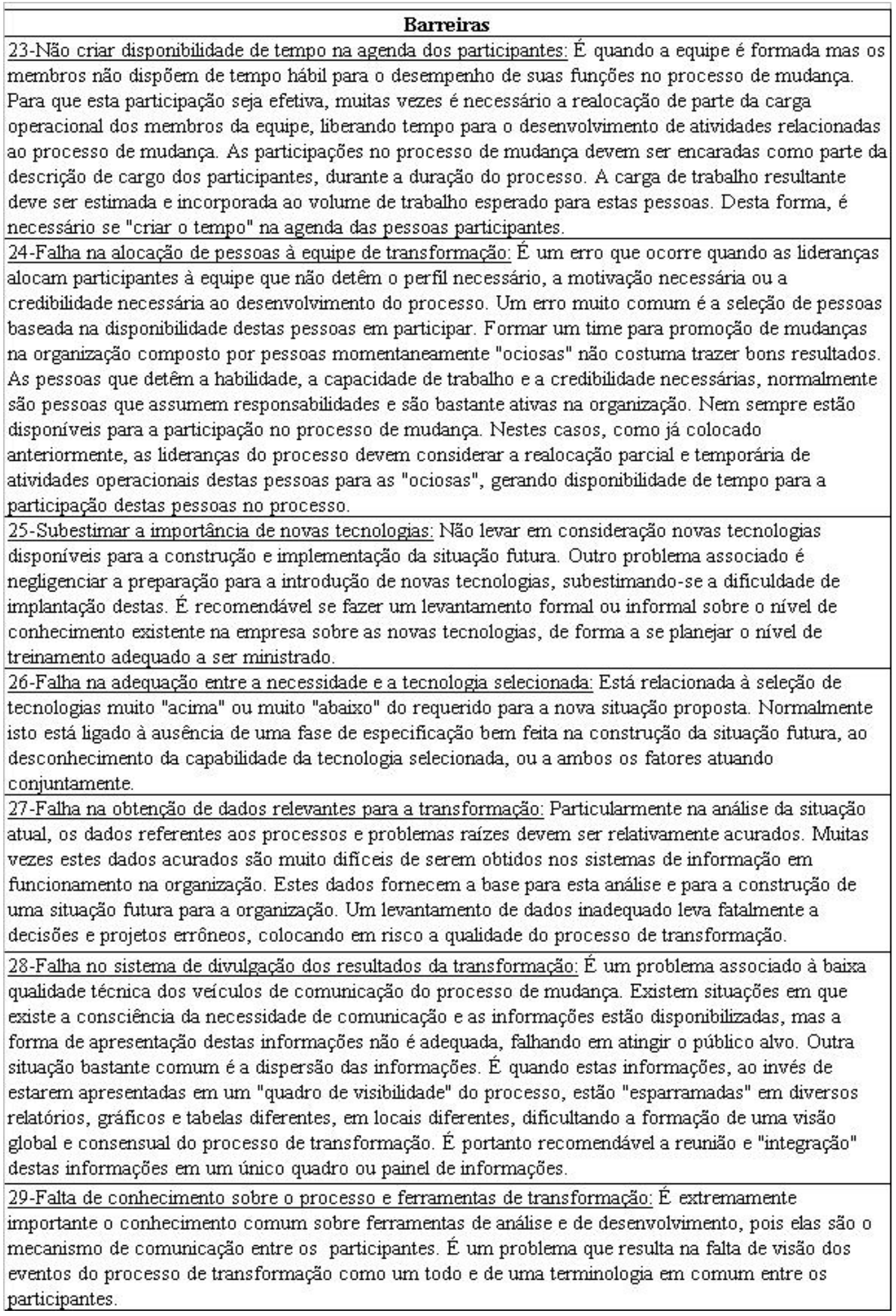

Fonte: Rentes (2000, pg.38-41) 


\section{CONTINUAÇÃO APÊNDICE 4: CONCEITOS UTILIZADOS PELA METODOLOGIA TRANSMETH - BARREIRAS AS MUDANÇAS (BLOQUEIOS)}

\begin{tabular}{|c|}
\hline Barreiras \\
\hline $\begin{array}{l}\text { 30-Falha no compartilhamento de conhecimentos: Normalmente é uma falha no processo de } \\
\text { identificação da necessidade de mudança ou de análise da situação atual. É quando a liderança falha em } \\
\text { envolver os participantes no levantamento de informações e detalhamento dos processos e problemas. É } \\
\text { uma falha relacionada também à questão de comunicação no processo de transformação. }\end{array}$ \\
\hline $\begin{array}{l}\text { 31-Falha no treinamento sobre novas tecnologias a serem utilizadas: Nem todas as pessoas participantes } \\
\text { têm que ter necessariamente o mesmo nivel de conhecimento sobre as tecnologias a serem empregadas. } \\
\text { Porém a falha na definição do nivel básico de treinamento induz a ocorrência de lacunas de } \\
\text { conhecimento que podem resultar eventualmente em erros conceituais no projeto da solução futura, } \\
\text { problemas na implementação destas novas tecnologias e falta de consenso e de motivaçäo entre os } \\
\text { participantes. }\end{array}$ \\
\hline $\begin{array}{l}\text { 32-Inexistência de cronograma de transformação com milestones : É a falta de uma visão das etapas do } \\
\text { processo ao longo do tempo, fornecendo ritmo a este processo. A falta de um cronograma significa a } \\
\text { falta de controle sobre a ocorrência das atividades, levando à falta de planejamento dos recursos a serem } \\
\text { empregados. Os milestones são pontos de controle deste cronograma. Eles indicam o cumprimento de } \\
\text { objetivos intermediários de curto prazo que são importantes para a motivação dos membros das equipes } \\
\text { de transformação. Eles auxiliam também uma avaliação do andamento do projeto, permitindo verificar } \\
\text { dificuldades de desenvolvimento e efetuar ações corretivas. }\end{array}$ \\
\hline $\begin{array}{l}\text { 33-Falha na escolha do momento de iniciar a mudança: Esta pode ser considerada outra dimensão do } \\
\text { erro anterior. Ela está relacionada à não consideração da situação momentânea da liderança. Hammer e } \\
\text { Champy (1993) alertam para o problema de se iniciar o processo de mudança "às vésperas da } \\
\text { aposentadoria" do presidente da empresa, por exemplo. Em situações deste tipo pode até existir um } \\
\text { comprometimento imediato com o processo em seu início, mas não existe necessariamente a garantia de } \\
\text { comprometimento futuro com a implementação, dado que um novo líder vai assumir e pode não } \\
\text { concordar com os rumos estabelecidos. Esta pode se tornar uma situação crítica, onde inicia-se o } \\
\text { processo de mudança, cria-se a estrutura, a motivação e a confiança necessária, e eventualmente aborta- } \\
\text { se o processo devido a uma divergência de visão da nova liderança da empresa. }\end{array}$ \\
\hline $\begin{array}{l}\text { 34-Conduzir o processo vagarosamente: A transformação de uma empresa se dá devido a uma } \\
\text { necessidade imperiosa, que ocorre em um determinado momento especifico. Perder esse momento } \\
\text { mobilizador é um pecado capital no processo de transformação. Muitas vezes esse processo fica à } \\
\text { mercê da disponibilidade de tempo de "folga" dos participantes, uma vez que estes podem considerar } \\
\text { suas atividades normais na empresa como prioritárias, relegando a participação no processo de } \\
\text { transformação a um segundo plano em termos de prioridade. Dessa forma, o processo passa a se } \\
\text { arrastar indefinidamente, restrito a uma ou duas reuniões semanais, sem pegar o embalo necessário e o } \\
\text { estado de espirito necessário para realmente efetuar as mudanças. O tempo de implementação das } \\
\text { iniciativas é equivalente ao tempo de reação da empresa, a partir do momento em que ela identifica a } \\
\text { burning platform. }\end{array}$ \\
\hline $\begin{array}{l}\text { 35-Falha na criação de uma visão de processos consensual e clara: Isso se aplica tanto para a visão da } \\
\text { situação atual (macro e detalhada), quanto para a visão da situação futura. É a ausência de uma } \\
\text { representação consensual dos processos envolvidos que possibilitem o compartilhamento de } \\
\text { conhecimentos sobre os processos entre os participantes na mudança. A ausência desta visão dificulta } \\
\text { tremendamente o processo de comunicação. }\end{array}$ \\
\hline 36-Fragmentaça dos processos entre subgrupos durante a transformaçäo: É importante que os \\
\hline
\end{tabular}

Fonte: Rentes (2000, pg.42-44) 
CONTINUAÇÃO APÊNDICE 4: CONCEITOS UTILIZADOS PELA METODOLOGIA TRANSMETH - BARREIRAS AS MUDANÇAS (BLOQUEIOS)

\begin{tabular}{l} 
Barreiras \\
\hline 37 -Falha no estabelecimento de critérios de avaliaça da transformação: O que não é mensurável não é \\
gerenciável. O estabelecimento de critérios de tempo de desenvolvimento, metas a serem atingidas, bem \\
como o estabelecimento claro de responsabilidades no processo, é vital para a ocorrência da \\
transformação pretendida no horizonte de tempo esperado. A ausência destes critérios básicos é um erro \\
fatal associado à questão de alinhamento de objetivos no processo de mudança. \\
38-Não manter aderência dos grupos às medidas de avaliação: Está relacionada ao relaxamento das \\
métricas de desempenho ao longo do projeto por parte dos líderes do processo de transformação. Isto \\
pode incluir ignorar as métricas, não atualizar os valores ao longo do tempo, não avaliar as pessoas e \\
grupos com base nestas métricas, etc.As medidas de desempenho estabelecidas são ferramentas \\
importantes para o gerenciamento do processo. É necessário que os líderes façam um monitoramento \\
constante do andamento do processo, fornecendo feedback sobre o nivel de atuação, reforçando a \\
motivação e oferecendo suporte aos setores mais problemáticos. Estas barreiras aqui apresentadas são \\
problemas que devem ser evitados ao longo do processo. É importante que a metodologia que aqui será \\
proposta tenha mecanismos de "desativação" destas barreiras.
\end{tabular}

Fonte: Rentes (2000, pg.44-45) 


\section{GLOSSÁRIO}

ABORDAGEM COMPORTAMENTAL - As informações contábeis deveriam ser feitas "sob medida", de forma que os usuários reagissem para tomar a decisão correta.

ADHOCRACIA - Expressão da autoria de Alvin Tofler aplicável a qualquer forma de organização que rompa com as tradicionais normas burocráticas dominantes em empresas em fase de maturidade, com vista à detecção de oportunidades, resolução de problemas e obtenção de resultados. A tônica é o incentivo à criatividade individual enquanto caminho para a renovação organizacional.

ADMINISTRAÇÃO POR OBJETIVO (APO) - Modelo de Gestão adotado por grandes empresas, nos Estados Unidos e Europa, em meados dos anos 1950 e que tem influenciado a Contabilidade por Responsabilidade desde então;

AGENTES ECONÔMICOS - São pessoas de natureza física ou jurídica que, através de suas ações, contribuem para o funcionamento do sistema econômico

ALINHAMENTO ESTRATÉGICO - Consistência entre capacidades diferenciadoras, vantagens competitivas, estratégias, planos, processos, ações, informações e decisões para apoiar as estratégias, objetivos e metas de uma organização.

AMBIENTE - Aquelas instituições ou forças do lado de fora da organização que têm o potencial de afetar seu resultado.

AMBIENTE TRADICIONAL DE ARQUIVOS - Forma de armazenamento de dados em que cada aplicação possui seu próprio arquivo ou arquivos de dados e programas de software separados.

ANÁLISE DA CADEIA DE VALORES - Identificar e explorar ligações internas e externas com o objetivo de fortalecer a posição estratégica de uma empresa.

ANÁLISE DE SISTEMAS - Estudo e análise dos problemas de sistemas de informação existentes; inclui a identificação tanto dos objetivos da organização como dos requisitos para a resolução dos problemas.

APRENDIZAGEM - Qualquer mudança relativamente permanente no comportamento, que ocorra como resultado de uma experiência.

ARQUITETURA ORGANIZACIONAL - É a arte de modelar o espaço organizacional para satisfazer necessidades e aspirações humanas. Refere-se a estrutura de uma organização, isto é, o resultado de um processo através do qual a autoridade é distribuída, as atividades são especificadas desde os níveis mais baixos até a alta administração e um sistema de comunicação é delineado, permitindo que as pessoas realizem as atividades e exerçam a autoridade que lhes compete para o atingimento dos objetivos organizacionais.

ARQUITETURA TECNOLÓGICA: A arquitetura tecnológica de informações engloba não só os recursos da tecnologia de informação mas, também, todo o conjunto de informações de uma organização, os modelos de dados e toda a infra-estrutura tecnológica necessária para suportar os fluxos de informações. 
ATIVIDADES - São processos físicos que consomem recursos e geram produtos/serviços. (1) Evento, tarefa ou unidade de trabalho com objetivo específico. (2) Uma unidade básica do trabalho desempenhada em uma organização.

AUTOMAÇÃO DE DADOS FONTE - Formas avançadas de tecnologia de entrada de dados que geram dados legíveis pela máquina em seus próprios pontos de origem; inclui o reconhecimento de caracteres óticos, o reconhecimento de caracteres de tinta magnética, digitalizadores e entrada de voz.

AUTOMAÇÃO DE ESCRITÓRIO - Aplicação da Tecnologia de informação para aumentar a produtividade dos trabalhadores da informação de escritórios.

BANCO DE DADOS. Grupo de arquivos relacionados; mais especificamente, uma coleção de dados organizados para parecerem estar em um só local de modo que possam ser acessados e utilizados em muitas aplicações diferentes.

BANCO DE DADOS ORIENTADO A OBJETO. Banco de dados que armazena dados e instruções de processamento como objetos que podem ser automaticamente recuperados e armazenados.

BENCHMARKING (níveis de referência). Uso das melhores práticas como o padrão para avaliar o desempenho da atividade.

BEST PRACTICE (Melhores práticas) - Designado a métodos e técnicas inovadoras que contribuem para um desempenho superior de uma organização, geralmente observado em organizações similares.

BPR (Business process reengineering) - Reengenharia do processo empresarial, uma concentração de melhorias de processos empresariais com objetivo de alcançar resultados mais satisfatórios.

BURNING PLATFORM (PLATAFORMA EM CHAMAS) - Significa que é preciso deixar claro que se a empresa não passar por um processo de transformação profundo ela afundará, pois a plataforma na qual ela navega está em chamas.

CADEIA DE VALORES.) O conjunto de atividades necessárias para projetar, desenvolver, produzir, comercializar, distribuir, e atender um produto / serviço.

CAPITAL INTELECTUAL. (1) A princípio se falava muito em capacidade intelectual humana. Com o tempo adicionou-se à inteligência, ao conhecimento existente dentro da empresa, outras variáveis, tais como: marcas, patentes, "designs", liderança tecnológica, clientes, lealdade de clientes, tecnologia de informação, treinamento de funcionários, indicadores de qualidade, relacionamento com fornecedores, desenvolvimento de novos produtos; (2) Contra-partida do Goodwill.

CENTRO DE CUSTO - Menor segmento organizacional ou área de responsabilidade para a qual é feita a acumulação de custos.

CIBERNÉTICA - Estudo das funções humanas de controle e da possibilidade da sua substituição por sistemas mecânicos e elétricos. Conceito da autoria de Norbert Weiner, desenvolvido nos anos 40 , e cuja evolução tem sido crítica para a concepção de complexos sistemas informáticos e experiências no âmbito da robótica.

CICLO CONTÁBIL - A seqüência de procedimentos contábeis que inicia no lançamento de diário das várias transações e eventos e termina com a elaboração das demonstrações financeiras e ajustes pós-balancete. 
CICLO DE VIDA DE SISTEMAS TRADICIONAIS - A mais antiga metodologia para a construção de um sistema de informação; consiste em seis estágios que devem ser completados seqüencialmente.

COMPUTAÇÃO CLIENTE / SERVIDOR - Modelo de computação que divide tarefas de processamento entre "clientes" e "servidores" em uma rede, com cada máquina executando as funções que desempenha melhor.

COMPUTADOR - É um recurso formado por duas partes, uma parte física (hardware) e outra parte lógica (software). A parte física é aquela que podemos ver e tocar, o que já não acontece com a parte lógica representada por um programa.

COMPUTADOR EM REDE - Computador reduzido que não armazena programas ou dados de modo permanente, obtendo-os quando necessário por meio de uma rede.

COMPUTADOR SERVIDOR - Computador projetado ou otimizado para suportar uma rede de computadores.

CONFIABILIDADE - Qualidade da informação contábil que faz com que o usuário aceite a informação contábil e a utilize como base para suas decisões, tornando-se, assim, um elo fundamental entre o usuário e a própria informação.

CONSELHO FEDERAL DE CONTABILIDADE -. Órgão máximo da classe contábil no Brasil que a regulamenta, registra os profissionais e orienta os Conselhos Regionais de Contabilidade.

CONSELHO REGIONAL DE CONTABILIDADE - Órgão fiscalizador da profissão contábil no Brasil, está subordinado ao Conselho Federal de Contabilidade e tem como função elaborar os registros profissionais e fiscalizar o trabalho dos profissionais contábeis.

CONSULTORIA DE GESTÃO - Atividade que consiste no recolhimento de informação e análise do funcionamento de uma empresa, diagnóstico dos seus problemas, apresentação de recomendações e orientações a seguir para a sua implementação.

CONTABILIDADE - Do ponto de vista do usuário, sistema de informação e avaliação destinado a prover seus usuários com demonstrações e análises de natureza econômica, financeira, física, de produtividade especial com relação à entidade objeto de contabilização. Quanto a seu objeto, ciência do Patrimônio, que evidencia as variações quantitativas e qualitativas do mesmo. Em uma visão macro, ciência que registra e avalia como e quão bem a entidade utilizou os recursos a ela confiados.

CONTABILIDADE EM BASE DE DADOS - É um modelo de dados visto da perspectiva da empresa como um todo, e não da perspectiva individual de usuários ou de sistemas de gerenciamentos de dados em particular.

CONTABILIDADE FISCAL - o termo é usado, genericamente, para definir os usos e procedimentos relativos ao controle, planejamento, organização e operação contábil em conexão com as normas fiscais vigentes.

CONTABILIDADE GERENCIAL - Especialização contábil voltada para fins internos, de caráter confidencial. Procura suprir os gestores de uma gama maior de informações, exclusivamente para a tomada de decisões. 
CONTADOR - Profissional que exerce as funções contábeis, com formação superior do ensino Contábil - Bacharel em Ciências Contábeis.

CONTROLADORIA - É o ramo do conhecimento que estuda a identificação, mensuração, decisão [gestão] dos eventos econômicos de uma entidade e a sua informação a todos os interessados. É a unidade administrativa que tem por função a gestão econômica de uma entidade.

CONTROLE - Tecnologias, normas e procedimentos específicos usados para proteger os recursos, a precisão e a confiabilidade dos sistemas de informação.

CONTROLE DE GERENCIAMENTO - Tipo de controle geral que proporciona supervisão e responsabilidade gerenciais apropriadas para sistemas de informação.

CONTROLLER - (1) Controlador. (2) Responsável pela Controladoria. (3) Executivo financeiro responsável principalmente pelas contabilidades gerencial e financeira.

COORDENAÇÃO - É o processo de gerir dependências entre atividades.

CORE SERVICE. O serviço principal que é oferecido como parte do pacote de serviços.

CRIAÇÃO DO PROCESSO - A instalação de um processo totalmente novo para satisfazer os objetivos financeiros e do cliente.

CRM (Customer Relationship Management) - Gestão do Relacionamento com os Clientes, conjunto de processos e tecnologias de apoio a gestão dos relacionamentos com os clientes, cujo objetivo é otimizar a satisfação dos clientes.

CROSS FUNCTIONAL - Termo usado para descrever um processo ou uma atividade que atravessa os limites entre as funções. Um time de função cruzada (cross functional) consiste de indivíduos de mais de uma unidade organizacional ou função.

CSFS (Critical Success Factors) - Fatores Críticos de Sucesso: Eventos, circunstâncias, condições, atividades, processos, ativos especializados, pessoas talentosas que são essenciais para a continuidade da entidade.

CULTURA ORGANIZACIONAL - É o conjunto de valores, atitudes, costumes, crenças e expectativas compartilhadas pelos membros da empresa, sendo resultante do clima organizacional.

CUSTO-BENEFÍCIO - Elemento de julgamento, muito importante em um sistema de informações, segundo o qual há determinadas informações contábeis cujo custo para evidenciá-la (tempo do pessoal da contabilidade, material, computador...) é maior do que o benefício que trará aos usuários (acionistas, administradores...) daquelas informações.

CUSTOS DE TRANSAÇÃO - Custos que acompanham uma venda, incluindo os custos de embarque, manuseio, seguro, e comissões de corretagem.

CYCLE TIME - Tempo de Ciclo, o tempo entre o início e o término de uma tarefa ou de um processo todo.

DADO - elemento que serve de base à resolução de um problema.

DECISÕES- As escolhas feitas entre duas ou mais alternativas. 
DECLARAÇÕES FISCAIS - Declarações de Impostos diretos ou indiretos (IR, IPI, ICMS).

DESCENTRALIZAÇÃO - É canalização de todas as tomadas de decisões para pessoas de nível hierarquicamente inferior, visando aumentar os centros decisórios ao máximo, principalmente em assuntos que necessitem de agilidade operacional e estejam vinculados à otimização da utilização dos recursos humanos e materiais para a obtenção da máxima eficiência e eficácia..

DFD (Diagrama de Fluxo de Dados) - Uma representação gráfica do fluxo de dados que descreve os componentes de um sistema, o fluxo de dados dentro do sistema, suas fontes, seus destinos e arquivos de dados.

DIAGRAMA DE CAUSA E EFEITO - Uma ferramenta para analisar a dispersão do processo (Diagrama de Ishikawa). O diagrama ilustra as causas principais e sub-causas levando a um efeito (sintoma). As quatro principais categorias das causas potenciais de falhas são os fatores humanos, de métodos e projeto, de materiais e de componentes

DIAGRAMA DE PARETO. Diagrama que indica a freqüência com que cada tipo de falha (defeito) ocorre.

DOCUMENTAÇÃO CONTÁBIL - Documentos que comprovam a veracidade dos registros.

DOCUMENTAÇÃO FISCAL - Documentos que indicam à fiscalização que os registros fiscais estão corretos.

DOCUMENTO FONTE - Um documento que descreve uma transação e que é usado para acompanhar o desenvolvimento de custos enquanto estes ocorrem.

DSS (Decision Support Systems) - Sistema de Apoio à Decisão (DAP) - Sistema de informação que apóia os gestores nas tomadas de decisões não-estruturadas por meio de recuperação de dados e geração de informações.

DUALIDADE - Para todas as transações contábeis, um valor é atribuído, consistindo em duas contas e em uma data (momento de tempo).

ECONOMIA DA INFORMAÇÃO E DO CONHECIMENTO - Economia na qual a maior parte da nova riqueza (produto interno bruto) é produzida pela criação ou pelo processamento de informações.

EFICÁCIA - é uma medida que reflete o grau de atingimento de um objetivo.

EFICIÊNCIA - Modo correto de realizar-se atividades, relaciona-se a volumes produzidos com recursos consumidos no processamento, onde objetiva-se obter menor custo por unidade produzida.

ELIMINAÇÃO DA ATIVIDADE - O processo de eliminar atividades que não adicionam valor.

EMPOWERMENT. Uma condição em que os empregados têm autoridade de tomar decisões e ações em suas áreas de trabalho sem aprovação prévia.

EMPRESA CONTÁBIL - é uma organização técnico-econômica constituída para produzir serviços, visando a lucros - com a missão: Tradicional - atender o processo de terceirização dos serviços contábeis das empresas-cliente, atuando como intermediária junto ao fisco na aplicação das normas fiscais e legais vigentes; Ampliada - gerir o 
sistema de informação da empresa-cliente através da implantação de gestão integrado, operado na arquitetura AS

ENFOQUE DO CUSTO-BENEFÍCIO - Critério principal de escolha, entre sistemas contábeis alternativos, de como cada sistema atinge as metas organizacionais em relação ao respectivo custo.

ENGENHARIA DO VALOR - Avaliação sistemática de todos os aspectos das atividades da cadeia de valor, com o objetivo de reduzir custos e ao mesmo tempo atender às necessidades do cliente.

ENTIDADE - Pessoa, lugar ou objeto sobre a qual são mantidas informações.

ENTRADA - Na linguagem sistêmica representa algo que entra no sistema para ser processada (input); Obtenção ou coleta de dados brutos de dentro de uma organização ou de seu ambiente externo.

ENTRADA E PROCESSAMENTO EM LOTES (BATCH). Método de entrada e processamento no qual os dados são agrupados como documentos-fonte antes de serem introduzidos; em seguida eles são armazenados como um arquivo de transações antes do processamento, que ocorre mais tarde.

EQUIPE DE TRABALHO - Um grupo em que os esforços individuais resultam em um nível de desempenho maior que a soma das entradas individuais.

EQUIPES MULTIFUNCIONAIS - Funcionários do mesmo nível hierárquico, mas de diferentes setores da empresa, que se juntam para cumprir uma tarefa.

ESCRITURAÇÃO CONTÁBIL - É um conjunto de procedimentos técnicos sistematizados que visam o registro, o controle e a demonstração das variações ocorridas no patrimônio de uma entidade num determinado período. Pode ser descrita, também, como a arte de registrar os fatos contábeis nos livros diário e razão, constituindo-se na técnica denominada escrituração. É pela escrituração que os fatos contábeis, particularizados em sua essência, vão sendo acumulados ordenadamente para formar os diversos demonstrativos contábeis.

ESCRITURÁRIO CONTÁBIL - Pessoa que efetua a escrita contábil.

ESPECIALIZAÇÃO - Divisão do trabalho em uma organização de forma que cada empregado realiza uma tarefa específica sob a suposição de obter-se máxima eficiência.

ESPECIFICAÇÕES DE PROCESSO - Etapas lógicas da execução de um processo; constam em documentos que acompanham os diagramas de fluxo de dados de baixo nível para mostrar as diversas etapas nas quais os dados são transformados, ou produtos são transformados.

ESTRATÉGIA - O processo de seleção dos segmentos de mercado e de cliente, a identificação dos processos críticos, internos e externos do negócio nos quais a empresa precisa se destacar para melhorar o valor ao cliente, e a seleção das competências individuais e organizacionais necessárias para se atingir os objetivos financeiros, do cliente e da empresa.

ESTRATÉGIA DE DIFERENCIAÇÃO - Uma abordagem que busca aumentar o valor ao cliente ao melhorar o que o cliente recebe. 
ESTRUTURA ORGANIZACIONAL - (1) Disposição dos níveis de responsabilidade dentro da entidade, organizada por funções. É o resultado do planejamento filosófico e estratégico a empresa; seus limites ou fronteiras são delineados de acordo com os objetivos, metas e projetos propostos nos níveis estratégico, tático e operacional. (2) Sistema formal de relações de trabalho que separa e integra tarefas (clarifica quem deve fazer o quê e que esforços devem ser integrados para fazer algo).

EVASÃO DE RECEITAS - Omissão de receitas da empresa.

EVENTO CONTÁBIL - Ocorrência econômica que produz efeito patrimonial.

EVENTO ECONÔMICO - é uma ocorrência no ambiente da firma, tanto externo quanto interno, que tem significância econômica para os tomadores de decisões;

FLUXO DE DADOS - Movimento de dados dentro de um sistema de informação; pode consistir em um simples elemento de dados ou em múltiplos elementos de dados agrupados, podendo ser manual ou automatizado.

FUNÇÃO - é utilizada normalmente para indicar o conjunto de tarefas desempenhado por uma ou mais pessoas, servindo como base para a departamentalização.

FUNÇÕES ORGANIZACIONAIS - Tarefas especializadas desempenhadas em uma organização empresarial - por exemplo, produção, marketing, finanças e recursos humanos.

GESTÃO - ato de gerenciar ou processo de tomada de decisão.

GESTÃO DA MUDANÇA - A idéia não é propriamente nova. O que mudou foi a própria natureza da mudança, que de incremental e passível de previsão passou a descontínua, veloz e imprevisível. As três forças geradoras da mudança são a tecnologia, a desregulamentação e a globalização. Os gestores devem preparar-se para a mudança através da resposta a três perguntas fundamentais: como será a organização do futuro? Qual o processo de mudança ideal? Qual o tipo de competências que é necessário?

GESTÃO ESTRATÉGICA - Processo por meio do qual se analisa as variáveis ambientais com propósito de processa-las, formar e formular estratégias, alinhando-as às vantagens competitivas e capacidades diferenciadoras, elaborar o planejamento, implementa-lo e controlar as decisões e ações para a satisfação dos objetivos organizacionais e stakeholders.

GESTÃO PARTICIPATIVA - Processo no qual os subordinados compartilham um grau significativo de poder de decisão com seus superiores imediatos.

GESTOR - Responsável pela gestão. Pressupõe aquele que tem autoridade sobre os recursos e atividades e responsabilidade com os resultados.

GUARDA-LIVROS - Nome que se dava há alguns anos atrás ao profissional contábil. Atualmente não é mais utilizado.

HABILIDADE - A capacidade de um indivíduo de desempenhar diversas tarefas em uma função.

HABILITAÇÃO PROFISSIONAL (EM CONTABILIDADE) - Capacidade técnica para que um profissional possa exercer sua profissão. Além disto, também é a 
capacidade legal (registro nos órgãos competentes) para exercer a profissão. A partir do ano 2000 tornou-se necessária para o exercício profissional.

HARDWARE - Parte física do computador. Equipamento físico usado para o trabalho de entrada, processamento e saída em um sistema de informação.

HONORÁRIO PROFISSIONAL - Remuneração recebida referente à prestação de serviços, pela empresa contábil, estabelecido em contrato específico.

INCONSISTÊNCIA - Falta de uniformidade na utilização dos critérios contábeis.

INFORMAÇÃO - (1) É um dado trabalhado, isto é, quem recebe a informação tomará alguma decisão, pois significa uma comunicação. (2) Aquilo que altera o estado precedente de coisas. (3) Dados que foram modificados para uma forma significativa e útil para seres humanos. Segundo a teoria da informação, é a medida da redução de incertezas. Ou, o conjunto de dados absorvidos pelos indivíduos com um objetivo.

INFORMAÇÃO DE NATUREZA ECONÔMICA - Deve ser entendida dentro da visão que a Contabilidade tem do que seja econômico e não, necessariamente, do tratamento que a Economia daria ao mesmo fenômeno; em largos traços, podemos afirmar que os fluxos de receitas e despesas (demonstração de resultado, por exemplo), bem como o capital e o patrimônio, em geral, são dimensões econômicas da Contabilidade, ao passo que os fluxos de caixa, de capital de giro, por exemplo, caracterizam a financeira.

INFORMAÇÃO DE NATUREZA FÍSICA - Importante desdobramento dentro da evolução da teoria dos sistemas contábeis. As mais recentes pesquisas sobre a evolução de empreendimentos têm revelado que um bom sistema de informação e avaliação não pode repousar apenas em valores monetários, mas deverá incluir, na medida do possível, mensurações de natureza física, tais como: quantidades geradas de produtos ou de serviços, número de depositantes em estabelecimentos bancários, e outras que possam permitir melhor inferência da evolução do empreendimento por parte do usuário.

INOVAÇÃO DO PROCESSO (REENGENHARIA DO NEGÓCIO) - o desempenho de um processo em uma forma radicalmente nova com o objetivo de atingir melhorias drásticas no tempo de resposta, custo, qualidade, e outros importantes fatores competitivos.

INPUTS - são as entradas em geral em um sistema.

INTEGRIDADE - Qualidade da informação contábil que se refere ao fato de a informação contábil ter de compreender todos os elementos relevantes e significativos sobre o que se pretende revelar ou divulgar, como transações, previsões, análises, demonstrações, opiniões e outros elementos.

INTERFACE -: interligação entre dois sistemas.

INTERNET - Uma vasta rede de redes interligadas ligando organizações empresariais, governamentais, científicas e educacionais e também pessoas por todo o mundo.

KNOW-HOW - Como fazer. Conhecimento e ou experiência específicos.

LANÇAR - Registrar um fato contábil. 
LAYOUT - Disposição, plano ou esquema dos equipamentos ou instalações de um determinado espaço físico.

LEARNING ORGANIZATION - Expressão criada por Chris Argyris, professor em Harvard, designa por learning organizations (organização em constante aprendizagem) as empresas que aprendem à medida que os seus trabalhadores vão ganhando novos conhecimentos. O conceito é baseado na idéia de Argyris, chamada double-loop learning (quando os erros são corrigidos através da alteração das normas empresariais que o causaram). Em 1990, Peter Senge, professor do MIT, popularizou o conceito através do livro As cinco disciplinas.

LIDERANÇA - A capacidade de influenciar um grupo em direção ao alcance dos objetivos.

LIVRO AUXILIAR - Devido ao volume de operações realizadas pela empresa, podese criar livros subsidiários que ajudam para o melhor controle contábil. Exemplos: Livro Diário Auxiliar de Caixa, Livro Diário Auxiliar de Recebimentos, Livro Diário Auxiliar de Pagamentos etc.

LIVRO CAIXA - Livro que registra todas as entradas e saídas de dinheiro.

LIVRO DE ENTRADAS - Livro que é um desmembramento do Livro Caixa, e que registra apenas as entradas de dinheiro na empresa.

LIVRO DE ESTOQUES - Livro que registra todas as entradas e saídas do estoque e mantém seu saldo atualizado.

LIVRO DIÁRIO - Livro obrigatório (exigido por lei) em todas as empresas. Registra os fatos contábeis em partidas dobradas, na ordem cronológica de dia, mês e ano. 
LIVRO FISCAL -. Livro que registra operações que possam vir a ser solicitadas pelo fisco.

MAPA DO CONHECIMENTO - É uma técnica de representação do conhecimento através de gráficos, formados por cadeias de conceitos, as quais se constituem em nós (pontos / vértices) e links ou vínculos (arcos / extremidades). Os nós representam os conceitos e os vínculos representam as relações entre os conceitos.

MÉTODO CONTÁBIL - Procedimentos de aplicação dos Princípios Fundamentais de Contabilidade.

MÉTODO DAS PARTIDAS DOBRADAS - Método que determina que cada operação contábil dá origem a um lançamento duplo: débito e crédito. .

MISSÃO - Define a razão de ser da organização, para que ela serve, qual a justificativa de sua existência para a sociedade, ou seja, qual a função social exercida por ela. A declaração de missão de uma empresa deve ser suficientemente especifica para orientar seus membros quanto à decisão de quais atividades devem ser priorizadas.

MODELO - Uma abstração da realidade, representação simplificada de um fenômeno real.

MODELO RELACIONAL DE BANCO DE DADOS - Organização de dados em um banco de dados em tabelas de duas dimensões chamadas relações; um elemento de dados em qualquer uma das tabelas pode ser relacionado a qualquer item de dados de uma outra tabela enquanto ambas as tabelas compartilharem um elemento de dados comum.

MOTIVAÇÃO - Processo responsável pela intensidade, direção e persistência dos esforços de uma pessoa em relação ao alcance de uma determinada meta

OBJETIVOS DA CONTABILIDADE - O principal objetivo da Contabilidade é o de permitir, a cada grupo principal de usuários, a avaliação da situação econômica e financeira da entidade, num sentido estático, bem como fazer inferências sobre suas tendências futuras.

OBRIGAÇÕES TRIBUTÁRIAS. Obrigações da empresa para com o fisco.

OLAP (On-Line Analytical Processing) - Processamento Analítico On-Line

OLRT (On-line Real-Time Systems) Sistemas que asseguram que os dados de transações sejam processados no momento da ocorrência, atualizados nos registros mestres instantaneamente, fornecendo resultados dessas transações num curtíssimo período de tempo.

OLTE (On-line Transaction Entry) - Lançamento da Transação On-line - O uso de dispositivos de lançamento de dados que permitem que os dados de eventos entrem nos sistemas de informação no momento e local em que a transação ocorre.

OLTP (On-Line Transaction Processing) - Processamento de Transações On-Line

OPERAÇÃO - é utilizada normalmente para indicar a parte menor de indivisível da execução de uma tarefa. Pode ser manual ou instrumental [automatizada].

ORGANIZAÇÃO - Qualquer grupo estruturado de pessoas reunido para atingir um conjunto de objetivos que um indivíduo sozinho não seria capaz de atingir. 
ORGANIZAÇÃO CONTÁBIL - Forma de organizar um escritório contábil ou um departamento de Contabilidade para que este seja eficiente.

ORGANOGRAMA - representação gráfica dos aspectos da estrutura organizacional. ÓRGÃO - Identifica uma entidade integrante do sistema, podendo ser do Governo Federal, Estadual, Municipal ou Privado.

OTIMIZAÇÃO - a maximização ou minimização de um efeito, ou resultado, desejado da interação de variáveis, conhecidas com certeza, dentro de um modelo, por meio de decisões e ações planejadas.

OUTPUTS - são os produtos/serviços gerados em um sistema [saídas].

OUTSOURCING - Terceirização

PAPEL - Conjunto de padrões comportamentais esperados, atribuídos a alguém que ocupa determinada posição em uma unidade social.

PERCEPÇÃO - Um processo pelo qual os indivíduos organizam e interpretam suas impressões sensoriais com a finalidade de dar sentido ao seu ambiente.

PERSPECTIVA SOCIOTÉCNICA - Abordagem de sistemas de informação que envolve a coordenação da tecnologia, organizações e pessoas.

PLANEJAMENTO - É um processo de decidir o que fazer, e como fazê-lo, antes que se requeira uma ação.

PLANEJAMENTO ESTRATÉGICO - é o processo de elaboração de diretrizes de caráter qualitativo que visa orientar o planejamento operacional no cumprimento da missão.

PLANEJAMENTO TRIBUTÁRIO - é a busca, pelo contribuinte, de opções lícitas de menor tributação.

PROBLEMA - Discrepância entre o estado atual das coisas e o estado desejável, exigindo a consideração de cursos de ação alternativos.

PROCESSO - É a seqüência de operações a serem executadas que levam a realização de produtos/serviços.

PROCESS IMPROVEMENT. A aplicação da filosofia PDSA aos processos, para produzir melhorias positivas e melhor satisfação às necessidades e expectativas dos clientes.

PROCESS MANAGEMENT - As técnicas pertinentes e ferramentas aplicadas a um processo para implementar e melhorar a eficácia do processo..

PROCESS MAP - Uma espécie de quadro que descreve as etapas em um processo, com identificação da responsabilidade para cada etapa e as medidas principais.

PROCESSAMENTO - Conversão da entrada de dados em sua forma original para uma forma mais apropriada para utilização.

PROCESSAMENTO DISTRIBUÍDO - Distribuição do processamento entre computadores múltiplos interligados por uma rede de comunicações. 
PROCESSAMENTO ONLINE EM TEMPO REAL - Abordagem de entrada na qual os dados são introduzidos no computador e processados à medida que se tornam disponíveis.

PROCESSO DE INOVAÇÃO - Processo que antecipa as necessidades emergentes e potenciais de clientes e cria novos produtos e serviços para satisfazer aquelas necessidades.

PRODUTIVIDADE - Uma medida de desempenho que inclui a eficiência e a eficácia.

PROJETO DE PRODUTOS, SERVIÇOS E PROCESSOS - Planejamento detalhado e execução de produtos, serviços e/ou processos.

PROJETO DE SISTEMAS - Modelo ou planta para uma solução de sistema de informação para um problema; mostra em detalhes como os componentes técnicos, organizacionais e de pessoal trabalharão em conjunto.

PROVEDOR DE SERVIÇOS DA INTERNET (INTERNET SERVICE PROVIDER - ISP). Empresa com conexão permanente com a Internet que oferece acesso à Internet aos assinantes.

QUALIDADES DA INFORMAÇÃO CONTÁBIL - Os requisitos mais importantes a destacar são: tempestividade, integralidade, confiabilidade, comparabilidade e compreensibilidade.

RAZÃO - É um livro obrigatório pelas Normas Brasileiras de Contabilidade, que registra os valores em contas de mesma natureza e de forma racional. No Razão tem-se um controle por conta.

REDUNDÂNCIA DE DADOS -. Presença de dados duplicados em múltiplos arquivos de dados.

REENGENHARIA - Re-projeto dos processos empresariais para melhorar significativamente o custo, a qualidade, os serviços e a velocidade e também maximizar os benefícios da Tecnologia de informação.

REORGANIZAÇÃO CONTÁBIL - Organizar novamente os trabalhos contábeis.

RESPONSABILIDADE - é o poder conferido a alguém para tomar decisões que afetam os resultados empresariais.

ROTINA CONTÁBIL - Procedimentos contábeis referentes ao trabalho contábil segundo a técnica contábil.

SAÍDA DA ATIVIDADE - Resultado ou produto de uma atividade.

SERVIÇO - Tarefa ou atividade realizada para um cliente ou uma atividade realizada por um cliente usando os produtos ou instalações de uma organização.

SERVIÇOS CONTÁBEIS - Trabalhos contábeis todas as tarefas desenvolvidas por profissionais contábeis.

SERVIDOR - Computador com um grande disco rígido. Sua função é permitir que outros dispositivos compartilhem arquivos e programas.

SINERGIA - Uma reação de duas ou mais substâncias que resulta em um efeito diferente da soma das duas substâncias individuais. No sistema social o trabalho coletivo é melhor e mais produtivo do que a soma dos trabalhos individuais. 
SISTEMA - é o conjunto de elementos interdependentes que interagem na consecução de um objetivo.

SISTEMA CONTÁBIL (EQUIPAMENTOS CONTÁBEIS) - Contabilidade que pode ser executada em quatro modalidades diferentes, conforme a disponibilidade de recursos materiais e humanos da empresa: manual, maquinizado, mecanizado e eletrônico.

SISTEMA DE APOIO À DECISÃO (SAD) - Sistemas interativos, sob controle do usuário, que são usados na solução de problemas semi-estruturados.

SISTEMA DE APOIO À DECISÃO EM GRUPO (SADG) - Sistema interativo baseado em computador destinado a auxiliar um grupo de tomadores de decisões, trabalhando juntos, a resolver problemas não-estruturados.

SISTEMA DE GERENCIAMENTO DE BANCO DE DADOS (SGBD) - Software que serve como interface entre um banco de dados comum e diversos programas aplicativos; permite que os dados sejam armazenados em um só lugar, embora estejam disponíveis para diferentes aplicações.

SISTEMA DE INFORMAÇÃO - Conjunto de componentes inter-relacionados que coletam, recuperam, processam, armazenam e distribuem informações com o propósito de facilitar o planejamento, o controle, a coordenação, a análise e a tomada de decisões nas organizações.

SISTEMA DE INFORMAÇÃO CONTÁBIL - Um sistema que consiste de partes manuais e de computador, inter-relacionadas, que usa processos como, coletar, registrar, resumir, analisar (usando modelos de decisão), e gerir dados para fornecer informações de saída para os usuários.

SISTEMA DE INFORMAÇÃO EXECUTIVA (SIE) - Sistemas baseados em gráficos, projetados para a administração de topo, que proporcionam recursos de computação e de telecomunicações e combinam informações internas e externas; são utilizados para planejamento a longo prazo.

SISTEMA DE PROCESSAMENTO DE TRANSAÇÕES - Sistema empresarial básico que controla as transações necessárias para conduzir um negócio e as utiliza para atualizar os registros da empresa.

SISTEMA ESPECIALISTA - Software aplicativo que busca obter capacitação em domínios limitados do conhecimento e experiência e aplicar essa capacitação para solucionar problemas.

SISTEMA MANUAL - Sistema de informação que utiliza apenas papel e lápis e não depende de computadores.

SISTEMA MANUALIZADO - Forma de execução da contabilidade que depende de instrumentos bem simples, de valor reduzido e abundantes no mercado, como canetas, livros ou fichas a serem escriturados etc.

SISTEMA MAQUINIZADO - Forma de execução da contabilidade que se utiliza de máquina de datilografar, máquina de somar e, normalmente, de um formulário denominado "Ficha Tríplice".

SISTEMA MECANIZADO - Forma de execução de contabilidade que se caracteriza pelo uso de equipamento contábil, ou seja, por uma máquina específica para fazer a 
contabilidade. Com rapidez maior que o sistema manualizado e o sistema maquinizado, permite um detalhamento maior de contas.

SISTEMAS DE CONHECIMENTO - Sistemas de informação utilizados pelos trabalhadores do conhecimento em organizações empresariais para solucionar questões que exigem conhecimento e capacitação técnica.

SISTEMAS DE INFORMAÇÕES GERENCIAIS (SIGs) - Sistemas de apoio gerencial que fornecem relatórios sumários rotineiros sobre o desempenho da empresa; são utilizados para monitorar e controlar a empresa e prever o desempenho futuro.

SISTEMAS DE NÍVEL ESTRATÉGICO - Sistemas de informação empregados na resolução de problemas de longo prazo, ou estratégicos, de uma organização empresarial.

SISTEMAS DE PONTOS-DE-VENDAS - Sistemas de vendas e de marketing que coletam dados de vendas no próprio ponto-de-venda, na caixa registradora ou em scanners portáteis.

SISTEMAS DE PROCESSAMENTO DE PEDIDOS - Sistemas de vendas e marketing que registram e processam pedidos de vendas, emitem faturas e muitas vezes produzem dados para análise de vendas e controle de estoque.

SOCIEDADES CIVIS - Sociedade que, de maneira geral, prestam serviços, com ou sem fins lucrativos, e não praticam atos de comércio (mediações). As sociedades civis, portanto, podem ou não objetivar lucro. Quando visam ao lucro, não o fazem através de mediação, mas através de prestação de serviços.

SOFTWARE DE EDITORAÇÃO DE TEXTOS. Software que manipula aplicações como editoração eletrônica, formatação e impressão de documentos.

SONEGAÇÃO -. Fraude caracterizada pela falta intencional de pagamento, principalmente de impostos.

SQL (STRUCTURED QUERY LANGUAGE - LINGUAGEM ESTRUTURADA DE PESQUISA) -. Linguagem de manipulação de dados para sistemas de gerenciamento de bancos de dados relacionais.

STS (Sociotechnical Systems) - Sistemas sócio-técnicos, a idéia de que tanto a área social quanto a técnica, bem como sua interação, são importantes para uma organização.

SUBSISTEMA ORGANIZACIONAL - refere-se à organização formal da empresa, ou seja, a forma como são agrupadas suas diversas atividades em departamentos, aos níveis hierárquicos, as definições de amplitude e responsabilidades, ao grau de descentralização das decisões e a delegação de autoridade;

SUBSISTEMA SOCIAL - refere-se ao conjunto dos elementos humanos da organização, bem como as características próprias dos indivíduos;

TÉCNICA CONTÁBIL - Conjunto de procedimentos contábeis para registrar as operações da empresa, ou seja, é a escrituração contábil.

TECNOLOGIA - Os meios pelos quais uma empresa transforma insumos em resultados. 
TECNOLOGIA DE GERENCIAMENTO DE PROJETOS - Software que auxilia os gerentes a acompanhar e a planejar os projetos.

TEORIA - É um conjunto de conceitos ou hipóteses sistematicamente interrelacionados que buscam explicar e prever um fenômeno.

TERCEIRIZAÇÃO - O pagamento de uma empresa por uma função de negócios que antes era executada internamente.

TOMADAS DE DECISÃO - Processo de escolher entre alternativas competidoras.

TOMADAS DE DECISÃO CENTRALIZADAS - Sistema no qual decisões são tomadas no nível mais alto de uma organização e os gestores das áreas de responsabilidade são encarregados de implementá-las.

TOMADAS DE DECISÃO DESCENTRALIZADAS - Sistema no qual decisões são tomadas e implementadas por gestores em níveis inferiores.

TOMADAS DE DECISÃO ESTRATÉGICAS - Escolher entre estratégias alternativas com a finalidade de escolher uma estratégia, ou estratégias, que dão uma garantia razoável de crescimento e de sobrevivência a longo prazo a uma empresa.

TRABALHO DA INFORMAÇÃO - Trabalho que envolve principalmente a criação ou o processamento de informações.

TRABALHO DO CONHECIMENTO - Trabalho cujo principal interesse é a criação de novas informações ou conhecimentos.

TRANSAÇÃO. (1) Qualquer evento que afete a posição financeira de uma entidade e exija registro contábil. (2) Registro de um evento ao qual uma empresa deve responder.

VALOR - Representa o preço de troca dos bens ou serviços, desembolsos passados, presentes ou futuros.

VALOR AO CLIENTE - Diferença entre o que um cliente recebe (realização do cliente), e o que o cliente entrega (sacrifício do cliente).

VANTAGEM COMPETITIVA - Criação de um valor melhor ao cliente por um custo igual, ou inferior, do que os competidores, ou um valor equivalente por um custo mais baixo do que os competidores.

VARIÁVEL - É qualquer característica geral que possa ser medida e que se modifique em amplitude e/ou intensidade.

VISÃO - Pode ser definida como um macro-objetivo, não quantificável, de longo prazo. Onde e como a organização espera estar no futuro. É um misto de sonho, utopia e desejos de uma pessoa ou de um grupo.

WORK FLOW - (Fluxo de trabalho) o termo tem sido aplicado para representar o mapeamento de atividades dentro de um processo sujeito a re-engenharia de processos negociais (BPR), em que se valoriza sobremaneira a informação e o capital intelectual aplicável nos processos (automated workflow) que criam valor aos clientes por meio da gestão total da qualidade e Tecnologia de informação, na revelação das competências essenciais residentes ou necessárias a serem incorporadas para obtenção do sucesso do negócio. 


\title{
AUTORIZAÇÃO PARA REPODUÇÃO / DIVULGAÇÃO DO DOCUMENTO
}

\author{
A empresa Conjel Serviços Contábeis e Administrativos S/C Ltda, pessoa \\ jurídica de direito privado inscrita no CNPJ/MF. Sob $n^{\circ}$ 78.843.455/0001-66, \\ estabelecida a Rua 990, 161 - centro em Balneário Camboriú, Estado de Santa \\ Catarina, legalmente representada pelo seu sócio-gerente AUTORIZA O AUTOR \\ DESTA PESQUISA A UTILIZAR OS DADOS COLETADOS NO AMBIENTE DA \\ EMPRESA NO PERÍODO DE 01 DE JANEIRO DE 2002 À 31 DE DEZEMBRO DE \\ 2002.
}

Balneário Camboriú SC, 14 de Junho de 2003.

Autorizo a reprodução total e / ou parcial deste trabalho (por qualquer meio existente ou que venha a ser criado) desde que citada a fonte.

Balneário Camboriú SC, 14 de Junho de 2003.

JOSÉ SANTOS PEREIRA

Av. Brasil Esq. Rua 3.700 - no 323 (Edf. Villa Germânica) - centro

88.330-000 Balneário Camboriú - SC [jsp@conjel.com.br] 